\title{
O indivíduo na condição de sujeito ativo e passivo do direito internacional contemporâneo
}

Isabela Maia Mesquita Martins ${ }^{1}$

\begin{abstract}
"Ninguém é tão grande que não posa aprender, nem tão pequeno que não possa ensinar' Esopo

"Aqui não há tribunais, porque aqui há espaço para o sucesso e dignidade de todos os seres viventes, porque - diferente daquele mundo, em que sobejam a aridez do orgulho e a secura do egoísmo e onde reina a miséria material e a tristeza moral - no nosso mundo a felicidade de um ser é a felicidade de todos os seres, de tal forma que ninguém está sozinho e somos regidos pelas leis do amor e da solidariedade".
\end{abstract}

Alegrus Felicius

\section{Resumo}

Perante crescentes violações de direitos humanos e diante de omissões ou arbitrariedades do Estado, nasce uma alternativa interestatal para socorrer o cidadão: o sistema de Proteção Internacional dos Direitos Humanos (PIDHs). Neste sistema, destacam-se o mecanismo de petição individual perante a Corte Européia de Direitos Humanos (CtEDHs) e o mecanismo de participação individual perante a Corte Interamericana de Direitos Humanos (CtIDHs). Desencadeado pela Carta de São Francisco e pela Declaração Universal dos Direitos Humanos (DUDHs), o Direito Internacional (DI) transitou de um DI tradicional estatocêntrico (regido pelo princípio da soberania absoluta dos estados) para um DI contemporâneo universal (regido pelo princípio da dignidade intrínseca do ser humano), conforme defendem Antônio A. C. Trindade e Juan A. C. Salcedo. Tal processo de humanização do DI fez com que este incorporasse, através de instrumentos internacionais de Direitos Humanos, o reconhecimento e a PIDHs e das garantias fundamentais, dando passo significativo em direção à aceitação do indivíduo como sujeito ativo e

\footnotetext{
Monografia apresentada, em 2009 como requisito para conclusão do curso de bacharelado em Direito no Centro Universitário de Brasília. Orientador: Antônio Paulo Cachapuz de Medeiros. Monografia classificada em $2^{\circ}$ lugar no Concurso "Victor Nunes Leal" do Núcleo de Pesquisa e Monografia do Uniceub (2009).
} 
passivo de Direito Interno (Di) e de Direito Internacional (DI). Através do Direito Internacional dos Direitos Humanos (DIDHs) e do Direito Internacional Penal é possível compreender os desenvolvimentos recentes dos mecanismos de petição individual perante a CtEDHs (transição de um locus standi in judicio para um jus standi in judicio) e de participação individual perante a CtIDHs (alcance de um locus standi in judicio), assim como entender o mecanismo de responsabilização penal individual perante o Tribunal Penal Internacional (TPI), a fim de se concluir como é a atuação do indivíduo no plano internacional e inferir se o indivíduo é ou não sujeito ativo e passivo de DI, com plena capacidade e pesonalidade jurídica internacional.

Palavras-chave: Direito Internacional dos Direitos Humanos (DIDHs). Direito Internacional Penal. Corte Européia de Direitos Humanos (CtEDHs). Corte Interamericana de Direitos Humanos (CtIDHs). Tribunal Penal Internacional (TPI). Proteção Internacional dos Direitos Humanos (PIDHs).

\section{Introdução}

Consciente de que "o respeito ao direito internacional é o único caminho na construção de uma ordem mundial um pouco mais harmônica”, analisar-se-á, sob a perspectiva de 2 grandes ramos do Direito Internacional Publico (DIP) - o Direito Internacional dos Direitos Humanos (DIDHs) e o Direito Penal Internacional (DPI) -, 3 mecanismos atuais e importantes do Direito Internacional Contemporâneo: 1) o mecanismo de participação individual do sistema interamericano; 2) o mecanismo de petições individuais do sistema europeu; e 3) o mecanismo de responsabilização individual penal internacional. Tal análise se esteia sobre um pressuposto fundamental: o indivíduo é sujeito passivo e ativo de direito interno (Di) e de direito internacional (DI), porque tem capacidade e personalidade jurídica nacional e internacional. O referido pressuposto longe de ser consenso na

2 VIDIGAL, Carlos Eduardo. A Nova Ordem Mundial. In: Política Internacional Contemporânea: mundo em transformação. Henrique Altemani de Oliveira et al.; [organizadores, Henrique Altemani de Oliveira, Antônio Carlos Lessa. São Paulo: Saraiva, 2006. p. 4. 
doutrina, tem suscitado acalorados debates, que não serão aprofundados na presente monografia, já que esta visa aprofundar e compreender os 3 mecanismos supramencionados, que são apresentados como argumentos de defesa do indivíduo como sujeito de DI, a fim de se concluir sobre a possibilidade ou não de o individuo ser realmente visto como sujeito do DI Contemporâneo.

O capítulo 1 trata dos pressupostos teóricos que darão sentido à elaboração dos demais capítulos: a transição da ordem internacional estatocêntrica (sociedade internacional) para uma nova ordem universalista (comunidade internacional); as características gerais do DIP; e os sistemas regionais de proteção dos direitos humanos (DHs). No capítulo 2 discorre-se sobre o mecanismo de petições individuais na Corte Européia de Direitos Humanos (CtEDHs), com ênfase nas mudanças trazidas pelo Protocolo Onze, que transformou o acesso dos indivíduos à CtEDHs de um locus standi in judicio em um jus standi in judicio. No capitulo 3 explana-se sobre o mecanismo de participação individual na Corte Interamericana de Direitos Humanos (CtIDHs), com ênfase nas mudanças trazidas pelo Regulamento Quarto, que permitiu a atuação dos indivíduos em todas as etapas do processo na CtIDHs (locus standi in judicio), visto como a"última esperança para os que não alcançaram justiça no nível nacional" e a "mais luminosa estrela do universo dos direitos humanos"3. No capitulo 4 explicita-se o mecanismo de responsabilização penal individual do Tribunal Penal Internacional (TPI), visto como "o fim da impunidade da criminalidade universal"4.

3 TRINDADE, A. A. Cançado. "International Law for Humankind: Towards a new Jus Gentium (I): General Course on Public International Law", Hague Academy of International Law: offprint from the Collected Courses, Volume 316(2005), Leiden/Boston: Martinus Nijhoff Publishers, 2006. p. 279 (tradução livre da autora).

4 LIMA, Renata Mantovani de \& BRINA, Marina Martins da Costa. O tribunal Penal Internacional. Belo Horizonte: Del Rey, 2006. p. 179. 


\section{0 indivíduo como sujeito de direito internacional}

\subsection{Do direito internacional tradicional (estatocêntrico) ao direito contemporâneo (universalista) na ótica de Trindade e Salcedo}

Decorrente da Paz de Westfalia (1648), o Direito Internacional (DI) Tradicional, consolidado entre o Congresso de Viena e a Primeira Guerra Mundial, descrevia um sistema jurídico descentralizado, regulador das relações de coexistência e cooperação entre Estados soberanos e independentes, de que o indivíduo estava excluído como sujeito de direito. Fruto desta forma de conceber o mundo, no início do século XX, autoridades doutrinárias (predominantemente positivistas), como Dionísio Anzilotti, afirmavam que os Estados eram os únicos sujeitos de direitos e obrigações do DI, e, como Lassa Francis L. Oppenheim, afirmavam que o DI não poderia proteger os Direitos Humanos (DHs), porque aquele regula exclusivamente as relações entre estados e não entre indivíduos. ${ }^{5}$

A fundação da Organização das Nações Unidas (ONU), em 1945, fez com que o DI deixasse de ser exclusivamente interestatal e os indivíduos deixassem de ser meros objetos da ordem internacional. Com a Carta da ONU e a Declaração Universal dos Direitos do Homem (DUDHs), surgiu o princípio de que todo ser humano possui direitos inerentes à condição de pessoa humana (dignidade física e moral), oponíveis juridicamente a todos os Estados; consequentemente, o tratamento de seus nacionais pelo Estado deixou de ser meramente uma questão de jurisdição interna e passou a ser uma questão de obrigação internacional e de respeito à comunidade internacional. A partir de então o DI incorporou, através dos instrumentos internacionais de DHs, o reconhecimento e a proteção internacional dos direitos humanos (PIDHs) e das garantias fundamentais, dando passo

\footnotetext{
SALCEDO, Juan Antonio Carrillo. "Algunas Reflexiones sobre la Subjetividad Internacional del Individuo y el Proceso de Humanización del Derecho Internacional”. In: Os rumos do Direito Internacional dos direitos humanos em homenagem ao professor Antônio Augusto Cançado Trindade/Renato Zerbini Ribeiro Leão, coord. - Porto Alegre: Sergio Antonio Fabris Ed. 2005. pp. 277-279; Para saber mais: cf. SPERDUTI, Giuseppe. "Curso do professor Giuseppe Sperduti em la Academia de Derecho Internacional de La Haya et le droit international', Recueil des Cours de l'Académie de Droit International, 1956, vol. 90 .
} 
significativo em direção à aceitação do indivíduo como sujeito de Direito Interno (Di) e de Direito Internacional (DI). ${ }^{6}$

Até início do séc. XXI, a forma como o indivíduo é considerado como Sujeito de DI é reduzida e limitada ${ }^{7}$, não se podendo afirmar, antes do Regulamento Quarto à Convenção Americana e do Protocolo Onze à Convenção Européia e da instauração do Tribunal Penal Internacional (TPI), que há plena subjetividade internacional do indivíduo. A construção da subjetividade internacional do indivíduo começou pela admissão da responsabilidade penal individual internacional por violação de obrigações jurídicas internacionais, sendo a personalidade individual internacional ativa (legitimidade para apresentar uma reclamação internacional contra um estado perante instâncias internacionais) vista como exceção, limitada a casos concretos, ocorrendo conforme os ditames do Estado. ${ }^{8}$

Desencadeado pela Carta da ONU, o processo de Humanização da Ordem Internacional, por si só argumento insuficiente para afirmar que o indivíduo é realmente sujeito de DI, acrescentou ao principio constitucional tradicional (princípio da soberania dos estados) - ainda vigente, mas erodido e relativizado-, um novo princípio constitucional (princípio da dignidade intrínseca de todo ser humano). Além disso, tal processo de Humanização superou a divisão entre Di e DI. Para entender a complexidade e contradições intrínsecas do Direito Internacional dos Direitos Humanos (DIDHs) em sua atual evolução histórica é preciso entender a tensão dialética (coexistência e a interação recíproca) entre os dois Princípios Constitucionais supra-citados do DI: da soberania dos Estados e dos direitos humanos. ${ }^{9}$

A soberania dos Estados, além da sua função de excluir os outros Estados da sua esfera de atuação, possui também um papel importante para o desenvolvi-

${ }^{6}$ Ibid, p. 279-280.

7 Para mais informações: cf. SALCEDO, J. A Carrillo. "Soberania de los Estados y Derechos Humanos em Derecho internacional contemporâneo", Editorial Tecnos, 2a edición, Madrid, 2001. p. 36.

8 SALCEDO, Juan Antonio Carrillo. op. cit. supra n. (3), 2005, pp. 280-281.

9 Ibid, p. 281-283. 
mento do DI, na medida em que pode atuar como instrumento para a realização deste direito. Tal afirmativa se esclarece perante o fato de que há obrigações positivas que o DI Contemporâneo impõe aos Estados para promoção e proteção dos DHs através das seguintes medidas: a) incorporação de normas de DI protetoras dos DHs no ordenamento jurídico interno para garantir seu efetivo cumprimento; b) cooperação para respeito de todos os $\mathrm{DHs}$ (civis, políticos, econômicos, sociais e culturais, dentre outros); c) prevenção e repressão de graves ilícitos contra a comunidade internacional (genocídio, crimes de guerra e crimes contra humanidade). ${ }^{10}$

O fim de todo direito é o ser humano, de tal modo que a obrigação de respeitar os DHs fundamentais é um princípio constitucional civilizador e universal na construção de uma ordem de paz. A soberania perde seu caráter absoluto, se remodelando e transformando perante o interesse público universal (fator moderador da discricionariedade dos Estados e do relativismo do DI) e as obrigações positivas - em matéria de DHs- dos Estados perante a Comunidade Internacional (fator revalorizador do Estado enquanto elemento fundamental para cumprimento das funções do DI). Neste diapasão, o DI Contemporâneo é menos formalista (mais aberto às exigências éticas e à dimensão finalista do Direito), menos neutro (mais sensível aos valores comuns coletivamente legitimados pela Comunidade Internacional) e menos voluntarista (aceitação geral da idéia de que existem regras imperativas que prevalecem sobre a vontade do estado) que o DI Tradicional. ${ }^{11}$

Tal mudança (denominada de institucionalização, socialização e humanização do DI) permite a compreensão do DI a partir de uma consciência multilateral da Ordem Internacional, no sentido da interdependência de seus atores, o que permite a compreensão de noções inovadoras como Comunidade Internacional, Patrimônio Comum da Humanidade, regras imperativas de Direito Internacional Geral, obrigações dos Estados perante à Comunidade Internacional (independentes da vontade do Estado, ou mesmo contra esta, mas que os vinculam juridicamente, e imodificáveis pela sua vontade unilateral), crimes internacionais com a

\footnotetext{
${ }^{10}$ Ibid., p. 282-284.

${ }^{11}$ Ibid., p. 284-286.
} 
responsabilidade penal internacional dos indivíduos e a noção de ilícito internacionais contra a Comunidade Internacional, dentre outros exemplos. ${ }^{12}$

A função civilizadora da Comunidade Internacional, que começa a se consolidar, substitui o conceito clássico de Sociedade Internacional (grupo social interestatal, atomizado e fragmentado, composto de relações bilaterais, dominada por interesses nacionais, reciprocidade e $u t$ des) por um conceito de Comunidade Internacional interdependente, unida e solidária (novo paradigma de ordem internacional, fundado sobre os princípios da Equidade, da Legitimidade e da Comunidade Internacional e não mais pelos princípios do DI Tradicional, que eram os da Reciprocidade; da pretendida Neutralidade axiológica e da exclusividade de Soberania territorial dos Estados) ${ }^{13}$. Resumindo, é a conversão histórica de uma Ordem Internacional estatocentrista (positivista) para uma Ordem universalista, formada por uma Comunidade-Mundo ${ }^{14}$, em que avança um Jusinternacionalismo (internacionalização dos direitos individuais - Jus Gentium como Direito Internacional da Humanidade), defensor de uma Recta Ratio (princípios imanentes à espécie humana, de validade perene, inderrogável, intransigível, de todas as nações e épocas) ${ }^{15}$.

\subsection{0 atual direito internacional público}

\subsubsection{Origem e fontes do direito internacional público}

O primeiro trabalho a moldar a expressão direito internacional (international law), ainda hoje usado como sinônimo de Direito Internacional Público (DIP), foi de Jeremias Bentham que, no século XVIII, pretendia diferenciá-lo de um direto meramente nacional (national law) ou municipal (municipal law). Embora

${ }^{12}$ Ibid, p. 286-287.

${ }^{13}$ Para maiores informações: cf. PUREZA, José Manuel, “El patrimônio común de la humanidad. ?Hacia um Derecho internacional de solidariad?”, Editorial Trotta, Mdrid, 2002, em especial págs. 375 e ss.

${ }^{14}$ SALCEDO, Juan Antonio Carrillo, op. cit. supra n. (3), 2005, pp. 286-289.

15 TRINDADE, A. A. Cançado, A humanização do direito internacinal. I - A Recta Ratio nos Fundamentos do Jus Gentium como Direito Internacional da Humanidade. - Belo Horizonte: Del Rey, 2006. p. 3-30. 
dispensável, o qualificativo público do direito internacional surgiu também para diferenciá-lo da matéria direito internacional privado, evitando conflito de leis ${ }^{16}$. Assim, o DIP é um conjunto de normas jurídicas de regulação das relações entre as pessoas internacionais (Estados, organizações internacionais e indivíduos) ${ }^{17}$, que, segundo Jellinek, resulta da vontade metafísica do Estado e é importante para limitar seu poder absoluto ${ }^{18}$.

O DIP possui fontes formais e fontes materiais, que devem ser consideradas quando da aplicação do DI. As fontes formais do DIP estão em constante e dinâmica interação, e, dentre outras, serão aqui enumeradas as seguintes: 1) o costume internacional (constituído pelo elemento objetivo de prática internacional reiterada dos sujeitos do DI; e pelo elemento subjetivo de crença de que tal prática é aceita e está de acordo com o direito, tal elemento subjetivo é denominado opinio juris sive necessitatis ${ }^{19}$ ); 2) os tratados (fruto da soberania dos Estados e da autonomia dos sujeitos de DI, os tratados são fontes de obrigação, que codificam as práticas internacionais e guiam as condutas no plano internacional e mesmo interno ${ }^{20}$ ); 3 ) os princípios gerais do direito (mais do que princípios do direito comparado dos Estados, os princípios gerais do direito são a ligação entre o DI e o Di, embora sejam vistos pelo prisma jusnaturalista como os princípios universais da justiça objetiva e pelo prisma positivista como os princípios de direito reconhecidos e cristalizados na ordem legal doméstica ${ }^{21}$ ); 4) as decisões arbitrais e judiciais (os tribunais internacionais tem contribuído para esclarecer certas questões de DI e de Di, assim como tem contribuído para enriquecer e humanizar o DI Contemporâneo, além de combater a impunidade e fomentar o cumprimento do direito no nível nacional e

\footnotetext{
${ }^{16}$ ACCIOLY, Hildebrando \& SILVA, G. E.do Nascimento e. Manual de Direito Internacional Publico. 14. ed. São Paulo: Saraiva, 2000. p. 4.

17 Ibid, p. 3.

${ }^{18}$ Ibid, p. 17.

19 TRINDADE, A. A. A. Cançado, "International Law for Humankind: Towards a new Jus Gentium (I): General Course on Public International Law", Hague Academy of International Law: offprint from the Collected Courses, Volume 316(2005), Leiden/Boston: Martinus Nijhoff Publishers, 2006. p. 150-154.

${ }^{20}$ Ibid., p. 154-157. Para maiores informações: cf. Convenções de Viena sobre Direito dos Tratados de 1969 e Convenção de Viena sobre Direito dos Tratados entre Estados e OIs ou entre OIs de 1986.

${ }^{21}$ Ibid, p. 157-158.
} 
internacional $^{22}$ ); 5) a doutrina (é a influência na evolução do DI, tanto do ensino de autores individuais, como os relatórios e livros provenientes de órgãos colegiados de $\mathrm{OIs}^{23}$ e de associações ou institutos acadêmico-científicos $\left.{ }^{24}\right)^{25} ; 6$ ) a equidade ( a equidade é usada em três situações: infra legem, para adaptar o direito aos fatos do caso concreto; preter legem, quando há lacuna no direito; contra legem, para evitar aplicar leis injustas $\left.{ }^{26}\right)^{27} ; 7$ ) os atos jurídicos unilaterais dos Estados (perante um regime internacional descentralizado de coexistência, os sujeitos de DI podem se manifestar unilateralmente, o que provoca conseqüências jurídicas, tais como, protesto, notificação, promessa, renúncia ou reconhecimento ${ }^{28}$; 8) resoluções das OIs (tais resoluções, embora meramente recomendatórias, externalizam as atividades e decisões das OIs e influenciam a prática internacional, servindo como instrumentos de exortação, de enunciação de princípios gerais ou de recomendação de dada conduta para alcançar dados fins $\left.{ }^{29}\right)^{30}$.

Na visão jusnaturalista renovada de DI (inspirada no direito natural e na espontaneidade do direito, que nasceria ideal e espontaneamente na consciência dos membros da comunidade internacional), contrária à visão reducionista e hermética do positivismo voluntarista tradicional de DI (inspirada no direito positivado e na imposição de vontade, que nasceria de atos voluntários de criação do direito), a consciência humana jurídica universal é uma força moral (direito cogente com obrigações erga omnes) e também fonte de DIP (é o denominado - direito de consciência, cujos valores estão acima da vontade de alguns), que se expressaria na

\footnotetext{
22 Ibid, p. 158-160.

${ }^{23}$ Dentre os órgãos colegiados, destacam-se os seguintes: a Comissão de Direitos Internacional da ONU; o Comitê Jurídico Inter-Americano da OEA; o Comitê Consultivo Legal Asiático-Africano; dentre outros.

${ }^{24}$ Dentre os institutos ou associações destacam-se os seguintes: o Instituto de DI de Paris; a Associação de DI; o Instituto Hispano-Luso-Americano de DI (IHLADI), dentre outros.

${ }^{25}$ TRINDADE, A. A. A. Cançado, op. cit. supra n. (18), 2006. p. 160-162.

${ }^{26}$ Ibid, p. 163-164.

${ }^{27}$ As fontes formais enumeradas de 1 a 6 estão elencadas no art. 38 do Estatuto da Corte Internacional de Justiça (ECIJ). Tal rol do art. 38 do ECIJ é meramente exemplificativo das fontes formais do DI.

${ }^{28}$ TRINDADE, A. A. A. Cançado, op. cit. supra n. (18), 2006, pp. 164-165.

${ }^{29}$ Ibid, p. 166-168.

${ }^{30}$ Ibid, p. 147-168.
} 
opinio juris communis. ${ }^{31}$ Logo, as fontes materiais do DIP seriam as "manifestações da consciência jurídica universal" (substrato metajurídico de onde se originam as fontes formais, ou seja, crenças, valores, ética, idéias, necessidades e aspirações do homem), fruto do pensar jurídico dos diversos sujeitos de DI (quais sejam, os Estados, as OIs, entidades da sociedade civil organizada, os povos, os grupos e os indivíduos) contra a injustiça, opressões e atrocidades ${ }^{32}$. A existência da consciência jurídica universal (de natureza universal e cogente, com obrigações erga omnes, é a razão da humanidade impondo limite para a razão do Estado) estaria demonstrada pelos textos de tratados internacionais ${ }^{33}$; pelos processos perante tribunais internacionais $^{34}$; pela jurisprudência internacional ${ }^{35}$; e pela doutrina ${ }^{36} \mathrm{de}^{3{ }^{37}}$.

\subsubsection{Princípios do direito internacional público}

A legalidade e legitimidade do DIP são embasadas pelos seus princípios (que regem o DIP e formam a opinio iuris communis da comunidade internacional, estão acima da vontade do Estado, e são válidos para todo ser humano e em todas as épocas), dando-lhe coesão e coerência como um todo, tais princípios (re-

${ }^{31}$ Ibid, p. 172-176.

${ }^{32}$ Ibid, p. 177-186.

${ }^{33}$ Para exemplificar há os seguintes exemplos: a Convenção contra Genocídio de 1948 remete ao "espírito da Nações Unidas"; os preâmbulos dos $2^{\circ}$ Protocolos Adicional às Convenções de Genebra de 1977 considerou "os princípios da humanidade e os ditames da consciência publica”; a Convenção Interamericana sobre Desaparecimento Forçado de Pessoas de 1994 se refere à "consciência do hemisfério"; o Estatuto de Roma de 1998 trata da "consciência da humanidade".

${ }^{34}$ Para exemplificar há o caso perante a CIJ da Opinião Consultiva de 1996 sobre a legalidade das armas nucleares, em que foram expressamente invocados os "princípios da humanidade" e os "ditames da consciência publica".

${ }^{35}$ A jurisprudência da Corte Interamericana de Direitos Humanos (CtIDH) e dos Tribunais ad hocs de Ruanda e da Ex-Iugoslávia trazem muitas referências, de diversas formas, à "consciência jurídica universal".

${ }^{36}$ Usado no início do seculo XX como civitas maxima para promover o espírito de solidariedade internacional, a denominação de "consciência jurídica universal" emergiu com o uso do conceito de communis opinio juris. Para exemplificar: Alejandro Alvarez afirmou que "a justiça internacional seria manifestação da consciência jurídica universal"; B. V. A. Roling reconheceu os "interesses superiores da comunidade internacional".

${ }^{37}$ TRINDADE, A. A. A. Cançado, op. cit. supra n. (18), 2006. p. 186-203. 
veladores dos valores e fins da ordem legal internacional, são influenciadores do processo de interpretação, de aplicação e legislativo do próprio DI e mesmo do Di) seriam os sete seguintes: 1) princípio da proibição do uso ou da ameaça de uso da força nas Relações Internacionais (RIs); 2) princípio da solução pacífica das disputas internacionais presentes ou futuras (através da negociação, da mediação, da conciliação, da arbitragem ou do judiciário); 3) princípio da não-intervenção (um Estado não deve usar seu poder econômico, político ou outros elementos de poder para submeter, explorar ou restringir a soberania de outro Estado ou interferir nos seus sistemas político, econômico, social ou cultural); 4) princípio da cooperação internacional (para as mais diversas finalidades, tais como, promoção do respeito aos direitos humanos, eliminação de todas as formas de discriminação e de intolerância religiosa, desarmamento, proteção do meio-ambiente, erradicação da fome); 5) princípio da igualdade de direitos e auto-determinação dos povos (muito evocado na época das descolonizações e emancipação dos países colonizados ); 6) princípio da igualdade soberana dos Estados (os Estados são livres para dispor de suas riquezas e recursos naturais e para desenvolver seus sistemas políticos, sociais, econômicos e culturais); 7) princípio da boa-fé no cumprimento das obrigações internacionais ${ }^{38}$ (pacta sunt servanda, bona fides). ${ }^{39}$ Tais princípios guiam as condutas dos sujeitos de DI e foram proclamados na Carta da ONU de $1945^{40} \mathrm{e}$ reafirmados na "Declaração sobre os Princípios do Direito Internacional referente à Revisão das Relações de Amizade e Cooperação entre Estados” de 1970 da ONU.

Os princípios supra-delineados estão interrelacionados e são os "pilares do sistema legal internacional" e formam a "consciência jurídica universal ou da humanidade" ${ }^{\text {, }}$ eles fornecem as bases éticas para a aplicação e interpretação do

\footnotetext{
${ }^{38}$ Ver art. 26 e o preâmbulo da Convenção de Viena sobre Direitos dos Tratados de 1969.

39 TRINDADE, A. A. A. Cançado, op. cit. supra n. (18), 2006. p. 97-121. Para maiores informações sobre princípios do DIP cf. BROWLIE, Ian. "Principles of Public International Law", Av. De Berna/Lisboa: Fundação Calouste Gulbenkian, 1997. 809 p.

${ }^{40}$ Vide art. 2 da Carta da ONU. Em 2 ocasiões recentes valorizou-se e consagrou-se os princípios da Carta da ONU, que foram tidos como universais e atemporais: na Declaração do Milênio das Nações Unidas (adotada pela AGNU em 18.09.2000 através da resolução $55 / 2$ ) e no Outcome Summit World (a AGNU consagrou os princípios da Carta da ONU e da Declaração de Princípios de 70 em 15.09.2005).

${ }^{41}$ TRINDADE, A. A. A. Cançado, op. cit. supra n. (18), 2006, p. 97-121.
} 
DI, estando acima do DI e do Di (fruto da vontade dos Estados) positivados ${ }^{42}$, de modo que seus objetivos se resumiriam nos seguintes: 1) a busca do bem comum e da satisfação das necessidades e aspirações de todos os seres humanos individualmente (da humanidade como um todo e não de uma coletividade abstrata); 2) a realização da justiça no plano nacional e internacional; 3) a preservação da paz através da prevalência do direito sobre a força e o respeito de todo ser humano (pelo simples fato de ser humano, independentemente das circunstâncias ou condições); 4) a inalienabilidade dos direitos inerentes ao ser-humano; 5) o respeito pelo pluralismo, pela diversidade cultural e pelas diversas formas de expressão da consciência humana no mundo. ${ }^{43}$. Trindade resumiu a importância dos Princípios do DIP, na seguinte frase: "Os princípios gerais do direito abrangem os princípios do DI, e expressam a opinio juris communis da comunidade internacional, na construção de um novo jus gentium: o DI da Humanidade" ${ }^{44}$.

\subsubsection{Sujeitos do direito internacional público}

Sujeito de DIP , na definição convencional, é “[...] uma entidade com capacidade para possuir direitos e deveres internacionais e com capacidade pra defender os seus direitos através de reclamações internacionais [..]” ${ }^{45}$. Em outras palavras, para ser sujeito de DIP é preciso possuir personalidade jurídica internacional (titularidade de direitos e obrigações emanadas direta e imediatamente do DI) e capacidade jurídica internacional (parte ativa e passiva em processos internacionais).

A doutrina concorda que Estados e OIs sejam sujeitos de DI; contudo, somente parte da doutrina reconhece os indivíduos como sujeitos do DIP. Dentre os argumentos apresentados por aqueles que discordam que os indivíduos sejam sujeitos de DIP estão os seguintes: 1) os indivíduos não participam na produção de normas internacionais nem tem relação direta e imediata com estas; 2) os indiví-

\footnotetext{
42 Ibid, p. 121.

${ }^{43}$ Ibid, p. 86-88.

${ }^{44}$ Ibid, p. 121 (tradução livre da autora).

${ }^{45}$ BROWLIE, Ian. "Principles of Public International Law”, Av. De Berna/Lisboa: Fundação Calouste Gulbenkian, 1997. p. 71.
} 
duos não dispõem da prerrogativa de reclamar a garantia de seus direitos em foros internacionais de modo independente da vontade do seu Estado; 3) os indivíduos não têm deveres diretamente impostos pelo DIP, mas sim é preciso que seu Estado aceite tal compromisso internacional ${ }^{46}$.

Dentre os argumentos apresentados por aqueles que concordam que o indivíduo seja sujeito de DIP estão os seguintes: 1) todos os seres humanos são titulares de direitos humanos emanados diretamente do DI e estão acima de Estados e qualquer forma de organização política, que são ficções criadas pelos indivíduos para defender seus interesses (personalidade jurídica internacional) ${ }^{47} ; 2$ ) os indivíduos podem e devem defender seus direitos independentemente da tutela do Estado, ou até mesmo contra este, através do acesso direto aos tribunais internacionais contemporâneos, podendo inclusive figurar como autor em processos internacionais (jus standi ou capacidade jurídica internacional, consubstanciada no mecanismo de petição individual) ${ }^{48}$; 3) os indivíduos podem ser responsabilizados no plano internacional, podendo figurar como réu em processos internacionais (capacidade jurídica internacional, consubstanciada no mecanismo de responsabilização individual penal internacional ). Tais argumentos são apresentados por Trindade como sendo a Humanização do DI através do avanço do DIDHs.

\subsubsection{Sanções do direito internacional público}

O Estado infrator, que viola os direitos estabelecidos no plano internacional ou descumpre as decisões ou obrigações internacionais, estará sujeito à responsabilização internacional através de sanções (coercitivas/satisfativas para impor penalidades ao pretenso Estado infrator até cumprimento da obrigação internacional, ou punitivas/retaliatórias para punir o Estado violador por suas condutas passadas), que podem ser coletivas (processos internacionais coletivos aplicados por tribunais ou instâncias internacionais) ou unilaterais (contramedidas - me-

\footnotetext{
${ }^{46}$ RESEK, RESEK, J. F. Direito Internacional Público: curso elementar. 9. ed. São Paulo: Saraiva, 2002. p. 146-147.

${ }^{47}$ TRINDADE, A. A. A. Cançado, op. cit. supra n. (18), 2006, p. 252-284; p. 285.

${ }^{48}$ Ibid, p. 285-317.
} 
didas adotadas por um pretenso Estado lesado como reação para reparação de violação por outro pretenso Estado ofensor de prévia obrigação internacional), ou meramente morais (pressão moral ou social ou da opinião publica mundial, é o “poder de embaraço ou da mobilização da vergonha”, usado por Estados, organizações não-governamentais ou indivíduos $\left.{ }^{49}\right) .{ }^{50}$

A fim de limitar a aplicação de contramedidas, a Comissão de Direito Internacional elaborou um projeto de Convenção Internacional sobre a Responsabilidade Internacional do Estado e estabeleceu os 6 seguintes limites, sob pena de responder pelos abusos, à adoção de contramedidas: 1) constatação da violação ou descumprimento de obrigação internacional (ilícito internacional); 2) prévia tentativa de solução pacifica da controvérsia (para dar oportunidade ao Estado infrator de reconhecer e reparar o dano $)^{51}$; 3 ) controle da proporcionalidade entre o ato do Estado violador de DI e a reação ou contramedida do Estado ofendido pelo mesmo ${ }^{52}$; 4) proibição do uso da força armada ${ }^{53}$ (permitida somente para casos de legítima defesa); 5) proibição de contramedidas que ofendam as normas imperativas de DI (respeito aos direitos humanos básicos ou fundamentais) ${ }^{54}$; 6) verificação prévia dos regimes especializados de responsabilização internacional

\footnotetext{
${ }^{49}$ As pressões morais podem ser criticadas por sua manipulação, seletividade e ausência de força jurídica (trata-se de mera recomendação), ao não se preocupar com a imparcialidade e o devido processo legal ao condenar publicamente um Estado. Contudo, tais sanções são valorizadas como instrumentos auxiliares do processo de responsabilização internacional do Estado.

${ }^{50}$ RAMOS, André de Carvalho. Responsabildiade inernacional por violação de direitso humanos: seus elementos, a reparação devida e sanções possíveis: teoria e prática do direito internacional. Rio de janeiro: Renovar, 2004. p. 313-326.

${ }^{51}$ Tais como os elencados no art. 33 da Carta da ONU

${ }^{52}$ A CIJ tem adotado o critério da proporcionalidade ao julgar contramedidas, como no seguinte caso: CIJ, Caso do Projeto Gabcikovo-Nagymaros (Hungria x Eslováquia), julgamento de 25.09.1997.

${ }^{53}$ Este princípio está consagrado no $\$ 4$ do art. 2 da Carta da ONU, no Pacto Briand-Kellog de 1928 que definiu o banimento da guerra de agressão, no art. 33 da Convenção de Genebra de 1949 relativa à proteção de civis em tempo de guerra, e mais recentemente o art. 50.1 do projeto de Convenção Internacional sobre Responsabilidade Internacional do Estado da Comissão de Direito Internacional.

${ }^{54}$ Este princípio está consagrado na alínea c do art. 50.1 do Convenção Internacional sobre Responsabilidae Internacional do Estado da Comissão de Direito Internacional.
} 
do Estado por violação de $\mathrm{DHs}^{55}$ (cortes regionais, comitês de supervisão e controle de convenções internacionais e órgãos da ONU). ${ }^{56}$.

Quanto às sanções coletivas, estas estão pouco desenvolvidas pela prática e pela doutrina internacional, mas sabe-se que são as sanções pelas OIs ${ }^{57}$, que deverão constatar as violações de obrigações internacionais, decidir sobre a necessária reparação dos danos, assim como sobre o conteúdo, limites e formas de implementação de suas sanções ao Estado infrator (já que as OIs agiriam em nome da comunidade internacional como um todo). ${ }^{58}$ Como instrumentos do DI, as sanções visam à responsabilização do Estado para cessar a conduta violadora, para reparação da violação de normas internacionais e para preservação da normalidade internacional para pleno respeito aos direitos humanos e ao próprio DI.

No caso de obrigações de garantia e respeito de DHs, a jurisprudência internacional ${ }^{59} \mathrm{e}$ a doutrina de DIDHs têm considerado tais "obrigações como erga omnes" no caso de direitos básicos fundamentais (encerra valores e é direito subjetivo de toda a comunidade internacional, quando então todos os Estado desta última podem exigir seu respeito, porque todos seriam material e juridicamente lesados), cabendo -no caso de desrespeito aos demais direitos humanos- o recurso aos mecanismos coletivos de responsabilização internacional do Estado violador

${ }^{55}$ CIJ, Atividades Militares e Paramilitares (Nicarágua x EUA), relatório de 1986, p. 134. Assim, a existência de procedimentos próprios de solução de controvérsias (dispositivos de monitoramento e garantias) em tratados ou convenções internacionais de direitos humanos impede o uso de contramedidas.

${ }^{56}$ RAMOS, André de Carvalho, op. cit. supra n. (49), 2004. p. 358-381.

${ }^{57}$ Dentre as sanções coletivas destacam-se as previstas em 3 órgãos internacionais: o Comitê de Ministros do Conselho da Europa( que podem expulsar Estados da UE no caso de descumprimento de decisões da $\mathrm{CtEDH}$ ); a OEA ( que pode suspender, por maioria de 2/3, qualquer de seus Estado membros cujo governo tenha sido destituído pela força - art. 9 da Carta da OEA); a ONU (que pode, através do CSNU, obriga, para assegurar a paz e segurança internacionais, seus membros a aplicar sanções contra o Estado infrator - art. 103 da Carta da ONU).

${ }^{58}$ RAMOS, André de Carvalho. op. cit. supra n. (49), 2004, p. 393-409.

59 Tal entendimento foi consolidado, no caso Barcelona Traction da CIJ. Cf: CIJ, The Barcelona Traction, Light and Power Company Limited, sentença de 05.02.1970, CIJ Relatórios, p. 32 . 
(procedimentos institucionalizados de aferição de responsabilidade das OIs) ${ }^{60}$, e - na ausência destes - tolera-se o unilateralismo (princípio da subsidiariedade) ${ }^{61}$.

\subsection{0 direito internacional dos direitos humanos como ramo autônomo do direito internacional público}

Atualmente, dentre os vários ramos do DIP, destacam-se 3 vertentes da Proteção Internacional da Pessoa Humana : 1) o Direito Internacional Humanitário (nascido para proteger vitimas de conflitos armados, respaldado pelas 4 Convenções de Genebra de 1949 e seus Protocolos Adicionais de 197762, assim como pelas resoluções fruto das Conferências Internacionais da Cruz Vermelha - CICV);2) o Direito Internacional dos Refugiados (nascido para restabelecer direitos humanos mínimos dos indivíduos refugiados, abarcando hoje também os deslocados internos e os repatriados, respaldado pelo Estatuto dos Refugiados de 1951 e seu Protocolo de 1967, a Declaração de Cartagena sobre os Refugiados de 1984, a Declaração de São José de 1994 e pela atuação do Alto Comissariado das Nações Unidas para Refugiados - ACNUR); 3) e o Direito Internacional dos Direitos Humanos (DIDHs) ${ }^{63}$, que tratará do mecanismo de petições individuais e de participação individual.

${ }^{60} \mathrm{O}$ art. 53 do projeto de Convenção Internacional sobre Responsabilidade Internacional do Estado da Comissão de Direito Internacional estabelece como obrigação de todos os Estados cooperar entre si para reparação e superação da violação de DI (fato ilícito).

${ }^{61}$ RAMOS, André de Carvalho. op. cit. supra n. (49), 2004. p. 346-350; p. 352.

${ }^{62}$ Adotadas em 12.08.1949 e frutos da conferencia diplomática para elaboração de convenções internacionais para proteger vítimas de guerra, as Convenções de Genebra entraram em vigor em 21.10.1950. A $1^{\text {a }}$ Convenção é a convenção para melhoria do destino dos feridos e dos doentes nas Forças Armadas no campo. A $2^{\text {a }}$ Convenção é a convenção para melhoria da sorte dos feridos, doentes e náufragos das Forças Armadas no mar. A $3^{\mathrm{a}}$ Convenção é sobre o tratamento dos prisioneiros de guerra. A $4^{\mathrm{a}}$ Convenção é sobre a proteção dos civis em tempos de guerra. Posteriormente complementadas por 2 Protocolos adicionais (fruto da conferência diplomática sobre a reafirmação e desenvolvimento do DI aplicável em conflitos armados), que foram adotados em 08.06.1977 e entraram em vigor em 07.12.1978. O $1^{\circ}$ Protocolo sobre proteção das vitimas de conflitos armados internacionais e o $2^{\circ}$ Protocolo sobre proteção das vitimas de conflitos armados não-internacionais.

${ }^{63}$ TRINDADE, A.A. Cançado. As três Vertentes da Proteção Interancioanal dos Dieriteos da Pessoa Humana: Direitos Humanos, Direito Humanitário, Direito dos Refugiados. Brasília/San José: IIDH/CICV/ACNUR, 1996. p. 1-121. 
Posteriormente à DUDHs de 1948 e os dois Pactos de Direitos Humanos das Nações Unidas de 1966 (PDHsNU), seguidos pelas Conferências Mundiais de Direitos Humanos (Teerã, 1968 e Viena, 1993), o DIDHs afirma-se atualmente como um novo ramo autônomo da ciência jurídica contemporânea, cuja principal fonte material é uma "consciência jurídica universal”, cujo objeto de proteção é o ser humano, cujos instrumentos de proteção internacional são múltiplos, e cujo mais importante legado para o DI contemporâneo no séc. XX é a consolidação do direito de acesso do indivíduo à justiça no plano internacional.

A “consciência jurídica” universal do DIDHs se embasa nas premissas de que os direitos humanos (inalienáveis, indivisíveis, inter-relacionados e inerentes a todos os seres humanos sob quaisquer condições), assim como a justiça, antecedem as formas de organização política. No DIDHs, prevalece a visão integral e indivisível de todos os direitos humanos (perspectiva holística), e não mais a compartimentalização de direitos representada na teoria das gerações de direitos (visão atomizada ou fragmentada). Os direitos humanos não se substituem uns aos outros, mas sim eles se expandem e se fortalecem na interação entre direitos individuais e sociais (natureza complementar de todos os direitos humanos). ${ }^{64}$

A proteção ao ser humano - visto pelo DIDHs como sujeito de Di e DI, com personalidade e capacidade jurídicas para atuar nestes dois âmbitos - pelo DIDHs abrange a proteção integral do ser humano sob quaisquer circunstâncias, em qualquer atividade, contra todas as formas de dominação e arbitrariedade, remediando os efeitos dos desequilíbrios e das disparidades, baseado nas considerações de ordem pública e na defesa da realização da justiça. ${ }^{65}$

O DIDHs possui múltiplos instrumentos internacionais de proteção nacional ou internacional do ser humano (tratados, convenções, resoluções de organismos internacionais, etc.), com natureza e efeitos jurídicos variáveis, atuando de forma complementar em âmbito global (sistema ONU) e regional (sistemas intera-

\footnotetext{
${ }^{64}$ TRINDADE, A. A. Cançado. Tratado de Direito Internacional dos Direitos Humanos, vol. I. $2^{\text {a }}$ ed. Porto Alegre, Sergio Antonio Fabris Editor, 2003. p. 33-38.

${ }^{65}$ Ibid, p. $38-44$.
} 
mericano, europeu e africano), através de mecanismos de supervisão ou controle (mecanismo de petições ou denúncias, de relatórios e de investigações). ${ }^{66}$

Além da consolidação do direito de acesso à justiça no plano internacional, a importância do DIDHs se perfaz sobre suas outras contribuições, quais sejam: a) integração das distintas categorias de direitos para mais eficaz proteção do ser humano; b) consolidação da capacidade e personalidade jurídicas do indivíduo no âmbito internacional (direito de petição individual como emancipador do ser humano como sujeito de Di e de DI); c) a responsabilização do Estado, mesmo por agentes não-estatais, por omissão na repressão à violação de direitos humanos; d) consolidação de obrigação erga omnes de proteção (fim da polêmica entre monistas e dualistas e ascensão do princípio da primazia da norma mais favorável às vitimas perante um conflito de competência entre normas de proteção dos DHs, seja na interação entre o ordenamento jurídico interno e internacional, ou seja, na interação entre obrigações gerais convencionais ou obrigações especificas de proteção de DHs); e) normatização internacional das relações jurídicas entre indivíduos e poder público. ${ }^{67}$

\subsection{Contribuição do DIDHs para desenvolvimento dos mecanismos de petições individuais e de participação individual}

Apesar da inexistência de um legislador e um órgão judiciário supranacionais e da descentralização do ordenamento jurídico internacional, antes mesmo da DUDHs, os indivíduos podiam beneficiar-se diretamente de mecanismos de proteção previstos em tratados e instrumentos internacionais, embora sem órgãos internacionais permanentes de supervisão, de controle e de implementação e sem o reconhecimento da capacidade processual no plano internacional. As seguintes experiências internacionais demonstram a assertividade de tal conclusão: a) intervenções humanitárias (petições de indivíduos e grupos particulares a conferências diplomáticas ad hoc para realização de intervenções humanitárias para manuten-

\footnotetext{
${ }^{66}$ Ibid, p. 38 e 48.

${ }^{67}$ Ibid, p. 33-50.
} 
ção de um padrão mínimo ou internacional de civilização) ${ }^{68}$; b) o sistema de minorias (indivíduos de certos países europeus podiam enviar petições aos Comitês de Minorias da Liga das Nações) ${ }^{69}$, cuja expressão mais sofisticada era da Convenção sobre a Alta- Silésia em que o individuo poderia escolher entre o Conselho da Liga, um Tribunal Arbitral ou uma Comissão Mista ${ }^{70}$; c) o sistema de mandatos (os habitantes do território sob mandato enviavam petições à Comissão Permanente da Liga das Nações ${ }^{71}$; d) o sistema de tutela, sucessor do sistema de mandatos ${ }^{72}$, das Nações Unidas. ${ }^{73}$

Posterior à I Conferência Mundial de Direitos Humanos (Teerã, 1968) marcada pela adoção de resoluções, pela visão global/integral dos direitos humanos e presenciada por representantes de 84 países, de OIs e de ONGs -, a concretização, a partir de 1976, da Carta Internacional dos Direitos Humanos marcou o fim da transição da fase legislativa (elaboração dos diversos instrumentos internacionais de proteção, reuniões, trabalhos preparatórios etc.) para fase de consolidação destes tratados e instrumentos internacionais de proteção, desencadeando um processo de generalização da PIDHs. Marcado pelos conflitos ideológicos da época de Guerra Fria e pela incipiente descolonização, além das várias interpretações das distintas filosofias acerca dos principais problemas teóricos levantados pela elaboração de uma Declaração Universal, o plano geral de redação da Carta Internacional de Direitos Humanos desenvolveu-se na Comissão de Direitos Humanos das Nações Unidas (ComDHsNU) e previa a elaboração de uma DUDHs, complemen-

${ }^{68}$ Para saber mais sobre estas experiências iniciais: cf. A.A. Cançado Trindade, "Exhaustion of Local Remedies in International Law Experiments Granting Procedural Status to Individuals in the First Half of the Twentieth Century", 24 Netherlands International Law Review (1977), p. 373-392.

${ }^{69}$ Para saber mais sobre estas experiências: cf. J. Stone, "The Legal Nature of Minorities Petition”, British Year Book of International Law (1931) p. 76-88.

${ }^{70}$ Para saberr mais sobre esta experiência: cf. M. St. Korowicz, "La personnalité internationale de líndividu d'après la Convention relative à la Haute-Silésie (1922-1937)”, Revue internationale française du droit des gens (1938) p. 13-14.

${ }^{71}$ Para saber mais sobre esta experiência: cf. M. Sibert, "Sur la procédure em nmatière de pétitions dans les pays sous mandat et quelques-unes de sés insuffisances", Revue générale de droit international public (1933) p. 257-272;

${ }^{72}$ Para saber mais sobre esta experiência: cf. J. Beautè, "Le droit de pétition dans lês territoires sous tutelle", Paris, LGDJ, 1962, p. 1-256;

${ }^{73}$ TRINDADE, A. A. Cançado. op. cit. supra n. (63), 2003. p. 51-55. 
tada por uma Convenção ou Convenções (atuais Pactos), e efetivada por medidas de implementação ${ }^{74}$. Apesar de adotada a DUDHs em 1948; somente em 1996, foram adotados os dois Pactos de Direitos Humanos das Nações Unidas (PDHsNU). Ao passo que as medidas de implementação foram longamente consideradas nos trabalhos preparatórios (que perduraram de 1947-1966) - fruto do trabalho conjunto da ComDHsNU, da Assembléia Geral e do Conselho Econômico e Social (ECOSOC) - para elaboração dos 2 Pactos - Pacto Internacional sobre Direitos Civis e Políticos (PIDCP) e Pacto Internacional sobre Direitos Econômicos, Sociais e Culturais (PIDESC) - e do Protocolo Facultativo das Nações Unidas. As medidas de implementação foram compostas de 3 medidas principais: o Sistema de Relatórios (presentes nos 2 pactos); o sistema de comunicações inter-estatais (constante no PDCP e supervisionado pelo Comitê de Direitos Humanos) e o sistema de comunicações individuais (constante no Protocolo Facultativo do PDCP). ${ }^{75}$

A II Conferência Mundial de Direitos Humanos (Viena, 1993) deu continuidade à fase de implementação internacional dos DHs, em que os sistemas ou métodos de implementação dos $\mathrm{DHs}$ adotados pelos órgãos de supervisão dos tratados de DHs passam a interagir entre si e também com os mecanismos e procedimentos sem base convencional (sistema sob o ECOSOC e a ComDHsNU), com ação coordenada entre os métodos de implementação dos DHs numa visão sistêmica (coordenação e coexistência dos mecanismos de proteção dos DHs no nível global e regionais). Assim, a denúncia de um caso de violação de DHs pode acionar o sistema de investigação, que por sua vez acaba por movimentar o sistema de relatórios com a elaboração de um relatório sobre o caso. ${ }^{76}$

Sob outro enfoque, o direito de petição individual às autoridades centrais no plano interno teve desenvolvimento gradual, ocorrendo normalmente perante tribunais para reparação de danos. Já o direito de petição no plano internacional

\footnotetext{
${ }^{74}$ Para saber mais sobre o processo de elaboração da DUDH e dos 2 Pactos de Direitos Humanos das Nações Unidas (PDHNU): ler René Cassin, "La Déclaration Universelle et la mise em oeuvre des droits de l'homme", 79 Recueil des Cours de l'Acadèmie de Droit International (1951) p. 241-362.

75 TRINDADE, A. A. Cançado. op. cit. supra n. (63), 2003. p. 55-62, 77-84.

${ }^{76}$ Ibid., 2003, p. 91-100.
} 
surgiu perante as OIs, se dividindo entre as petições por reparação decorrentes de violação de direito privado individual (direito civil) e as petições por medidas públicas decorrentes de violação de interesses gerais de um grupo (direito político). ${ }^{77}$ A partir de meados do século XX, os órgãos da ONU deveriam receber e examinar as petições decorrentes de violações de DHs e tomar as medidas adequadas. No último quarto do século XX, firmou-se o direto de petição nos mecanismos convencionais (tratados e convenções de DHs) e extra-convencionais (resoluções) no nível global. O sistema de petições contemporâneo consolida a posição do indivíduo como sujeito e beneficiário último de todo direito, recuperando a presença que lhe havia sido negada no processo de formação do Estado moderno. ${ }^{78}$

Muito mais usado do que o direito de petição interestatais, o direito de petição individual encontra-se previsto, no plano global, no Protocolo Facultativo do PDCP (art. 1,2,3 e 5), na Convenção sobre a Eliminação de Todas a s Formas de Discriminação Racial (art. XIV) e na Convenção das Nações Unidas contra a Tortura (art. 22); e , no plano regional, na Convenção Européia de DHs (art. 25), na Convenção Americana de DHs (art. 44) e na Carta Africana de Direitos Humanos e dos Povos (arts 55,56,57 e 58). ${ }^{79}$

Os tratados de DHs estabelecem os seguintes parâmetros ou condições de admissibilidade das denúncias ou petições individuais ${ }^{80}$ : a) a petição não pode ser anônima, nem deve ser manifestamente infundada ou improcedente (quando não

\footnotetext{
${ }^{77}$ Para maiores informações sobre tais sistemas de petições em geral: cf. a coletânea de M. E. Tardu, Human Rights - The International Petition System, binders 1-3, Dobbs Ferry N.Y., Oceana, 1979-1985; cf T. Zwart, "The Admissibility of Human Rights Petitions - The Case Law of the Europen Commission of Human Rights and the Human Riths Committee, Dordrecht", Nijhoff, 1994, p. 1-237; cf Bertha Santoscoy, "La Commission Interméricaine des Drois de l'Homme et le dévelopement de sa compétene par le sytème des pétitions individuelles", Paris, PUF, 1995, p. 3-123 ;

78 TRINDADE, A. A. Cançado. op. cit. supra n. (63), 2003, p. 100-106.

${ }^{79}$ Ibid, p. 106.

${ }^{80}$ Para saber mais sobre condições de admissibilidade: cf.. H. Danelius, "Conditions of Admissibility in the Jurisprudence of the European Commission of Human Rights", 2 Revue des drois de l'homme/Human Rights Journal (1969), p. 284-336; cf. A.A. Cançado Trindade, "The Aplication of the Rule of Exhaustion of Lcal Remedies in International Law", Cambridge, Cambridge University Press, 1983, p. 271-272 e 407.
} 
viola disposições de tratados de DHs e não está devidamente provada a violação); b) não admissão da litispendência (identidade de objeto das reclamações e identidade das partes) entre órgãos de supervisão internacional, evitando-se o uso concomitante ou sucessivo do procedimento de petições; c) invocação do abuso de direito de petição ${ }^{81}$, quando o demandante usa linguagem difamatória contra o demandado e quando o demandante não atende as solicitações de esclarecimento dos órgãos de supervisão; d) não aceitação de petições incompatíveis (fora da competência) com os tratados ou convenções de DHs, ou mesmo com a organização internacional a eles vinculados; e) prévio esgotamento dos recursos do $\mathrm{Di}^{82}$ (interação e subsidiariedade entre o Di e o DI), daí a importância da função e aprimoramento dos órgãos e tribunais nacionais como integrantes do sistema internacional de proteção dos DHs. ${ }^{83}$

$\mathrm{O}$ atual aprimoramento e fortalecimento da capacidade processual internacional dos indivíduos se deve aos seguintes fatores: a) liberdade de escolha do procedimento pela suposta vítima; b) a aplicação do princípio da norma mais favorável à suposta vítima; c) complementaridade nos níveis global e regional dos procedimentos de proteção dos direitos humanos; d) os progressos da Corte Européia de DHs (CtEDHs). ${ }^{84}$

\subsection{Sistemas regionais de proteção internacional dos direitos humanos (diferença entre locus e jus)}

Dentre as vantagens trazidas pelos órgãos internacionais de supervisão nos planos global e regional estão as seguintes: a) salvar vidas: b) reparar danos; c) acabar com práticas administrativas violatórias dos DHs garantidos; d) alterar medidas le-

\footnotetext{
${ }^{81}$ Para saber mais sobre o abuso de direito de petição: cf. E. Schwelb, "The abuse of the Right of Petition", 3 Revue des droits de l'homme/Human Rights Journal (1970), p. 313-332.

${ }^{82}$ Para saber mais sobre esgotamento dos recursos internos: cf. A.A.Cançado Trindade, "O Esgotamento de Recursos Internos no Direito Internacional”, 1a ed., Brasília, Editora Universidade de Brasília, 1984, p. 243; cf. A.A. Cançado Trindade, "Origin and Historical Development of the Rule of Exhaustion of Local Remedies in International Law”, 12 Revue belge de droit internatonal (1976), p. 499-527

${ }^{83}$ TRINDADE, A. A. Cançado. op. cit. supra n. (63), 2003, p. 108-115.

${ }^{84}$ Ibid, p. 117-121.
} 
gislativas; e) adotar programas educativos; f) mudar o ordenamento jurídico interno; f) melhorar a prática dos órgãos públicos do Estado. Apesar do surgimento de uma nova mentalidade quanto à proteção dos $\mathrm{DHs}$ nos planos internacional e nacional, $\mathrm{e}$ de a maioria dos países terem ratificado os tratados de DHs, muitos DHs continuam a ser desrespeitados e novas formas de violação destes direitos surgiram. ${ }^{85}$

Os sistemas regionais de proteção internacional de direitos humanos (PIDHs) vivem momentos históricos distintos. A história e prática revelam as insuficiências e distorções do mecanismo da intermediação das Comissão Européia e Comissão Interamericana de Direitos Humanos (respectivamente ComEDHs e ComIDHs) entre os indivíduos e as Corte Européia e a Corte Interamericana de Direitos Humanos (respectivamente CtEDHS e CtIDHs). Desde seus primeiros casos contenciosos, tanto a CtEDHs quanto a CtIDHs desenvolveram mecanismos contrários à intermediação das suas respectivas Comissões. ${ }^{86}$

No sistema regional europeu de proteção, em 1960, no caso Lawless versus Irlanda, a CtEDHs recebeu de delegados de sua Comissão argumentos escritos pelos próprios demandantes. Ainda em 1970, nos casos Vagrancy, relativos à Bélgica, a CtEDHs deu a palavra, por solicitação da ComEDHs, a um advogado dos demandantes. Assim, com a entrada em vigor da Reforma do Regulamento da Corte de 1982 foi reconhecido o locus standi aos representantes legais dos indivíduos demandantes perante a Corte em casos a ela submetidos pela Comissão ou pelos Estados Partes. Com a adoção em 1990 do Protocolo no 9 à Convenção Européia foi reconhecido um locus standi aos indivíduos perante a Corte, sem intermediação dos delegados da Comissão, mas sem garantia da igualdade processual das partes (equality of arms/égalité des armes). Somente com a entrada em vigor em 1998 do Protocolo $\mathrm{n}^{\circ} 11$ à Convenção um jus standi foi reconhecido aos indivíduos perante a CtEDHs como verdadeiro sujeitos de DIDHs. ${ }^{87}$

\footnotetext{
${ }^{85}$ TRINDADE, Antônio Augusto Cançado. Direitos Humanos no Século XXI: "A consolidação da Capacidade Processual dos Indivíduos na Evolução da Proteção Internacional dos Direitos Humanos: Quadro Atual e Perspectivas na Passagem do Século”. Organizadores: Paulo Sérgio Pinheiro e Samuel Pinherio Guimarães. Brasília: IPRI, 2002. p. 21-22.

${ }^{86}$ Ibid., p. 21, 28-31.

${ }^{87}$ Ibid., p. 33-35.
} 
No sistema regional americano de proteção, no Regulamento de 1991, a Convenção Americana previa tímida participação das vítimas ou seus representantes perante a CtIDHs, somente para reparações e se convidado. Desde seus primeiros casos contenciosos a CtIDHs percebeu as fraquezas de seu sistema, tendo decidido, juntamente com a ComIDHs numa reunião em 1994, que aceitaria a participação dos representantes legais das vítimas como assistentes integrantes da delegação da ComIDHs. Em 1996, no caso El Amparo, um dos magistrados no interrogatório passou a dirigir perguntas diretamente aos representantes das vítimas e não aos delegados da ComIDHs ou aos agentes do governo; assim como tomaram nota dos pontos de vista da ComIDHs, do Estado demandado e também dos peticionários e dos representantes legais das famílias das vítimas. A partir de 01.01.1997 entrou em vigor novo Regulamento da Corte. ${ }^{88}$

No sistema regional africano de proteção, primeiramente foi constituída a Comissão Africana de Direitos Humanos e dos Povos, e posteriormente o Protocolo à Carta Africana de Direitos Humanos e dos Povos estabeleceu a Corte Africana de Direitos Humanos e dos Povos ${ }^{89}$. Quanto a um sistema regional árabe de proteção, em 1994, o Conselho da Liga dos Estados Árabes adotou a Carta Árabe de Direitos Humanos, mas ainda não há nem uma Comissão nem uma Corte de Direitos Humanos. ${ }^{90}$

Nos casos enviados à CtIDHs já é reconhecida a atuação em juízo (locus standi in judicio) das supostas vítimas (ou seus representantes legais). Enquanto nos casos enviados à $\mathrm{CtEDHs}$ há o reconhecimento do direito de acesso direto do indivíduo à uma corte internacional de DHs (jus standi in judicio), que é o ponto culminante da evolução da PIDHs, quando então há a consolidação da capacidade processual dos indivíduos, sendo o ser humano finalmente reconhecido como sujeito do DIDHs, dotado de plena capacidade e personalidade jurídica internacional. O locus standi e o jus standi demonstram uma nova fase do DIDHs, representando a passagem de uma ordem internacional das soberanias absolutas (com

\footnotetext{
${ }^{88}$ Ibid, p. 36-39.

${ }^{89}$ Para maiores informações sobre a Corte Africana, cf. ANEXO A.

${ }^{90}$ TRINDADE, A. A. Cançado. op. cit. supra n. (84), 2002, p. 21.
} 
monopólio estatal da titularidade de direitos, em que os indivíduos são submetidos à intermediação discricionária de seus Estados) para uma ordem internacional da solidariedade (tendo o ser humano como ente central das normas jurídicas) pela assunção dos seguintes cânones: I) realização de valores comuns superiores; II) titularidade de direitos do próprio ser humano e sua realização via garantia coletiva; III) reconhecimento do caráter objetivo das obrigações de proteção. ${ }^{91}$

O direito de petição individual é uma conquista definitiva do DIDHs, consagrado, como instrumento de PIDHs pela emancipação do ser humano, no art. 25 da Convenção Européia e no art. 44 da Convenção Americana sobre Direitos Humanos. Ademais, o Programa de Ação de Viena, principal documento da II Conferência Mundial de Direitos Humanos, recomendou a adoção dos procedimentos facultativos de petições e comunicações individuais. Acrescente-se ainda que a jurisdição obrigatória das CtEDHs e da CtIDHs em casos contenciosos está prevista no art. 46 da Convenção Americana e no art. 62 da Convenção Européia. ${ }^{92}$

\section{Petições individuais na Corte Européia de direitos humanos (CtEDHs) após o protocolo onze}

\subsection{Justificativas preliminares pela escolha da CtEDHs e da CtIDHs}

\subsubsection{A ONU e a Corte Internacional de Justiça}

Fundada em 1945 (através do Tratado de São Francisco, atual Carta da ONU) como sucessora da Liga das Nações, a ONU ${ }^{93}$ é uma organização internacional, sediada em Nova York (EUA), com o objetivo de promover o diálogo e a cooperação internacional através do progresso social, do DI, do desenvolvimento econômico, da promoção da paz e da proteção dos DHs. A ONU é composta pelos seguintes órgãos principais: Assembléia Geral (AGNU - órgão representativo, deliberativo

\footnotetext{
${ }^{91}$ Ibid, p. 32-33, 39-43.

92 Ibid, p. 31-32.

${ }_{93}$ Para melhor compreender a ONU, consultar seus documentos no site: <http://www. un.org/en/documents/index.shtml $>$. Ultimo acesso: 07.09.09.Cf. ANEXOS B a E.
} 
e político da ONU) ${ }^{94}$; Conselho de Segurança (CSNU - órgão responsável pela manutenção da paz e segurança internacionais) ${ }^{95}$; Conselho Econômico e Social (ECOSOC - órgão responsável pelo desenvolvimento e cooperação econômica e social internacional) ${ }^{96}$; o Secretariado ( é o conjunto de todo os funcionários da ONU por todo o mundo $)^{97}$; a Corte Internacional de Justiça (CIJ - principal órgão judiciário da ONU) ${ }^{98}$; e Trusteeship Council (órgão da ONU encarregado de

${ }^{94}$ A Assembléia geral da ONU trata das questões de paz e segurança internacionais; aprova o orçamento da ONU; define o aporte financeiro de cada país, além de indicar o Secretário-Geral da ONU e eleger os membros não permanentes do CSNU, os membros dos demais conselhos e órgãos da ONU. Para maiores informações sobre a AGNU cf. o site: $<$ http://www.un.org/ga/>; e cf. as Regras de Procedimento da AGNU no site: <http:// www.un.org/ga/ropga.shtml $>$. Ultimo acesso: 07.09.09.

${ }^{95} \mathrm{O}$ CSNU, composto de 5 Estados-membros permanentes (China, Estados Unidos, França, Inglaterra e Rússia) e 10 Estados-membros não permanentes, trata de qualquer questão ou situação que possa levar a conflitos internacionais; recomenda métodos de solução das disputas; formula planos de controle dos armamentos e estratégias de ação para evitar atos de agressão (como sanções econômicas e ação militar); e apóia a admissão de novos membros à ONU. Para maiores informações do CSNU cf. o site: <http://www.un.org/ Docs/sc/>; e verificar as Regras de Procedimento da CSNU no site: $<$ http://www.un.org/ Docs/sc/scrules.htm $>$. Ultimo acesso: 07.09.09

${ }^{96}$ Detentor de $70 \%$ do capital humano e financeiro da ONU, o ECOSOC (composto de 54 membros eleitos pela AGNU para mandatos de 3 anos) é o fórum central de discussão das questões econômicas e sociais, coordena o trabalho das agências especializadas da ONU, recebe relatórios dos fundos e programas da ONU, além de formular recomendações políticas para os Estados-Membros e para o sistema ONU. Para maiores informações sobre o ECOSOC cf. o site: <http://www.un.org/ecosoc/>; e verificar as Regras de Procedimento do ECOSOC no site: <http://www.un.org/ecosoc/about/pdf/rules.pdf $>$.

${ }^{97}$ Chefiado pelo Secretário-Geral da ONU (recomendado pelo CSNU e eleito pela AGNU para um mandato de 5 anos), o Secretariado da ONU é que mantém a instituição funcionando, eles administram os programas e as políticas estabelecidas pelos órgão principais. Para maiores informações sobre o Secretariado, cf. o site: <http://www.un.org/en/mainbodies/secretariat/>. Ultimo acesso: 07.09.09.

${ }^{98}$ Sediado em Haia, a CIJ é órgão responsável por resolver disputas legais entre os Estados e prestar opiniões consultivas à $\mathrm{ONU}$ e suas agências especializadas. Para maiores informações sobre a CIJ, cf. o site <http://www.icj-cij.org/>. Para análise mais aprofundada CIJ, ler o Relatório da CIJ no site <http://unbisnet.un.org:8080/ipac20/ipac. jsp ? $i p=20 \& s p=20 \&$ profile $=$ bib\&ri $=$ \&index $=$. TW\&term $=$ Report + of + the + Interna tional + Court + of + Justice\&matchopt $=2 \% 7$ C0\&oper $=$ not\&aspect $=$ power\&index $=$. UD\&term=A\%2FDEC\%2F\#focus $>$; o Estatuto e o Regulamento da CIJ no site: $<$ http:// www.icj-cij.org/documents/index.php?p1=4\&p2=3\&p3=0 >. Ultimo acesso: 07.09.09. Cf. ANEXO F.

${ }^{98}$ Composto pelos cinco membros permanentes do CSNU, o Trusteeship Council objetiva examinar relatórios e petições (em matéria política, econômica, social ou educacional) 
supervisionar e administrar os Trust Territories sob a custódia do Trusteeship System $)^{99}$.

Embora, quando da criação da Corte Permanente de Justiça Internacional (CPJI - atual CIJ), tenha sido aventada e discutida a possibilidade de um indivíduo poder acionar um Estado, a idéia não vingou face à idéia de que os indivíduos não eram sujeitos de DI, porque este seria domínio reservado aos Estados; tal postura foi duramente criticada na época, já que havia instrumentos de DI que consagravam "a capacidade de intervenção do indivíduo no processo", tais como a Comissão Central para a Navegação do Reno (1816); o projeto de Criação do Tribunal Internacional de Presas (1907); o Tribunal Centro-americano de Justiça (1907-1908); a Convenção sobre a Alta Silésia (1922-1937) e os Tribunais mistos. ${ }^{100}$

Composta atualmente por 15 juízes, a CIJ possui 2 papéis principais: julgar os conflitos legais entre Estados, desde que solicitados por estes; e dar opiniões consultivas em matérias legais, desde que solicitada pelos órgãos da ONU ou suas agências especializadas. Conforme o Estatuto da CIJ (ECIJ) todos os Estados (não somente os 192 Estados-membros da ONU) podem submeter casos à jurisdição da CIJ, em outras palavras, a CIJ não possui jurisdição sobre demandas ou solicitações de indivíduos, de ONGs, de corporações ou quaisquer entidades privadas. Embora a CIJ seja um dos foros pioneiros na solução de litígios entre Estados soberanos e venha se expandindo atualmente, ela tem sido muito criticada devido sua jurisdição facultativa (as partes voluntariamente determinam sua submissão ou não à jurisdição da CIJ, o tempo e a matéria de competência da CIJ) e ao não reconhecimento da legitimidade ativa das OIs (já que as OIs tem participação proeminen-

das autoridades administrativas nos Trust Territories, perdurando enquanto os estes últimos não alcançarem sua independência ou auto-governo (separação de estados ou união de países independentes). Para mais dados, cf. o site, seja pela separação de estados ou pela união a países independentes. Para maiores informações, cf. o site: <http://www. un.org/en/mainbodies/trusteeship/>. Ultimo acesso: 07.09.09.

${ }^{100}$ BARRETTO, Ireneu Cabral. O recurso individual no tribunal europeu dos direitos do homem. In: Os rumos do Direito Internacional dos direitos humanos: ensaios em homenagem ao professor Antônio Augusto Cançado Trindade/Renato Zebini Ribeiro Leão, coord. - Porto Alegre: Sergio Antonio Fabris Ed. 2005, TOMO I, p. 290-291. 
te no atual cenário internacional $)^{101}$. As solicitações de nacionais somente serão aceitas, se seus Estados aceitarem advogar suas causas e se forem contra outros Estados, quando então os conflitos poderão ser julgados pela CIJ. Face ao exposto, apesar de importante órgão do sistema universal de PIDHs, a CIJ não será objeto de análise aprofundada nesta monografia, porque não é um exemplo de tribunal internacional que aceite a petição, a comunicação ou responsabilização judicial individual, como o são as CtEDHs (em Estraburgo, França), a CtIDHs (em São José, Costa Rica), a CtEJ (em Luxemburgo) e o TPI (em Haia, Holanda).

\subsubsection{A ONU e seu Conselho dos Direitos Humanos}

Contudo, ainda dentro do sistema universal de proteção dos DHs, cabe destacar o sistema de petições individuais do Conselho dos Direitos Humanos das Nações Unidas (ConDHsNU). No sistema internacional de DHs, especificamente no concernente ao sistema ONU (treaty body system), há 3 procedimentos principais de denunciar violações dos tratados de direitos humanos: comunicações individuais (individual communications); reclamações interestaduais (state-to-state complaints) e investigações (inquiries). Além destes três, há 2 procedimentos de rito especial: o da resolução 1503 da ConDHsNU (antiga Comissão de Direitos Humanos) ${ }^{102}$, e o da Comissão sobre a Condição da Mulher ${ }^{103}$.

No sistema internacional, há 6 Comitês (que podem em caráter de urgência requerer a suspensão de sentenças de morte, a realização de exames médicos urgentes ou evitar ameaças de expulsão), que são órgãos criados para monitorar o

${ }^{101}$ LOCATELLI, Liliana. Corte Internacional da Justiça. In: Tribunais internacionais: mecanismos contemporâneos de solução de controvérsias /Welber Barral, organizador. Florianópolis: Fundação Boiteux, 2004, p. 13-30.

${ }^{102}$ Para entender o procedimento especial perante o ConDHsNU, cf. site <http://www2. ohchr.org/english/bodies/chr/complaints.htm>; para maiores informações sobre tal procedimento cf. site: <http://www2.ohchr.org/english/bodies/chr/special/index.htm>; para saber sobre a petição individual perante o ConDHsNU cf. o site: <http://www2.ohchr. org/english/bodies/chr/special/communications.htm >. Ultimo acesso: 07.09.09.

${ }^{103}$ Para entender o procedimento especial perante a Comissão sobre Condição da Mulher da ONU, consultar informações em < http://www2.ohchr.org/english/bodies2/petitions/ CSW.htm>. Ultimo acesso: 07.09.09. 
cumprimento de um tratado específico de DHs, cuja competência inclui a análise de relatórios dos Estados-partes sobre medidas internas de implementação dos direitos protegidos; o recebimento de queixas interestatais sobre o descumprimento do tratado internacional e o reconhecimento (desde que em petição escrita, não anônima, sobre violação de DHs protegidos por convenções ou tratados internacionais, que não tenha sido ou estejam sendo examinada por outro órgão internacional de monitoramento, e que haja prévio esgotamento dos recursos internos ${ }^{104}$ ) de petições ou comunicações de indivíduos ou grupos de indivíduos que se considerem vítimas de violação cometida por um Estado que tenha aceito a competência dos Comitês. ${ }^{105}$

Tais Comitês e os documentos legais de previsão de petições individuais são respectivamente os seguintes: 1) o Comitê de Recursos Humanos (CRHNU ou $H R C)^{106}$, disciplinado no Primeiro Protocolo Adicional da Convenção Internacional de Direitos Civis e Políticos ${ }^{107}$; 2) o Comitê sobre a Eliminação da Discriminação contra Mulheres (CEDMNU ou $C E D A W)^{108}$, disciplinado no Protocolo Facultativo à Convenção sobre a Eliminação de Todas as Formas de Discrimina-

\footnotetext{
${ }^{104} \mathrm{Tal}$ requisito do prévio esgotamento dos recursos internos pode ser flexibilizado em 5 situações: 1) quando não houver razoável prestação jurisdicional no ordenamento jurídico interno; 2) quando houver demora excessiva no processo; 3) quando inexistir a conexão entre a vítima e o Estado responsável; 4) quando as circunstâncias do caso não recomendarem a exaustão dos recursos internos; 5) ou quando o Estado responsável tenha dispense o esgotamento dos recursos internos. PETIOT,Patrick. A responsabilidade internacional do Estado brasileiro por violação de diretos humanos: o pagamento de reparações. Brasília, 2005, p. 75.

${ }^{105}$ Para maiores informações, cf. os sites: <http://www2.ohchr.org/english/bodies/petitions/index.htm>; e <http://www2.ohchr.org/english/bodies/complaints.htm>. Ultimo acesso: 07.09.09,

${ }^{106}$ Para mais dados, cf. o site: < http://www2.ohchr.org/english/bodies/hrc/procedure.htm $>$. Ultimo acesso: 07.09.09. Cf. ANEXO G.

${ }^{107}$ Cf. conteúdo da Convenção no site: $<$ http://www2.ohchr.org/english/law/ccpr.htm $>$; cf. o conteúdo do Primeiro Protocolo no site: $<$ http://www2.ohchr.org/english/law/ccpr-one.htm >. Ultimo acesso: 07.09.09. Cf. ANEXO H.

${ }^{108}$ Para mais dados, cf. o site: <http://www2.ohchr.org/english/bodies/cedaw/index.htm>. Ultimo acesso: 07.09.09. Cf. ANEXO I.
} 
ção contra Mulheres de $\left.1979^{109} ; 3\right)$ o Comitê contra a Tortura $(\text { CTNU ou CAT) })^{110}$, disciplinado através do art. 22 da Convenção contra Tortura de $1984^{111}$; 4) Comitê sobre a Eliminação de todas as formas de Discriminação Racial (CEDRNU ou $C E R D)^{112}$, disciplinado através do art. 14 da Convenção contra a Eliminação da Discriminação Raciall ${ }^{113}$; 5) Comitê dos Direitos das Pessoas com Deficiências (CDPDNU ou CRPD) $)^{114}$ através do Protocolo Opcional da Convenção sobre Direitos de Pessoas com Deficiência ${ }^{115}$. Ressalte-se ainda outros 2 Comitês importantes da ONU na defesa de DHs: o Comitê dos Trabalhadores Migrantes (CTMNU ou $C M W)^{116}$, cujo instrumento legal prevê o direito de petição individual, que não foi ainda implantado, no art. 77 da Convenção dos Trabalhadores Migrantes de 1990 ${ }^{117}$; enquanto o Comitê dos Direitos da Criança (CDCNU ou $\left.C R C\right)^{118}$ não traz previsão legal para petições individuais.

Embora o sistema ONU disponha do atual e recente procedimento de petições individuais (novo tipo de procedimento imparcial, objetivo, eficiente e vol-

\footnotetext{
${ }^{109} \mathrm{Cf}$. o conteúdo da Convenção no site: < http://www2.ohchr.org/english/law/cedaw. htm>; e cf. conteúdo do Primeiro Protocolo no site: <http://www2.ohchr.org/english/ law/cedaw-one-about.htm>. Ultimo acesso: 07.09.09. Cf. ANEXO J. O Brasil assinou o Protocolo Facultativo m 13/03/2001, que foi aprovado pelo CN pelo Decreto Legislativo $\mathrm{n}^{\circ}$ 107/02 e promulgado pelo Presidente mediante o Decreto ${ }^{\circ} 4.316 / 02$.

${ }^{110}$ Para mais dados, cf. o site: <http://www2.ohchr.org/english/bodies/cat/procedure. htm>. Ultimo acesso: 07.09.09. Cf. ANEXO J.

${ }^{111}$ Cf. conteúdo da Convenção no site: <http://www2.ohchr.org/english/law/cat.htm>. Ultimo acesso: 07.09.09. Cf. ANEXO L.

${ }^{112}$ Para mais dados, cf. o site: <http://www2.ohchr.org/english/bodies/cerd/procedure. htm>. Ultimo acesso: 07.09.09. Cf. ANEXO M.

${ }^{113}$ Cf. conteúdo da Convenção no site: < http://www2.ohchr.org/english/law/cerd.htm>. Ultimo acesso: 07.09.09. Cf. ANEXO N.

${ }^{114}$ Para mais dados, cf. o site: <http://www.ohchr.org/EN/HRBodies/CRPD/Pages/CRPDIndex.aspx $>$. Ultimo acesso: 07.09.09.

${ }^{115}$ Cf. conteúdo da Convenção no site: <http://www2.ohchr.org/english/law/disabilities-convention.htm>, e cf. conteúdo do Protocolo no site: <http://www2.ohchr.org/english/law/disabilities-op.htm>. Ultimo acesso: 07.09.09. Cf. ANEXO O.

${ }^{116}$ Para mais dados, cf. o site: < http://www2.ohchr.org/english/bodies/cmw/index.htm>. Ultimo acesso: 07.09.09.

${ }^{117} \mathrm{Cf}$ o conteúdo da Convenção no site: < http://www2.ohchr.org/english/law/cmw.htm > Ultimo acesso: 07.09.09. Cf. ANEXO P.

${ }^{118}$ Para mais dados, cf. o site: < http://www2.ohchr.org/english/bodies/crc/index.htm>. Ultimo acesso: 07.09.09. Cf. ANEXO Q.
} 
tado para as vítimas de violações de $\mathrm{DHs}$ ) dirigidas ao ConDHsNU (estabelecido em conformidade com a Resolução 60/251 de 15/03/2006 da AGNU para revisão, melhoramento e racionalização dos mandatos, mecanismos, funções e responsabilidades da antiga Comissão de Direitos Humanos da ONU), desde a adoção em 18/06/2007 da Resolução 5/1, intitulada "UN Human Rights Council: Institution Building" a fim de combater as violações de todos os DHs e liberdades fundamentais ocorridas em qualquer parte do mundo, sob quaisquer circunstâncias, o presente trabalho não se dignará a aprofundar o assunto, por não se tratar de um órgão judiciário propriamente dito, embora trate-se de petições individuais em matérias de violação de DHs.

\subsubsection{A União Européia e a Corte Européia de Justiça}

A fim de frear o avanço comunista e estabelecer a defesa mútua e cooperação econômica, social e cultural entre os países da Europa, foram assinados (pela Bélgica, França, Luxemburgo, Países Baixos e Reino Unido) o Tratado de Bruxelas de 1948 e os Acordos de Paris de 1954 (com inclusão da Alemanha Oriental e da Itália), que criaram a União da Europa Ocidental (UEO ou WEU) ${ }^{119}$. Neste mesmo período, a fim de evitar mais conflitos entre a França e a Alemanha, foi sugerida a criação de uma Comunidade Supranacional, atualmente assentada sobre 3 pilares: 1) o pilar econômico, resultando na assinatura (pela Alemanha Ocidental, Bélgica, França, Itália, Luxemburgo e Países Baixos) do Tratado de Paris de 1951, que criou a Comunidade Européia do Carvão e do Aço (CECA ou ECSC), que se fundiu em 1967 à Comunidade Econômica Européia (CEE ou EEC, estabelecida pelo Tratado de Roma de 1957, que também criou a Comunidade Européia da Energia Atômica - CEEA ou EURATOM ${ }^{120}$ ), passando a se chamar Comunidade Européia (CE), que em 2002 foi absorvida pela União Européia (UE); 2) o pilar político, iniciado com a Cooperação Política Européia- CPE ou EPC (resultante da Cúpula de Haia de 1969 e do Relatório de Luxemburgo/Davignon de 1970, emendado pelo Rela-

\footnotetext{
${ }^{119}$ Para mais dados sobre a UEO, cf o site : <http://www.weu.int/>. Ultimo acesso: 07.09.09. Cf. ANEXO R e S.

${ }^{120}$ Para mais dados sobre a CEEA, cf. o site: < http://www.euratom.org/>. Ultimo acesso: 07.09.09.
} 
tório de Copenhague de 1973 e Relatório de Londres de 1981, até ser codificado pelo Ato Europeu Simples de 1986 - AES ou SEA para revisão dos Tratados de Roma $^{121}$ ), atualmente denominada Política Externa de Segurança Comum (PESC - CFSP ${ }^{122}$ ) da União Européia; 3) e o pilar político-jurídico, a cooperação judicial da Comunidade Européia se transformou na Justiça e Relações Domésticas (JRD ou JHA) surgido com o Tratado de Masstricht de 1992 (tratado da UE) até evoluir para o atual sistema de Cooperação Política e Judicial em Matérias Criminais (CPJMC ou PJCC) surgido com o Tratado de Amsterdã de 1999. Assim atualmente a União Européia (UE) reúne 27 países membros, e é composta pelas seguintes instituições principais: Comissão Européia; o Parlamento Europeu, o Conselho da União Européia, o Conselho Europeu, a Corte Européia de Justiça (CtEJ) e o Banco Central Europeu.

Estabelecida em 1952 pelo Tratado de Paris de 1952 e com sede em Luxemburgo, a Corte de Justiça das Comunidades Européias (CtJCE ou ECJ) ou Corte Européia de Justiça (CtEJ) ${ }^{123}$ é a mais alta Corte da UE em termos de Direito Internacional Comunitário (atua para assegurar a interpretação e aplicação uniforme dos tratados da UE, para sancionar ou esclarecer o descumprimento das obrigações comunitárias pelos Estados membros ${ }^{124}$, para anular medidas anticomunitárias adotadas pelas instituições da $\mathrm{UE}^{125}$, para arbitrar conflitos entre estas e para receber apelações em matéria de direito contra decisões da Corte Européia de Primeira Instância $\left.{ }^{126}\right)$. A Corte Européia de Primeira Instância ${ }^{127}$, por sua vez, possui

\footnotetext{
${ }^{121}$ Sobre o Single European Act, cf. o site: < http://www.historiasiglo20.org/europe/acta. htm>. Ultimo acesso: 07.09.09.

${ }^{122}$ Para mais dados sobre a PESC, cf. os sites: <http://ec.europa.eu/external_relations/ cfsp/intro/index.htm $>$; e $<$ http://europa.eu/pol/cfsp/index_en.htm $>$. Ultimo acesso: 07.09.09.

${ }^{123}$ Para mais dados sobre a CtJCE, cf. o site: $<$ http://curia.europa.eu/jcms/jcms/j_6/>. Ultimo acesso: 07.09.09. Cf. ANEXO T.

${ }^{124}$ Art. 226 do Tratado Constitutivo da Comunidade Européia. Neste caso de descumprimento das obrigações comunitárias pelo Estado, a questão pode ser levada à CtEJ pelo Estado-membro ofendido ou pela Comissão.

${ }^{125}$ Arts. 230 e 231 do Tratado Constitutivo da Comunidade Européia.

${ }^{126}$ Art. 225 do Tratado Constitutivo da Comunidade Européia.

${ }^{127} \mathrm{O}$ Regulamento do Tribunal de Primeira Instância das Comunidades Européias, no site: $<$ http://curia.europa.eu/jcms/upload/docs/aplication/pdf/2008-09/txt7_2008-0925_10-34-31_908.pdf>. Ultimo acesso: 07.09.09. Cf. ANEXO U.
} 
as seguintes competências: receber ações contra atos das instituições comunitárias; analisar recursos dos Estados contra a Comissão ou Conselho da UE; apurar ações de ressarcimento de danos causados pelas instituições comunitárias ou seus agentes; admitir ações previstas em contratos celebrados pelas Comunidades; além de examinar recursos em matérias de marcas comunitárias e recursos contra as decisões do Tribunal da Função Pública. ${ }^{128}$

Desde 1950, todos os Estados-membros da UE ${ }^{129}$ são membros do Conselho da Europa e assinaram a Convenção Européia de Direitos Humanos, estando obrigados pelo art. 6 do Tratado Constitutivo da União Européia (TCUE ou CTEU) a respeitar os DHs protegidos pela Convenção Européia de DHs, embora nem todos sejam necessariamente obrigados à jurisdição da CtEDHs (sediada em Estrasburgo), seriam obrigados se o Tratado de Lisboa de 2007 (Tratado da Constituição Européia) tivesse sido ratificado. Além disso, se, o Tratado da União Européia (TUE ou TEU) e o Tratado da Comunidade Européia (TCE ou TEC), tivessem se transformado com a vigência do Tratado de Lisboa de $2007^{130}$, a CtEJ passaria a chamar-se Corte de Justiça da União Européia, e a Corte de Primeira Instancia passaria a se chamar Corte Geral.

Surgido de uma experiência política inédita na história das relações internacionais, a CtEJ - último intérprete sobre a adequação de normas comunitárias e nacionais ao Tratado da Comunidade Européia (Constituição Comunitária) - integra um sistema jurisdicional comunitário e está encarregado de efetuar um triplo controle: quanto à legalidade de atuação das instituições comunitárias; quanto ao cumprimento dos Tratados (ordenamento jurídico comunitário); e quanto à

${ }^{128}$ Para mais dados sobre a CtEJ, cf. o site: < http://curia.europa.eu/jcms/jcms/j_6/pagina-incial $>$. o Estatuto e o Regulamento do Tribunal de Justiça serão respectivamente nos sites: <http://curia.europa.eu/jcms/upload/docs/aplication/pdf/2008-09/statut_2008-09-26_10-55-50_46.pdf $>$ e $<$ http://curia.europa.eu/jcms/upload/docs/aplication/pdf/2008-09/txt5_2008-09-26_10-57-1_914.pdf >. Ultimo acesso: 07.09.09.

${ }^{129}$ Sobre a União Européia (UE), cf. o site: < http://europa.eu/ > . Ultimo acesso: 07.09.09. Cf. ANEXOS V e X.

${ }^{130}$ Sobre o Tratado de Lisboa, cf. o site: < http://europa.eu/lisbon_treaty/index_en.htm >. Ultimo acesso: 07.09.09. Cf. ANEXO Y. 
aplicação do Direito Comunitário pelos Estados-membros ${ }^{131}$. Embora a CtEJ seja um importante órgão judiciário e bom exemplo de órgão que aceita as petições individuais, não será aqui aprofundada sua análise, por se tratar de um órgão que não está adstrito às violações de direitos humanos, mas por abarcar 2 funções muito amplas e referentes ao Direito Comunitário: a interpretação e a validade da vasta legislação da Comunidade Européia, o que iria além das pretensões da atual pesquisa.

Face o exposto, conclui-se que há basicamente duas técnicas de controle das violações de DHs: as técnicas não jurisdicionais (usadas no âmbito dos instrumentos universais de DHs, têm caráter facultativo, baseadas na soberania dos Estados no domínio da política interestadual, podem ser estabelecido através de queixas como as dos supracitados Comitês do Conselho de Direitos Humanos da ONU ou através de relatórios, como ocorre ns demais órgãos da ONU) e as técnicas jurisdicionais (usadas no âmbito dos instrumentos regionais de DHs, têm caráter obrigatório, buscando oferecer garantia efetiva de proteção dos DHs, já que as decisões possuem a autoridade da coisa julgada, como ocorre na CtEDH e na CtIDH).

\subsection{Petições individuais na CtEDHs}

\subsubsection{Conselho da Europa}

Os traumas gerados com as duas Guerras Mundiais, com a Guerra Civil Espanhola, com o Holocausto, com as bombas de Hiroshima-Nagasaki, com os conflitos de Guernica geraram a necessidade da instrumentalização da proteção dos DHs. A Carta de São Francisco (1945) e a DUDHs (1948) criaram paradigmas para a instrumentalização de um minimum standard de proteção jurídica internacional dos DHs nos ordenamentos jurídicos nacionais. Neste contexto em 1949 foi assinado o tratado que instituiu o Conselho da Europa ${ }^{132}$ a fim de defender os DHs fundamentais e manter a paz continental. Consequentemente, em 1950, o

\footnotetext{
${ }^{131}$ KEGEL, Patrícia Luíza. Tribunais internacionais: mecanismos contemporâneos de solução de controvérsias /Welber Barral, organizador. - Florianópolis: Fundação Boiteux, 2004, p. 155-176.

${ }^{132}$ Cf. ANEXO W.
} 
Conselho adotou a Convenção Européia para Proteção dos Direitos do Homem e das Liberdades Fundamentais ${ }^{133}$, que institucionalizou 3 órgãos: o Comitê de Ministros do Conselho da Europa (CMCoE -Comitê executava as sentenças da CtEDHs), a Comissão Européia de Direitos Humanos (ComEDHs era órgão imparcial, independente, funcionando como verdadeiro filtro das queixas contra autoridades públicas, decidia sobre a admissibilidade das demandas e pronunciava-se sobre a existência ou não de violações à Convenção ${ }^{134}$ ) e a Corte Européia de Direitos Humanos (CtEDHs , que pronunciava-se somente sobre a existência de violação nos casos apresentados pela ComEDHs). ${ }^{135}$

Fundado pelo Tratado de Londres de 1949 e sediada em Strasbourg na França, o Conselho da Europa (CoE), assim como a UE (composta por 27 Estados-membros), também objetiva a integração européia; contudo, o Conselho da Europa (composto por 47 Estados-membros europeus, 5 observadores no Conselho e 3 observadores na Assmbléia) enfatiza os padrões legais, os DHs, o desenvolvimento democrático, o império do direito e a cooperação cultural. Em matéria de DHs, o CoE se fundamenta em 2 documentos principais, ambos guiados pelo valor fundamental da dignidade humana: a Convenção Européia de Direitos Humanos de 1950 e seus Protocolos Adicionais ${ }^{136}$ (para proteção principalmente de direitos civis e políticos; supervisionada pela CtEDHs); e a Carta Social Européia de $1959^{137}$ (para proteção principalmente dos direitos econômicos, sociais e culturais; supervisionada pelo Comitê Europeu de Direitos Sociais - CEDS). ${ }^{138}$

${ }^{133}$ A Convenção Européia entrou em vigor desde 3/setembro/1953, com o depósito do décimo instrumento de ratificação.

${ }^{134}$ SANCTIS, Fausto Martins de. A Corte Européia de Direitos do Homem. Revista Jurídica Consulex, Ano V, no 97, 31/1/2001, p. 62-63.

${ }^{135}$ FERREIRA, Gustavo Assed. “Corte Européia de Direitos Humanos”. In Tribunais Internacionais: mecanismos contemporâneos de solução de controvérsias/ Welber Barral, organizador. - Florianópolis: Fundação Boiteux, 2004, p. 277.

${ }^{136}$ Sobre a Convenção Européia e seus Protocolos Adicionais, cf o site: <http://conventions. coe.int/Treaty/EN/Treaties/Html/005.htm >. Ultimo acesso: 07.09.09. Cf. ANEXO Z.

${ }^{137}$ A Cata Social Européia de 1959 foi adotada em 18.10.1961 e enrou em vigor em 26.02.1965. ${ }^{138}$ LEÃO, Renato Zerbini Ribeiro. La construcción jurisprudencial de los sistmas europeo e interamericano de protección de los derechos humanos em matéria de derechos econômicos, sociales y culturales. Porto Alegre: Núria Fabris Ed., 2009, p. 101-105. 


\subsubsection{Direitos e proibições presentes na convenção e seus protocolos}

Basicamente a Convenção Européia e seus Protocolos Adicionais trazem as seguintes garantias expressas: o direito à vida (art. 2) ${ }^{139}$; direito à liberdade e à segurança (art. 5) ${ }^{140}$; direito a um julgamento justo com duração razoável do processo (art. 6) ${ }^{141}$; direito ao respeito à vida privada e familiar (art. 8$)^{142}$; direito à liberdade de pensamento, de consciência e de religião (art. 9); direito à liberdade de expressão (art. 10); direito à liberdade de reunião e associação (art. 11); direito ao casamento (art. 12); direito a um recurso efetivo (art. 13), seguindo o devido processo legal processos civil e criminal; direito à propriedade(art. 1 do Protocolo Adicional); direito à educação (art. 2 do Protocolo Adicional); direito à propriedade e ao gozo pacífico das suas posses (art. 1 do Protocolo Adicional); direito de votar e ser votado livremente (art. 3 do Protocolo Adicional), direito a um duplo grau de jurisdição em matéria penal (art. 2 do Protocolo $n^{\circ} 7$ ); direito a indenização no caso de erro judicial (art. 3 do Protocolo $n^{\circ} 7$ ); direito de não ser punido ou julgado duas vezes pela mesma razão (art. 4 do Protocolo $n^{\circ} 8$ ); direito de igualdade entre os cônjuges (art. 5 do Protocolo no 7 ).

Além das garantias supracitadas estão presentes na Convenção e seus Protocolos as proibições a seguir: proibição de tortura ou qualquer tratamento desumano ou degradante (art. 3 da Convenção) ${ }^{143}$; proibição do trabalho escravo ou forçado (art. 4 da Convenção); proibição de detenção arbitrária ou pena sem lei (art. 7 da Convenção); proibição da discriminação ao usufruto dos direitos e liberdades presentes na Convenção (art. 14 da Convenção); proibição do abuso de

${ }^{139}$ CtEDHs: Ver o Caso Streletz, Kessler y Krenz x Alemanha, sentença de 22/3/2001; Caso Calavelli y Coglio x Itália, sentença de 17/1/2002. ZERBINI LEÃO destaca que, embora não haja normativa específica expressa de proteção ao meio ambiente, pode-se invocar, para proteção do mesmo, violações do direito à vida, do respeito à vida privada e familiar e do direito à liberdade de expressão, op. cit supra n (137), p. 129.

${ }^{140}$ CtEDHs: Ver o Caso de Ifran Bilgin x Turquia, sentença de 17/7/2001; Caso Cicek x Turquia, sentença de 27/2/2001 (desaparecimentos forçados).

${ }^{141}$ CtEDHs: Ver o Caso X x França, sentença de 31/3/1992. BARRETTO acrescenta que a duração razoável do processo na CtEDHs depende da complexidade do caso, do comportamento do queixoso e das autoridades competentes, op. cit infra n. (147), p. 319.

${ }^{142}$ CtEDHs: Ver o Caso Mzurek x França, sentença de 1/2/2000, p. 50.

${ }^{143}$ CtEDHs: Ver o Caso Peers x Grécia, sentença de 21/5/1998; o Caso Kunda x Polônia, sentença de 26/10/2000; o Caso Valasinas x Lituânia, sentença de 14/3/2000. 
direito (art. 17); proibição da prisão por dívida (art. 1 do Protocolo $n^{\circ} 4$ ); proibição da expulsão dos nacionais ou de estrangeiros (art. 3 e 4 do Protocolo no 4 ); proibição da pena de morte (art. 1 do Protocolo n ${ }^{\circ}$ 6); proibição de qualquer forma de discriminação (art. 1 do Protocolo no 12$)^{144}$; abolição da pena de morte (art. 1 do Protocolo $\left.n^{\circ} 13\right)$. Quanto a Protocolo $n^{\circ} 14$, este, apesar de ainda não ratificado (já conta com 46 ratificações das 47 necessárias para sua entrada em vigor), traz novidades, tais como, uma nova forma de julgamento dos casos simples, um novo critério de admissibilidade das demandas e o prazo de 9 anos para o mandato dos juízes da CtEDHs. ${ }^{145}$

Há, contudo, que se falar em princípios implícitos, ou seja, proteções e proibições que, embora não formalmente previstos e especificados, podem ser protegidos, quais sejam: o direito ao meio ambiente ${ }^{146}$; o direito à assistência médica ${ }^{147}$; garantia do devido processo legal ${ }^{148}$; proibição da eutanásia ${ }^{149}$; o direito a um juízo justo $^{150}{ }^{151}$. Zerbini, atual coordenador do ACNUR no Brasil e doutor em Direito das Relações Internacionais pela Universidade de Madrid, também defensor da

${ }^{144}$ CtEDHs: Ver o Caso Certos aspectos do regime lingüístico de ensino na Bélgica, sentença de 23 de julho de 1968, p.34/35; o Caso Thlimmenos x Grécia, sentença de 6/4/2000; o Caso X eY x Países Baixos, sentença de 26/3/1985, p. 23/30. CONSELHO DA EUROPA: Ver o Caso Chahal x Reino Unido, sentença de 15/11/1996 (discriminação disfarçada na luta contra imigração ilegal); o Caso E.B x França, demanda 43546/2002, sentença de 22/1/2008 (discriminação de homossexuais no processo de adoção). Para mais dados sobre como a CtEDHs vem lidando com a discriminação. cf: LEÃO, Renato Zerbini Ribeiro, op. cit.supra n (137), 2009, p. 133-135.

${ }^{145}$ Sobre a Corte Européia, cf. o site: < http://www.echr.coe.int/NR/rdonlyres/65172EB7DE1C-4BB8-93B1-B28676C2C844/0/FactsAndFiguresENG10ansNov.pdf > . Ultimo acesso: 07.09.09. Cf. ANEXOS AA, BB e CC.

${ }^{146}$ CtEDHs: ver o Caso López Ostra x Espanha, sentença de 9/12/1994; Caso Maria Guerra e outros x Itália, sentença de 19/12/1998. ZERBINI LEÃO destaca que, embora não haja normativa específica expressa de proteção ao meio ambiente, pode-se invocar, para proteção do mesmo, violações do direito à vida, do respeito à vida privada e familiar e do direito à liberdade de expressão,op. cit ., 2009, p. 129.

${ }^{147}$ CtEDHs: ver o Caso Nitecki x Polônia, sentença de 10/5/2001.

${ }^{148}$ CtEDHs: ver o Caso Feldbrugge x Holanda, sentença de 29/4/2002;Caso Salesi x Itália, sentença de 26/2/1993; Caso Deumeland x Alemanha, sentença de 29/5/1986.

${ }^{149}$ CtEDHs: ver o Caso Pretty x Reino Unido, sentença de 29/4/2002.

${ }^{150}$ CtEDHs: ver o Caso Luedicke, Belkacem y Koç x Alemanha, sentença de 28/11/1978.

${ }^{151}$ Tais princípios foram invocados por ZERBINI LEÃO, op. cit. supra n (137), 2009, p. 128-131. 
"indivisibilidade, inerência, integridade e universalidade dos direitos humanos"152, destaca a importância da interrelação entre princípios : "A interrelação entre o Princípio da Autonomia, o Princípio da Igualdade e o Princípio da Não Discriminação é fundamental para a consolidação da dignidade humana no Direito. Consequentemente, estes constituem três princípios essenciais do DIDHs" ${ }^{153}$.

\subsubsection{As etapas de evolução até o jus standi in judicio}

Segundo Ireneu Barreto, são quatro as etapas da evolução até a consagração do jus standi in judicio (possibilidade de o indivíduo apresentar sua queixa contra um Estado diretamente a um tribunal internacional, sem restrições, num verdadeiro processo de partes - perfeita igualdade processual entre o individuo e o Estado-, em que estão assegurados os princípios do contraditório e da igualdade) perante a CtEDHs: 1) do Congresso Europeu até o Regulamento do Tribunal de 1950, em vigor a partir de 1/JAN/1983; 2) de 1/JAN/1983 até o Protocolo no 9, em vigor a paritr de 1/OUT/1994; 3) de 1/OUT/1994 até o Protocolo n ${ }^{\circ} 11$, em vigor a partir de 1/NOV/1998 (locus standi in judicio); 4) de 1/NOV/1998 até hoje (jus standi in judicio). ${ }^{154}$

Na primeira etapa, a possibilidade de apresentação de queixas individuais perante a CtEDHs esteve primeiramente presente no Projeto de Convenção Européia dos Direitos do Homem, elaborado no Congresso Europeu de maio de 1948, mas acabou rejeitada sob o argumento de que os interesses individuais seriam protegidos pela ComEDHs ou pelos Estados-partes da Convenção; deste modo, a ComEDHs receberia (juízo de admissibilidade da demanda) e instruiria (com seu parecer sobre o mérito) as queixas dos Estados e dos indivíduos (tidos como sujeitos de DI, mas sem locus standi in judicio) e poderia remetê-las, se tal, ao Comitê

\footnotetext{
${ }^{152}$ LEÃO, Renato Zerbini Ribeiro, op. op. cit. supra n (137), 2009, p. 164 (tradução livre da autora).

${ }^{153}$ Ibid., p.138 (tradução livre da autora).

${ }^{154}$ BARRETTO, Ireneu Cabral. O recurso individual no tribunal europeu dos direitos do homem. In: Os rumos do Direito Internacional dos direitos humanos: ensaios em homenagem ao professor Antônio Augusto Cançado Trindade/Renato Zebini Ribeiro Leão, coord. - Porto Alegre: Sergio Antonio Fabris Ed. 2005, TOMO I, p. 291-295.
} 
de Ministros (CM) ou, se mais complexas, à CtEDHs (a pedido da ComEDHs ou dos Estados, seria o órgão sancionador dos Estados por descumprimento das obrigações convencionais). Como a CtEDHs não se apresentava como parte litigiosa, o indivíduo, embora não fosse parte no processo, deveria comparecer no processo para garantir o contraditório (art. 44 do Regulamento do $1950^{155}$ ), de modo que a ComEDHs poderia apresentar as observações do queixoso e a CtEDHs poderia ouvir o queixoso (art. 38 do Regulamento de 1950156) e admitir que os Delegados da ComEDHs fossem assistidos pelo queixoso ou seu representante (art. 29 $\$ 1$ do Regulamento de $1950^{157}$ ). Contudo, nos Pareceres de 1974 da ComEDHs e da CtEDHs sobre o "Projeto de Programa a curso e médio prazo do CoE" foi criticado o caráter contraditório do processo, já que o queixoso deveria participar como parte no processo, porque sob a tutela da ComEDHs ele ou seu representante não poderiam defender com total autonomia suas teses; além de ser difícil para a ComEDHs conciliar o papel de assistência à CtEDHs e de intermediária entre o queixoso e a CtEDHs ${ }^{158}$

Na segunda etapa, a partir de 1/JAN/1983, o processo perante a CtEDHs atingiu um caráter verdadeiramente contraditório, ao possibilitar que o queixoso, desde que autorizado pelo presidente da CtEDHs, apresentasse-se diretamente ou por representante, sem mediação da ComEDHs, perante a CtEDHs para defender sua posição. Contudo, ainda prevalecia a decisão da ComEDHs ou dos Estados de permitir ou não a intervenção da CtEDHs. ${ }^{159}$

Na terceira etapa, a partir de 1/OUT/1994, com a adoção do Protocolo nº 9, foi aberto ao indivíduo a possibilidade de demandar tanto à ComEDHs quanto à CtEDHs (para ser admitido na CtEDHs o caso passava pelo juízo de admissibilidade de um comitê da própria corte, e no caso de recusa poderia ser transferido seu julgamento para o $\mathrm{CM}$ do $\mathrm{CoE}$ ), mas sem garantia de receber um julgamento de

\footnotetext{
${ }^{155}$ ComEDHs: Caso Lawless, Série B, p. 512

${ }^{156}$ ComEDHs: Caso Lauless, exceções preliminares e questões de procedimento de 14/11/1970, Série A, no 1, p. 16

${ }^{157}$ ComEDHs: Caso De Wilde, Ooms e Versyp, sentença de 18/11/1970, Série A, no 12, p. 6 e ss. ${ }^{158}$ BARRETTO, Ireneu Cabral. op. cit. supra n (153), 2005, p. 291-293.

${ }^{159}$ Ibid, p. 293-294.
} 
mérito (locus standi in judicio). Tal estrutura tripartida da Convenção (ComEDHs, CtEDHs e CM), foi criticada pelo número crescente de demandas e por não conseguir responder em prazo razoável às queixas individuais, o que levou, durante a Conferência Ministerial de Viena de Março de 1985, às propostas de fusão entre a ComEDH e a CtEDHs e de criação de uma nova CtEDHs (órgão único e permanente com a competência das antigas ComEDHs e CtEDHs) ${ }^{160}$. Em 1/NOV/1998, foi instituído uma nova CtEDHs, em que os indivíduos são considerados como sujeitos de DI, gozando de um jus standi in judicio, em que respeitam-se os princípios da igualdade e do contraditórios ${ }^{161}$.

\subsubsection{Petições individuais na CtEDHs após o Protocolo Onze}

\subsubsection{A nova composição do CoE e a nova CtEDHs}

Atualmente, no entanto, após a adoção do Protocolo n 11 , a ComEDHs se fundiu à $\mathrm{CtEDHs}^{162}$, de modo que, o $\mathrm{CoE}$ se fundamenta sobre se seguintes instituições: o Comitê de Ministros $(\mathrm{CMCoE})^{163}$; a Secretaria e a Assembléia Par-

\footnotetext{
${ }^{160}$ Ibid., p. 294.

${ }^{161}$ Ibid., p. 295. Cf. ANEXOS DD e EE.

${ }^{162}$ Ver art. 19 a 51 da Convenção Européia;

${ }^{163} \mathrm{O}$ CM é uma instituição do CoE, criada para defesa dos valores do CoE e monitoramento do comprometimento dos Estados com estes, composta pelos Ministros de Relações Exteriores (reuniões anuais) ou Representantes Diplomáticos Permanentes (reuniões semanais) de todos os Estados-membros, funcionando tanto como órgão governamental como fórum coletivo. Maiores informações e documentos disponíveis no site: <http://www.coe. int $/ \mathbf{t} / \mathbf{c m} /$ home_en.asp $>$. Ultimo acesso: 07.09.09.

${ }^{164}$ A APCoE é uma instituição do CoE, composta de 318 Parlamentares titulares e 318 Parlamentares Substitutos (4 reuniões anuais) provenientes dos Parlamentos Nacionais dos atuais 47 Estados-Membros do $\mathrm{CoE}$, serve como órgão consultivo sobre os tratados internacionais sob o CoE, como órgão de supervisão do cumprimento da obrigação pelos Estados, além de órgão eletivo dos juízes da CtEDHs, o comissário de DHs, o secretário geral do CM e seu próprio secretário geral. Além disso, a APCoE adota resoluções, recomendações e opiniões que influenciam todo sistema europeu. Cf. o site: $<$ http://assembly. coe.int/default.asp >. Ultimo acesso: 07.09.09.

${ }^{163} \mathrm{O}$ Congresso de Autoridades Regionais e Locais é uma instituição do CoE com importante papel político na Europa para promoção de uma sociedade pacifica, democrática e estável através de recomendações, resoluções, opiniões e declarações. Mais dados, cf. o site: <http://www.coe.int/t/congress/default_en.asp >. Ultimo acesso: 07.09.09.
} 
lamentar (APCoE ou PACE) ${ }^{164}$; Congresso de Autoridades Regionais e Locais ${ }^{165}$; a CtEDHs; além do importante papel do Comissário de $\mathrm{DHs}^{166} \mathrm{e}$ da Conferência das ONGs Internacionais (ONGsIs ou INGOs) ${ }^{167} .{ }^{168}$ Dos 13 protocolos da Convenção Européia, o 10 perdeu seu objeto; o 9 foi revogado; os protocolos 1, 4, 6 e 7 adicionaram à Convenção garantias de novos direitos materiais; enquanto os protocolos $2,3,5,8,12$ e 13 reestruturam os mecanismos procedimentais de controle ${ }^{169}$. A recente reforma da CtEDHs, criadora da nova CtEDHs em 1/NOV/1998, trazida pelo Protocolo 11 acarretou conseqüências positivas para ampliação da PIDHs.

A nova CtEDHs, órgão permanente internacional do sistema regional de PIDHs, passa a ter a competência para interpretar e aplicar a Convenção ${ }^{170}$, recebendo diretamente as queixas impetradas pelas vítimas, a princípio sob 2 condições : tenham sido esgotados os recursos do Estado demandado; e tenha sido violado direito protegido pela Convenção. A CtEDHs passou a ter jurisdição obrigatória tanto para as ações movidas pelos indivíduos quanto para as ações interestatais. ${ }^{171}$

${ }^{164}$ Eleito pela APCoE, o Comissário de DHs é o responsável pela promoção do diálogo entre os governos, OIs, as instituições da sociedade civil - principalmente as de ensino - e os defensores dos DHs a fim de promover a implementação dos compromissos assumidos pelos Estados Membros do CoE e avançar rumo ao pleno desenvolvimento dos DHs. Cf. site: <http://www.coe.int/t/commissioner/default_en.asp >.Ultimo acesso: 07.09.09.

${ }^{165}$ As ONGsIs são vistas pelo CoE como instituições responsáveis pela manutenção da liberdade de expressão e associação; sendo, portanto, possível às ONGsIs adquirir uma condição participativa para cooperação com o $\mathrm{CoE}$, através do formulário do site: <http:// www.coe.int/t/e/ngo/public/Questionnaire_2009_en.doc $>$. Ultimo acesso: 07.09.09.

${ }^{166}$ Mais dados sobre o CoE (estrutura e funções das suas instituições), cf o Estatuto do CoE no site: $<$ http://conventions.coe.int/Treaty/en/Treaties/Html/001.htm $>$; as Regras de Procedimento do CMCoE no site: <https://wcd.coe.int/ViewDoc.jsp?id=814763\&BackCo lorInternet $=9999 \mathrm{CC} \&$ BackColorIntranet $=$ FFBB55\&BackColorLogged $=$ FFAC75 $>$; as Regras de Procedimento da APCoE no site: $<$ http://assembly.coe.int/RulesofProcedure/2009/Reglement_2009.pdf $>$; as Regras de Procedimento do Congresso de Autoridades Regionais e Locais no site: $<$ https://wcd.coe.int/ViewDoc.jsp?id=1384493\&Site=Co ngress $\&$ BackColorInternet $=\mathrm{e} 0$ cee $1 \&$ BackColorIntranet $=\mathrm{e} 0$ cee $1 \&$ BackColorLogged =FFC679 $>$; as Regras de Procedimento das ONGsIs no site $<$ http://www.coe.int/t/e/ngo/ public/ingo_conference/rules_of_procedure/Rules_Proceduree_250608_280109_ en.asp\#TopOfPage $>$. Ultimo acesso: 07.09.09.

${ }^{167}$ FERREIRA, Gustavo Assed. “Corte Européia de Direitos Humanos”. In Tribunais Internacionais: mecanismos contemporâneos de solução de controvérsias/ Welber Barral, organizador. - Florianópolis: Fundação Boiteux, 2004, p. 278.

${ }^{168}$ Art. 19, da Convenção Européia de DHs.

${ }^{169}$ FERREIRA, Gustavo Assed. op. cit. supra n (168), 2004, p. 278-283. 
Tem legitimidade para apresentar sua queixa individual perante a CtEDHs (independentemente das normas de Di relativas ao interesse ou qualidade para agir), não somente quem se considera vítima direta e efetiva, mas também quem pretende-se vítima potencial ou eventual ${ }^{172}$ de uma violação futura ou risco (eminência) de violação de um direito protegido pela Convenção Européia de DHs por uma Parte Contratante. Além disso, também é legitimado ativo, as vítimas indiretas ${ }^{173}$, ou seja, aquelas, desde que preenchidas 2 condições (existência de uma vítima direta ou efetiva, potencial ou eventual de uma violação; e presença de uma ligação direta e pessoal entre a vítima direta e indireta), que sofrem prejuízos em decorrência de violação de direitos de um terceiro ou que tenham interesse pessoal e válido no fim da violação. A condição de vítima (direta ou efetiva; potencial ou eventual; ou indireta) deve permanecer até o fim do processo; caso contrário, haverá a extinção do processo por perda do objeto ${ }^{174}$. Caso a vitima inicie o processo e morra durante o processo, seus herdeiros podem, se desejarem, prosseguir com o mesmo perante a CtEDHs. ${ }^{175}$

A CtEDHs possui 3 limitações: 1) a limitação ratione materiae (a CtEDHs só é competente para examinar queixas contra violações de direitos e garantias previstos na Convenção e seus Protocolos; o queixoso não é obrigado a mencionar o artigo violado, porque cabe à CtEDHs saber o direito de ofício e qualificar juridicamente os fatos alegados); 2) a limitação ratione temporis (a partir do Protocolo 11, a ratificação da Convenção torna obrigatória a competência da CtEDHs para todos Estados Contratantes, mesmo sem reconhecimento expresso do direito de

\footnotetext{
${ }^{172}$ É o caso de pessoas que se sentem lesadas pela simples existência de um legislação, cujos efeitos serão diretamente sofridos pelas vítimas potenciais, mesmo sem atos individuais de aplicação. Ireneu trata dos seguintes casos: caso da mulher que se queixava, sem estar grávida, da legislação que proíbe aborto; caso da legislação que incriminava os homossexuais; caso da decisão de extradição ou expulsão para país em que a pessoa tenha risco de sofrer maus tratos. Nestes casos, pode-se responsabilizar o país, mesmo que a decisão não seja executada.

${ }^{173}$ É o caso das pessoas que tem relação particular e pessoal com a vítima, não somente laços familiares. Ireneu traz o caso de pessoas afetadas pela morte de parente próximo (pais e irmãos, por exemplo) ou de pessoa próxima (conviventes).

${ }^{174} \mathrm{E}$ o caso do acusado que é inocentado e que alegou violação da equidade do processo penal; assim como é o caso das autoridades nacionais que reconhecem a violação alegada e a reparam.

${ }^{175}$ BARRETTO, Ireneu Cabral. op. cit. supra n (153), 2005, p. 300-302.
} 
queixa ou sem declaração de aceitação a jurisdição da $\mathrm{CtEDHs}^{176}$ ); e 3) a limitação ratione loci (a CtEDHs é competente para conhecer dos fatos cometidos nos territórios onde a Convenção se aplica para proteção de todos aqueles que estejam sob a jurisdição de um Estado Parte da Convenção). ${ }^{177}$ Além disso, para garantir a eficácia do mecanismo da petição individual, o Estado não só deve evitar pressionar o indivíduo de quaisquer modos ${ }^{178}$ (coerção direta, atos flagrantes de intimidação ou contatos diretos de má fé para dissuadir ou desencorajar as queixas perante a CtEDHs) para entravar o exercício de seu direito de apresentar e defender sua causa na $\mathrm{CtEDHs}{ }^{179}$, como deve proporcionar que os indivíduos sejam livres para se comunicar com a CtEDHs e fornecer todas as facilidade para viabilizar o exame sério e efetivo das queixas. ${ }^{180}$

As queixas apresentadas perante a CtEDHs serão de ofício examinadas conforme 2 condições de admissibilidade ${ }^{181}: 1$ ) esgotamento dos recursos internos (exige-se o exercício dos recursos ordinários para reparação de danos, nos prazos e formas previstas no sistema jurídico interno dos Estados Partes na Convenção, desde que disponíveis, eficazes, suficientes e acessíveis - trata-se de exceção preliminar, que pode ser invocada ou não pelo Estado até a admissibilidade da queixa); e 2) apresentação da queixa após prazo de 6 meses a partir da data da decisão interna definitiva (com duplo objetivo - garantir a segurança jurídica das decisões e

${ }^{176}$ Antes do Protocolo no 11 e de conformidade com o art. 28 da Convenção de Viena sobre o Direito dos Tratados, a CtEDHs só passava ser competente para examinar as queixas com o depósito do instrumento de ratificação da Convenção Européia de DHs.

${ }^{177}$ BARRETTO, Ireneu Cabral. op. cit. supra n (153), 2005, p. 302-304.

${ }^{178}$ CtEDHs: Caso Campbell (a CtEDHs entendeu que as autoridades penitenciárias não poderiam abrir as correspondências entre os órgãos da CtEDHs e os presos), sentença de 25/3/1995, série A, nº 233.

${ }^{179}$ Art. 34 da Convenção Européia de DHs.

${ }^{180}$ Art. 38, §1, alínea a da Convenção Européia de DHs. BARRETTO, Ireneu Cabral. op. cit. supra n (153), 2005, p. 304.

${ }^{181}$ Art. $35 \$ 1$ da Convenção Européia de DHs. A regra do esgotamento dos recursos internos vem sendo cada vez mais aplicada com menos formalismo, ou seja, com certa flexibilidade. Desta forma, a aplicação desta condição não é automática nem tem caráter absoluto, variando conforme o caso concreto. Barretto acrescenta ainda que, desde que haja uma prática administrativa ou jurisprudência bem estabelecida demonstrando a repetição de fatos ilícitos e a tolerância das autoridades do Estado justifica-se a não aplicação do esgotamento dos recursos internos. 
permitir que o queixoso reflita sobre a introdução e o conteúdo da queixa perante a CtEDHs). ${ }^{182}$ Quanto ao esgotamento dos recursos internos como condição de admissibilidade, acrescente-se a flexibilidade e o realismo seguintes: "o Tribunal deve ponderar de uma forma realista não só os recursos previstos em teoria no sistema jurídico da Parte Contratante implicada, mas igualmente o contexto jurídico no qual eles se situam assim como a condição pessoal dos queixosos". ${ }^{183}$

Além das queixas que não cumprirem os 2 requisitos de admissibilidade supramencionados, não serão admitidas as seguintes queixas: as anônimas; as já submetidas a outras instâncias internacionais de inquérito ou de decisão (exceto se fatos novos surgirem); as incompatíveis com o disposto na Convenção ou seus Protocolos; as manifestamente mal fundadas (os fatos alegados não tem sequer a aparência de violação dos direitos ou liberdades previstos na Convenção) ou de caráter abusivo $^{184}$ (queixa apoiada sobre falsa declaração de fatos). ${ }^{185}$

As queixas são consideradas admitidas a partir da data da primeira comunicação do queixoso (expondo o objeto da queixa, numa das línguas oficias de um dos Estados Partes na Convenção, através de carta, fax, telegrama, e-mail ou telefone, desde que posteriormente confirmados por escrito), exceto quando decorre um lapso temporal substancial entre a primeira comunicação e a outras informações relativas à queixa, quando então a data de admissão pode ser posterior. ${ }^{186}$

Admitida a queixa, ela poderá ser, a qualquer momento do processo, arquivada, desde que presentes as seguintes condições: o queixoso não pretender manter a queixa (no caso em que ele retira a queixa ou se comporta com desinteresse); for resolvido o litígio (no caso de um acordo amigável ou obtenção da reparação no âmbito interno ${ }^{187}$ ); se a CtEDHs entender que não é justificável prosseguir na

182 BARRETTO, Ireneu Cabral. op. cit. supra n (153), 2005, p. 305-307.

183 BARRETTO, Ireneu Cabral, op. cit. supra n (153), 2005, p. 307.

184 ComEDHs: Decisão de 19/10/1994, queixa n 21987/93, décision et raports n 79, p. 60; Decisão de 27/06/1996, queixa $n^{\circ} 24760 / 94$, décisions et raports no 86, p. 54.

185 Art. 35, $\$ \$ 2$ e 3 da Convenção Européia.

186 BARRETTO, Ireneu Cabral, op. cit. supra n (153), 2005, p. 308-209.

187 Art. 39 da Convenção Européia de DHs. 
análise da queixa. ${ }^{188}$ Não sendo o caso de arquivamento, a CtEDHs irá prosseguir na análise contraditória da queixa com os representantes das partes ${ }^{189}$, com ou sem audiência pública ${ }^{190}$, até a analise de mérito em acórdão fundamentado sobre a violação ou não da Convenção, arbitrando uma satisfação justa ${ }^{191}$.

\subsubsection{Acréscimos conceituais}

Cabe fazer algumas considerações acerca dos conceitos legais e jurisprudenciais resultantes da instituição da CtEDHs. Dentre estes destacam-se por ora 3 conceitos-chaves: o conceito de vítima; o conceito de família; e o conceito de discriminação.

Primeiramente é importante esclarecer o conceito de vítima. De conformidade com o sistema europeu legal (artigo 34 da Convenção) e jurisprudencial ( $A i$ rey $\mathrm{x}$ Reino Unido, sentença de 6/2/1981, series A, n 41; Le Compte, Van Leuven e De Meyere x Bélgica, sentença de 18/10/1982), a doutrina vem definindo vítimas como todas as pessoas, independentemente da sua nacionalidade ou residência, diretamente afetadas pela violação de direitos e garantias protegidos pela Convenção Européia de DHs, desde que sob a jurisdição (vai além do território das Estados-membros, já que abarca atos de órgãos fora do território, como no caso de forças armadas do Estado ou administração local subordinada) de um Estado-membro da Convenção ${ }^{192}$. Embora excepcionalmente haja o exercício extraterritorial da jurisdição de um Estado-Contratante da Convenção Européia de DHs (desde que haja consentimento, convite ou aquiescência do outro Estado ou nos casos de justificação especial, como nacionalidade, pavilhão, relações diplomáticas e consulares, efeito, proteção, personalidade passiva e universalidade), a Convenção não deve se

\footnotetext{
188 Art. $37 \$ 1$ da Convenção Européia de DHs.

189 Art. $38 \$ 1$ da Convenção Européia de DHs.

190 Art. 40 da Convenção Européia de DHs.

191 Art. 41 da Convenção Européia de DHs. Cf. ANEXOS FF e GG.

192 BARRETTO, Ireneu Cabra. . op. cit. supra n (153), 2005, p. 295.
} 
aplicar no mundo todo ${ }^{193}$, já que o objetivo da extraterritorialidade nestes $\operatorname{casos}^{194}$ seria evitar lacunas ou soluções de continuidade na proteção dos DHs. ${ }^{195} \mathrm{E}$ ainda possível a transferência de jurisdição de um Estado Contratante para uma OI ${ }^{196}$, desde que não afete a proteção dos direitos fundamentais, com a preeminência do direito numa sociedade democrática e com o principio fundamental do art. 6, $\$ 1$ da Convenção Européia de DHs (direito a um processo justo). ${ }^{197}$

Em segundo lugar, é importante esclarecer quanto à família, não propriamente para conceituar, mas para determinação dos beneficiários de indenizações por sucessão, de modo que, conforme entendimento jurisprudencial, no caso de indenização por danos materiais, os sucessores da vítima estão legitimados para substituí-la, enquanto, no caso de indenização por danos morais, só serão considerados herdeiros aqueles determinados pela CtEDHs. ${ }^{198}$

Em terceiro lugar, cabe trazer à tona o conceito de discriminação, já que trata-se de um tema de suma importância, que - mesmo estando previsto como interdição de discriminação do usufruto dos direitos protegidos (art. 14 da Convenção) - foi objeto de um protocolo específico para interdição geral da discriminação (Protocolo 12), além de esclarecido pela jurisprudência: "ocorre a violação de direito garantido pelo art. 14 de não sofrer discriminação no usufruto dos direitos

\footnotetext{
${ }^{193}$ CtEDHs: Caso Bankovic e outros x 17 Estados Partes na Convenção e Membros da OTAN, sentença de 12/12/2001, queixa no 52207/99 (a CEDH decidiu que a queixa de vitimas e familiares do bombardeio da OTAN sobre a RFJ era inadmissível, porque a Convenção seria tratado multilateral sob reserva do art. 56, operando no espaço jurídico dos Estados Contratantes, no qual não se inclui a Republica Federativa da Iugoslávia-RFJ).

${ }^{194}$ CtEDHs: Caso Loizidou, de 23/3/1995 (exceções preliminares), Série A, n o 310, p. 23, \$62 (responsabilidade turca sobre zona invadida no Chipre após a invasão turca de 1974); Caso Issa, sentença de 20/5/2000, queixa no 31821/96; Caso Oçalan, sentença de 14/12/2000, queixa $n^{\circ} 46221 / 99$ (foram admitidas queixas relatiavas a ações de agente turcos fora do território turco); Caso Xhavara, sentença de 11/1/2001, queixa n 39473/98 (navio albanês que transportava albaneses que desejavam entrar clandestinamente na Itália afundou no Mediterrâneo); Caso Ilascu e outros, sentença de 4/7/2001, queixa no 348787/99 (questionamento sobre o controle das forças russas sobre uma parte do território da Moldávia)

${ }^{195}$ BARRETTO, Ireneu Cabral. op. cit. supra n (153), 2005, p. 297-298.

${ }^{196}$ CtEDHs: Caso McElhinney, sentença de 21/11/2001, \$24.

${ }^{197}$ BARRETTO, Ireneu Cabral. op. cit. supra n (153), 2005, p. 298-299.

${ }^{198}$ CtEDHs: Caso Montserrat Enrich Mas, at. 782, X x Reino Unido, 55B para 18-19, 1982.
} 
reconhecidos pela Convenção quando os Estados tratam de modo diferente e sem razão objetiva e razoável as pessoas que se encontram em situações análogas”199.

Finalmente, Zerbini acrescenta que pela Doutrina da "Margem de Apreciação Nacional" ou "Margem de Interpretação", os Estados-Partes do CoE devem dar interpretação ampliada aos artigos específicos de Direitos Civis e Políticos da Convenção Européia de DHs para buscar seu viés econômico-social e político e, a partir de seus próprios ordenamentos jurídicos nacionais, interpretar e definir os conceitos jurídicos ausentes na Convenção Européia de $\mathrm{DHs}^{200}$, de modo que, a determinação conceitual da CtEDHs longe de ser uma imposição unilateral e pré-existente, é obra de uma construção jurisprudencial coletiva e continua dos países sob jurisdição da CtEDHs.

\subsubsection{Entraves à expansão do sistema europeu de proteção dos direitos humanos}

A formação de uma nova CtEDHs, com a entrada em vigor do Protocolo 11 e o aumento da quantidade de membros do CoE, - com a condição de que para integrar a Organização dever-se-ia automaticamente aderir à Convenção e consequentemente à Corte-, vem ameaçando a celeridade e efetividade das decisões, ao mesmo tempo que promove a busca por soluções. ${ }^{201}$

\subsubsection{Críticas à CtEDHs}

O alcance jurisdicional da CtEDHs está triplamente limitado:1) pela heterogeneidade de obrigações jurídicas assumidas pelos Estados-partes da Convenção Européia de DHs, já que nem todos aderiram a todos os Protocolos Adicionais, o que impede a operação homogênea do sistema; 2) pela apresentação de reservas e pela divergência de interpretações formuladas pelos Estados-partes da Convenção;

\footnotetext{
${ }^{199}$ CtEDHs: Caso Thlimmenos x Grécia, sentença de 6/4/2000, parágrafo 44.(tradução livre pela autora).

${ }^{200}$ LEÃO, Renato Zerbini Ribeiro. op. cit. supra n (137), 2009, p. 140-141.

${ }^{201}$ FERREIRA, Gustavo Assed. op. cit. supra n (168), 2004, p, 284-285,
} 
e 3) pela permissão de limitação da aplicação territorial da Convenção e seus Protocolos nos âmbitos nacionais (conforme possibilita o art. 56 da Convenção; o art. 4 do Protocolo Adicional; art. 5 do Protocolo no 4; art. 5 do Protocolo $n^{\circ}$ 6; art. art. 6 do Protocolo no 7; art. 2 do Protocolo $n^{\circ} 12$; art. 4 do Protocolo $n^{\circ} 13$ ). ${ }^{202}$

Além disso, a entrada de membros ao CoE com sistemas judiciários nacionais com problemas estruturais (dada a subsidiariedade da CtEDHs em relação aos tribunais internos ${ }^{203}$ ) e o acesso simples e fácil do indivíduo à CtEDHs contribuem para o crescimento exponencial do número de queixas, muito além das estatísticas de outros órgãos importantes ${ }^{204}: 15.000$ decisões de inadmissibilidade de queixas, 30.000 queixas introduzidas e 844 acórdãos em $2002^{205}$. Tais cifras, mesmo que simples e repetitivas, acabam por inviabilizar a prestação jurisdicional em prazos razoáveis ${ }^{206}$ e cria a necessidade de desenvolver soluções e discutir reformas.

A nova CtEDHs vem enfrentando um déficit mensal de demandas/distribuição, o que vem suscitado pressões para limitação do número de casos. O déficit mensal de queixa/distribuição desta Corte se deve à apreciação e aceitação

${ }^{202}$ CARRILO SALCEDO, Juan Antonio: El Convenio Europeo de Derechos Humanos. Madrid: Tecnos, 2003, p. 32. In.: FERREIRA, Gustavo Assed. "Corte Européia de Direitos Humanos”. In Tribunais Internacionais: mecanismos contemporâneos de solução de controvérsias/ Welber Barral, organizador. - Florianópolis: Fundação Boiteux, 2004, p. 106.

${ }^{203}$ CtEDHs: Caso Z e outros x Reino Unido, sentença de 10/5/2001, $\$ 103$; Caso Kudla, sentença de 26/10/2000, Recueil des Arrêts et Décisions, 2000-XI, p. 197 e ss. Sobre a subsidiariedade, ver art. 13 (oferecimento de recurso efetivo na ordem interna) e art. $35 \$ 1$ (esgotamento dos recursos internos) da Convenção Européia de DHs. Barretto - opus cit. supra n (153), p. 316 - acrescenta que, dentre os países membros da CtEDHs, o recurso específico nacional contra violações de $\mathrm{DHs}$ ou não existem ou são meios rígidos, lentos e caros, além de desprovidos de soluções de conciliação e de arbitragem.

${ }^{204}$ Barretto traz os números de acórdãos anuais dos seguintes órgãos: Tribunal Federal dos EUA (80 a 90); Tribunal Supremo do Canadá (120); Tribunal Constitucional da Alemanha (30 a 40); TJCE (240 em 2001).

${ }^{205}$ BARRETTO, Ireneu Cabral. op. cit. supra n (147), 2005, p. 310.

${ }^{206}$ Sobre esta questão de prazo razoável, verificar a Lei Pinto de 24/3/2004 do Parlamento Italiano, conforme art. 111 da CF Italiana, que trata do direito a uma reparação razoável, caso seja violado o art. $6 \$ 1$ da Convenção Européia de DHs (recurso judiciário). Além disso, na ordem jurídica espanhola existe um meio específico para violação de prazo razoável, previsto no art. $24 \$ 2$ da CF Espanhola, que é o "recurso de amparo" (recurso judiciário e administrativo). Para mais dados, cf. BARRETTO, Ireneu Cabral, op. cit. supra n (153), 2005, p. 318-320. 
pela Corte de pequenas ocorrências como o caso simples Vasileva x Denmark (n. 52792/99), em que a Corte fixou indenização para Vasileva pela Dinamarca devido violação ao direito de liberdade ${ }^{207}$ por excesso de tempo de detenção.

\subsubsection{Soluções apresentadas}

Em 2000, na Conferência Ministerial de Roma (3 e 4/NOV) foi constatada a necessidade de reformar a nova CtEDHs. Em 2001, no Relatório do CMCoE (27/ SET) foram sugeridas a recusa de exame pormenorizado de queixas sem questão substancial relativa à Convenção e criação de uma divisão para exame prévio das queixas. Em 2001, num Seminário do Conselho da Europa (9 e 10/SET) foram sugeridas reformas na CtEDHs (criação de $5^{\mathrm{a}}$ seção; admissão de juizes auxiliares aos juizes nacionais; rejeição de casos não substanciais; estabelecimento de processo de reparação das queixas admitidas junto a instâncias nacionais; possibilidade de reenvio de certos casos aos tribunais internos; alargamento da competência da CtEDHs em pareceres consultivos) e medidas externas (tais como criação de tribunais regionais de DHs e instituição de comissões nacionais de filtragem de queixas direcionadas à $\mathrm{CtEDHs}) .{ }^{208}$

A partir disto, o Comitê Diretivo para Direitos Humanos (CDDHs) apresentou um Relatório Provisório ${ }^{209}$ apresentado 3 tipos de propostas: 1) as inaceitáveis (a criação de sistema de filtros nacionais, o que ensejaria novas arbitrariedades pelo Estado; a criação de Cortes Regionais que demandariam custo e teriam suas próprias peculiaridades; e a criação de uma divisão de assessores, sem conhecimento técnico ou prática processual, para exame preliminar de admissibilidades

\footnotetext{
${ }^{207}$ Art. $5 \$ 1$ da Convenção Européia de DHs.

${ }^{208}$ BARRETTO, Ireneu Cabral op. cit. supra n (153), 2005, p. 312-313.

${ }^{209}$ Para saber mais sobre o CDDH: Committee of Ministers Documensts, CM (2002) 146, p.2. Interim Report of the $\mathrm{CDDH}$ to the Committee of Ministers "Guaranteeing the long-term effetiveness of the European Cout of Human Rights" Disponível no site: $<$ https://wcd.coe.int/ViewDoc.jsp? Ref=CM(2002)4\&Language=lanEnglish \&Site=CO E\&BackColorInternet $=$ DBDCF2\&BackColorIntranet $=$ FDC864\&BackColorLogged $=$ FDC864>. Acesso em setembro de 2008.
} 
das petições) ${ }^{210} ; 2$ ) as que demandam exame prioritário (a restrição da matéria das petições analisadas pela Corte a temas efetivamente garantidos pela Convenção; a criação de Comitê misto com juiz e assessores; e a criação de procedimento sumário para casos repetitivos) $)^{211}$; e 3 ) as que podem ser examinadas posteriormente num momento adequado (a eleição de juízes para mandato único de mais de 9 anos, o que proporcionaria maior independência, experiência e desenvoltura com os procedimentos internos da Corte) ${ }^{212}$. Em 2003, face à necessidade de reforma da CtEDHs, adotou-se na 112a Sessão do CMCoE a Declaração denominada "Garantindo a efetividade da CtEDHs no longo prazo". ${ }^{213}$

Frente à necessidade de operacionalização dinâmica do sistema se faz premente mais uma reforma na CtEDHs. A CtEDHs, como subsistema do CoE e o mais efetivo tribunal internacional de caráter regional de proteção dos DHs, aumentou durante a década de 90 seus Estados Partes, o que elevou o número de processos pós-1998, o que acabou impondo o início da reforma, já institucionalizada com o Protocolo 11. O principal problema atual da CtEDHs é combater o déficit queixa/distribuição sem diminuir o nível de proteção aos DHs resguardados pela Convenção; além disso é preciso combater a imunidade internacional alegada pelos Estados Partes e a não executividade das sentenças da CtEDHs junto aos Estados condenados. ${ }^{214}$

Há os que defendem que a CtEDHs deveria funcionar como um tribunal constitucional europeu (concentrar esforços na decisão de princípios para construção de uma ordem pública européia) e outros que ela deveriam mudar, mas sempre respeitando a substância do recurso individual ${ }^{215}$.Entre 2000 e 2003, a CtEDHs adotou 3 medidas para aumentar sua produtividade: um procedimento simplificado de registro da queixa, em que os contatos entre o queixoso e o cartório ( $\mathrm{Greffe}$ ) foram restritos ao estritamente necessário (não mais se tenta convencer o queixoso de que sua queixa

\footnotetext{
${ }^{210} \mathrm{CM}(2002) 146-\mathrm{CDDH}$, p. 7,8 e 10

${ }^{211} \mathrm{CM}$ (2002)146-CDDH, p. 11 e 19.

${ }^{212} \mathrm{CM}$ (2002)146 - CDDH, p. 15.

${ }^{213}$ FERREIRA, Gustavo Assed. op. cit. supra n (162), 2004, p. 285-288.

${ }^{214}$ Ibid., p. 294.

${ }^{215}$ BARRETTO, Ireneu Cabra. op. cit. supra n (153), 2005, p. 311.
} 
é inviável) ${ }^{216}$; atribuiu ao Comitê (Comité) o encargo de avaliar as queixas e enviar carta ao queixoso com indicação sucinta dos motivos de inadmissibilidade da sua queixa; no caso de queixas repetitivas simples (clones) ${ }^{217}$; já as decisões sobre admissibilidade e fundo são tomadas de uma vez e comunicadas em grupo. ${ }^{218}$

Há ainda os que defendem, como Lopes Moreira, que a solução para os problemas dos sistemas regionais e internacional de proteção da pessoa humana está "na aproximação cada vez mais estreita entre os regimes coexistentes de proteção" ${ }^{219}$. E há aqueles que pugnam, como Silveira Job, que a efetividade das decisões jurídicas internacionais no âmbito das CtEDHs ou da CtIDHs dependem "sobremaneira do cúmplice envolvimento de todos os agentes e instituições responsáveis pela feitura, interpretação e execução das leis no ambiente interno e internacional"220. Independentemente das medidas adotadas, "se o direito de recurso individual for eliminado da ordem jurídica européia será dado um grande passo atrás na proteção dos DHs da Europa”, já que este representa a "jóia da coroa do sistema jurídico europeu"221, além de servir de inspiração para o resto do mundo, porque é "última esperança para todos aqueles vítimas de violações dos direitos e garantias fundamentais" 222 . Por outro lado, com a melhoria e eficácia dos sistemas internos de recursos para proteção dos DHs e conhecimento da jurisprudência da CtEDHs e aplicação da Convenção (vista como lei interna em nível superior às leis ordinárias) pelos magistrados nacionais $^{223}$, seria possível um efetivo sistema europeu de proteção de DHs.

${ }^{216}$ Art. 25 da Convenção Européia de DHs.

${ }^{217}$ Art. 28 da Convenção Européia de DHs.

${ }^{218}$ BARRETTO, Ireneu Cabral. op. cit. supra n (153), 2005, p. 311.

${ }^{219}$ MOREIRA, Luiz Carlos Lopes. Os sistemas de Proteção de Direitos Humanos em que a Corte Interamericana e a Corte Européia estão inseridas. Direito e Democracia, Revista de Ciências Jurídicas - ULBRA. Vol. 6, nº 1, 1 semestre de 2005, p. 67-77

${ }^{220} \mathrm{JOB}$, Ulisses da Silveira. Proteção Internacional dos Direitos Humanos: Comissões e cortes interamericanas e européias de direitos humanos e questões afins. Revista de Informação Legislativa /Senado Federal, Subsecretaria de Edições Técnicas. Ano 1, n. 1 (mar. 1964) - Brasília: Senado Federal, Subsecretaria de Edições Técnicas, 1964, p. 81-90.

${ }^{221}$ BARRETTO, Ireneu Cabral, op. cit. supra n (153), 2005, p. 322.

${ }^{222}$ Ibid., p. 313.

${ }^{223}$ Ibid., p. 315. 


\section{Participação individual na corte interamericana de direitos humanos}

\subsection{Relações internacionais da América}

\subsubsection{Prelúdios da concertação interamericana}

As relações interamericanas são marcadas por 7 condicionantes principais: 1) os Estados da América possuem níveis distintos de desenvolvimento, apresentando grandes disparidades sob os aspectos político, econômico, militar, cultural ou religioso; 2) a presença de um poder hegemônico (os EUA); 3 ) dificuldade na formação de macrointeresses devido à grande dimensão espacial do Continente; 4) o alcance diferenciado da materialização das políticas dos Estados em suas relações recíprocas: marcada pela estratégia mundial no âmbito dos EUA e pelo localismo ou regionalismo no âmbito dos demais países; 5) as distintas naturezas das ações estatais: ofensivas (EUA) e defensivas (demais países); 6) oposição dos EUA a uma cooperação regional intralatino-americana; e 7) falta de elementos suficientes pra fomentar uma política de cooperação. ${ }^{224}$

Contudo, apesar destas condicionantes, desfavoráveis à institucionalização das relações interamericanas, os Estados americanos empreenderam esforços no sentido de criar mecanismo de defesa e concertação (pan-americanismo), de tal forma que a "Declaração de Lima" (decorrente da Reunião VIII Conferência Pan-Americana em 1936) foi um marco neste sentido, apesar de trazer meras recomendações, sem força coercitiva. Durante a Segunda Guerra Mundial, ocorreram quatro importantes Reuniões Extraordinárias dos Ministros das Relações Exteriores das Américas: 1) em 1939 no Panamá para proteger a paz continental e promover a cooperação econômica continental, de que resultou a "Declaração Geral de Neutralidade" com a criação de um Comitê Interamericano de Neutralidade (BR) e um Comitê Financeiro e Econômico (EUA); 2) em 1940 em Havana para decidir o destino das colônias dos países derrotados, de que resultou a "Declaração de Havana" com a criação de uma Comissão Interamericana para a Administração Territorial das Colônias e Possessões Européias na América; 3) em 1942 no Rio de Janeiro para unir a América Latina a favor dos EUA pela ruptura diplomática-

\footnotetext{
${ }^{224}$ SEITENFUS, Ricardo Antônio Silva. Manual das organizações internacionais. 4 ed. rev. , atual. e amp. - Porto Alegre: Livrara do Advogado Ed., 2005, p. 255-256.
} 
-comercial-financeira com o Eixo Roma-Berlim-Tóquio; 4) em 1945 no México para organizar as relações interamericanas no pós-guerra, com adoção da "Ata de Chapultepec". 225

\subsubsection{Formação e estrutura da OEA}

Todos estes empreendimentos foram o prenúncio dos fundamentos da Organização dos Estados Americanos (OEA), postos com a IX Conferência dos Estados Americanos (1948; Bogotá) com a adoção de 3 documentos históricos, em vigor a partir de 1951: a "Declaração dos Direitos do Homem" (sobre os princípios); a "Carta de Bogotá" (sobre a organização - tratado constitutivo da OEA ${ }^{226}$ ); e o "Pacto" (sobre os processos decisórios). A estrutura institucional da OEA modificou-se a partir do Protocolo de Buenos Aires, quando a Carta da OEA passou a ter a estrutura atual da $\mathrm{OEA}^{227}$ : Assembléia Geral (AG/OEA - reunião anual com representação de todos os países para decidir sobre ações e política geral, orçamento, estrutura e funções da organização ${ }^{228}$ ); a Reunião dos Ministros de Ministérios das Relações Exteriores (RMRE - órgão de ligação entre OEA e o TIAR ${ }^{229}$ para convocações em caso de problemas de caráter urgente e interesse comum contra a paz continental ${ }^{230}$ ); Conselho Permanente (CP/OEA - possui uma Comissão Interamericana para Soluções Pacíficas para manter a amizade entre estados

\footnotetext{
${ }^{225}$ Ibid., p. 256-260

${ }^{226}$ Vide os art. 2 e art. 3 da Carta de Bogotá sobre seus principais objetivos norteadores da atuação dos Estados americanos, quais sejam a prevenção de eventuais conflitos e a solução pacífica dos litígios via negociação, mediação, investigação, conciliação ou arbitragem;

${ }^{227}$ Cf. ANEXO HH.

${ }^{228}$ Art. 54 a 60 da Carta da OEA, cf. o site: $<$ http://www.oas.org/juridico/portuguese/carta. htm\#Capítulo\%20X>. Ultimo acesso: 07.09.09.

${ }^{229}$ Tratado Interamericano de Assistência Recíproca (TIAR ou Pacto do Rio) concluído em 02/09/1947, ratificado em 05/03/1948, foi promulgado em 13/10/1948 pelo Brasil pelo Decreto $n^{\circ}$ 25.660. Vide preâmbulo do Pacto do Rio. Busca de entendimento inicial em âmbito regional (manutenção da paz. solução pacífica do litígio e institucionalização da cooperação militar e do princípio da dupla segurança coletiva continental contra ataques armados entre Estados americanos ou de origem extracontinental) para só depois recorrer à AG e CS da ONU (âmbito universal). Vide art. 3 do TIAR art. 51 da Carta da ONU. ${ }^{230}$ Vide art. 61 e 69 da Carta da OEA.
} 
americanos e garantir a solução pacífica de controvérsias entre seus Estados-mem$\operatorname{bros}^{231}$ ); o Conselho Interamericano de Desenvolvimento Integral (CIDI/OEA), abrangendo o Conselho Interamericano Econômico Social (CIES/OEA - possui uma Comissão Executiva - CIAP para viabilizar o desenvolvimento econômico e social dos Estados-membros) e o Conselho Interamericano de Educação, Ciência e Cultura (CIECC/OEA - possui uma Comissão Executiva Permanente para fomentar a cooperação e intercâmbio educacionais, científicos e culturais entre os Estados-Membros); o Secretariado Geral (antiga União panamericana, sediado em Washington) ${ }^{232}$; além de Conferências Especializadas ${ }^{233}$ e Organismos Especializa$\operatorname{dos}^{234}$. Além disso ligadas ao CP/OEA, mas não submetidas a ele, a OEA possui 3 órgãos jurídicos : Corte Interamericana de Direitos Humanos (CtIDHs - localizada na Costa Rica, responsável pelo julgamento dos casos de violação ${ }^{235}$ ); a Comissão Interamericana de Direitos Humanos (ComIDHs - órgão consultivo e de promoção do respeito e defesa dos DHs através de petições - apresentadas por pessoa (s), ONGs ou Estado-membro - com denúncias ou queixas de violação da Convenção Americana); e a Comissão Jurídica Interamericana (CJI/OEA - sediada no RJ, para promoção da codificação do DI e para consulta jurídica da $\left.\mathrm{OEA}^{236}\right){ }^{237}$

Todos os Estados-membros da OEA estão em "perfeita igualdade jurídica”, já que todos seus Estados-Membros participam do conjunto das instâncias, exceto na CtIDHs, o que revela - apesar das questões de segurança, dos conflitos políticos e do medíocre desenvolvimento social (narcotráfico, conflitos na América Central, Guerra das Malvinas, crescimento geométrico da dívida externa e a crise econômica) - a democratização de tal OI e a constituição de um verdadeiro sistema interamericano. Outras Organizações Regionais para organização das relações exteriores ${ }^{238}$, além de novos fóruns são criados para enfrentar os desafios da OEA e alcançar seus objetivos (cooperação para manutenção da paz e segurança,

\footnotetext{
${ }^{231}$ Vide art. 80 a 92 da Carta da OEA.

${ }^{232}$ Vide art. 93 a 98 da Carta da OEA

${ }^{233}$ Vide art.. 122 e 123 da Carta da OEA.

${ }^{234}$ Vide art. 124 a 130 da Carta da OEA

${ }^{235}$ Vide art. 61 da Carta da OEA.

${ }^{236}$ Vide art. 99 a 105 da Carta da OEA.

${ }^{237}$ SEITENFUS, Ricardo Antônio Silva. op. cit. supra n (223), 2005, p. 260-268.

${ }^{238} \mathrm{Cf}$. ANEXO II.
} 
desenvolvimento socioeconômico e preservação do Estado de Direito nas Américas), tais como o Grupo do Rio, o de Contadora, o de apoio a Contadora, o SELA, as integrações econômicas regionais, as negociações bilaterais e principalmente o Protocolo de Reformas da Carta da OEA de 1991 (Protocolo de Washington - luta por questões sociais e luta pela democracia e pelo Estado de direito). ${ }^{239}$

\subsubsection{Movimento de constitucionalização dos tratados de direitos humanos}

Os arts. 1 e 2 da Convenção Americana sobre DHs estabelecem a competência da ComIDHs e da CtIDHs para conhecer e decidir sobre violações ou ameaças de violação de DHs de seus Estados-partes, de modo que estes têm o dever de adequar seu ordenamento jurídico interno ao ordenamento jurídico internacional, a fim de garantir a eficácia dos tratados e honrar seus compromissos internacionais ${ }^{240}$. Apesar do pequeno avanço dos Estados-partes da Convenção Americana rumo à aprovação de mecanismos que permitam a pronta execução das decisões emanadas do sistema interamericano de $\mathrm{DHs}^{241}$, houve uma tendência dos Estados-partes da Convenção Americana de atribuírem, como corolário da constitucionalização dos direitos fundamentais no plano interno, hierarquia diferenciada ou especial aos tratados de $\mathrm{DHs}^{242}$, a fim de que não se submetam às modificações legislativas ordinárias; que seu processo de denúncia seja dificultado e mais complexo e que haja garantia de manutenção dos compromissos internacionais assu-

${ }^{239}$ SEITENFUS, Ricardo Antônio Silva. op. cit. supra n (223), 2005, p. 270-274. Vide art. 3 e art. 9 do Protocolo de Washington.

${ }^{240} \mathrm{O}$ art. 27 da Convenção de Viena sobre Direito dos Tratados e a opinião Consultiva de 31/7/30 da Corte Permanente de Justiça Internacional trazem o princípio Direito do Internacional de vedação à alegação pelo Estado de disposição de direito interno para justificar o inadimplemento de um tratado.

${ }^{241}$ Neste sentido, destacam-se as iniciativas de 2 países: a Colômbia que aprovou a mais extensa legislação para cumprimento das decisões do sistema interamericano, consubstanciada na Lei $\mathrm{n}^{\circ}$ 288/96, disponível em < http://www.secretariasenado.gov.co/senado/ basedoc/ley/1996/ley_0288_1996.html >, e o Peru que disciplinou a jurisdição internacional nos casos de reparação nos casos de violação ou ameaça de violação de um direito constitucional, consubstanciada nos arts. 39 a 41 da Lei no 23506/82, disponível em <http://www.congreso.gob.pe/ntley/Imagenes/Leyes/23506.pdf > . Acesso em: 09.04.09.

${ }^{242}$ Para saber mais sobre este tal movimento de constitucionalização, cf. ANEXO JJ. 
midos pelos Estados. ${ }^{243}$ Logo, os direitos previstos em convenções internacionais de DHs são internalizados como cláusulas pétreas (direitos ou garantias individuais fundamentais) das constituições nacionais, que no Brasil significa que nem emenda constitucional pode abolir (art. 60, $\$ 4$, IV da CFB) ${ }^{244}$.

Os DHs atualmente conformam o DI geral, de modo a integrar o jus cogens (cume da pirâmide jurídica, padrões éticos mínimos de conduta nas RIs, conjunto de princípios imperativos gerais de vedação do uso da força, proibição de crimes contra humanidade ou de segregação social e de auto-determinação dos povos), extinguindo - por serem direitos superiores aos tratados, aos costumes e normativa interna - normas contrárias e somente sendo derrogadas por normas posteriores de mesma natureza supraconstitucional, conforme arts. 53 a 64 da Convenção de Viena sobre Direitos dos Tratados ${ }^{245}$.

O Brasil pode ser considerado defensor dos DHs, já que possui atitudes internacionais e nacionais condizentes com o desempenho de tal papel. Internacionalmente o Brasil é signatário da DUDHs (1948); da Declaração Americana de Direitos e Deveres do Homens (1948); da Convenção sobre Genocídio (1948); das Convenções de Genebra e seus 2 Protocolos Adicionais (1948); da Convenção sobre Refugiados (1951); do Pacto Internacional de Direitos Civis e Políticos PIDCP (1966); do Pacto Internacional dos Direitos Econômicos Sociais e Culturais - PIDESC (1966) ${ }^{246}$. Além disso, o Brasil participou da I Convenção Mundial sobre DHs, em Teerã (1968) e da II Convenção Mundial sobre DHs, em Viena (1993) ${ }^{247}$. Nacionalmente o Brasil defende no preâmbulo, no inciso III do art. 1 e no inciso II do art. 4 de sua Carta Magna um Estado democrático, cuja finalidade precípua

\footnotetext{
${ }^{243}$ PETIOT, Patrick. A responsabilidade internacional do Estado brasileiro por violação de diretos humanos: o pagamento de reparações. Brasília, 2005, p. 146-157.

${ }^{244}$ Ibid., p. 163-164. Para maiores informações sobre a tramitação dos tratados de DHs, verificar o projeto de resolução no $204 / 05$; e sobre as tentativas de elevar tratados de DHs à categoria de emenda constitucional verificar os projetos de decretos legislativos $\mathbf{n}^{\mathbf{o}} \mathbf{S}$ 1.595 e 1.598 .

${ }^{245}$ PETIOT, Patrick. op. cit. supra. n (242), 2005, p. 157-160.

${ }^{246}$ Para saber mais sobre a adesão do Brasil aos tratados de DHs, cf. ANEXO KK.

${ }^{247}$ Sobre a promulgação de tratados multilaterais de DHs pelo Brasil, consultar a data de promulgação dos respectivos tratados no site: <http://www2.mre.gov.br/dai/dhumanos. htm>. Ultimo acesso: 07.09.09.
} 
é "assegurar o exercício dos Direitos Sociais e Individuais", fundamentado sobre o princípio da "dignidade humana", norteado em suas RIs pela "prevalência dos Direitos Humanos".

\subsection{O direito de participação individual no sistema interamericano}

\subsubsection{Antecedentes internacionais do direito de participação individual no sistema interamericano}

O primeiro órgão internacional administrativo e judicial de recursos dotado de poder decisório sobre os Estado participantes foi a Comissão Central para Navegação do Reno (disciplinada no Regulamento para a Livre Navegação dos Rios), criada em 1816 para decidir questões internacionais privadas dos particulares que perdessem causas sobre direitos de navegação nos tribunais domésticos com jurisdição sobre o Reno. Antecedidos pelas comissões bilaterais de arbitragem, o acesso direto dos indivíduos (petições individuais) a instâncias internacionais se consolidou após a Primeira Guerra Mundial com os tribunais arbitrais mistos para reparação de danos da guerra (disciplinados pelos Tratados de Versailles, Saint-Germain, Trianon e Neuilly). Contudo, a primeira previsão do direito de acesso individual a um órgão internacional foi, com a Segunda Conferência de Paz de Haia, na Convenção relativa ao Estabelecimento de uma Corte Internacional de Presas de 1907 (captura de navios e suas cargas em tempo de guerra), que não entrou em vigor por falta de ratificação. Entre 1907 e 1918, na América Central se manteve a Corte de Justiça Centro-Americana (primeiro órgão judicial internacional para dirimir controvérsias interestaduais através de sentenças de cumprimento obrigatório), que recebia petições individuais contra os demais países por violação de tratados internacionais, foram 5 todas rejeitadas devido a aplicação rigorosa do requisito do prévio esgotamento dos recursos internos. Com a criação da Liga das Nações, sucederam-se os debates para criação do Estatuto da Corte Permanente de Justiça Internacional (CPJI) e decidiu-se majoritariamente que somente os Estados poderiam ser partes (fator empobrecedor de algumas decisões da CPJI), mas deixaram espaço para reconsideração posterior. $O$ direito de petição existe em órgãos judiciais regionais não-especializados, como o Tribunal de Justiça da Comunidade 
Andina de $1979^{248}$. Em 1991 o Protocolo de Tegucigalpa (responsável pela reforma da Carta da OEA) estabeleceu a Corte Centro-Americana de Justiça no âmbito do Sistema de Integração Centro-Americana (sob a Convenção sobre o Estatuto da Corte Centro-Americana de Justiça de 1992), com competência para receber petições individuais (sobre dispositivos legais contrários a tratados internacionais, a normas do direito centro-americano e resoluções dos órgãos do sistema) e para remeter as causas ligadas a DHs à CtIDHs. Em 2005 foi inaugurada a Corte Caribenha de Justiça que reconhece o interesse dos particulares (desde que com interesse direto na causa, seu Estado de nacionalidade tenha aceitado a demanda, e a Corte aceite sua legitimidade) para interpretar e aplicar o tratado da Comunidade Caribenha. Além desses, o Tribunal de Justiça das Comunidades Européias e o Tribunal de Justiça do Mercado Comum para a África Oriental e Austral também admitem petições individuais. ${ }^{249}$

\subsubsection{A luta pelo direito de atuação em juízo das vítimas à CtIDHs}

O direito de participação individual no sistema interamericano não é um direito que se conseguiu sem esforço; pelo contrário, o direito de atuação em juízo (locus standi) é fruto de esforço conjunto e persistência dos jusinternacionalistas defensores do reconhecimento do indivíduo com plena capacidade jurídico-processual no plano internacional. No inicio do séc. XXI, duas teses foram defendidas

\footnotetext{
${ }^{248}$ Modificado pelo Protocolo de Cochabamba de 1996, o Tribunal aceita que os particulares proponham ação de nulidade e de requisição de cumprimento de obrigações ao Conselho Andino de Ministros das Relações Exteriores, à Comissão da Comunidade Andina e à Secretária-Geral. Ademais, os particulares também podem submeter conflitos de aplicação ou interpretação de contratos privados à arbitragem do Tribunal. Cf. PETIOT, Patrick. op. cit. supra. n (236), 2005, p. 80-86.

${ }^{249}$ PETIOT, Patrick. op. cit. supra. n (242), 2005, p. 87.

${ }^{249} \mathrm{O}$ Regulamento de 2000 da ComIDHs revela a posição favorável em relação ao aceso direto do indivíduo perante a CtIDHs.

${ }^{249}$ Apesar de favorável ao acesso direto do indivíduo à CtIDHs, Pedro Nikken, ex-presidente da CtIDHs de 1983-1985 e presidente do IIDH em 1999, mostrou-se não favorável à reforma da Convenção Americana, conforme artigo publicado em 1998, intitulado "Perfeccionar el Sistema Interamericano de Derechos Humanos sin refomar el Pacto de San José", cf. o site: <http://www.bibliojuridica.org/libros/4/1991/5.pdf $>$, quando comparou
} 
para o fortalecimento do sistema interamericano de DHs: a adotada pela ComI$\mathrm{DHs}^{250}$ e pelo IIDHs ${ }^{251}$ (Instituto Interamericano de Direitos Humanos) que defendia que bastaria reformar os Regulamentos da ComIDHs e da CtIDHs; e a tese adotada pelo governo da Costa Rica ${ }^{252}$ e pela $\mathrm{CtIDHs}^{253}$, que defendia que não só deveria haver reforma nos Regulamentos da ComIDH e da CtIDHs, como também deveria haver um Protocolo à Convenção Americana para mudanças permanentes e profundas, consultando-se os órgãos de proteção, a CtIDHs, a ComIDHs, a sociedade civil e os experts independentes. ${ }^{254}$ Ressalte-se que o mais ferrenho defensor do acesso direto do indivíduo à CtIDH e da evolução do locus standi (plena participação do indivíduo demandantes a todo procedimento da CtIDH) para um verdadeiro jus standi (direito de acesso direto dos indivíduos à CtIDH com plena igualdade jurídica com o Estado) no sistema interamericano foi Antônio A. Cançado Trindade ${ }^{255}$, cujo ideal se expressa em toda sua magnitude (abarcando o indivíduo na sua esfera bio-psico-social-espiritual) nas seguinte fundamentação filosófica-doutrinária:

a Convenção a uma catedral, nos seguintes termos: "Como no es oportuno, necesario ni conveniente demoler uma catedral para matar um ratón que tiene sus galerias em ella. A menos que lo que se quiera verdaderamente sea destruir la catedral y el ratón sea solo el pretexto para lograrlo". Ultimo acesso: 07.09.09.

${ }^{251}$ O governo da Costa Rica foi o único Estado-Membro da OEA a apresentar proposta concreta de Protocolo Facultativo à Convenção Americana para possibilitar o pleno acesso do indivíduo à CtIDHs. Cf. o site: <http://scm.oas.org/DOC_SEARCH_ENGINE/ PORTUGUESE/hist_01/ag01643p06.doc > . Ultimo acesso: 07.09.09. Cf. ANEXO LL. 251 O grande defensor do acesso direto do indivíduo á jurisdição internacional foi o ex-presidente da CtIDHs, juiz Antônio A. Cançado Trindade, relator de 2 volumes contendo as propostas da Corte sobre reforma e fortalecimento do sistema interamericano e das recomendações do seminário dos experts, cf. os sites: <http://www.corteidh.or.cr/ libros.cfm $>;<$ http://www.corteidh.or.cr/docs/libros/Semin1.pdf $>;<$ http://www.corteidh.or.cr/docs/libros/Semin2.pdf>. Ultimo acesso: 07.09.09.

${ }^{252}$ ROBLES, Manuel E. Ventura. El acceso directo de la víctima a la Corte Interamericana de Derechos Humanos: um ideal y uma llucha de Antonio A. Cançado Trindade. In: Os rumos do Direito Internacional dos direitos humanos: ensaios em homenagem ao professor Antônio Augusto Cançado Trindade/Renato Zebini Ribeiro Leão, coord. - Porto Alegre: Sergio Antonio Fabris Ed. 2005.

${ }^{253} \mathrm{O}$ juiz Trindade, desde 1979 na sua tese de doutorado (ganhadora do Premio Yorke) na Universidade de Cambridge, defendeu tais idéias, e continua lutando por elas não só perante os órgãos da OEA (a AG em 4/6/01, o CP em 17/4/02 e em 16/10/2002, a CAPJ em 5/4/01 e na reunião conjunta com ComIDHs em 19/4/02), como também em foros acadêmicos internacionais e em conferências na América e na Europa. 
“26. O movimento universal em prol dos direitos humanos é irreversível, não admite retrocessos. Tem sua mística própria, reforçada pelo ideal de justiça internacional, que ganha corpo em nossos dias. Resta, sem dúvida, um longo caminho a percorrer. Deve-se equipar os mecanismos internacionais de proteção para enfrentar novas formas de violação dos direitos humanos e combater a impunidade. Deve-se lograr definitivamente a justiciabilidade dos direitos econômicos, sociais e culturais, negligenciados até o presente. Deve-se fomentar a aceitação integral (sem reservas), pelos Estados, dos tratados de direitos humanos e assegurar a aplicabilidade direta de suas normas no plano de direito interno dos Estados. Deve-se consolidar o acesso direto dos indivíduos à justiça no plano internacional, teses pelas quais venho lutando há muito tempo. Devese desenvolver as obrigações erga omnes de proteção do ser humano, tornando seus direitos fundamentais como parte integrante do jus cogens. E deve-se expandir o rol da sociedade civil na construção de uma cultura universal de observância dos direitos humanos." ${ }^{\text {256 }}$

Das discussões supra-delineadas acerca do acesso direto do indivíduo à CtIDHs (jus standi), resultaram os seguintes documentos preliminares: 1) o Plano de Ação e a Declaração da Cidade de Quebec da Cidade de Quebec de 22/04/2001, resultantes da Terceira Cúpula das Américas realizada em Quebec, Canadá, em 2001 entre os chefes de Estado e Governo das Américas ${ }^{257}$; 2) as recomendações decorrentes das Reuniões ${ }^{258}$ (de 20/9 e 24/11 de 1999; 5/2, 6/2, 8/2 e 9/2 de 2000) de Experts convocados pela CtIDHs para debater perante os Estados, a CtIDHs, a ComIDHs e a sociedade civil os pontos centrais para fortalecimento do sistema

\footnotetext{
${ }^{256}$ TRINDADE, Antônio Augusto Cançado. Discurso del Presidente de la Corte Interamericana de Derechos Humanos, Juez Antõnio Augusto Cançado Trindade, em la cerimônia de incorporación como Professor Honorário de la Universidad Nacional Mayor de San Marcos. Lima, Peru, 13 de septiembre de 2001 (grifo nosso, tradução livre da autora).

${ }^{257}$ Tanto o Plano de ação, quanto a Declaração de Quebec de 22/4/2001 estão respectivamente disponíveis nos sites: $<$ www.americascanada.org/eventsummit/declarations/plan-s. pdf $>$; $<$ www.americascanada.org/eventsummit/declarations/declara-s.asp $>$; Ultimo acesso: 07.09.09.

${ }^{258}$ Sobre a visão dos experts sobre a participação dos indivíduos perante a CtIDHs, cf. ANEXO MM.
} 
interamericano de $\mathrm{DHs}^{259}$; 3) as recomendações decorrentes da Reunião do Grupo de Trabalho ad hoc sobre os DHs celebrada em São José, Costa Rica em 10 e $11 / 03 / 2000^{260}$; 4) a Resolução 1828, intitulada "Avaliação do Funcionamento do Sistema Interamericano de Proteção e Promoção dos Direitos Humanos para seu Aperfeiçoamento e Fortalecimento" e a Resolução $1833^{261}$, intitulada “Estúdio sobre el Acesso de Las Personas a la Corte Interamericana de Derechos Humanos", ambas de 5/06/2001 e resultantes da 31 a AG/OEA ${ }^{262}$; 5) a Resolução 1890, intitulada "Avaliação do Funcionamento do Sistema Interamericano de Proteção e Promoção dos Direitos Humanos para seu Aperfeiçoamento e Fortalecimento” e a Resolução $1895^{263}$, intitulado "Estúdio sobre el Acesso de Las Personas a la Corte Interamericana de Derechos Humanos", ambas de 4/06/2002 e resultantes da 32a AG/OEA ${ }^{264}$.

\subsubsection{Participaçōes individuais na CtIDHs após o regulamento quarto}

A adoção do Quarto Regulamento de 2000 à Convenção Americana de DHs fortaleceu a capacidade processual internacional dos indivíduos sob a Convenção Americana. A CtIDHs criada em novembro de 1969, aprovou, inspirada no Regulamento vigente na CtEDHs - que por sua vez se inspirara no Regulamento da CIJ -, seu Primeiro Regulamento em julho de 1980. Contudo, tal regulamento, inspirado no contencioso entre Estados, juridicamente iguais, era muito diferente do atual contencioso internacional dos DHs. Apresentado o caso à CtIDHs, seu Presidente

${ }^{259}$ Vide as conclusões destas reuniões no OEA/Res.G/CP/CAJP-1627/00 e o Seminário "El Sistema Interamericano de Protección de los Derechos Humaonos em el Umbral del Siglo XXI", disponíveis no site $<\mathbf{h t t p : / / w w w . o a s . o r g / p t / > . ~ U l t i m o ~ a c e s s o : ~ 0 4 . 0 4 . 0 9 . ~}$

${ }^{260}$ Vide as recomendações desta Reunião, OEA/Res.G/CP/CAJP-1620/00, estão disponíveis no site $<$ http://www.oas.org/pt/ >. Ultimo acesso: 04.04.09.

${ }^{261}$ Sobre a Resolução 1833, cf. ANEXO NN.

${ }^{262}$ Tanto a AG/RES. 1828 (XXXI-O/01) e AG/RES. 1833 (XXXI-O/01) estão disponíveis respectivamente sites: <http://www.oas.org/juridico/portuguese/2001/agres1828. htm >; <http://www.oas.org/juridico/spanish/ag01/agres_1833.htm >. Ultimo acesso: 07.09.09.

${ }^{263}$ Sobre a Resolução 1895, cf. ANEXO OO.

${ }^{264}$ Tanto a AG/RES 1890 (XXXII-O/02) e AG/RES 1895 (XXXII-O/02) estão disponíveis respectivamente nos sites: <http://www.oas.org/juridico/portuguese/2002/agres1890.htm>; $<$ http://www.oas.org/juridico/spanish/ag02/agres_1895.htm >. Ultimo acesso: 07.09.09. 
convocava os representantes da ComIDHs e do Estado demandado para uma reunião para entrarem em consenso quanto à ordem e aos prazos para apresentação das razões (memória), contra-razões (contramemoria), réplica (réplica) e tréplica (dúplica); quanto à apresentação das exceções preliminares, estas dar-se-iam até o prazo final de apresentação das contra-razões (contramemoria). Sob este regulamento, ocorreram 3 casos contenciosos e 12 opiniões consultivas. Quanto ao trâmite das medidas provisórias (MPs), teoricamente o Presidente deveria consultar a Comissão Permanente da Corte; contudo, os escassos recursos humanos e materiais e o caráter não-permanente da Corte inviabilizaram tais medidas. ${ }^{265}$

Em 01.08.1991 entrou em vigor o Segundo Regulamento da CtIDHs. A diferença deste Regulamento para o anterior era que o Presidente da Corte passou a fazer um exame preliminar de admissibilidade da demanda, estipulando um prazo de até 20 dias para cumprimento dos requisitos fundamentais para prosseguimento do processo. Notificado, o Estado demandado tinha 30 dias da notificação para interposição das exceções preliminares (30 dias para resposta às exceções) e 3 meses da notificação para responder por escrito à demanda. Em 1993, iniciou-se uma reforma quanto às MPs a fim de que mesmo sem a reunião da Corte o Presidente pudesse requerer ao Estado demandado a tomada de medidas urgentes e necessárias contra danos irreparáveis aos demandantes (tal resolução deveria ser ratificada ou não pela próxima reunião do pleno da Corte). Neste período, a Corte conheceu 18 caos contenciosos e proferiu várias opiniões consultivas. O caso El Amparo (reparaciones, 1996) foi verdadeiro marco da necessidade de reforma, quando em audiência pública o magistrado passou a perguntar diretamente aos representantes das vítimas e não aos delegados da Comissão ou agentes do Estado Demandado ${ }^{266}$.

\footnotetext{
${ }^{265}$ TRINDADE, Augusto Cançado Trindade. "El Nuevo Regulamento de la Corte Intera-Mericana de Derechos Humanos (2000): La Emancipación del ser humano como sujeto del Derecho Internacional de los Derechos Humanos”. In: REVISTA UNIVERSITAS/Relações Internacionais; Vol. I; n² 2; Janeiro a Julho de 2003, Série Nacional, p. 10-13. ${ }^{266}$ Mais dados: cf. CtIDHs: Transcripción de la Audiência Pública Celebrada em la Sede de La Corte el Dia 27 de Enero de 1996 sobre Reparaciones - Caso El Amparo, p. 72-76 (mecanografado, circulación interna).
} 
Também nos caso Gordínez Cruz y Velásquez Rodríguez, foi permitida apresentação pelos representantes das vítimas de escritos á $\mathrm{CtIDHs}^{267}$.

Continuando o processo de racionalização e simplificação do procedimento da CtIDHs, considerados os princípios da economia processual e do equilíbrio entre as partes, foi adotado em 16.09.1996 e entrou em vigor em 01.01.1997, o Terceiro Regulamento do CtIDHs. O Terceiro Regulamento cuidou de precisar a terminologia e a estrutura dos procedimentos da CtIDHs, formando um verdadeiro Código de Processo Internacional (interna corporis). Foi estabelecido momentos processuais adequados para apresentação de provas de cada etapa do processo na CtIDHs, permitindo prova extemporânea no caso de força maior, impedimento grave ou fatos supervenientes. Figuras processuais, como conciliação, sobrestamento, chamamento ao processo também foram introduzidas. ${ }^{268}$. A partir do Terceiro Regulamento os indivíduos alcançaram Locus Standi in Judicio perante a CtIDHs, ou seja, possibilidade de participação (ou outorga da faculdade de apresentar argumentos próprios e provas) pelas supostas vítimas, seus familiares, seus representantes legais na etapa de reparações. Sob tal Regulamento foram conhecidos 17 casos contenciosos. ${ }^{269}$

Adotado em 24.11.2000, o Quarto Regulamento, que entrou em vigor em 01.06.2001 é um marco da evolução do DIDHs, tendo sido também fruto de 4 Reuniões (composta pelos representantes dos órgãos de supervisão do sistema de proteção, da OEA, dos Estados membros e das entidades da sociedade civil) na sede da CtIDHs (20.09.1999; 24.11.1999; 15/16.02.2000 e 08/09.02.2000) que resultaram no Seminário Internacional "El sistema Interamericano de Protección de los Derechos Humanos em el Umbral del Siglo XXI”270. A outorga de participação direta das supostas vítimas, seus familiares e representantes em todas as etapas do proces-

\footnotetext{
${ }^{267}$ Mais dados: Corte I.A.D.H., Informe Anual de la Corte Interamericana de Derechos Humanos - 1996, p. 207-213.

${ }^{268}$ Art. 23 do Terceiro Regulamento.

${ }^{269}$ TRINDADE, Augusto Cançado Trindade. Op. cit. supra. n (264), 2003, p. 13-19.

${ }^{270} \mathrm{Tal}$ Seminário Internacional resultou na seguinte obra: Corte Interamericana de Direitos Humanos, El Sistema Interamericano de Protección de los Derechos Humanos em el Umbral del Siglo XXI - Memória del Seminário, San José de Costa Rica, CtIADH, 2001, p. 1-726.
} 
so perante a Corte foi o marco qualitativo do Quarto Regulamento para o Sistema Interamericano de Proteção dos DHs. Além disso, tal Regulamento privilegiou a celeridade e agilidade do processo (evitando custos desnecessários; sem, contudo, prejudicar a segurança jurídica) e a economia processual (possibilidade de uma só sentença julgar exceções preliminares e questão de mérito; sem, contudo, prejudicar o contraditório) $)^{271}$.

Tendo em vista que justiça atrasada é justiça denegada, o Quarto Regulamento trouxe reduções dos prazos processuais, tais como, a contestação da demanda passa a ser possível até 2 meses após a notificação da demanda ${ }^{272}$, de tal modo que os fatos não negados e as pretensões não controvertidas serão tida como verdadeiras ${ }^{273}$. As supostas vítimas, seus familiares ou representantes legais podem trazer solicitações, argumentos e provas de forma autônoma durante todo o processo $^{274}$, com prazo de 30 dias para apresentar tudo por escrito ${ }^{275}$ ou mesmo apresentar em audiência como partes do processo $^{276}$. Assim todas as apresentações de demandas e solicitações de opiniões consultivas devem ser encaminhadas não só ao Presidente e demais Juízes da CtIDHs, mas também ao CP/OEA, ao Estado demandado, à ComIDHs, ao denunciante original e à suposta vítima, seus familiares e representantes ${ }^{277}$. Podem ser realizadas audiências públicas sobre as MPs de proteção ${ }^{278}$. A partir do Regulamento Quarto, foi alcançado o Locus Standi in Judicio (participação direta das supostas vítimas, seus familiares e representantes perante a CtIDHs). Concluindo, em um processo perante a CtIDHs, podem coexistir 3 posturas distintas: a postura da suposta vítima, seus familiares ou representante legal

\footnotetext{
${ }^{271}$ Art. 36 do Quarto Regulamento.

${ }^{272}$ Art. 37 (1) do Quarto Regulamento.

${ }^{273}$ Art. 37 (2) do Quarto Regulamento.

${ }^{274}$ Art. 43 e 23 do Quarto Regulamento.

${ }^{275}$ Art. 35(4) do Quarto Regulamento.

${ }^{276}$ Art.40 (2) do Quarto Regulamento.

${ }^{277}$ Art. 35 (2) e 62(1) do Quarto Regulamento.

${ }^{278}$ Art. 25 e 63 (2) do Quarto Regulamento
} 
(sujeito de DIDHs); a postura da ComIDHs (órgão de supervisão da Convenção Americana e auxiliar da Corte $)^{279}$; e a postura do Estado Demandado. ${ }^{280}$

Embora o Regulamento Quarto ${ }^{281}$ tenha reconhecido o indivíduo como sujeito de DIDHs com plena capacidade jurídico-processual internacional, tal reconhecimento não é suficiente para garantir-lhe o direito de petição individual perante a CtIDHs. Para o aperfeiçoamento do mecanismo de proteção regional da pessoa humana é necessária a adoção do Protocolo de Reformas à Convenção Americana de $\mathrm{DHs}^{282}$. Para fazer frente a esta nova conquista, juridicamente revolucionária nos planos conceitual, processual, filosófico e material serão necessários consideráveis recursos humanos e materiais. A fim de atender às novas necessidades de proteção do ser humano, as instituições terão de renovar-se ${ }^{283}$ a partir da elaboração de um Protocolo de Reformas à Convenção Americana sobre DHs (via mais segura de obter compromissos reais do que Regulamentos, que podem ser facilmente alterados), resultante de consultas aos Estados partes, entidades da sociedade civil e beneficiários do sistema. São necessárias reformas relativas ao mecanismo de proteção e os procedimentos ${ }^{284}$, embora seja possível ampliar-se o rol de direitos convencionalmente protegidos ${ }^{285}$ Dentre os requisitos básicos presentes ao

\footnotetext{
${ }^{279} \mathrm{~A}$ ComIDHs disponibiliza formulário para apresentação de petições por pessoa, grupo de pessoas e organizações que julguem estar sendo violados direitos protegidos na Convenção Americana, cf. ANEXO P.

${ }^{280}$ TRINDADE, Augusto Cançado Trindade. Op. cit. supra. n (264), 2003, p. 19-25.

${ }^{281}$ Ainda corroborado pelo atual Regulamento da CtIDHs, conforme verificado pelos 37 novos artigos adicionados pela Corte durante seu Octagésimo Segundo Período Ordinário de Sessões, na sessão celebrada no dia 29 de janeiro de 2009. Cf. ANEXO QQ.

${ }^{282}$ Para informações mais detalhadas sobre o Projeto o de Protocolo à Convenção Americana de Direitos Humanos: cf. A.A.Cançado Trindade, Informe del Relator de la Corte Interamericana de Derechos Humanos sobre el Proceso de Fortalecimiento del Sistema Interamericano de Protección de los Derechos Humanos: Bases para um Proyect de Protocolo a la Convención Americana sobre Derechos Humanos, San José de Costa Rica, CtIADH, 15.06.2000 (vérsion preliminar, circulación interna).

${ }^{283}$ Para melhor compreensão desta necessidade de renovação, cf. APÊNDICES A e B.

${ }^{284}$ Art. 77(1) da Convenção Americana.

${ }^{285}$ TRINDADE, Augusto Cançado Trindade. Op. cit. supra. n (264), 2003, p. 29-34.
} 
Protocolo deverão estar os 3 seguintes $^{286}$ : a) ratificação sem reservas da Convenção Americana de DHs por todos os Estados-membros da OEA; b) aceitação integral e sem restrições da jurisdição automática e obrigatória de todos os Estados membros da OEA; c) incorporação da normativa substantiva dos direitos protegidos ao Di dos Estados-partes. ${ }^{287}$

A incorporação da normativa substantiva da Convenção Americana ao Di dos Estados-partes coexiste em harmonia com o princípio da subsidiariedade dos mecanismos e procedimentos de proteção internacional, porque o primeiro se aplica ao plano substantivo, ao passo que o segundo se aplica no plano processual. ${ }^{288}$ Para fiel execução das sentenças e decisões da CtIDHs e recomendações da ComIDHs, é preciso que os Estados-partes atuem como garantes da Convenção Americana, respeitando o princípio da garantia coletiva subjacente às convenções e tratados de DHs. Outro ponto a constar no Protocolo será a defesa da aceitação universal e integral dos tratados de DHs (prevalência do Direito sobre outro meios para realização da Justiça), consagrado no documento final da II Conferência Mundial de DHs (Viena, junho d 1993): Declaração e Programa de Ação de Viena. ${ }^{289}$

\subsection{Desdobramentos das decisões do sistema interamericano}

\subsubsection{A responsabilidade estatal internacional dentro do sistema interamericano}

O instituto da responsabilidade estatal remonta à doutrina clássica romana, se consolidou a partir da formação dos Estados modernos e da assinatura dos tratados geradores da Paz de Vestfália (1648), e se desenvolveu com o fim do antigo

\footnotetext{
${ }^{286}$ Informações mais detalhadamente apresentadas no seguinte documento: OEA/CAJIP, Informe del Presidente de la Corte Interamericana de Derechos Humanos, Juez Antônio A. Cançado Trindade, ante la Comisión de Asuntos Jurídicos y Políticos del Consejo Permanente de la Organización de los Estados Americanos, Washington D.C., OEA, 09 de marzo de 2001,

${ }^{287}$ TRINDADE, Augusto Cançado Trindade. Op. cit. supra. n (264), 2003, p. 35-39.

${ }^{288}$ Ibid, p. 38.

${ }^{289}$ TRINDADE, Augusto Cançado Trindade Op. cit. supra. n (264), 2003, p. 35-39.
} 
regime e a consolidação da noção de Estado de Direito ${ }^{290}$ (Estado regulamentado por constituições nacionais, com submissão do poder público ao ordenamento jurídico), positivando-se em 2001 no âmbito da $\mathrm{ONU}^{291}$ e ainda vem sendo regulamentado com a assinatura de instrumentos internacionais sobre DHs. A importância de tal instituto está, além da garantia da ordem jurídica e do equilíbrio entre os Estados ${ }^{292}$, na obrigação (erga omnes) de reparação, seja pelo Estado ${ }^{293}$ ou pelo indivíduo, dos danos oriundos da violação de uma norma (extensão das garantias fundamentais a terceiros indiretamente atingidos). ${ }^{294}$ Assim, a prática de um ato ilícito (inadimplemento de um tratado ou prática de um ato ilícito extracontratual) resulta na responsabilização internacional do Estado violador (obrigação de reparação plena ${ }^{295}$, fazer cessar os atos lesivos e oferecer garantais de não-reincidência), exceto quando incidirem as causas de exoneração da responsabilidade internacio-

${ }^{290} \mathrm{~A}$ responsabilidade civil do Estado (consequentemente possível ações contra o Estado) só foi admitida pela primeira vez na França por força do art. 75 da Constituição de 1799; na Inglaterra com o advento do Crown Proceeding Act de 1947; nos EUA somente com a aprovação do Federal Tort Claims Act de 1946; e no Brasil através do art. $37 \$ 6$ da CF de 1988. PETIOT, Patrick. op. cit. supra. n (242), 2005, p. 76 e 77.

${ }^{291} \mathrm{O}$ tema é desenvolvido pela ComDHsNU. Vide o art. 1 do Projeto de Convenção das Nações Unidas. Em 2001 a ComDINU conclui um projeto relativo à responsabilidade internacional dos Estados, disponível no site: <http://www.un.org/law/ilc/ reports/2001/2001 report.htm> . Ultimo acesso: 07.09.09.

${ }^{292}$ Ressalte-se ainda que a responsabilidade internacional por violação de DHs do Estado ao colocar o ser humano no centro da proteção jurídica, representa a superação do princípio da reciprocidade, do paradigma da não-interferência nos assuntos domésticos e do voluntarismo estatal.

${ }^{293}$ Pela teoria objetiva de responsabilidade estatal internacional, exige-se 3 requisitos: conduta omissiva ou comissiva do Estado; violação de obrigação internacional; e a prova do nexo de causalidade entre a conduta e a violação. Mais dados: cf. MELLO, Celso D. Albuquerque. Responsabilidade Internacional do Estado. Rio de Janeiro: Renovar, 1995.

${ }^{294}$ COELHO, Rodrigo Meirelles Gaspar. Proteção internacional dos direitos humanos: a Corte Interamericana e a implementação de suas sentenças no Brasil. Curitiba: Juruá, 2008, p. 41-50.

${ }^{295}$ A reparação plena pode se dar sob a forma de restituição, de indenização ou de satisfação. A mais desejável das reparações é a restituição integral ou restabelecimento das coisas ao estado anterior à violação. CPJI: Usina de Chorzów, acórdão de 21/11/27, p. 21. Quando impossível a restituição, deve haver a indenização dos danos. CIJ: Projeto Gabcikovo-Nagymaros, acórdão de 25/9/97). Quando os danos não forem economicamente mensuráveis, mas haja afronta ao Estado lesado, a satisfação pode ser o reconhecimetno do ato ilicito, a expressão de pesar ou pedido de desculpas, desde que não humilhe o Estado responsável. 
nal (consentimento do Estado lesado, autodefesa conforme Carta da ONU, contramedidas, força maior, estado de perigo ou estado de necessidade) ${ }^{296}$.

O sistema regional interamericano de proteção de DHs é organizado pela OEA e composto pela ComIDHs e pela CtDHs. A CtIDHs é um organismo jurisdicional autônomo; contudo, somente são submetidos a ela os Estados -partes na Convenção Americana de $\mathrm{DHs}^{297}$. É possível aos Estados da OEA aderir ou não à Convenção Americana de DHs (1969); ao Pacto de São José da Costa Rica (1969); à Convenção sobre Tráfico Internacional de Menores (1994); ou à Convenção para Eliminação de Todas as Formas de Discriminação contra as Pessoas Portadoras de Deficiência (1999). ${ }^{298}$

Dentro da OEA há níveis ou camadas de responsabilidade estatal, já que há 2 procedimentos distintos e complementares de responsabilização estatal ${ }^{299}$. O primeiro procedimento é o geral, mais antigo e subsidiário, para membros da OEA; o segundo procedimento, mais sofisticado e completo, é o da Convenção Americana, para partes da Convenção Americana. O Brasil é parte nos 2 processos contenciosos perante a CtIDHs, já que o Brasil ratificou em 1992 a Convenção Americana e a promulgou pelo Decreto 678/92, assim como reconheceu a obrigatoriedade da Corte em 1998, mas promulgou tal declaração sob reserva de reciprocidade através do Decreto 4.463/2002. A partir de então, as decisões da CtIDHs tem natureza jurídica de título executivo com plena eficácia no Brasil, sendo que uma vez responsabilizado pela Corte, o país fará uso dos mecanismos (administrativos e processuais) de seu ordenamento jurídico, além da conscientização da sociedade civil e da vontade política (de combater a impunidade, a corrupção e a exclusão social) das autoridades e das instituições públicas, para cumprir com as determinações da sentença, que inclui diferentes espécies de reparação (de pagar quantia,de fazer,

\footnotetext{
${ }^{296}$ PETIOT, Patrick. op. cit. supra. n (242), 2005, p. 73-74.

${ }^{297}$ Para saber quais os Estados-membros da OEA são parte da Convenção Americana, do Protocolo de São Salvador e quais reconheceram a competência contenciosa da ComIDH e da CIDH, cf. APÊNDICE C.

${ }^{298}$ Vide a situação atualizada de assinatura, ratificação e reservas dos países membros da OEA nestes instrumentos internacionais através do site $<$ http://www.cidh.oas.org/Basicos/English/Basic.TOC.htm $>$. Ultimo acesso: 07.09.09.

${ }^{299}$ Para saber mais sobre os 2 procedimentos, cf. APÊNDICE D e E.
} 
de não fazer, indenização, restituição na íntegra, cessação do ilícito, satisfação, de investigação de fatos, de identificação e sanção dos responsáveis, etc.). ${ }^{300}$

Segundo Relatório Final de 2006 da OEA, até o $2^{\circ}$ semestre de 2006 havia 2 sentenças (com natureza jurídica internacional) da CtIDHs contra o Brasil: do Caso Damião Ximenes Lopes e do Caso Gilson Nogueira Carvalho. Em 2004, totalizava-se 90 casos (petições declaradas admitidas por meio de um relatório de admissibilidade) e peças (queixas encaminhadas ao Estado envolvido para prestar informações, mas sem relatório de admissibilidade) contra o Brasil. ${ }^{301}$

\subsubsection{Formas de reparação nas sentenças da Corte Interamericana}

Conforme a teoria da responsabilidade internacional do Estado por violação de DHs (diferentemente da teoria clássica de responsabilidade internacional do Estado em que o indivíduo só dispunha do mecanismo precário de proteção diplomática ${ }^{302}$, limitado ao nacional residente no exterior e dependente da iniciativa estatal), desenvolvida pelo DIDHs (indivíduo no centro da proteção e goza do direito de petição para reivindicar sues direitos perante órgão de controle internacional), o sistema universal ou os sistemas regionais de DHs prevêem em seus tratados ou convenções cláusulas gerais de reparação (compreende todas as espécies possíveis de ressarcimento, como a restituição integral a indenização e a satisfação), tais como, o art. 9.5 do PIDCP ${ }^{303}$; o art. 63.1 da Convenção America-

\footnotetext{
${ }^{300}$ COELHO, Rodrigo Meirelles Gaspar. op. cit. supra. n (293), 2008, p.33-35.

${ }^{301}$ Dados encontrados no Relatório Anual de 2006 da ComIDHs, disponível em : <http:// www.cidh.oas.org/annualrep/2006eng/chap.3a.htm >. Acesso em : abril/2007.

${ }^{302} \mathrm{O}$ instituto da proteção diplomática está disciplinado na Convenção de Viena sobre Relações Consulares. Para maiores informações sobre a proteção diplomática, consultar a página da Comissão de Direito Internacioanl: <http://daccessdds.un.org/doc/UNDOC/ GEN/N04/260/16/PDF/N0426016.pdf?OpenElement >. Ultimo acesso: 07.09.09.

${ }^{303}$ Comitê de Direitos Humanos: Comunicado no 971/2001, de 13/04/05, sobre o Uzbequistão; Comunicado no 973/2001, de 13/04/2001, de 13/04/05, sobre o Tadjiquistão. CPJI: Usina de Chorzów, acórdão de 13/9/28, p. 27-28.
} 
na ${ }^{304}$; o art. 41 da Convenção Européia; e o art. 27.1 do Protocolo à Carta Africana. Além disso, há de se ressaltar que a obrigação de reparar rege-se pelo DI e o Estado responsabilizado deve se esforçar para tomar as medidas administrativas e legislativas para implementação da reparação, já que não pode invocar a insuficiência do seu Di para se eximir de cumpri-la ${ }^{305}$. O sistema interamericano consagra a plena reparabilidade dos danos materiais (danos emergentes e lucros cessantes), sejam os danos concretos ${ }^{306}$ ou danos presumidos ${ }^{307}$; assegura a reparabilidade do dano moral ${ }^{308}$, seja através da sentença condenatória ${ }^{309}$ ou através de compensação pecuniária (pretium doloris), baseada na equidade ${ }^{310}$ ou na apreciação prudente da Corte $^{311}$; reconhece a reparação do dano decorrente da interrupção do projeto de vida $^{312}$ (perda de uma chance, das opções de realização pessoal de que foi injustamente privada), através de reparação simbólica. ${ }^{313}$

A teoria contemporânea sobre responsabilidade internacional do Estado traz o caráter vinculante das sentenças de Cortes Internacionais, tais como a CtI-

${ }^{304}$ CtIDHs: Velásquez Rodíguez versus Honduras, acórdão de 21/07/89, §25; Godínez Curz versus Honduras, acórdão de 21/7/89, \$23; “Cinco Pensionistas” versus Peru, acórdão de 28/02/03, \$173; Loayaza Tamayo versus Peru, acórdão 27/11/98,\$85.

${ }^{305}$ CtIDHs: Aloeboetoe e outros versus Suriname, acórdão de 10/9/93, \$44; El Amparo versus Venezuela, acórdão de 14/9/96,\$15; Neira Alegria e outros versus Peru, acórdão de 19/9/96,\$37; Caballero Delgado y Santana versus Colômbia, sentença de 29/1/97, \$16; Garrido y Baigorria versus Argentina, acórdão de 27/8/98, $\$ 42$.

${ }^{306}$ ComIDHs: Jorge Alberto Rosal Paz e Guatemala, caso n ${ }^{\circ}$ 9168, solução amistosa de 11/3/04, \$19; Jailton Néri da Fonseca e Brasil, caso nº 11634, relatório de mérito nº 33/04, de $11 / 3 / 04, \$ 136$.

${ }^{307}$ CtDHs: "Instituto de Reeducación del Menor" versus Paraguai, acór do de 2/9/4, § 293294; Massacre Plan de Sánchez versus Guatemala, acórdão de 19/11/04, \$74-76)

${ }^{308}$ CtIDHs: Velásquez Rodriguez versus Honduras, acórdão de 21/7/89, \$27; Godínez Cruz versus Honduras, acórdão de 21/7/89,\$25)

${ }^{309}$ CtIDHs: Castillo Paez versus Peru, acórdão de 27/11/98, \$84; Tibi versus Equador, acórdão de 7/9/04,\$243; “Instituto de Reeducación del Menor" versus Paraguai, acórdão de 2/9/04,\$299; Ricardo Canese versus Paraguai, acórdão de 31/8/4,\$205.

${ }^{310}$ CtIDHs: Godínez Curz versus Honduras, acórdão de 21/7/89,\$25.

${ }^{311}$ CtIDHs : Castillo Paez versus Peru, acórdão de 27/11/98,\$84.

${ }^{312}$ CtIDHs: Loayza Tamayo versus Peru, acórdão de acórdão 27/11/98,\$85.

${ }^{313}$ PETIOT, Patrick. op. cit. supra. n (242), 2005, p.102-122.

${ }^{313}$ No caso brasileiro, o pagamento de indenizações por danos materiais (art. $186 \mathrm{c} / \mathrm{c}$ art. 927 do CC e art. $37 \$ 6$ da CF) ou morais (incisos V e X do art. 5 da CF, art. 186 do CC; incisos VI e VII do art. 6 da lei 8078/90; art. 17 da lei 8069/90, súmulas 37/92; 227/99 e 281/04 do STJ) é totalmente compatível com o ordenamento jurídico brasileiro, não havendo 
DHs, gerador de responsabilidade internacional do Estado ${ }^{314}$, não mais enfatizando o caráter punitivo ${ }^{315}$ das sanções impostas aos Estados, mas sim privilegiando 2 papéis: o papel educativo de coagir o Estado infrator a reparar os danos causados às vítimas; e o papel preventivo de desencorajar novas condutas contrárias ao ordenamento jurídico internacional e violadoras dos DHs. A reparação é a forma que a CtIDHs dispõe para assegurar às vítimas o restabelecimento pleno de direitos ou liberdade que lhe foram cerceados; ou a reparação das conseqüências das violações de seus direitos ou o pagamento de indenização.

Há 2 grandes espécies de reparações previstas nas sentenças da CtIDHs: 1) as indenizações compensatórias ${ }^{316}$ (prevista no art. $682^{\circ}$ da Convenção, é a reparação mais comum, forma de compensar a vitima e seus familiares pelos danos sofridos, complementa a restituição na íntegra se esta for insuficiente para reparar danos, de modo a conferir consolo financeiro à situação irremediável, podendo abarcar dano moral, dano material, lucros cessantes e danos emergentes, tais indenizações devem ser executadas no território do país infrator conforme procedimentos internos e específicos aplicáveis à execução de sentenças de pagamento de valores); e 2) as obrigações de fazer e não fazer (é a forma de reparação mais abrangente, obedecen-

precedentes judicias relativos a concessão de reparações por danos ao projeto de vida, mas há previsão genérica que permite sua aplicação (art. 927 do CC). Quanto à indenização punitiva, esta resta inviabilizada pelo princípio do enriquecimento ilícito, a menos que o montante indenizatório seja depositado em fundo especialmente constituído para promoção de interesses sociais, a exemplo do Fundo de Defesa de Direitos Difusos (art. 13 da Lei 7347/85), mas controlado pela Corte.

${ }^{315}$ Indenizações pecuniárias punitivas (punitive damages) são comuns da common law para punir o réu e dissuadi-lo de reincidir na conduta violadora, servir de exemplo à comunidade e reduzir a sede de vingança da vitima . Corte Suprema dos EUA: Pacific Mutual Life Insurance Co. versus Haslip, acódão de 4/3/91. A CtIDHs, embora não outorgue indenização punitiva, reconhece a imputação de responsabilidade internacional agravada ao Estado em caso de violações graves e sistemáticas dos DHs para por fim à impunidade e assegurar a justiça, como no caso Myrna Mack Chang versus Guatemala.

${ }^{316}$ Sentenças da CtIDHs com indenização compensatória: Caso Suárez Rosero vs. Equador, sentença d 12.11.1997, Série C, n.35, § 108; Caso Ximenes Lopes vs. Brasil, sentença de 4.07.2006, Série C, n. 149, $\$ \$$ 225-226; Caso Blake vs. Guatemala (Reparaciones), sentença de 22.01.1999, Série C, n. 48, \$34; Caso Loayza Tamayo vs. Peru (Reparaciones), sentença de 27.11.1998, Série C, n. 42, \$138; Caso Aloeoetoe e outros vs. Suriname (Reparaciones), sentença de 10.09.1993, Série C, n. 15, \$ 52; Caso Neira e outros vs.s Peru (Reparações), sentença de 19.09.1996, Série C, n. 29, §38. 
do o art. 2 da Convenção, o que implica na execução das reparação de caráter não pecuniário conforme regras e mecanismos de implementação de decisões judiciais internas de cada Estado), envolvem uma multiplicidade de espécies de reparação separadas em 3 grandes grupos: 1) a restituição na íntegra ${ }^{317}$ (prevista no art. 63 $1^{\circ}$ da Convenção, é a reparação mais desejável das reparações, retorno à situação anterior á violação, eliminando completamente os resquícios e efeitos da conduta violadora dos DHs, mas nem sempre possível); 2) a cessação do ilícito ${ }^{318}$ (consiste na interrupção da conduta omissiva ou comissiva ensejadora da infração do DI); e 3) a satisfação ${ }^{319}$ (reparações não pecuniárias, de cunho meramente declarativo, visa restaurar a dignidade humana, restituindo a integridade psíquica e social da vítima, através da publicação dos fatos da sentença internacional, de ato de desagravo da vítima e seus familiares, capacitação de agentes da segurança dos DHs, denominação de rua ou praça e colocação de placa em memória da vitima ${ }^{320}$; através da persecução dos agentes responsáveis pelos atos imputados ao Estado violador; da construção de estabelecimentos de ensino, de postos de saúde ou de fundação para gestão financeira dos valores provenientes de indenização ${ }^{321}$; atribuição do nome da vítima a centro educativo ${ }^{322}$; oferecimento de bolsa de estudos universitários

\footnotetext{
${ }^{317}$ Sentença da CtIDHs defensoras de tal reparação: Caso Loayza Tamayo versus Peru (Reparações), sentença de 27.11.1998, Série C, n. 42, \$\$ 147-149, que tratou da inovação jurisprudencial do direito de "restauração do projeto de vida da vítima", ou seja, o conjunto de todas as opções que o indivíduo hipoteticamente, teria ao longo de sua vida para alcançar os seus objetivos, considerando sua vocação, aptidões, circunstâncias, potencialidades e aspirações; Caso dos "Meninos de Rua" (Villagrán Morales e outros) versus Guatemala (Reparaciones), sentença de 26.05.2001, Série C, n. 77; Caso Cantoral Benavides versus Peru (Reparaciones), sentença de 03.12.2001, Série C, n. 88.

${ }^{318}$ Sentença da CtIDHs neste sentido : Caso Hilaire, Constantine e Benjamim e outrs versus Trinidad e Tobago, sentença de 21.06.2002, Série C, n. 94, \$212.

${ }^{319}$ Caso dos "Meninos de Rua" (Villagrán Morales e outros) vs. Guatemala (Reparações), sentença de 19.11.1999, Série C, n. 63, $\$ \$$ 225-226; Cso Velásquez Rodríguez vs. Honduras, setneça de 29.07.1988, n. 4, \$134; Caso Ximenes Lopes vs. Brasil, sentença de 04.07.2006, Série C, n. 149, \$\$245-248; Caso Aloeboetoe e outros vs. Suriname (Reparacones); sentença de 10.09.1993, Série C, n. 15. \$96; Caso Loayza Tamayo vs. Peru (Reparaciones), sentença de 27.11.1998, Série C, n. 42, \$122; Caso Aloeoboetoe e outros vs. Suriname (Reparaciones); sentença de 10.09.1993, Série C, n. 15, \$ 103; Caso Hilaire Constantine e Benjamin e outros vs. Trinidad e Tobago, sentença de 21.06.2002, Série C, n. 94, \$205.

${ }^{320}$ CtIDHs: Myrna Mack Chang versus Guatemala.

${ }^{321}$ CtIDHs: Aloeboetoe vs. Suriname, acórdão de 10/9/93, \$116.

${ }^{322}$ CtIDHs: Villagran Morales e outros vs. Guatemala, caso "Niños de la Calle", acródão de 26/5/01; Trujillo Oroza versus Bolívia, acórdão de 27/2/02.
} 
para a vítima ${ }^{323}$; oferecimento de prestações educativas ${ }^{324}$; pagamento de gastos de serviços de saúde ${ }^{325}$; anulação dos precedentes criminais da vítima, determinação de abstenção pelo Estado de aplicar lei interna, criação de data ou colocação de placa em homenagem à vítima, a denominação de parque em memória da vítima, obtenção de salvaguardas do Estado para que a conduta não se repita etc). ${ }^{326}$

\subsubsection{Execução das sentenças da Corte Interamericana}

Os Estados-partes se comprometem a cumprir a decisão da Corte em todo caso contencioso em que sejam partes, de tal modo que a execução das sentenças internacionais é uma garantia coletiva dos Estados-Partes na Convenção para efetivação do princípio do pacta sunt servanda. Há 2 resoluções sobre cumprimento de sentença no âmbito da OEA: a Resolução de 22/11/2002 (o principio básico das responsabilidade internacional dos Estados é que os Estados devem cumprir de boa-fé suas obrigações internacionais) e a Resolução de 06/06/2003 (a obrigação de reparação não pode ser modificada ou denunciada pelo Estado obrigado invocando disposição de Di). ${ }^{327}$ Frise-se ainda que o art. 31.1 da Convenção de Viena sobre Direitos dos Tratados consagra os princípio da boa-fé, de modo que a assinatura e a ratificação da Convenção Americana gera a obrigação de todos os Estados-partes envidarem esforços para aplicar as recomendações da ComIDHs, mesmo considerando a natureza meramente recomendatória de suas deliberações contidas nos relatórios.

Somente 2 Estados-partes da Convenção Americana efetivamente adotaram mecanismos permanentes para execução das sentenças internacionais: o Peru (modelo judicial, em que há a atribuição ao órgão judiciário supremo do ordenamento interno a função de execução das sentenças internacionais) e a Colômbia

\footnotetext{
${ }^{323}$ CtIDHs: Cantoral Benavides versus Peru, acórdão de 3/12/01.

${ }^{324}$ CtIDHs Barrios Altos versus Peru, acórdão de 30/11/01.

${ }^{325}$ CtIDHs: Durand y Ugarte versus Peru, acórdão de 3/12/01.

${ }^{326}$ Sobre reparações: cf. COELHO, Rodrigo Meirelles Gaspar. op. cit. supra. n (293), 2008, p. 105-117.

${ }^{327}$ COELHO, Rodrigo Meirelles Gaspar. op. cit. supra. n (293), 2008, p. 19-23.
} 
(modelo executivo, em que há atribuição a um Comitê de Ministros a função de execução das sentenças internacionais). O Brasil ${ }^{328}$ e os demais países submetidos à jurisdição da CtIDHs não possuem um mecanismo permanente de Di para a execução das sentenças internacionais, de tal forma que tal execução ocorre por meio de critérios empíricos, casuísticos. Já que somente 2 países implementaram mecanismos de Di para execução de sentenças internacionais, tal execução não está inteira e legalmente assegurada. Motivo este que embasa a defesa do professor Cançado Trindade ${ }^{329}$ de criação, em face dos escassos recursos materiais e sobrecarga de trabalhos da CtIDHs, de um Mecanismo Permanente de Supervisão Internacional da execução das sentenças internacionais, ou seja, ele sugere a criação de um Grupo de Trabalho (GT) da Comissão para Assuntos Jurídicos e Políticos (CAJP) no âmbito da OEA (equivalente ao Comitê de Ministros no âmbito da UE), ligado ao CP/OEA e submetido a AG/OEA. ${ }^{330}$

\subsection{Estabelecimento de parâmetros conceituais}

\subsubsection{Diferença entre sentença estrangeira e sentença internacional}

A fim de evitar equívocos de interpretação do ordenamento jurídico nacional e desconhecimento da natureza jurídica das decisões provenientes das Cortes Internacionais (CtIDHs ou CtEDHs), como os gerados pelo Projeto de Lei

\footnotetext{
${ }^{328} \mathrm{O}$ art. 682 da Convenção Americana , prevê que o processo interno ditará o procedimento de execução de sentenças contra o Estado. Para maiores detalhes sobre a implementação das sentenças da CtIDHs no Brasil: cf. PETIOT, Patrick. op. cit. supra. n (242), 2005, p. 157-187. Cf. APÊNDICE F.

${ }^{329}$ Para mais dados: cf. os Relatórios de 17.03.2000, de 05.04.2001 sobre as "Bases para um Proyecto de Protocolo a la Cnvención Americnaa sobre Derechos Humanos, para Fortalecer Su Mecanismo de Protección”; de 19.04.2002; de 16.10.2002 sobre "El Derecho de Acceso a la Justicia Internacional y lãs Cndiciones para Su Realización ele l Sistema Interamericnao de Protección de los Derechos Humanos"; do professor Tindade, apresentados à CAJP do CP/OEA; TRINDADE, A. A. Cançado. Informe: Bases para um Proyecto de Protocolo a la Convención Americana sobre Derechos Humanos, para Fortalecer Su Mecanismo de Protección. 2. ed. San José de Costa Rica: Corte Interamericana de Derechos humanos, 2003.

${ }^{330}$ COELHO, Rodrigo Meirelles Gaspar. op. cit. supra. n (293), 2008, p. 13-19.
} 
$3214 / 00^{331}$, e mesmo para prevenir futuros atos atentatórios contra a Teoria do Ato Próprio (em que defende-se que há uma obrigação negativa do Poder Legislativo, já que o $\mathrm{CN}$ ao aprovar um tratado internacional se responsabiliza por não editar leis posteriores contrárias a tal norma, a fim de manter a coerência e interpretação sistemática entre o ordenamento jurídico nacional e internacional, o que resultaria em prejuízos à efetiva proteção dos DHs no país), é preciso - para o presente estudo- fazer a diferenciação entre 2 institutos jurídicos que, embora ambos sejam sentenças não-nacionais, são distintos pela ótica do ordenamento jurídico brasileiro: sentença estrangeira e sentença internacional. Nestes termos, a sentença internacional - proferida por tribunal internacional e fundamentada no DI (pressupõe que a prévia recepção de normas pelo país alvo da decisão) - é vinculadora somente dos Estados que tenham acordado previamente em se submeter à jurisdição do tribunal internacional que proferiu a sentença, dispensando a homologação pelo STJ para ter eficácia perante o Di, ou seja, tem eficácia plena e imediata em território nacional ${ }^{332}$. Já a sentença estrangeira - proferida por tribunal ou órgão do Poder Judiciário de outro Estado que não o Brasil e fundamentada no Direito Estrangeiro (normas de outro Estado) é vinculadora somente do Estado de origem do tribunal ou órgão do Poder Judiciário que proferiu a sentença, e para ter eficácia (poder ser executada) no território nacional necessita de homologação pelo STJ. Concluindo,

\footnotetext{
${ }^{331}$ Atualmente arquivado pela Câmara dos Deputados do Brasil, tal Projeto de Lei 3.214 de 13.06.2000, de autoria do Deputado Marcos Rolim (PT/RS) visava concretizar a aceitação da competência contenciosa da CtIDHs em mecanismos processuais para salvaguarda dos direitos fundamentais, conforme disposto no art. 62 da Convenção Americana. Contudo ao ser acrescentada a Emenda Substitutiva do relator Deputado Pedro Almeida Valadares Neto (PSB/SE) condicionou a efetividade das sentenças da CtIDHs à homologação pelo STF, o que revela a confusão entre os institutos da sentença estrangeira e da sentença internacional. Para mais detalhes: COELHO, Rodrigo Meirelles Gaspar. Proteção internacional dos direitos humanos: a Corte Interamericana e a implementação de suas sentenças no Brasil. Curitiba: Juruá, 2008, p. 99-103.

${ }^{332}$ Conforme art. 44 e art. 68 I da Convenção Americana, a necessidade de homologação das decisões da CtIDHs depende do ordenamento jurídico dos Estados. No Brasil, não se homologa sentença internacional da CtIDHs e decisões da ComIDHs, porque previamente houve sujeição à jurisdição destes órgãos internacionais.
} 
as sentenças da CtIDHs não necessitam de homologação pelo STJ ${ }^{333}$ para ter eficácia plena (serem implementadas) no território do Brasil. ${ }^{334}$

Há que se destacar ainda que as sentenças arbitrais privadas emitidas no exterior equiparam-se a sentenças estatais estrangeiras, devendo, para alcançar eficácia interna e tornar-se obrigatória, obedecer ao rito de homologação das sentenças estatais estrangeiras ou outro procedimento internos de reconhecimento e execução das sentenças arbitrais ${ }^{335}$.

\subsubsection{Diferença entre medida provisória e medida cautelar na CtIDHs}

No âmbito do sistema interamericano de proteção dos DHs, é importante ressaltar ainda a diferença entre 2 medidas presentes na esfera da PIDHs: a medida cautelar (MC) e a medida provisória (MP). Em tal esfera, de um lado, as MCs são institutos jurídicos de competência da ComIDHs (previstas no art. 29 do Regulamento da Comissão), usadas em situações de urgência, cuja titularidade é da Comissão e das partes do processo, a fim de serem implementadas medidas cautelares contra o Estado infrator para prevenir danos irreparáveis aos seres humanos. Por outro lado, as MPs são institutos jurídicos de natureza cautelar (preserva uma situação jurídica) e tutelar (protege os DHs e previne violações), de competência da CtIDHs (prevista no art. 63 inc. $2^{\circ}$ da Convenção Americana e art. 25 do Regu-

\footnotetext{
${ }^{333}$ Conforme disposto nos arts. 15 a 17 da LICC, arts 483 e 484 do CPC, e 215 a 224 do RISTF, Resolução 9/05 do STJ. Além disso, há que se ressaltar que no Brasil, desde o Império, todos os tratados assinados e ratificados pelo Brasil, inclusive os de DHs, são internalizados por meio de assinatura e publicação de decreto presidencial, evitando a responsabilização do Brasil por descumprimento de tratados e dando executoriedade ao tratado na ordem interna.

${ }^{334}$ COELHO , Rodrigo Meirelles Gaspar. op. cit. supra. n (293), 2008, p. 89-97.

${ }^{335}$ Conforme disciplina o art. 3 da Convenção sobre o Reconhecimento e Execução de Sentenças Arbitrais Estrangeiras (Convenção de Nova York) de 1958; o art. da Convenção Interamericana sobre Arbitragem Comercial Internacional (Convenção do Panamá) de 1975; o art. 19 do Protocolo de Cooperação e Assistência Jurisdicional em Matéria Civil, Comercial, Trabalhista e Administrativa (Protocolo de Lãs Lenas) de 1992; e, no Brasil, o art. 35 da Lei no 9.307 (Lei Marco Maciel) exige a homologação de sentenças arbitrais proferidas no estrangeiro.
} 
lamento da Corte), cujos legitimados para solicitar são uma das partes do litígio, a própria Corte ou mesmo a pedido da Comissão, não implicando uma prévia decisão sobre o mérito da controvérsia existente entre peticionário e Estado, muito menos há necessidade de prévio esgotamento dos recursos internos da jurisdição interna do país demando ou de prévia demanda de MC à Comissão, já que trata-se de medidas para casos de extrema gravidade e urgência a fim de evitar danos irreparáveis às pessoas. ${ }^{336}$

\subsubsection{Evolução e definição de conceitos na Corte Interamericana}

A fim de salvaguardar os indivíduos do exercício arbitrário ou negligente do poder público e garantir a efetiva PIDHs pelos mecanismos de proteção dos sistemas regionais e universal, o DIDHs (mesmo reconhecendo-se seu papel subsidiário e complementar perante o Di, nacional) passou a reconhecer o indivíduo como sujeito de direitos internacionais com plena capacidade jurídico-processual e, para tanto, estabeleceu o direito de petição, participação e responsabilização individual. No caso do sistema interamericano de proteção dos DHs, o acesso do ser humano à jurisdição internacional passa pela definição do conceito legal e jurisprudencial de vitima(s) e beneficiário(a)(s), que podem ensejar a responsabilização do Estado por determinados fatos, a solução amistosa ou a condenação deste a pagamento de reparações.

Verifica-se a partir da análise do art. 44 da Convenção Americana e dos casos introduzidos na CtIDHs a partir de 1994 (Caso Cinco Pensionistas vs Peru; Caso Gómez Paquiyaui vs. Peru; Caso El Periódico La Nación vs. Costa Rica; e Caso Alfonso Martín del Campo vs. México), que foram reconhecidas denúncias interpostas não só pelas supostas vítimas, mas também pelos seus familiares e até por terceiros, como ONGs. Além disso, a CtIDHs exige a identificação e individualiza-

\footnotetext{
${ }^{336}$ COELHO, Rodrigo Meirelles Gaspar. op. cit. supra. n (293), 2008, p. 133-148. Coelho traz 3 casos envolvendo o Brasil de adoção de MPs:Caso Urso Branco, em Porto Velho, Rondônia; Caso das Pessoas Privadas de Liberdade da Penitenciária "Dr. Sebastião Martins Silveira”, em Araraquara, SP; e o Caso das Crianças e Adolescentes Privados de Liberdade no "Complexo do Ttauapé" da Febem, na zona leste de SP.
} 
ção das supostas vítimas (art. 2, inciso 23, e art. 33 do seu Regulamento), mesmo quando trata-se de centenas de vítimas (Caso Baena Ricardo y otros vs. Panamá) ou de comunidades (Caso Aloeboetoe vs. Surinam e Caso Comunidad Mayagna vs. Nicaragua). Diferentemente do Di, em que se costuma exigir uma legitimação conforme a reclamação específica, no DIDHs, vislumbram-se 3 tipos de vítimas: a vitima direta ("o titular do bem jurídico lesionado ou menosprezado por conduta, comissiva ou omissiva, de um agente do Estado ou de outra pessoa pela qual deve responder este"337); a vítima indireta ("quem sofre um dano em seus próprios bens ou direitos como efeito reflexo ou como conseqüência do que se inflinge à vitima direta"338); e a vítima potencial ("aquelas que possuem um interesse pessoal potencial reconhecidamente válido na reivindicação de seus direitos" ${ }^{339}$ ). O sentido de parte lesionado do art. 63 da Convenção Americana vem sendo ampliado, conforme se amplia o sentido de vítima direta, qual seja:

"a Corte vem progredindo e tem declarado como vítimas diretas não somente aqueles que recebem diretamente a ação de um agente do Estado ou de um terceiro sob a omissão deste último; mas também os familiares dessa vítima primária que sofreu as consequências, e,por conseguinte, também foram violentados em seus direitos fundamentais consagrados na Convenção Americana"340

Logo, na CtIDHs tem se reconhecido, respaldado no artigo 8.1 da Convenção Americana, a condição de vítimas aos familiares ${ }^{341}$ de vítimas de desapa-

${ }^{337}$ GARCIA RAMIREZ, Sergio. Los derechos humanos y la jurisdicción interamericana. México: Universidad Nacional Autônoma de México, 2002, p. 117. (tradução livre da autora)

${ }^{338}$ Ibid, p. 118. (tradução livre da autora)

${ }^{339}$ TRINDADE, A. Cançado. Coexistence and Co-Ordination of Mechanims of International Protection of Human Rights (At Global and Regional Levels), Vol. 202 , Recueil des Cours de l'Académie de Droit International de La Haye (1978-II), 1987, p. 243 y ss. (tradução livre da autora)

${ }^{340}$ LAAT, Paula Lizano Van der. La evolución del Concepto de víctima em la jurisprudencia de la Corte Interamericana de Derechos Humanos. In: Os rumos do Direito Internacional dos direitos humanos: ensaios em homenagem ao professor Antônio Augusto Cançado Trindade/Renato Zebini Ribeiro Leão, coord. - Porto Alegre: Sergio Antonio Fabris Ed. 2005, p. 353.(tradução livre da autora)

${ }^{341}$ Art. 2.15 da Convenção define familiares da seguinte forma: "el término familiares significa los familiares inmediatos, es decir, ascendientes y descendientes em línea directa, hermanos, cónyuges o companeros permanentes, o aquellos determinados por la Corte em su caso". 
recimento forçado (Caso Blake vs Guatemala - $\$ 97$ - “todo acto de desaparición forzada sustrae a la víctima de la proteción de la ley y le causa graves sufrimientos, lo mismo que a sua familia", assim como esposa, irmãs e pai do Sr. Bámaca no Caso Bámaca Velásquez vs Guatemala), de tortura (mães e uma avó dos meninos de rua - no Caso Villagrán Morales y otros ), ou de outras violações de direitos consagrados (Caso del Caracazo vs. Venezuela). E no caso em que a vítima direta morre em conseqüência das violações declaradas, a justa indenização devida (art. 63.2 da Convenção) deve ser paga aos seus beneficiários, normalmente familiares, como sucessores (a CtIDHs tem ampliado a indenização para companheira e filhos extramatrimoniais, mesmo quando o Di não reconhece tal direito, como da mulher e companheira reconhecidas no Caso El Amparo vs. Venezuela, como dos dois filhos extramatrimoniais reconhecidos no Caso Garrido y Baigorria; do suposto filho no Caso Paniagua Morales y otros vs. Guatemala). A CtIDHs também reconheceu a propriedade coletiva e o direito à indenização a múltiplos filhos e esposas, embasado em costume tribal de poligamia (como no Caso Aloeboetoe vs. Surinam e no Caso Mayagna (Sumo) Awas Tingni vs Nicaragua) ou por direito próprio (desde que o reclamante demonstre que recebia pensão efetivas e regulares da vítima; e que, se a vítima não tivesse morrido, a prestação continuaria; e que a prestação da vítima satisfazia necessidades econômicas do reclamante); tais critérios vem sendo flexibilizados devido às dificuldades probatórias (como no Caso Castillo Paez Reparaciones e Caso Paniagua Morales). Ressalte-se ainda que cada caso é analisado a partir de suas especificidades. ${ }^{342}$

Enfim, com o Regulamento quarto da CtIDHs, os avanços jurisprudenciais supra-delineados foram definitivamente incorporados ao corpo legal do sistema interamericano, de modo que a definição de vítima passou a ser definido como "quien alega han sido violados los derechos protegidos em la Convención" (art. 2.30 do Regulamento da CIDH) e a definição de família passa a ser delimitado como "los ascendientes y descendientes em línea directa, hermanos, cónyuges, o compañeros permanentes, o aquellos determinados por la Corte em su caso" (art. 2.15 do Regulamento da CIDH). Assim a evolução jurisprudencial de ampliação do conceito de vítima e do conceito de beneficiários das reparações, finalmente se consubstan-

\footnotetext{
${ }^{342}$ LAAT, Paula Lizano Van der. Op. cit. supra. n (339), 2005, p. 348-365.
} 
ciou na reforma do Regulamento Quarto, que possibilitou uma participação ativa pelas supostas vítimas através da interposição de solicitações, argumentos e provas da violação de seus direitos (locus standi in judicio).

\subsection{Os 4 desafios e os problemas da participação individual na Corte Interamericana (CtIDHs)}

A CtIDHs se depara hoje com 4 desafios: 1) descobrir meios eficazes para o cumprimento de sentenças da Corte; 2 ) aperfeiçoamento dos mecanismos internos de pagamento de indenizações (como o sistema de precatórios no Brasil) de modo a executar a reparação das violações de direitos humanos de modo célere, como o sistema de precatórios no Brasil; 3) adequação da legislação interna aos preceitos da Convenção Americana para melhor implementação da sentenças internacionais; 4) a possibilidade de uma sentença internacional da CtIDHs poder contrariar o princípio do direito interno da coisa julgada. ${ }^{343}$

Embora seja certo que o mecanismo de participação individual perante à CtIDHs vem contribuindo para o reconhecimento do indivíduo como sujeito de DI, há fatores e argumentos que obstam ou limitam seu desenvolvimento rumo a um direito de petição individual, tais como os seguintes: 1) o direito de petição individual é visto por alguns como uma ameaça à soberania dos Estados; 2) a falta de publicidade e conscientização da população dos meios para defender seus direitos são fatores que diminuem a eficácia da participação individual; 3) a omissão governamental ajuda a evitar ou reduzir o escrutínio internacional sobre violações estatais de direitos humanos; 4) o conteúdo do direito de petição individual são reduzidos devidas às inúmeras reservas opostas aos tratados internacionais de direitos humanos, restringindo o conjunto de direitos protegidos; 5) a inócua discussão de desconsideração do indivíduo como sujeito de DI, por não poder celebrar tratados ou participar da produção do acervo normativo internacional, já que os sujeitos de

\footnotetext{
${ }^{343}$ COELHO , Rodrigo Meirelles Gaspar. op. cit. supra. n (293), 2008, p. 179-192.
} 
DI são diferentes na sua natureza e na extensão dos seus direitos ${ }^{344}$.O desenvolvimento do direito de participação individual depende da retirada das reservas que inibem seu exercício e da maior adesão dos Estados aos tratados internacionais e regionais de $\mathrm{DHs}^{345}$

\subsubsection{De um locus standi a um jus standi na Corte Interamericana?}

É possível e vantajoso o desenvolvimento de Locus Standi a um Jus Standi, ou seja, plena participação individual em todas as etapas do processo e também acesso direto dos indivíduos (peticionários ou demandantes) à CtIDHs? A possibilidade de tal desenvolvimento está presente nos seguintes documentos oficiais: a) votos de Cançado Trindade nas sentenças da Corte, nos casos Castillo Paez (30.01.1996); Loayza Tamayo (31.01.1996); Castillo Pertruzzi (04.09.1998); voto na Opinião Consultiva no 16 da Corte (01.10.1999); b) a resolução (07.04.2000) pra o caso Tribunal Constitucional. Ademais o acesso do ser humano à jurisdição internacional do sistema interamericano de proteção foi particularmente notável na Opinião Consultiva $n^{\circ} 16$, em que compareceram às audiências públicas 8 representantes dos estados demandados; 4 representantes de 4 ONGs de DHs; 2 indivíduos de ONG a favor da abolição da pena de morte; 2 representantes de uma entidade nacional de advogados; 4 professores universitários; 3 indivíduos representantes de um condenado à pena de morte $\mathrm{e}^{346}$.

${ }^{344}$ O Comentário Geral n o 24 do Comitê de Direitos Humanos, disponível em < http:// www.unhchr.ch/tbs/doc.nsf/(Symbol)/69c55b086f72957ec12563ed004ecf7a?Opendo cument $>$,defendeu que para reforçar o direito de petição seria preciso que os Estados retirassem as reservas ao PIDCP. Da mesma forma a Recomendação Geral no 4 do Comitê sobre a Eliminação da Discriminação contra Mulheres, cf. o site: < http://www.un.org/ womenwatch/daw/cedaw/recommendations/recomm.htm\#recom4 $>$, defendeu a retirada de reservas à Convenção é fundamental para a plenitude do direito de petição individual. Ultimo acesso: 07.09.09.

${ }^{345}$ PETIOT, Patrick. op. cit. supra. n (242), 2005, p. 92-94, 99, 80.

${ }^{346}$ TRINDADE, Antônio Augusto Cançado. Direitos Humanos no Século XXI: "A consolidação da Capacidade Processual dos Indivíduos na Evolução da Proteção Internacional dos Direitos Humanos: Quadro Atual e Perspectivas na Passagem do Século". Organizadores: Paulo Sérgio Pinheiro e Samuel Pinheiro Guimarães. Brasília: IPRI, 2002. p. 26-29. 
O Jus Standi in Judicio (ao permitir o acesso individual direto à CtIDHs, além da participação das supostas vítimas, seus familiares e seus representantes legais em todas as etapas do processo) traria as seguintes conseqüências: a) o exercício do contraditório (essencial para a busca da verdade e da justiça) e do devido processual legal (através da liberdade de expressão); b) uma melhor instrução do processo; c) a igualdade processual das partes no sistema judicial de proteção dos DHs (equality of arms); d) a jurisdicionalização do mecanismo de proteção, colocando a ComIDHs no seu lugar de guardiã da aplicação correta da Convenção Americana e preparada para expressar seus pontos de vista perante a CtIDHs mesmo que divergentes dos das supostas vitimas ou seus representantes legais; e) comprovadas as violações de DHs, as próprias vítimas recebem as indenizações e reparações devidas; f) enfim, pela superação do contexto anterior de denegação do papel do indivíduo no DI, traria o reconhecimento da personalidade e capacidade jurídicas internacionais plena da pessoa humana para fazer valer seus direitos ${ }^{347}$.

\section{A responsabilização penal individual no TPI}

\subsection{A importância do TPI para a proteção internacional dos direitos humanos}

A partir do início do séc. XX, motivada pelo terror e preocupação instaurados com as duas grandes guerras mundiais (marcadamente as atrocidades sofridas pelas vitimas do regime nazista nos campos de concentração), não só o DI passou a vislumbrar a idéia de um jus puniendi internacional - alicerçado sobre a necessidade da proteção dos DHs internacionalmente consagrados, da justa reparação às vitimas de violações decorrentes de crimes monstruosos que afrontam a dignidade humana e da punição e isolamento dos responsáveis por tais crimes -, como efetivamente nasceu a moderna Justiça Penal Internacional, a fim de garantir uma efetiva PIDHs e impedir novas atrocidades contra a humanidade. ${ }^{348}$

\footnotetext{
${ }^{347}$ CtIDHs, Carta do Juiz Antonio Augusto Cançado Trindade ao Presidente Héctor Fix-Zamudio, de 07.09.1996, p. 4-5 (original depositado nos arquivos da Corte).

${ }^{348}$ MAZZUOLI, Valério de Oliveira. A importância do Tribunal Penal Internacional para a Proteção Internacional dos Direitos Humanos. Revista Jurídica UNIGRAN /Centro Universitário da Grande Dourados, v. 6, n. 11 (1999- ). Dourados: UNIGRAN, 2004, p. 167-168.
} 
Com a elaboração dos grandes tratados internacionais de proteção dos DHs, ocorre o "resgate da cidadania mundial" e o "início da humanização do Direito Internacional" ${ }^{449}$ através da jurisdicionalização do DI Contemporâneo e da internacionalização dos DHs, que juntos vão consolidar a dogmática do DI Penal com a criação do Tribunal de Nuremberg, do Tribunal Militar Internacional de Tóquio, do Tribunal da Iugoslávia, do Tribunal de Ruanda e, finalmente, do Tribunal Penal Internacional (TPI). ${ }^{350}$

\subsection{História da justiça penal internacional: antecedentes do TPI}

\subsubsection{Tribunal Militar de Nuremberg e de Tóquio}

Embora sem sucesso, a sociedade internacional tentou consagrar responsabilidade penal internacional, quando o Tratado de Versalhes (art. 227) tentou responsabilizar o ex-Kaiser Guilherme II por ofensa aos tratados internacionais, e quando o Tratado de Sèvres tentou responsabilizar o Governo Otomano pelo massacre dos armênios ${ }^{351}$. Ademais, o advento da Guerra Fria, a sedimentação da realpolitik e a politica externa baseada em blocos influenciaram negativamente o desenvolvimento de uma justiça internacional penal ${ }^{352}$.

As atrocidades nazistas do Holocausto motivaram a assinatura do Acordo de Londres de 08/08/1945 entre EUA, URSS, Grã-Bretanha e França para a criação do Tribunal Militar Internacional de Nuremberg (TMIN) para processar e julgar os criminosos do regime nazista que cometessem crimes contra a paz, contra a humanidade ou de guerra, conforme competência definida no art. 6 do Acordo de Londres. A responsabilização de indivíduos no plano internacional fica clara

${ }^{349}$ Ibid., p. 169.

${ }^{350}$ Este trabalho não dirá respeito aos tribunais que exercem funções internacionais (como o tribunal híbrido de Serra Leoa e os tribunais de Camboja, do Iraque, de Kosovo e de Timor Leste, dentre outros), nem dirá respeito aos tribunais nacionais que julgam crimes contra a humanidade.

${ }^{351}$ MAZZUOLI, Valério de Oliveira. op. cit. supra n (347), 2004, p. 174.

${ }^{352}$ DELGADO, José Manuel A. de Pina \& TIUJO, Liriam Kiyomi. Tribunais penais internacionais. In: Tribunais internacionais: mecanismos contemporâneos de solução de controvérsias/Welber Barral, organizador. - Florianópolis: Fundação Boiteux, 2004, p. 57. 
nos artigos 7 e 8 do Estatuto do TMIN (ETIMIN), em que fica patente que os acusados não deixariam de ser responsabilizados pela posição oficial que ocupassem nem por terem agido por ordem de seu governo ou de um superior. ${ }^{353}$ Além disso, a AGNU, ao se posicionar sobre o TMIN, recepcionou o princípio da responsabilidade individual penal na esfera internacional. ${ }^{354}$ Por outro lado, os crimes perpetrados pelas autoridades políticas e militares do Japão Imperial motivaram a criação de um Tribunal Militar Internacional de Tóquio (TMIT).

\subsubsection{Tribunais Penais Internacionais ad hocs: da Ex-Iugoslávia e para Ruanda}

Para julgar as atrocidades praticadas (massacres de civis e operações de migrações forçadas provocadas pela disputa do poder entre sérvios, croatas e muçulmanos) no território da antiga Iugoslávia desde 1991, foi criado em 1993, por deliberação do $\mathrm{CSNU}^{355}$ (imbuído do dever de proteger minorias de genocídio), o Tribunal Internacional Penal para a ex-Iugoslávia (TIPI), sediado na Holanda ${ }^{356}$. Para julgar as violações de DHs perpetradas (massacre de milhares de tutsis e hutus) em Ruanda, foi criado em 1994, por deliberação do CSNU, o Tribunal Internacional Penal para Ruanda (TIPR), sediado na Tanzânia ${ }^{357}$.

\footnotetext{
${ }^{353}$ MAZZUOLI, Valério de Oliveira. op. cit. supra n (347), 2004, p. 169-170.

${ }^{354}$ Resolução da AGNU no 174 (1946), AG/R/174 (1946), de 11.12.1946.

${ }^{355}$ Resolução do CSNU no 955 (1994), NU-Doc. S/Res/955 (1994), de 08.11.94.

${ }^{356}$ Primeiramente foi nomeado um comitê de especialistas pra discutir sobre a necessidade do TIPI (CS/R/780 de 06.10.1992), o que redundou no Estatuto do TIPI (CS/R/827, de 25.05.1993) e no seu Regulamento Processual. Mais dados: cf. PELLET, Alain. Le Tribunel Criminel International pour l'Ex-Yougoslavie. Poudre aux yeux ou avancée decisive? Revue Générale de Droit International Public, t. 98, n. 1, p. 7-60, 1994; TIPI: Procurador c. Dusko Tadic, Caso n. IT/94/1, Decisão sobre Pedido de Defesa relativo a Jurisdição, 10.08.95; TIPI: Procurador c. Slobodan Milosevic, Caso n. IT/99/37, Decisão sobre pedidos preliminares, JJPI, 08.11.01.

${ }^{357}$ Primeiramente, foi nomeado um comitê de especialistas para discutir sobre a necessidade do TIPR , que culminou na elaboração do Estatuto do TIPR (CS/R/955, Anexo, de a 08.11.1994). Mais dados: cf. MUBIALA, Mutoy. Lê Tribunal International pour lê Ruanda: vraie ou fausse copie du Tribunal Penal pour l'Ex-Yougoslavie? Revue Générale de Droit International Public, t. 99, n. 4, p. 931-954,1995; TIPR: Procurador c. Joseph Kanyabashi, II JJPI, Caso n. ICTR 96-15-T, Decisão sobre Pedido da Defesa Relativo à Jurisdição, 18.06.97.
} 
Os tribunais ad hocs ${ }^{358}$ foram criticados por seu caráter temporário e não-permanente; por terem sido criados por resoluções do $\operatorname{CSNU}^{359}$ e não por tratados multilaterais (estes últimos de conclusão e vigência mais demorada), o que os tornaria órgãos subsidiários do CSNU; além de não obedecerem aos princípios basilares do direito penal de que o juiz deve ser preconstituído ao cometimento do fato e da não-retroatividade da lei (a defesa alegou que tratava-se de regras costumeiras); não representando, portanto, uma Justiça Penal Internacional efetiva (que somente seria alcançada com uma Corte Penal Internacional Permanente, independente, imparcial e competente para processar e julgar crimes posteriores à sua vigência). ${ }^{360}$

\subsubsection{Corte Internacional Permanente: TPI}

Críticas a parte, as experiências provenientes dos tribunais ad hocs contribuíram para o avanço da Teoria da Responsabilidade Penal Internacional dos indivíduos por não reconhecerem como excludentes de responsabilidade internacional ordens superiores ou a imunidade de jurisdição para crimes definidos no DI; assim como acabaram por acelerar a criação do TPI ${ }^{361}$. Antecedido por diversos documentos internacionais importantes ${ }^{362}$ e pela conjuntura política internacional favo-

\footnotetext{
${ }^{358}$ Para mais dados sobre funcionamento e as regras básicas dos tribunais ad hocs: DELGADO, José Manuel A. de Pina \& TIUJO, Liriam Kiyomi. op cit supra. n (351), 2004, p. 66-76. ${ }^{359}$ A possibilidade de criação de tribunais ad hocs está amparada pelo Capítulo VII da Carta da ONU, referente às "ameaças à paz, ruptura da paz e atos de agressão" (para manter ou restaurar a paz e segurança internacionais). Art. 29 da Carta da ONU: "o CS poderá estabelecer os órgãos que entender necessários para auxiliá-lo no cumprimento de suas funções”. Além disso, Mazzuoli - op. cit. supra. n (338), 2004, p. 173 - defende que a Convenção de Viena sobre Direito dos Tratados, nos arts. 53 a 64, adotou a regra de jus cogens, segundo a qual "há certos tipos de crimes tão abruptos e hediondos que existem independentemente de estarem regulados por norma jurídica positiva".

${ }^{360}$ MAZZUOLI, Valério de Oliveira. op. cit. supra n (347), 2004, p. 171-173.

${ }^{361}$ Ibid., p. 172 e 174.

${ }^{362}$ Destes documentos, destacam-se os seguintes: a DUDHs de 1948; a Convenção para Prevenção e Repressão d Crime de Genocídio de 1948; as 4 Convenções de Genebra sobre Direto Humanitário de 1949 e seus 2 Protocolos Adicionais de 1977; a Conveção sobre a Imprescritibilidade dos Crimes de Guerra e dos Crimes de Lesa Humanidade de 1968; os Princípios de Cooperação Internacional para Identificação, Detenção, Extradição e Castigo dos Culpáveis de Crimes de Guerra ou de Crimes de Lesa Humanidade de 1973.
} 
rável, além de expressamente almejado conforme disposto no $\$ 52$ da Declaração e Programa de Ação de Viena ${ }^{363}$, o TPI, sediado em Haia, foi criado pelo Estatuto de Roma de $1998^{364}$ na Conferência Diplomática de Plenipotenciários da ONU ${ }^{365}$, sendo a "primeira instituição global permanente de justiça penal internacional" ${ }^{366}$.

\subsection{Estrutura, marco legal e competências do TPI}

\subsubsection{Estrutura do TPI}

Os encontros de preparação para a Conferência de Roma revelaram as imensas divergências entre as várias delegações sobre os mais diversos pontos (estrutura, normas a adotar, critérios de competência, aplicação da pena de prisão perpétua ou de pena de morte), já que reuniu representantes (de diversas tradições do direito e filosofia penais, e com diferentes políticas externas) a fim de "acordar um mínimo denominador comum que fosse simultaneamente aceitável a todos"367, visto que o TPI, conforme a constituição convencional baseada no direito dos tratados, necessitava para ser instituído de consenso entre as partes contratantes.

O TPI é mantido financeiramente pelas contribuições de seus EstadosMembros $^{368}$ e pelas contribuições voluntárias de outras entidades (Estados não-

\footnotetext{
${ }^{363} \$ 92$ da Declaração e Programa de Ação de Viena: "A Conferência Mundial sobre DHs recomenda que a Comissão de DHs examine a possibilidade de melhorar a aplicação de instrumentos de DHs existentes em níveis internacional e regional e encoraja a Comissão de DI a continuar seus trabalho visando ao estabelecimento de um tribunal penal internacional".

${ }^{364} \mathrm{O}$ Estatuto de Roma (ETPI) entrou em vigor internacional em 01.07.2002, dia subseqüente ao fim do período de 60 dias após o deposito do $60^{\circ}$ instrumento de ratificação, de aceitação, de aprovação ou de adesão junto ao Secretário-Geral das Nações Unidas (art. 126 do ETPI). Atualmente, 94 Estados aderiram ao ETPI.

${ }^{365}$ Nesta Conferência, o ETPI foi aprovado por 120 Estados, desaprovado por 7 Estados (China, Estados Unidos, Iêmen, Iraque, Israel, Líbia e Quatar), sendo que 21 Estados se abstiveram. Destes Israel e Estados Unidos acabaram assinando o Estatuto em 31.12.2000; contudo, após os atentados terroristas de 11.09.2001 e operações de guerra no Afeganistão e Palestina, ambos notificaram o Secretário-Geral da ONU que não desejariam ser parte do Tratado de Roma.

${ }^{366}$ MAZZUOLI, Valério de Oliveira. op. cit. supra n (347), 2004, p. 175.

${ }^{367}$ DELGADO, José Manuel A. de Pina \& TIUJO, Liriam Kiyomi. op cit supra. n (351), 2004, p. 66. ${ }^{368} \mathrm{Cf}$. ANEXO RR.
} 
Membros, OIs, indivíduos, corporações etc). Em janeiro de 2009, seu quadro funcional era composto de 285 mulheres e 302 homens, originários de mais de 85 diferentes países ${ }^{369}$. Quanto à estrutura do TPI, o TPI divide-se, conforme o art. 34 do ETPI, nos 4 seguintes órgãos: a presidência do TPI; uma Seção ou Juízo de Recursos (JR), uma Seção ou Juízos de Julgamento em Primeira Instância (JJPI) e uma Seção de Instrução; o Gabinete do Procurador; e a Secretaria.

\subsubsection{Marco legal e competências do TPI}

O regime jurídico do TPI (ICP) é compostos pelos 3 seguintes documentos básicos: O Estatuto do TPI (ETPI) ou Convenção de Roma (de 17.07.1998); o Regulamento Processual do TPI (RP/TPI); e os Elementos dos Crimes (EC/TPI).

\subsubsection{Competência material}

O TPI tem competência material para julgar somente os crimes mais graves contra a humanidade, conforme definido no art. 5 do ETPI, quais sejam: o crime de genocídio; o crime contra a humanidade; os crimes de guerra; e o crime de agressão. O EC/TPI traz de forma minuciosa a definição de todas as condutas passíveis de serem enquadradas nos tipos penais previstos no ETPI.

O crime de genocídio, previsto no art. 6 do ETPI $^{370}$ (também presente no art. 2 do ETPIR e no art. 4 do ETIPI), "categoria particular de crime contra humanidade com elemento intencional especifico" ${ }^{371}$, remonta ao art. 2 da Convenção para a Prevenção e Repressão do Crime de Genocídio de 9.12.1948, e, embora

\footnotetext{
${ }^{369}$ Paramaisdados,cf.osite: $<$ http://www.icc-cpi.int/Menus/ICC/Structure+of+the+Court $>$. Ultimo acesso: 07.09.09.

${ }^{370} \mathrm{Cf}$. ANEXO SS.

${ }^{371}$ BAZELAIRE, Jean-Paul \& CRETIN, Thierry. A justiça penal internacional: sua evolução, seu futuro: de Nuremberg a Haia; tradução de Luciana Pinto Venâncio. Barueri, SP: Manole, 2004, p. 77.
} 
haja dúvidas sobre sua constituição em dados $\operatorname{casos}^{372}$, não hão dúvida de que sua constituição requer o elemento intencional de destruir um grupo por causa de sua nacionalidade, etnia, raça ou religião ${ }^{373}$.

O crime contra a humanidade está previsto no art. 7.1 do ETPI ${ }^{374}$ (também presente no art. 3 do ETPIR e no art. 5 do TIPI) e sua definição é fixada por lista; contudo, apesar da abertura da alínea k do seu artigo, seu campo é limitado pela aplicação do princípio da interpretação estrita da norma penal ${ }^{375}$. Além disso, o avanço jurisprudencial acabou por incorporar a generalização ou sistematicidade (widespread or systematic) do ataque como pré-condições para a existência dos crimes contra a humanidade ${ }^{376}$, devendo ficar os atos isolados e individuais a cargo da justiça nacional.

O crime de guerra ou de violações graves às Convenções de Genebra está previsto no longo art. 8 do ETPI $^{377}$ (também previsto no art. 4 do ETPIR e art. 2 do ETIPI), que remonta a tudo que convencionalmente denomina-se de direito de Genebra ${ }^{378}$ (sobre vítimas de guerra) e de direito de Haia ${ }^{379}$ (sobre condução de conflitos), e seus elementos constitutivos estão detalhados no art. 9 do ETPI. ${ }^{380}$

\footnotetext{
${ }^{372}$ Para mais informações sobre o crime de genocídio e sua constituição para o caso de estupro: ler a carta de 17.10.1997 endereçada a Louise Arbour, procuradora-chefe dos TPIR e TIPI, no Caso Jean-Paul Akayesu (violência sexual contra mulheres tutsis), disponível no site: <http://www.ichrdd.ca/PublicationsF/femtri.html >. Sobre a constituição do crime de genocídio em caso de arma nuclear: ler o parecer de 08.07.1996 da CIJ no sentido de que não basta o uso de arma de destruição em massa para configurar o genocídio, mas precisa da prova da intenção de destruir um grupo. Ultimo acesso: 07.09.09.

${ }^{373}$ BAZELAIRE, Jean-Paul \& CRETIN, Thierry. op. cit. supra n (370), 2004, p. 69-73.

${ }^{374}$ Cf. ANEXO SS.

${ }^{375}$ BAZELAIRE, Jean-Paul \& CRETIN, Thierry. op. cit. supra n (370), 2004, p. 73-77.

${ }^{376}$ DELGADO, José Manuel A. de Pina \& TIUJO, Liriam Kiyomi. op cit supra. n (351), 2004, p. 85.

${ }^{377} \mathrm{Cf}$. ANEXO SS.

${ }^{378}$ Bazelaire e Cretin esclarecem que o Direito de Genebra é entendido como o disposto nas 4 Convenções de Genebra de 12.08.1949 e os 2 Protocolos Adicionais de 1977.

${ }^{379}$ Bazelaire e Cretin explicam que o Direito de Haia engloba o disposto na Convenção de Haia de 14.05.1954 sobre a proteção dos bens culturais em caso de conflito armado e o disposto no $1^{\circ}$ Protocolo das Convenções de Genebra de 12.08.1949 sobre proteção de pessoas expostas aos efeitos indiretos das hostilidades.

${ }^{380}$ BAZELAIRE, Jean-Paul \& CRETIN, Thierry. op. cit. supra n (370), 2004, p. 77-81.
} 
O crime de agressão previsto no art. 5 do $\operatorname{ETPI}^{381}$, é inspirado no tipo penal “crimes contra a paz", previsto no art. $6^{\circ}$ da Carta do TMIN ${ }^{382}$ e no art. $5^{\circ}$ (a) da Carta do TMIT. Tal tipo penal ainda é alvo de intensas negociações diplomáticas devido a dificuldades de se consensualizar os elementos do tipo ${ }^{383}$.

Os debates de definição da competência material nos trabalhos preparatórios da conferência das superpotências de Roma foram intensos; contudo, apesar de serem fenômenos criminais internacionais ameaçadores da paz, da dignidade, da saúde e da segurança do mundo, os seguintes crimes (a fim de aumentar o número de adesões e ampliar a eficácia jurisdicional do TPI) foram excluídos do âmbito do TPI: o terrorismo (embora as atividades dos grupos terroristas estejam incluídas nos crimes contra humanidade $)^{384}$; os crimes cometidos contra os funcionários da ONU; formas graves de criminalidade organizada ${ }^{385}$, como o tráfico ilícito de entorpecentes ${ }^{386}$, dentre outros. ${ }^{387}$

${ }^{381}$ Cf. ANEXO SS.

${ }^{382}$ Art. 6 Carta do TIMIN - "a direção, a preparação, o desencadeamento ou a continuidade de uma guerra de agressão, ou de uma guerra violando tratados, garantias ou acordos internacionais, ou a participação em um plano orquestrado ou em um complô para o cumprimento de qualquer um dos atos anteriores".

${ }^{383}$ DELGADO, José Manuel A. de Pina \& TIUJO, Liriam Kiyomi. op cit supra. n (351), 2004, p. 76.

${ }^{384}$ Para maiores informações: JUROVICS, Y. Les controverses sur la question de la qualification du terrorisme: crime de droit commun, crimde de guerre ou crime contre l'humanité? Lê droit international face au terrorisme. Cedin Paris I: Pedone, 2002.

${ }^{385} \mathrm{Na}$ Resolução 53/11 de 09.12.1998, a AGNU decidiu criar um comitê intergovernamental para elaboração de um convenção internacional sobre a criminalidade transnacional organizada. Ademais na Conclusão 46 do Conselho Europeu, o Conselho Europeu de Tampere (Finlândia) de 15 e 16.10.1999 decidiu criar o Eurojust (unidade composta por procuradores, magistrados ou oficias de policia) para reforçar a luta contra as formas graves da criminalidade organizada.

${ }^{386} \mathrm{~A}$ regulação internacional do crime de tráfico de entorpecentes (para controle e repressão do comércio de drogas pela incriminação e cooperação judicial internacionais) se estrutura sobre 3 Convenções Universais da ONU: Convenção Única (CU - assinada em Nova York em 30.03.1961 e entrou em vigor em 1964); Convenção sobre as substancias psicotrópicas (CSP - de 21.02.1971); e Convenção contra o tráfico ilícito de entorpecentes e de substancias psicotrópicas (CTS - de 19.12.1988).

${ }^{387}$ BAZELAIRE, Jean-Paul \& CRETIN, Thierry. op. cit. supra n (370), 2004, p. 83-86. 


\subsubsection{Competência territorial}

Conforme o princípio da jurisdição territorial e da soberania estatal, o TPI, embora não tenha adotado o princípio da jurisdição universal ou da personalidade passiva $^{388}$ e seja acusado de violar o princípio de que nenhum tratado pode criar obrigações para terceiros (o pacta tertiis nec nocent nec prosunt) ${ }^{389}$, tem competência para julgar os crimes cometidos no territórios de seus Estados-Partes (art. 12.2 do ETPI), ou os crimes cometidos nos territórios de Estados não-Partes por nacional de Estado-Parte (art. 12.2, b, do ETPI), ou na hipótese de um Estado não-Parte - com competência territorial para julgar o crime cometido por seu nacional querer submeter-se à jurisdição do TPI (art. 12.3 do ETPI e regra 44 do RP/TPI). ${ }^{390}$

\subsubsection{Competência temporal}

O TPI, tendo em vista a salvaguarda integral do princípio da reserva legal ${ }^{391}$, tem sua competência para julgar os crimes cometidos a partir da sua entrada em vigor (01.07.2002) com a consignação da $60^{\circ}$ instrumento de ratificação ${ }^{392}$ ou, para os Estados que aderiram posteriormente ao Estatuto de Roma, a partir da adesão do Estado, conforme preconizado nos artigos 11.1 e 11.2 do ETPI. ${ }^{393}$ Além disso, os crimes de competência do TPI são imprescritíveis, conforme art. 29 do ETPI.

\footnotetext{
${ }^{388}$ DELGADO, José Manuel A. de Pina \& TIUJO, Liriam Kiyomi. op cit supra. n (351), 2004, p. 77.

${ }^{389}$ Ibid., p. 78.

${ }^{390}$ Sobre competência territorial, ler os art. 7 do ETPIR (criado para julgar os criminosos de guerra dos países europeus do Eixo) e o art. 7 do ETIPI (criado para julgar os criminosos de guerra do Extremo Oriente).

${ }^{391}$ DELGADO, José Manuel A. de Pina \& TIUJO, Liriam Kiyomi. op cit supra. n (351), 2004, p. 77

${ }^{392}$ Arts. 24.1 e 126.1 do ETPI.

${ }^{393}$ Sobre competência temporal ler os arts. 1 e 8 do ETIPI (o TIPI foi criado para julgar violações a partir de 01.01.1991 até restauração da paz definida pelo CSNU, Resolução 827 DE 25.05.1993) e os arts. 1 e 7 do TPIR (o TPIR julgará os crimes cometidos durante o período de 01.01.1994 a 31.12.1994). Após tais períodos, no entanto, os tribunais permanecem para revisão dos processos, execução das sanções e comutações das penas.
} 


\subsubsection{Competência pessoal, imunidades e exonerações}

A responsabilidade penal consagrada no TPI é pessoal ou individual (art. 25.1 e art. 25.2 do ETPI) e - não a responsabilidade de organizações criminosas como no TMIN-, ou seja, podem ser assim criminalmente responsabilizados “[...] aqueles que cometem, estimulam ou ordenam os crimes da alçada da competência material dos TPIs ou da CPI, planejam ou preparam sua execução, ou então são cúmplices por ajuda ou assistência [...]" ${ }^{394}$ e também aqueles que, sendo superiores, tinham o dever de vigilância e controle sobre seus inferiores, desde que soubessem ou tivessem condições de saber que seu subordinado cometeria crimes e não tomou as medidas necessárias para impedir o crime ou punir seus autores ${ }^{395}$. Ressalte-se que os menores de 18 anos, na data da prática dos atos, não serão responsabilizados no TPI (art. 26 do ETPI); assim a menoridade é prevista como causa de ausência de jurisdição.

Não há imunidades de jurisdição no TPI, isto é, o ETPI será aplicado igualmente a todos sem distinção alguma de qualidade oficial (chefe de Estado ou de Governo, membro de Governo ou do Parlamento, representante eleito ou funcionário público) e independentemente de normas de imunidade ou de procedimentos especiais ${ }^{396}$, já que trata-se dos piores crimes cometidos contra a humanidade. Também não há exonerações, por motivo de execução de ordens, mas pode ocorrer diminuição das penas a critério dos juízes ${ }^{397}$.

\subsection{Procedimento e funcionamento do TPI}

O procedimento criminal perante o $\mathrm{TPI}^{398}$ está discriminado nos arts. 53 a 61 do Estatuto de Roma, que veio suprir uma lacuna das Convenções de Genebra de 1949 , ausente de regras materiais e processuais da ciência jurídica criminal ${ }^{399}$.

\footnotetext{
${ }^{394}$ BAZELAIRE, Jean-Paul \& CRETIN, Thierry. op. cit. supra n (370), 2004, p. 90.

${ }^{395}$ Art. 28 do TPI, nos moldes do art. $7 \$ 3$ do ETIPI e art. $6 \$ 3$ do TPIR.

${ }^{396}$ LIMA, Renata Mantovani de \& BRINA, Marina Martins da Costa. O tribunal Penal Internacional. Belo Horizonte: Del Rey, 2006, p. 147-148.

${ }^{397}$ BAZELAIRE, Jean-Paul \& CRETIN, Thierry. op. cit. supra n (370), 2004, p. 91.

${ }^{398}$ Para maiores informações sobre a estrutura do TPI e o processo perante o TPI, cf. ANEXOS TT e UU.

${ }^{399}$ MAZZUOLI, Valério de Oliveira. op. cit. supra n (347), 2004, p. 178.
} 
Possuem a prerrogativa para provocar a jurisdição do TPI os 3 entes seguintes: o CSNU (mesmo perante as críticas da delegação indiana de que isto implicaria a intromissão de Estados não-Partes no TPI, prevaleceu sua missão de garantir a paz e segurança internacionais), o Estado-Parte e o Procurador.

A fase inicial do inquérito é o crivo do Procurador. O Procurador deve obrigatoriamente fazer o primeiro juízo de admissibilidade (verifica se há condições para se abrir inquérito) de todos os casos a serem submetidos ao TPI (art. 13 e 14 do ETPI). Para desempenho de tal função, o Procurador pode coletar e examinar provas, interrogar indivíduos acusados, solicitar cooperação de Estado, etc (art. 15.2 do ETPI). No caso de juízo de admissibilidade negativo, o Procurador (imbuído não só da sua função de acusador, mas de seu papel de fiscal da lei e comprometido com a veracidade dos fatos ${ }^{400}$ ) deve comunicar as razões da improcedência ao CSNU ou ao Estado-Parte (art. 15.6 e 53.1 do ETPI e regra 105 do RP/TPI), que podem requerer ao Juízo de Instrução que examine a decisão do Procurador (art. 61 do ETPI).

A outra fase do inquérito, ocorre quando o Procurador julga que o caso deve prosseguir, porque há base suficiente para abertura do inquérito, e pede autorização para tal ao Juízo de Instrução (art. 15.3 do ETPI). O Juízo de Instrução, dentre outras funções, pode expedir mandados (após aberto o inquérito policial, a qualquer momento, desde que a pedido do Promotor, o Juízo de Instrução pode expedir mandado de detenção contra o indivíduo que cometer crime de competência do TPI para impedir a continuidade do crime, para impedir obstrução do inquérito e para garantir seu comparecimento perante o tribunal ${ }^{401}$ ); pode autorizar o Procurador a adotar medidas de investigação no território de um Estado-Parte (recolher, examinar, reunir ou verificar provas); pode tomar medidas para proteção das vítimas e testemunhas (art. 56 e ss do ETPI). A fase de inquérito encerra-se com audiência que confirma ou rejeita as acusações (art. 61 do ETPI).

\footnotetext{
${ }^{400}$ DELGADO, José Manuel A. de Pina \& TIUJO, Liriam Kiyomi. op cit supra. n (351), 2004. p. 80 .

${ }^{401}$ Ver. art. $58, \$ 1^{\circ}$, alíneas a e b do Estatuto de Roma.
} 
Se as acusações forem consideradas procedentes, o Juízos de Julgamento em Primeira Instância (JJPI) apreciará o processo, admitirá a pertinência ou admissibilidade (art. 69.3 e 4 do ETPI) das provas a serem produzidas (admitindo-se recursos a tecnologias como áudio e vídeo, conforme art. 69.2 do ETPI e regra 67 do RP/TPI) e outras providencias serão tomadas. Toda a fase de julgamento o JJPI respeita os princípios gerais processuais - direitos amplos aos acusados, princípio da presunção da inocência, ampla defesa, dentre outros ( art. 67 e 68 do ETPI) -, podendo o acusado admitir sua culpa (plea of guilty da Common Law), conforme art. 64.8 e art. 65 do ETPI e regra 139 do RP/TPI. Avaliadas as provas e finalizado os procedimentos, o JJPI prolatará a sentença absolutória ou condenatória.

Se condenatória, a sentença conterá a pena a ser aplicada, que pode ser de 4 espécies: 1) pena de multa ; 2) perda de produtos, bens e haveres decorrentes, direta ou indiretamente, do crime, desde que não prejudique direitos de terceiros de boa fé (art. 77.1 e 2 do ETPI); ou 3) pena de prisão até o limite máximo de 30 anos; 4) pena de prisão perpétua, desde que condizentes com o "elevado grau de ilicitude do fato e as condições pessoais do condenado o justificarem" ${ }^{402}$.

No processo perante o TPI há possibilidade de apelação (quando houver vícios processuais, erros de fato ou de direito, ou quaisquer defeitos contrários à equidade ou regularidade do processo ou sentença, como a desproporção entre o crime e a pena aplicada, decisões concernentes à jurisdição ou admissibilidade ou que autorize ou denegue o livramento de indivíduos) ${ }^{403}$ ou de revisão (o condenado ou, no caso de sua morte, seu cônjuge, descendentes, ascendentes ou procurador com poderes outorgados pelo mesmo ou Procurador, em nome próprio, poderão requerer a revisão da sentença condenatória ou da pena; se houver descobertas de novas provas, constatação de falsidade da prova decisiva de condenação ou de que julgadores praticaram atos de conduta reprovável ou descumpriram suas funções) ${ }^{404}$ da sentença perante o Juízo de Recursos (JR).

\footnotetext{
${ }^{402}$ DELGADO, José Manuel A. de Pina \& TIUJO, Liriam Kiyomi. op cit supra. n (351), 2004, p. $81-82$.

${ }^{403}$ Ver art. 81 do ETPI.

${ }^{404}$ Ver art. 84 do ETPI
} 


\subsubsection{Participação das vítimas no processo perante o TPI}

O Regulamento 81 do TPI representou um avanço no Sistema Penal Internacional, porque procurou assegurar a participação efetiva das vitimas ${ }^{405}$ no processo perante o TPI através do estabelecimento do Escritório de Conselho Público para Vítimas (criado em 19.09.2005), que proporciona, se for o caso gratuitamente, apoio e assistência legal para as vítimas e seus representantes legais. Com Regra 90(1) das Regras de Procedimento e Evidência, as vitimas passam a ser livres para escolher seus representantes legais (advogado ou pessoa com experiência como juiz ou promotor e fluente em inglês ou francês). O ETPI permite que as vítimas participem (possam fazer solicitações, presenciar audiências e serem notificadas de todas as decisões do TPI) de todos os estágios do processo perante o TPI (inquérito, processo e apelação). Para tanto as vítimas ou seus representantes (no caso de crianças ou deficientes) devem escrever para a Seção de Reparação e Participação das Vitimas do TPI, que irá submeter o pedido da vítima à Câmara competente que decidirá sobre a participação da vítima no processo. ${ }^{406}$

Na história da humanidade, é a primeira vez que um tribunal internacional tem o poder de obrigar um individuo (julgado e condenado) ou seus sucessores a pagar para outro indivíduo ou coletividade uma reparação (restituição, indenização ou reabilitação física e psicológica), uma multa ou um perdimento, cujos pagamentos são feitos por intermédio do Trust Fund for Victims (TFV) ${ }^{407}$, estabelecido em setembro de 2002 pela Assembléia dos Estados-Membros do TPI. ${ }^{408}$

\footnotetext{
${ }^{405}$ Há 2 tipos de vítimas: a vitima do caso e a vítima da situação, cf. ANEXO VV.

${ }^{406}$ Para entender o processo da petição da vítima perante o TPI, cf. ANEXO XX.

${ }^{407}$ Para maiores informações sobre o TFV, são disponibilizados os seguintes contatos: o endereço (Trust Fund for Victims, International Criminal Court, Maanweg 174, 2516 AB The Hague, The Netherlands), telefone/fax (+31 70515 9000; +31 70515 9898); e-mail ( trust.fund@icc-cpi.int).

${ }^{408}$ Para facilitar a aceitação do pedido de participação da vítima no processo perante o TPI, a "Seção de Reparação e Participação das Vitimas" do TPI disponibilizou Formulários Padrões, cf. ANEXO YY.
} 


\subsubsection{Regras básicas e princípios do Direito Internacional Penal}

Os princípios gerais que norteiam o DI Penal ${ }^{409}$ foram elencados principalmente no Capítulo 3 do ETPI (arts. 22 a 33), sendo integrados, ampliados e precisados em seu alcance pela jurisprudência do TPI, destacando-se os seguintes: princípio da responsabilidade penal internacional individual; princípio da complementaridade; princípio da legalidade; princípio do ne bis in idem; princípio da irretroatividade; princípio da imprescritibilidade; e princípio da irrelevância da função do oficial. ${ }^{410}$

O Estatuto de Roma de 1998, além de "conseguir consubstanciar em um único instrumento normas de direito material e formal julgadas as mais justas e coerentes com os princípios gerais do direito" ${ }^{411}$, consagrou o princípio da responsabilidade penal internacional dos indivíduos ${ }^{412}$ (conquista da humanidade sedimentada desde Hugo Grotius), de forma que as eventuais imunidades, privilégios, posições ou cargos oficiais não devem obstar a jurisdição sobre qualquer pessoa ${ }^{413}$, tendo o TPI competência para julgar e punir os indivíduos violadores do $\mathrm{DI}^{414}$. Este princípio da responsabilidade internacional penal do indivíduo preconiza que qualquer pessoa física pode ser sujeito passivo de DI (julgada e condenada por tribunais internacionais). ${ }^{415}$ Assim, a sociedade internacional a fim de assegurar “um nível mínimo de ordem pública internacional” demandou a responsabilização

\footnotetext{
${ }^{409}$ Para maiores informações sobre os princípios gerais de direito penal no ETPI, ler: AMBOS, Kai. Os princípios gerais de direito penal no Estatuto de Roma. In: CHOUKR, Fauzi Hassan; AMBOS, Kai (Orgs). Tribunal Penal Internacional. São Paulo: RT, 2000, p. 25-61.

${ }^{410}$ LIMA, Renata Mantovani de \& BRINA, Marina Martins da Costa. op. cit. supra n (395), 2006, p. 86.

${ }^{411}$ DELGADO, José Manuel A. de Pina \& TIUJO, Liriam Kiyomi. op cit supra. n (351), 2004, p. 82.

${ }^{412}$ Para maiores informações: TIUJO, Liriam. A responsabilidade internacional penal do indivíduo, 2004. 281 f. Dissertação (Mestrado em Direito) - Curso de Pós-Graduação em Direito, Universidade Federal de Santa Catarina, Florianópolis, 2004.

${ }^{413}$ Ver art. 27, $\$ \$ 1^{\circ}$ e $2^{\circ}$ e art. 25 do Estatuto de Roma.

${ }^{414}$ MAZZUOLLI, Valério de Oliveira. op. cit. supra n (347), 2004, p. 176-179.

${ }^{415}$ DELGADO, José Manuel A. de Pina \& TIUJO, Liriam Kiyomi. op cit supra. n (351), 2004, p. 59.
} 
individual, ou seja, reconheceu a personalidade individual no plano internacional (atribuição de direitos e deveres aos indivíduos). ${ }^{416}$

Conforme o princípio da complementariedade ou subsidiariedade, a jurisdição do TPI (independente e imparcial, com personalidade e capacidade jurídicas internacionais) é subsidiária às jurisdições nacionais que não julguem, sejam incapazes para tal ou o façam de modo imparcial (art. 1 e 17 do ETPI), o que deveria incentivar os sistemas jurídicos nacionais a desenvolver e aperfeiçoar mecanismos processuais eficazes e capazes de aplicar a justiça eficazmente em relação aos crimes tipificados no Estatuto de Roma. ${ }^{417}$ Tal princípio se justifica pelos seguintes motivos: o conjunto probatório do crime está mais acessível e as custas serão menores, se o processo ocorrer no local do fato; as soberanias estatais são protegidas na medida em que o Estado pode desativar a competência do TPI ao assumir persecução penal eficaz (tarefa nacional de máxima prioridade ${ }^{418}$ ); e a estrutura do TPI é limitada e restrita a casos excepcionais. ${ }^{419}$

Conforme o princípio da legalidade (nullum crimen nulla pena sine lege), não é suficiente haver os métodos e meios de prevenção do delito, mas é preciso que haja uma "limitação do poder punitivo", com exclusão de toda arbitrariedade ou excesso de poder, de modo que os indivíduos devem ser protegidos contra o DI Penal, estando os atos incriminados previstos em lei, ${ }^{420}$ de modo que o ETPI estabelece "um equilíbrio entre os direitos do imputado, as garantais das vítimas e as obrigações sistêmicas de punir, prevenir e perseguir os delitos internacionais", contribuindo para a formação de "um sistema crível, independente e imparcial de justiça penal internacional" 421 . Ainda a favor do indivíduo, prevalecem o princípio nullum crimen (criminoso só pode ser punido se lei escrita e em vigor ao tempo do ato, e desde que o crime esteja definido com clareza suficiente e não estendido

\footnotetext{
${ }^{416}$ LIMA, Renata Mantovani de \& BRINA, Marina Martins da Costa. op. cit. supra n (395), 2006, p. 87-88.

${ }^{417}$ MAZZUOLI, Valério de Oliveira. op. cit. supra n (347), 2004, p. 181.

${ }^{418}$ Ver $\$ 6$ do Preâmbulo do ETPI.

${ }^{419}$ LIMA, Renata Mantovani de \& BRINA, Marina Martins da Costa. op. cit. supra n (395), 2006, p 90-92.

${ }^{420}$ Ibid., p. 95-98.

${ }^{421}$ Ibid., p. 97.
} 
por analogia, aplicando-se lei mais favorável posterior $)^{422}$ e o princípio da nula poena (somente a pena prevista no ETPI pode ser aplicada ao condenado) ${ }^{423}$. A possibilidade de defesa inclui as seguintes espécies de defesa: a defesa de superior hierárquico, de coação, de deficiência mental, de intoxicação, de agir em defesa própria ou de terceiro etc (art. 31 do ETPI).

Conforme o princípio do ne bis in idem, havendo conflito de leis penais no espaço, não pode haver dupla punição pela prática do mesmo crime, de modo que a competência do TPI é complementar às jurisdições criminais nacionais ${ }^{424}$, de modo que uma sentença do TPI esgota o litígio no campo internacional e interno ${ }^{425}$, podendo inclusive o TPI rejulgar um indivíduo desde que haja flagrante subtração do indivíduo à responsabilização penal ${ }^{426}$.

Conforme o princípio da irretroatividade, no caso de conflito de leis penais no tempo, propugna que a lei em vigor rege todos os atos a que se destina (tempus regit actum) durante sua vigência ${ }^{427}$, de modo que a lei penal não retroage nem tem ultratividade. Ademais, os crimes de competência do ETPI são imprescritíveis ${ }^{428}$ (não há perda do direito de punir), devido a gravidade de tais crimes.

Conforme o princípio da irrelevância da função oficial, as normas de imunidades ou de procedimentos especiais não eximirão o indivíduo da responsabilidade criminal, já que o ETPI será aplicado igualmente a todos sem distinção por qualidade oficial (comandantes ou superiores hierárquicos). ${ }^{429}$

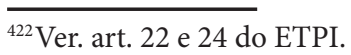

${ }^{423}$ Ver. art. 23 do ETPI.

${ }^{424}$ Ver. art. 20.2 do ETPI.

${ }^{425}$ LIMA, Renata Mantovani de \& BRINA, Marina Martins da Costa. op. cit. supra n (395), 2006, p. 99.

${ }^{426}$ Ver. art. 20.3 a e 20.3 b do ETPI.

${ }^{427}$ Ver. art. 24 do ETPI.

${ }^{428}$ Art. art. 29 do ETPI.

${ }^{429}$ LIMA, Renata Mantovani de \& BRINA, Marina Martins da Costa. op. cit. supra n (395), 2006, p. 100.
} 
Conforme o princípio da celeridade, os Estados-partes devem cooperar plenamente, da forma menos burocrática possível, com o TPI durante o inquérito e no procedimento criminal para julgamento e punição dos acusados de crimes da competência do $\mathrm{TPI}^{430}$. Além disso, conforme o princípio da boa-fé, os Estados-partes do Estatuto de Roma deverão cumprir de boa-fé e se esforçar para respeitá-lo através da edição de normatividade interna para sua implementação eficaz, sob pena de responsabilização no plano internacional ${ }^{431}$.

Frise-se ainda que o ETPI consagra o princípio segundo o qual todos os membros da comunidade internacional tem que cooperar com o TPI, seja através da extradição - medida de cooperação judicial horizontal (entre Estados) - ou da entrega - medida de cooperação judicial vertical (entre entes hierarquicamente distintos) $)^{432}$, conforme art. 102 do ETPI. ${ }^{433}$ Tal fato demonstra que a sociedade internacional compartilha valores primordiais de "segurança, paz e bem-estar da humanidade", de modo que se comprometem a compatibilizar a sistemática internacional do TPI à sua sistemática interna, através da “adaptação de medidas internas" e reforço da colaboração internacional" ${ }^{434}$. Além disso, o ETPI não admite reservas $^{435}$, assim como adota o princípio da interpretação restritiva dos textos penais. $^{436}$

\subsection{Problemas e limites do TPI}

Não mais tido como um fracasso, os tribunais penais internacionais têm contribuído para o desenvolvimento de uma dogmática jurídico-penal internacional (seja dando maior precisão aos termos da legislação penal internacional, seja

\footnotetext{
${ }^{430}$ Ver. art. 86 do Estatuto de Roma

${ }^{431}$ Ver. art. 27 da Convenção de Viena sobre o Direito dos Tratados de 1969.

${ }^{432}$ Ver art. 89.1 do ETPI.

${ }^{433}$ DELGADO, José Manuel A. de Pina \& TIUJO, Liriam Kiyomi. op cit supra. n (351), 2004, p. 68.

${ }^{434}$ LIMA, Renata Mantovani de \& BRINA, Marina Martins da Costa. op. cit. supra n (395), 2006, p. 168-169.

${ }^{435}$ Ver. art. 120 do ETPI.

${ }^{436}$ BAZELAIRE, Jean-Paul \& CRETIN, Thierry. op. cit. supra n (370), 2004, p. 81.
} 
esclarecendo as normas pela experiência jurisprudencial, sem descurar das garantias do réu) e para a consolidação de um direito penal internacional (como ramo jurídico autônomo, dotado de princípios, matéria e procedimentos próprios para julgamento dos mais graves crimes contra a humanidade), além de terem julgado um número razoável de pessoas - incluindo altas patentes militares e civis- e de terem gerado uma "verdadeira revolução no direito penal dos Estados" ao fomentar a internalização dos tipos penais previstos nos Estatutos. ${ }^{437}$

Apesar dos avanços significativos supra-delineados, o TPI também enfrenta problemas financeiros e infra-estruturais (impossibilidade material de responsabilizar individualmente todos os responsáveis pelas vias judiciais, como os enfrentados pelo TPR); e - apesar de suas disposições genéricas admissoras da responsabilização daquele que colabora de qualquer modo (mesmo por atos marginais) para a prática do crime $^{438}$ - tem apelado para a responsabilização apenas dos criminosos mais importantes ${ }^{439}$. Contudo, o pior obstáculo à adesão de mais Estados ao ETPI e da participação mais eficiente do CSNU na viabilização do TPI veio com a aprovação pelo Congresso dos EUA do ASPA (American Servicemember Protection Act), que prevê sanções expressas aos Estados que aderirem ao ETPI ${ }^{440}$. Além disso, a eficácia do TPI se encontra restringida por duas possibilidades previstas no ETPI: acordos bilaterais de consentimento prévio, que impedem a entrega de um suspeito ao TPI sem autorização dos Estados contratantes (art. 98 do ETPI) ${ }^{441}$; e imunidades concedidas por resoluções do CSNU a capacetes azuis de Estados não-signatários do ETPI (art. 16 do ETPI) ${ }^{442}$.

${ }^{437}$ DELGADO, José Manuel A. de Pina \& TIUJO, Liriam Kiyomi. op cit supra. n (351), 2004, p. $82-87$.

${ }^{438}$ Ver art. 25.3 do ETPI.

${ }^{439}$ DELGADO, José Manuel A. de Pina \& TIUJO, Liriam Kiyomi. op cit supra. n (351), 2004, p. 84.

${ }^{440}$ Ver ASPA, $107^{\circ}$ Congress, 23/01/2002.

${ }^{441}$ Os EUA possuem acordos deste tipo com os seguintes países: Romênia, Timor Leste, Maurícias, Republica Democrática do Congo e Colômbia.

${ }^{442} \mathrm{CS} / \mathrm{R} / 1422,12 / 07 / 2002 ; \mathrm{CS} / \mathrm{R} / 1487,12 / 07 / 2003$. 
Críticos das sanções penais internacionais ${ }^{433}$ apresentam soluções de caráter sociológico, como a criação de comissões de verdade e conciliação (fórum de debates entre as vitimas, os agressores e a sociedade civil); já os defensores das sanções penais internacionais ${ }^{44}$ alegam buscar a "cultura da responsabilização" para combater a "cultura da impunidade". ${ }^{45}$

\subsection{O ETPI e a Constituição Federal Brasileira}

Quando da Conferência de Roma de 1998, o Brasil teve destacada atuação, tendo o corpo diplomático brasileiro participado de uma Comissão Preparatória para o estabelecimento de um TPI, conforme preceito do art. 7 do ADCT, em que está assim disposto: "o Brasil propugnará pela formação de um tribunal penal internacional dos direitos humanos". Nestes moldes, em 07.02.2000, o Brasil assinou (amparado pelo Parecer do Prof. Dr. Antônio Paulo Cachapuz de Medeiros, consultor jurídico do MRE do Brasil) o tratado referente ao Estatuto de Roma do TPI; em 06.06.2002 o mesmo foi aprovado pelo Congresso Nacional através do Decreto Legislativo $\mathrm{n}^{\circ}$ 112; em 20.06.2002, o Brasil depositou o instrumento de ratificação perante o Secretário-Geral da ONU; sendo promulgado pelo Decreto $\mathrm{n}^{\circ} 4.388 \mathrm{em}$ 25.06.2002. A partir de então, amparado no $\$ 2$ do art. 5 da Constituição Federal Brasileira (CFB), o ETPI passou a integrar o ordenamento jurídico brasileiro como norma constitucional, tornando-se assim inabolíveis seus direitos e garantias ${ }^{446}$.

\footnotetext{
${ }^{443}$ Para maiores informações: OSIEL, Mark. Why prosecute? Critics of Punishment for Mass Atrocity. Human Rights Quarterly, v. 22, n. 1, p. 118-147, 2000; DRUMBL, Mark. Retributive Justice and the Rwandan Genocide. Punishment and Society, v. 2, n. 3, p. 287-307, 2000.

${ }^{444}$ Para maiores informações: cf. CASSESE, Antonio. Reflections on International Criminal Justice. The Modern Law Review, v. 61, n. 1, p. 1-10,1998; MORRIS, Madeline. International guidelines against impunity: facilitating accountability. Law and Contemporary Problems, v. 59, n. 4, p. 29-39, 1996.

${ }^{445}$ DELGADO, José Manuel A. de Pina \& TIUJO, Liriam Kiyomi. op cit supra. n (351), 2004, p. 84-85.

${ }^{446}$ MAZZUOLI, Valério de Oliveira. op. cit. supra n (347), 2004, p. 176.
} 
Frise-se ainda que os conflitos entre o ETPI e a CFB são meramente aparentes $^{447}$, de modo que não há incongruência entre o ordenamento jurídico interno brasileiro e internacional estabelecido pelo TPI ${ }^{448}$ nestes sentidos: obrigação de entrega de brasileiros para julgamento perante o TPI não fere o direito individual de não-extradição de nacional ${ }^{449}$ (na medida em que é limitado pelo princípio da subsidiariedade e foi fruto de delegação de jurisdição por tratado multilateral); desrespeito à coisa julgada ${ }^{450}$ (o ETPI excepciona tal princípio no caso de julgamento não imparcial ou independente para impunidade do acusado); prisão perpétua $^{451}$ (o TPI adotou a pena de prisão perpétua para evitar a pena de morte, não prejudicando a aplicação de penas dos direitos internos por serem aplicadas em esferas jurisdicionais diversas) e ausência de individualização da pena para cada tipo penal ${ }^{452}$ (os magistrados internacionais deverão compatibilizar as sanções com a sistemática jurídica do Estado do acusado); a desconsideração das imunidades de jurisdição e privilégios de foro por prerrogativa de função conferidas por normas

\footnotetext{
${ }^{447}$ No auditório do STJ, foi realizado, entre os dias 29.09 a 01.10.1999, o Seminário Internacional "O Tribunal Penal Internacional e a Constituição Brasileira", promovido pelo MRE e pelo Centro de Estudos Judiciários da Justiça Federal, a fim de debater os aspectos políticos e jurídicos da adoção do ETPI pelo Brasil. Disponível no site: < http://cjf.gov.br/ revista/numero1 1/PainellII.html>. Ultimo acesso: 07.09.09.

${ }^{448}$ LIMA, Renata Mantovani de \& BRINA, Marina Martins da Costa. op. cit. supra n (395), 2006, p. 161-162.

${ }^{449}$ Cf. art. 89(1), art. 102 e art. 91(II) do ETPI; e também art. 5, LI e art. 60, $\$ 4$, IV da CFB.

${ }^{450}$ Cf. art. 6,7,8 e 20(3) do ETPI; e também art. 5, XXXVI da CFB, art. 467 do CPCB e art. $95, \mathrm{~V}$, do CPB. Some-se ainda o fato de que a doutrina relativiza a coisa julgada, quando presentes decisões injustas e contrárias aos princípios constitucionais, e a lei permite a sua desconstituição nos casos de ação rescisória (art. 485 a 495 do CPCB).

${ }^{451}$ Cf. art. 77, 80 e 120 (reexame da pena após 25 anos de cumprimento) do ETPI. Cf. art. 4 II, art. 5, XLVII a e b, art. $5 \$ 4$ e art. 84, XIX da CFB. Ver também o art. 7 do ADCT. O próprio Código Penal Militar Brasileiro (art. 401 e art. 407 do CPMB) admite a pena de morte. Cachapuz de Medeiros defendem que "A proibição constitucional da pena de caráter perpétuo restringe apenas o legislador interno brasileiro. Não constrange nem legisladores estrangeiros, nem aqueles que labutam na edificação do sistema jurídico internacional". MEDEIROS, Antonio Paulo Cachapuz. O tribunal Penal Internacional e a Constituição Brasileira. Apud LIMA, Renata Mantovani de \& BRINA, Marina Martins da Costa, 2006. p. 170-1. Além disso o próprio STF tem se pronunciado no sentido de que a proibição de prisão perpétua interna não impede a extradição para países que permitem a prisão perpétua (Extradição 426 - RTJ 115/969).

${ }^{452}$ Cf. art. 77 do ETPI e art. 5, XLVI, da CFB.
} 
internas ou internacionais ${ }^{453}$ (para o TPI não importa a qualidade de oficial do agente delituoso, já que na sua maioria este se vale daquela para ficar impune, o que condiz com os preceitos da CFB de dignidade da pessoa humana e de PIDHs); e imprescritibilidade ${ }^{454}$ dos crimes previstos no ETPI ( tendo em vista que a lista das infrações abrangidas pela imprescritibilidade na CFB é de competência do legislador infraconstitucional e que o ETPI é incorporado no ordenamento nacional com eficácia de leis ordinárias, logo o rol da CFB pode ser ampliado pelo ETPI) ${ }^{455}$. Além disso, antes mesmo da ratificação do ETPI, o Ministério da Justiça estabeleceu, através da Portaria 1063 de 13.11.2001, um grupo de trabalho para elaborar o Anteprojeto de Lei para implementação do Estatuto de Roma (regulamentar internamente os procedimentos e a tipificação dos delitos do ETPI) a fim de sanar quaisquer incompabitibilidades entre a CFB e o ETPI.

Enfim, a relação entre o TPI e a CFB, pode ser resumida e esclarecida, nos seguintes termos do consultor jurídico do MRE, Cachapuz de Medeiros:

\begin{abstract}
“Crimes de guerra, contra a humanidade, genocídio, agressão - delitos da mais ampla gravidade e que afetam o conjunto da comunidade internacional - constituem atentados quase sempre cometidos à sombra de autoridades que segundo o ordenamento jurídico interno de seus Países desfrutam de prerrogativa de foro ou de imunidades. Ademais a Constituição Federal não repele a aceitação pelo Brasil da jurisdição de tribunais internacionais. Ao contrário, o art. 7 do ADCT estabelece que o país propugnará pela criação de um tribunal internacional de direitos humanos, sem estabelecer qualquer exceção para que cidadãos brasileiros investidos ou não em cargos públicos possam ser levados à barra de uma corte dessa natureza". ${ }^{456}$
\end{abstract}

${ }^{453}$ Tais prerrogativas e imunidades se justificam para resguardar a independência dos poderes (art. 53 caput e art. $53 \$ 2$ da CFB) e a soberania dos Estados (Convenção de Viena sobre relações diplomáticas de 1961). Cf. o art. 27 do ETPI.

${ }^{454}$ Ver art. 29 do ETPI e art. 5, XLII e XLIV, da CFB.

${ }^{455}$ LIMA, Renata Mantovani de \& BRINA, Marina Martins da Costa. op. cit. supra n (395), 2006, p. 162-177.

${ }^{456}$ Parecer n. 002, de 26.01.2001, disponível em: < http://www.dhnet.org.br > . Ultimo acesso: 07.09 .09 . 


\subsubsection{Eficácia interna das decisões e sentenças do TPI}

A CFB prevê que a eficácia de sentenças estrangeiras e a concessão de exequatur às cartas rogatórias dependem de homologação pelo STJ ${ }^{457}$; contudo, o STJ não possui competência para homologar as sentenças e decisões proferidas pelo TPI, porque se trata de sentenças e decisões internacionais proferidas por um tribunal internacional com jurisdição sobre vários Estados (fruto da vontade dos Estados e do DI, que regulamenta juridicamente a sociedade internacional) e não de sentenças ou decisões estrangeiras proferidas por um tribunal estrangeiro de um Estado soberano e sem jurisdição sobre o Estado Brasileiro (fruto do Di). ${ }^{458}$ Assim, uma vez que o Brasil aceitou a jurisdição obrigatória do TPI, mediante declaração formal, ele estará obrigado a cumprir suas sentenças e suas decisões, sob pena de responsabilização internacional, sem que seja preciso a homologação (de sentença) ou concessão de exequatur (de decisões, como entrega de nacional para julgamento) pelo ST ${ }^{459}$.

Dessa forma, os países signatários do TPI, devem zelar pela plena eficácia das sentenças e escolher os meios técnicos para implementação das decisões, já que, embora as sentenças e decisões do TPI sejam juridicamente obrigatórias, elas não são auto-aplicáveis, o que implica a necessidade de leis nacionais de implementação (enabling legislation) da decisão internacional no $\mathrm{Di}^{460}$. No caso brasileiro, compete ao juiz federal julgar as causas fundadas em tratado ou contrato da União com Estado estrangeiro ou organismo internacional ${ }^{461}$ e compete ao Ministério Publico Federal, como zelador dos $\mathrm{DHs}^{462}$, provocar o juiz para implementação interna das decisões internacionais. ${ }^{463}$

\footnotetext{
${ }^{457}$ Art. 105, inc. I, aliínea i, da CFB

${ }^{458}$ MAZZUOLLI, Valério de Oliveira. O Tribunal Penal Internacional e o direito brasileiro. Ed. atual. com a Emenda Constitucional 45/2004 - Reforma do Judiciário. São Paulo: Premier Máxima, 2005, p.79-83.

${ }^{459} \mathrm{O}$ STF, antes da EC 45/2004, já tinha se pronunciado sobre a incompetência constitucional para homologar ou aprovar a execução interna de qualquer das decisões de qualquer das decisões do TPI, ao afirmar que "a Constituição define, em numerus clausus, as hipóteses de competência originária do STF”. Cf. Informativo do STF, n $1^{\circ}$ 195, de 26 a 30.6.2000.

${ }^{460}$ MAZZUOLLI, Valério de Oliveira. op cit. supra n (457), 2005, p. 83

${ }^{461}$ Art. 109, III da CFB;

${ }^{462}$ Art. 127 e ss da CFB

${ }^{463}$ MAZZUOLLI, Valério de Oliveira. op cit. supra n (457), 2005, p.84.
} 


\subsection{Perspectivas para o séc. XXI}

O TPI, fruto do anseio da sociedade internacional e marco das ciências criminais do séc. XXI, é relevante não só para a efetivação da Justiça Penal Internacional no âmbito mundial, mas também para a PIDHs por 5 fatores: a) o TPI representa o fim da impunidade dos violadores do DI pela repressão (condenação dos culpados) e pela prevenção (inibir repetição dos crimes contra humanidade); b) o TPI sana eventuais falhas e insucessos dos tribunais nacionais; c) o TPI evita instituição de tribunais ad hocs, respeitando o princípio do juiz natural, segundo o qual o juiz deve ser previamente estabelecido e é vedado tribunal de exceção; d) o TPI cria instrumentos jurídicos-processuais, capazes de responsabilização individual dos seus condenados; e) o TPI contribui, interna e internacionalmente, para a instituição de uma Justiça Penal Internacional, que garante a eficácia da proteção dos DHs e do DI Humanitário ${ }^{464}$. Frise-se ainda que a consagração pelo TPI do "princípio da responsabilidade penal individual por atos atentatórios ao DI é uma conquista para a humanidade" 465 , além de ser "uma das maiores virtudes" do $\operatorname{ETPI}^{466}$.

Além disso, o fato de a jurisdição do TPI ser subsidiária às jurisdições nacionais fomenta os sistemas jurídicos nacionais a desenvolver, com a participação dos poderes executivo e legislativo ${ }^{467}$, mecanismos processuais eficazes e capazes de aplicar no âmbito nacional a justiça (processar, julgar e punir) eficazmente aos violadores de DHs, em especial dos crimes tipificados no Estatuto de Roma, o que colaborará para uma sociedade internacional mais justa, fundada sobre os acalentados princípios da liberdade, igualdade e fraternidade.

\footnotetext{
${ }^{464}$ MAZZUOLI, Valério de Oliveira. op. cit. supra n (347), 2004, p. 180; MAZZUOLI, Valério de Oliveira. . op cit. supra n (457), 2005, p. 85-86.

${ }^{465}$ LIMA, Renata Mantovani de \& BRINA, Marina Martins da Costa. op. cit. supra n (395), 2006, p. 147.

${ }^{466}$ Ibid., p. 88

${ }^{467}$ Ver. art. 84, inc. VIII, e art. 49 , inc I, da CFB.
} 


\section{Conclusão}

Em 1948, quando a Declaração Universal dos Direitos Humanos ressaltou que "todas as pessoas nascem livres e iguais em dignidade e direitos" e que "devem agir em relação umas às outras com espírito de fraternidade”, provavelmente objetivava promover a solidariedade universal, combater e evitar as desigualdades humanas: o direito de propriedade de um homem sobre outro (abolir a escravidão) ${ }^{468}$; o poder patriarcal na família (promover a igualdade entre gêneros) ${ }^{469}$; a ausência de direito das crianças (reconhecer a criança como sujeito de direitos) ${ }^{470}$; a exploração do empregado pelo patrão (melhorar as condições de trabalho) ${ }^{471}$, dentre outras. Infelizmente, as injustiças, as impunidades e as violações de Direitos Humanos (DHs) não acabaram; ao contrário, parecem estar se diversificando, de modo que as pessoas ainda lutam, sofrem e precisam de órgãos institucionalizados para as socorrer. Quais as opções que os indivíduos possuem no mundo contemporâneo para reparar injustiças, quando as instituições nacionais se omitem, falham ou os perseguem $^{472}$ ?

Nenhuma opção ${ }^{473}$, porque o indivíduo, embora sujeito de Direito interno (Di), não é sujeito de Direito Internacional (DI), como Estados e OIs; logo não possui personalidade (titularidade de direitos e obrigações emanadas direta e imediatamente do DI) nem capacidade jurídica internacional (possibilidade de ser parte ativa e passiva em processos internacionais) para atuar no plano internacional. Tal seria a provável resposta das autoridades de DI que afirmaram, no início do sé-

\footnotetext{
${ }^{468}$ No Brasil a escravidão só foi abolida com a assinatura da Lei Áurea em 13.05.1888.

${ }^{469} \mathrm{O}$ CC de 1916 declarava o poder patriarcal no lar, substituído pelo poder familiar com o CC de 2002.

${ }^{470}$ Somente com a CFB de 1988 , a criança passou a ser sujeito de direitos assegurados constitucionalmente.

${ }^{471}$ Somente com a CFB de 1988, foi limitada a jornada de trabalho normal para 44 horas semanais.

${ }^{472}$ É o caso das black lists e dos black sites das prisões secretas promovidas por Estados do mundo todo (teia de aranha global). Para maiores informações, cf.: MARTINS, Isabela M. M. \& KILIAN, Juliana N. Direitos Humanos no $3^{\circ}$ Milênio: captura, transferência ilegais, torturas e prisões secretas. Revista do Instituto Brasileiro de Direitos Humanos. Vol. 8, N. 8 (2007). Fortaleza, Ceará. Instituto Brasileiro de Direitos Humanos, 2007. Anual. P. 95-109.

${ }^{473}$ É muito comum entre os docentes brasileiros, dizer-se que transitada em julgado uma sentença perante o STF, só caberá recurso para o Papa.
} 
culo XX, que os indivíduos não são sujeitos de DI, nos seguintes termos: "Since the Law of Nations is a law between States, only and exclusively, States only and exclusively are subjects of the Law of Nations"474; ou das autoridades que, no início do século XXI, negaram a personalidade jurídica internacional dos indivíduos, nas seguintes palavras: "Não tem personalidade jurídica de direito internacional os indivíduos" ${ }^{775}$, porque somente "Sujeitos de direito internacional público - são os Estados soberanos e as organizações internacionais" ${ }^{\prime 47}$.

Há outras opções. É a resposta, por outro lado, dos que acreditam que os indivíduos são sujeitos ativos e passivos de Di e de DI, porque possuem plena capacidade e personalidade jurídicas internacionais - consubstanciados pelos mecanismos de petição individual perante a Corte Européia (CtEDHs), de responsabilização penal individual do Tribunal Penal Internacional (TPI) e de participação individual perante a Corte Interamericana (CtIDHs) -, de modo que, quando extinguem-se as opções no plano nacional, surge as opções do plano internacional.

Não há dúvidas de que novas idéias foram espraiadas pela ascensão do DI dos DHs (vertente de proteção internacional da pessoa humana) e do DI Penal (vertente da responsabilização internacional individual); de que uma nova ordem mundial vem se formando sobre um alicerce mais universalista; de que o mecanismo de participação individual permitiu a atuação em todas as etapas do processo perante a CtIDHs dos indivíduos dos países signatários da Convenção Americana de DHs (locus standi in judicio); de que o mecanismo de petição individual possibilitou o acesso direto com igualdade processual à CtEDHs dos indivíduos com direitos violados sob a jurisdição dos países signatários da Convenção Européia de DHs (jus standi in judicio); e de que é possível a responsabilização penal individual perante o TPI.

474“OPENHEIM, Lassa Francis L. 'International Law: A Treatise”. Vol I: Peace. Chapter III: Individuals. I -Position of Individuals in International Law. 289 - Individuals never Subjects of the Law of Nations. 1905 edition in Gallica, p. 341, disponível em <http://gallica. bnf.fr/ark:/12148/bpt6k93562g \.>. Acesso em setembro de 2008.

${ }^{475}$ RESEK, J. F. Direito Internacional Público: curso elementar. 9 ed. São Paulo: Saraiva, 2002, p. 146.

${ }^{476}$ Ibid, p. 145. 
Tais afirmativas demonstram que o indivíduo, antes excluído do cenário internacional pela visão estatocêntrica do DI, vem ganhando cada vez mais relevo no cenário internacional (tornando-se ente central das normas jurídicas internacionais), de modo que, sem dúvida, o indivíduo é ator no plano internacional (tem possibilidade de agir); contudo - face às críticas à CtEDHs, aos desafios à CtIDHs e aos problemas e limitações do TPI - ainda faltam a consolidação e superação das fraquezas e dos obstáculos enfrentados pelos 3 mecanismos apresentados; além do desenvolvimento de mecanismos em outros sistemas regionais de proteção dos DHs (africano, árabe e asiático por exemplo); assim como o aclaramento e delimitação dos termos jurídicos (tais como discriminação e duração razoável dos processo) necessários para compreensão e implementação de um verdadeiro sistema de Proteção Internacional dos Direitos Humanos (PIDHs), a fim de que possamos afirmar com todas as letras que o indivíduo é sujeito, não só de Di, mas também de DI, dotado de plena capacidade (possibilidade de postulação em juízo) e personalidade (titularidade de direitos e deveres) jurídica internacional.

Assim, embora pessoalmente desejável e embasado sobre autoridades do DI, seria temerário e precipitado - tendo em vista as limitações de páginas, de tempo, de amadurecimento intelectual, de experiência profissional e de recursos materiais para a presente pesquisa - afirmar que o indivíduo é sujeito passivo e ativo do DI Contemporâneo; embora deseje-se ardentemente que ele venha a ser sujeito de DI, para não cair refém e sem apelação das arbitrariedades do Estado ou vítima da ditadura de maiorias ou minorias. Contudo, sem dúvida nenhuma, o indivíduo é capaz de mudar as bases do DI Contemporâneo.

\section{The Individual as active and passive subject of the Contemporary International Law}

\section{Abstract}

In front of growing violations of human rights, omissions and arbitrarities of the State, it is born a international alternative to help the citizens: the system of International Protection of Human Rights. In this system, it is notable the mechanism of individual petition created by the European Court of Human Rights and the me- 
chanism of individual participation existent on the American Court of Human Rights. Originated from the San Francisco Chart and from the Universal Declaration of Human Rights, the International Right changed from a Statocentric and Traditional International Law (governed by the principle of absolute sovereignty of states) to a Contemporary and Universal International Law (governed by the principle of intrinsic dignity of human being), in accordance to Antônio A. C. Trindade and Juan A. C. Salcedo. This process of Humanization of International Law make possible the incorporation and acceptance of the International Protection of Human Rights and fundamental garanties, what is a significant passe towards the acceptance of the individual as active and passive subject of the Internal Law and of the International Law. Through the International Law of Human Rights and through the International Criminal Law, it is possible understand the recent developments of the individual petition mechanism of the European Court (transition between a locus standi in judicio to a jus standi in judicio) and the individual participation mechanism of the American Court (reach of a locus standi in judicio), as well as know how works the mechanism of individual criminal responsibilization of the International Criminal Court, in order to conclude how is the action of the individual in the international environment and infer if individual has or hasn't active and passive subjectivity of International Law, with complete international and legal capacity and personality .

Keywords: International Law of Human Rights (ILHRs). International Criminal Law (ICL). European Court of Human Rights (ECHRs). American Court of Human Rigths (ACHRs). International Criminal Court (ICC). International Protection of Human Rights.

\section{Referências}

ACCIOLY, Hildebrando; SILVA, G. E. do Nascimento e. Manual de Direito Internacional Publico. 14. ed. São Paulo: Saraiva, 2000.

BARRETTO, Ireneu Cabral. Recurso individual no tribunal europeu dos direitos do homem In: Os rumos do Direito Internacional dos direitos humanos: ensaios em homenagem ao professor Antônio Augusto Cançado Trindade/Renato Zebini Ribeiro Leão, coord. - Porto Alegre: Sergio Antonio Fabris Ed. 2005. 
BAZELAIRE, Jean-Paul; CRETIN, Thierry. A justiça penal internacional: sua evolução, seu futuro: de Nuremberg a Haia; tradução de Luciana Pinto Venâncio. Barueri, SP: Manole, 2004.

BROWLIE, Ian. “Principles of Public International Law”, Av. De Berna/Lisboa: Fundação Calouste Gulbenkian, 1997.

CENTRO UNIVERSITÁRIO DE BRASÍLIA. Faculdade de Ciências Jurídicas e Sociais. Curso de Direito. Manual de elaboração de monografias. Brasília, 2002.

COELHO, Rodrigo Meirelles Gaspar. Proteção internacional dos direitos humanos: a Corte Interamericana e a implementação de suas sentenças no Brasil. Curitiba: Juruá, 2008.

COMISSÃO INTERAMERICANA DE DIREITOS HUMANOS. Relatório Anual de 2006. Disponível em: <http://www.cidh.oas.org/annualrep/2006eng/chap.3a. htm>. Acesso em abril de 2009.

COMITÊ DE DIREITOS HUMANOS. Comentário Geral no 24. Disponível no site: <http://www.unhchr.ch/tbs/doc.nsf/(Symbol)/69c55b086f72957ec12563ed00 4ecf7a?Opendocument $>$. Acesso em abril de 2009.

COMITÊ SOBRE A ELIMINAÇÃO DA DISCRIMINAÇÃO CONTRA MULHERES. Recomendação Geral no 4. Disponível no site: <http://www.un.org/womenwatch/ daw/cedaw/recommendations/recomm.htm\#recom4>. Acesso em abril de 2009.

COMMITTEE OF MINISTERS DOCUMENTS. CM (2002)146. Interim Report of the $\mathrm{CDDH}$ to the Committee of Ministers "Guaranteeing the long-term effetiveness of the European Cout of Human Rights" Disponível no site: <https:// wcd.coe.int/ViewDoc.jsp? Ref $=\mathrm{CM}(2002) 4 \&$ Language $=$ lanEnglish $\&$ Site $=\mathrm{COE} \& \mathrm{~B}$ ackColorInternet=DBDCF2\&BackColorIntranet=FDC864\&BackColorLogged $=\mathrm{F}$ DC864>. Acesso em setembro de 2008.

CONSELHO DA EUROPA. Convenção Européia para a proteção dos Direitos do Homem e das Liberdades Fundamentais. <http://www.echr.coe.int/ECHR/ FR/Header/Basic+Texts/Basic+Texts/The+European+Convention+on+Human+ Rights+and+its+Protocols/>. Acesso em: setembro de 2008.

CORTE EUROPÉIA DE DIREITOS HUMANOS. “Rules of the Court." <http:// www.echr.coe.int/NR/rdonlyres/D1EB31A8-4194-436E-987E-65AC8864BE4F/0/ RulesOfCourt.pdf\#xml=http://www.search.coe.int/texis/search/pdfhi.txt?query=r ules+of+the+court\&pr=Internet_D2\&prox=page\&rorder $=500 \&$ rprox $=750$ \&rdfre 
$\mathrm{q}=500 \&$ rwfreq $=500 \&$ rlead $=500 \&$ rdepth $=250 \&$ sufs $=1 \&$ order $=$ r\&mode $=\&$ opts $=\&$ cq $=\& s r=\& i d=484966$ c0d $>$. Acesso em: setembro. 2008.

CORTE INTERAMERICANA DE DIREITOS HUMANOS. Regulamento da Corte. <http://www.corteidh.or.cr/Regulamento.pdf $>$.Acesso em : 11 de outubro de 2008 .

COSTA RICA. Proposta de Protocolo Facultativo à Convenção Americana. Disponível no site: <http://scm.oas.org/DOC_SEARCH_ENGINE/ PORTUGUESE/hist_01/ag01643p06.doc>. Acesso em maio de 2009.

DECLARAÇÃO DE QUEBEC. Documento da Cúpula das Américas de 22/4/2001. Disponível no site: <www.americascanada.org/eventsummit/ declarations/declara-s.asp >. Acesso em maio de 2009.

DELGADO, José Manuel A. de Pina \& TIUJO, Liriam Kiyomi. Tribunais penais internacionais. In: Tribunais internacionais: mecanismos contemporâneos de solução de controvérsias/Welber Barral, organizador. - Florianópolis: Fundação Boiteux, 2004.

FERREIRA, Gustavo Assed. “Corte Européia de Direitos Humanos”. In: Tribunais Internacionais: mecanismos contemporâneos de solução de controvérsias/ Welber Barral, organizador. - Florianópolis: Fundação Boiteux, 2004.

GARCIA RAMIREZ, Sergio. "Los derechos humanos y la jurisdicción nteramericana”. México: Universidad Nacional Autônoma de México, 2002.

ISKANDAR, Jamil Ibrahim. Normas da ABNT: comentadas para trabalhos científicos. 4. Edição. Curitiba: Juruá, 2009.

KEGEL, Patrícia Luíza. “Tribunal de Justiça das Comunidades Européias”. In: Tribunais internacionais: mecanismos contemporâneos de solução de controvérsias /Welber Barral, organizador. - Florianópolis: Fundação Boiteux, 2004.

LAAT, Paula Lizano Van der. "La evolución del Concepto de víctima em la jurisprudencia de la Corte Interamericana de Derechos Humanos". In: Os rumos do Direito Internacional dos direitos humanos: ensaios em homenagem ao professor Antônio Augusto Cançado Trindade/Renato Zebini Ribeiro Leão, coord. - Porto Alegre: Sergio Antonio Fabris Ed. 2005.

LIMA, Renata Mantovani de \& BRINA, Marina Martins da Costa. O tribunal Penal Internacional. Belo Horizonte: Del Rey, 2006. 
LEÃO, Renato Zerbini Ribeiro. "La construcción jurisprudencial de los sistemas europeo e interamericano de protección de los derechos humanos em matéria de derechos econômicos,sociales y culturales". Porto Alegre: Núria Fabris Ed., 2009.

LOCATELLI, Liliana. Corte Internacional da Justiça. In: Tribunais internacionais: mecanismos contemporâneos de solução de controvérsias /Welber Barral, organizador. - Florianópolis: Fundação Boiteux, 2004.

MAZZUOLLI, Valério de Oliveira. O Tribunal Penal Internacional e o direito brasileiro. Ed. atual. com a Emenda Constitucional 45/2004 - Reforma do Judiciário. São Paulo: Premier Máxima, 2005.

NIKKEN, Pedro. "Perfeccionar el Sistema Interamericano de Derechos Humanos sin refomar el Pacto de San José". Disponível no site <http://www.bibliojuridica. org/libros/4/1991/5.pdf>. Acesso em maio de 2009.

OPPENHEIM, Lassa Francis L. "International Law: A Treatise". Vol I: Peace. Chapter III: Individuals. I - Position of Individuals in International Law. 289 Individuals never Subjects of the Law of Nations. 1905 edition in Gallica p. 341, disponível em: <http://gallica.bnf.fr/ark:/12148/bpt6k93562g|l.>. Acesso em 15 outubro de 2008.

ORGANIZAÇÃO DOS ESTADOS AMERICANOS. "Convencion Americana sobre Derechos Humanos" (Pacto de San José). <http://www.oas.org/juridico/ spanish/tratados/b-32.html>, Acesso em: 11 de outubro de 2008.

PETIOT, Patrick. A responsabilidade internacional do Estado brasileiro por violação de diretos humanos: o pagamento de reparações. Brasília, 2005

PLANO DE AÇÃO. Documento da Cúpula das Américas de 22/4/2001. Disponível no site: <www.americascanada.org/eventsummit/declarations/plan-s. pdf $>$ Acesso em maio de 2009.

RAMOS, André de Carvalho. Responsabildiade inernacional por violação de direitso humanos: seus elementos, a reparação devida e sanções possíveis: teoria e prática do direito internacional. Rio de janeiro: Renovar, 2004

RESEK, J. F. Direito Internacional Público: curso elementar. 9 ed. São Paulo: Saraiva, 2002.

RESOLUÇÕES DA ASSEMBLÉIA-GERAL DA OEA. AG/RES 1828(XXXI-O/01). Disponível no site $<$ http://www.oas.org/juridico/portuguese/2001/agres1828.htm > 
. AG/RES 1890 (XXXII-O/02). Disponível no site: <http://www.oas.org/ juridico/portuguese/2002/agres1890.htm>.

. AG/RES. 1833 (XXXI-O/01). Disponível no site < http://www.oas.org/ juridico/spanish/ag01/agres_1833.htm>

. AG/RES 1895 (XXXII-O/02). Disponível no site: <http://www.oas.org/ juridico/spanish/ag02/agres_1895.htm $>$.

ROBLES, Manuel E. Ventura. "El acceso directo de la víctima a la Corte Interamericana de Derechos Humanos: um ideal y uma llucha de Antonio A. Cançado Trindade”. In: Os rumos do Direito Internacional dos direitos humanos: ensaios em homenagem ao professor Antônio Augusto Cançado Trindade/Renato Zebini Ribeiro Leão, coord. - Porto Alegre: Sergio Antonio Fabris Ed. 2005.

SALCEDO, Juan Antonio Carrillo. “Algunas Reflexiones sobre la Subjetividad Internacional del Individuo y el Proceso de Humanización del Derecho Internacional". In: Os rumos do Direito Internacional dos direitos humanos em homenagem ao professor Antônio Augusto Cançado Trindade/Renato Zerbini Ribeiro Leão, coord. - Porto Alegre: Sergio Antonio Fabris Ed. 2005.

SEITENFUS, Ricardo Antônio Silva. Manual das organizações internacionais. 4 ed. rev., atual. e amp. Porto Alegre: Livrara do Advogado, 2005.

TRINDADE, Antônio Augusto Cançado. A consolidação da Capacidade Processual dos Indivíduos na Evolução da Proteção Internacional dos Direitos Humanos: Quadro Atual e Perspectivas na Passagem do Século. In: Direitos Humanos no Século XXI: Organizadores: Paulo Sérgio Pinheiro e Samuel Pinheiro Guimarães. Brasília: IPRI, 2002.

A humanização do direito internacinal. I - A Recta Ratio nos Fundamentos do Jus Gentium como Direito Internacional da Humanidade. Belo Horizonte: Del Rey, 2006, pp. 3-30.

As três Vertentes da Proteção Interancioanal dos Dieriteos da Pessoa Humana: Direitos Humanos, Direito Humanitário, Direito dos Refugiados. Brasília/San José: IIDH/CICV/ACNUR, 1996, p. 1-121.

"Coexistence and Co-Ordination of Mechanims of International Protection of Human Rights (At Global and Regional Levels", Vol. 202 , Recueil des Cours de l'Académie de Droit International de La Haye (1978-II), 1987. 
"Discurso del Presidente de la Corte Interamericana de Derechos Humanos, Juez Antõnio Augusto Cançado Trindade”, em la cerimônia de incorporación como Professor Honorário de la Universidad Nacional Mayor de San Marcos. Lima, Peru, 13 de septiembre de 2001.

. "Informe del Relator de la Corte Interamericna de Derechos Humanos sobre el Proceso de Fortalecimiento del Sistema Interamericano de Protección de los Derechos Huamnos: Bases para um Proyect de Protocolo a la Convención Americana sobre Deerechos Humanos", San José de Costa Rica, CtIADH, 15.06.2000. .

."International Law for Humankind: Towards a new Jus Gentium (I): General Course on Public International Law", Hague Academy of International Law: offprint from the Collected Courses, Volume 316(2005), Leiden/Boston: Martinus Nijhoff Publishers, 2006

Tratado de direito internacional dos direitos humanos, volume I. 2. ed. Porto Alegre: Sergio Antonio Fabris, 2003.

VIDIGAL, Carlos Eduardo. A Nova Ordem Mundial. In: Política Internacional Contemporânea: mundo em transformação. Henrique Altemani de Oliveira et al; [organizadores, Henrique Altemani de Oliveira, Antônio Carlos Lessa. São Paulo: Saraiva, 2006.

Revistas:

JOB, Ulisses da Silveira. Proteção Internacional dos Direitos Humanos: Comissões e cortes interamericanas e européias de direitos humanos e questões afins. Revista de Informação Legislativa /Senado Federal, Subsecretaria de Edições Técnicas. Ano 1, n. 1 (mar. 1964) - Brasília: Senado Federal, Subsecretaria de Edições Técnicas, 1964.

MAZZUOLI, Valério de Oliveira. A importância do Tribunal Penal Internacional para a Proteção Internacional dos Direitos Humanos. Revista Jurídica UNIGRAN /Centro Universitário da Grande Dourados, v. 6, n. 11 (1999). Dourados: UNIGRAN, 2004.

MOREIRA, Luiz Carlos Lopes. Os sistemas de Proteção de Direitos Humanos em que a Corte Interamericana e a Corte Européia estão inseridas. Direito e Democracia, Revista de Ciências Jurídicas - ULBRA. Vol. 6, n 1,1 semestre de 2005. 
SANCTIS, Fausto Martins de. Corte Européia de Direitos do Homem. Revista Jurídica Consulex, Ano V, nº 97, 31/1/2001.

TRINDADE, Antônio Augusto Cançado "El Nuevo Regulamento de la Corte Intera-Mericana de Derechos Humanos (2000): La Emancipación del ser humano como sujeto del Derecho Internacional de los Derechos Humanos". In: REVISTA UNIVERSITAS/Relações Internacionais; Vol. I; n² 2; Janeiro a Julho de 2003, Série Nacional, pp. 9-41

\section{Sites Oficiais:}

Comissão Interamericana de Direitos Humanos: <http://www.cidh.oas.org > Comunidade Européia da Energia Atômica : <http://www.euratom.org/>

Conselho da Europa: < http://www.coe.int/t/cm/home_en.asp >

Conselho de Direitos Humanos das Nações Unidas <http://www2.ohchr.org/> Corte Européia de Direitos humanos: <http://www.echr.coe.int/ECHR/>

Corte Européia de Justiça: <http://curia.europa.eu/jcms/>

Corte Interamericana de Direitos Humanos: <http://www.corteidh.or.cr/index.cf $\mathrm{m}$ ?CFID=709300\&CFTOKEN=68591364>

Corte Internacional de Justiça: < http://www.icj-cij.org/>

Ministério das Relações Exteriores do Brasil. <http://www2.mre.gov.br/dai/ dhumanos.htm>.

Organização das Nações Unidas: < http://www.un.org/>

Organização dos Estados Americanos: <http://www.oas.org/pt/>

Tribunal de Primeira Instância: <http://curia.europa.eu/jcms/jcms/j_6/paginaincial>

Tribunal Penal Internacional: < http://www2.icc-cpi.int/>

União da Europa Ocidental : <http://www.weu.int/>

União Européia: <http://europa.eu/>

Documentos legais:

-Constituições

CONSTITUIÇÃO DA REPÚBLICA FEDERATIVA DO BRASIL

- Cartas

CARTA DE BOGOTÁ

CARTA DA OEA.

CARTA DA ONU.

- Convenções 
CONVENÇÃO AMERICANA DE DIREITOS HUMANOS.

CONVENÇÃO DE VIENA SOBRE DIREITO DOS TRATADOS

CONVENÇÃO EUROPÉIA DE DIREITOS HUMANOS

CONVENÇÃO INTERAMERICANA SOBRE ARBITRAGEM COMERCIAL INTERANCIONAL DE 1975. (Convenção do Panamá).

CONVENÇÃO SOBRE O RECONHECIMENTO E EXECUÇÃO DE SENTENÇAS ARBITRAIS ESTRANGEIRAS DE 1958 (Convenção de Nova York)

PROTOCOLO FACULTATIVO À CONVENÇÃO AMERICANA.

PROTOCOLOS À CONVENÇÃO EUROPÉIA

REGULAMENTO QUARTO DA CORTE INTERAMERICANA DE DIREITOS HUMANOS.

- Leis

LEI DE INTRODUÇÃO AO CÓDIGO CIVIL.

CÓDIGO CIVIL

- Tratados

TRATADO CONSTITTUTIVO DA COMUNIDADE EUROPÉIA.

TRATADO DE LISBOA.

TRATADO INTERAMERICANO DE ASSISTÊNCIA RECÍPROCA (Pacto do Rio)

Jurisprudências e Decisões:

DECISÕES DA COMISSÃO EUROPÉIA DE DIREITOS HUMANOS.

JURISPRUDÊNCIA DA CORTE EUROPÉIA DE DIREITOS HUMANOS.

JURISPRUDÊNCIA DA CORTE INTERAMERICANA DE DIREITOS HUMANOS.

JURISPRUDÊNCIA DA CORTE INTERNACINOAL DE JUSTIÇA. 


\section{ANEXO A - Informações sobre a Corte Africana}

\section{“INSTITUTIONAL BACKGROUND}

The African Court on Human and Peoples' Rights (African Court) was established by a Protocol to the African Charter on Human and Peoples' Rights, which was adopted by Member States of the then Organisation of African Unity (OAU) in Ouagadougou, Burkina Faso in June 1998. The Protocol entered into force in January 2004.

The first judges of the African Court were elected in January 2006, in Khartoum, the Sudan. They were later sworn in before the Assembly of Heads of State and Government on 2 July 2006, in Banjul, the Gambia. The judges were elected in their individual capacities from among African jurists and judges of proven integrity, qualifications and experience, having been nominated by individual Member States. The election was also based on equitable representation of the five major African regions, and major legal systems and jurisdictions.

In July 2008, the Executive Council of the African Union and the Assembly of Heads of State and Government during the Thirteenth and Eleventh Sessions of the African Union respectively, re-elected and re-appointed two judges whose terms had elapsed and were up for re-election. Two new judges were also elected and appointed.

The African Court started its operations in Addis Ababa, Ethiopia in November 2006 but moved to its permanent seat in Arusha, Tanzania in August 2007. It has now firmly established itself in Arusha where the government of the United Republic of Tanzania has provided it with temporary premises pending the construction of permanent structures.

The Court has since its establishment held eleventh ordinary sessions and one extraordinary session. One of the challenges of the African Court in its initial stages was to complete its operationalisation process. Judges have thus during the Court's sessions discussed issues which have included the preparation of the Court's budget and the development of the administrative structure of the Court's registry. The Policy Organs of the African Union approved the structure of the Court's registry. In total, the African Court will have 57 members of staff including the judges. The President of the African Court is resident at the seat of the African Court whereas the other ten (10) judges work on a part-time basis.

Most importantly, the African Court completed the complex but crucial task of drafting its Rules, which were adopted provisionally during the Court's ninth session in June 2008 pending the process of consultation with the African Commission on Human and Peoples' Rights, based in Banjul. The Protocol on the establishment of the Court required that the two institutions harmonise their respective Rules. The Court is now ready to receive cases."

FONTE: AfCHPR - African Court on Human and Peoples' Rights. Institutional Background. Disponível em: <http://www.african-court.org/en/court/history/>.Ultimo acesso em setembro de 2009. 


\section{Sistema Africano de Protección de los Derechos Humanos}

- African Charter on the Rights and Welfare of the Child (Sólo en inglés)

- Protocol to the African Charter on Human And Peoples' Rights on the Establishment of an African Court on Human and Peoples' Rights (Sólo en inglés)

- Protocol to the African Charter on Human and Peoples' Rights on the Rights of Women in Africa (Sólo en inglés)

- Protocol of the Court of Justice of the African Union (Sólo en inglés)

- Carta Africana de los Derechos Humanos y de los Pueblos "Carta de Banjul"

- African Union Convention on Preventing and Combating Corruption (Sólo en inglés)

- African Union Non-Aggression and Common Defence Pact (Sólo en inglés)

- African Convention on the Conservation of Nature and Natural Resources (Sólo en inglés)

- Protocol Relating to the Establishment of the Peace and Security Council of the African Union (Sólo en inglés)

- African Nuclear Weapon-Free Zone Treaty (Pelindaba Treaty) (Sólo en inglés)

- Treaty Establishing the African Economic Community (Sólo en inglés)

- OAU Convention Governing the Specific Aspects of Refugee Problems in Africa (Sólo en inglés)

FONTE: Corte Interamericana de Derechos Humanos. Instrumentos do Sistema Africano. Disponível no site: <http://www.corteidh.or.cr/sistemas.cfm?id=4>. Último acesso em setembro de 2009. 


\section{WHO CAN MAKE NA APPLICATION TO THE COURT?}

- The Commission

- A State party to the Court's Protocol which has lodged a complaint before the Commission

- A State party to the Court's Protocol against which the complaint has been lodged at the Commission

- A State party to the Court's Protocol whose citizen is a victim of a human rights violation

- African Intergovernmental Organisations

- State parties to the Court's Protocol with an interest in a case may be permitted by the Court to join the proceedings

- Relevant non-governmental organisations (NGOs) with Observer Status before the Commission, and individuals can institute cases directly before the Court, if the State party from which they come from has made a declaration allowing such direct applications.

FONTE: AfCHPR - African Court on Human and Peoples' Rights. FAQ. Disponível em: $<$ http://www.african-court.org/en/court/faq/\#c83>. Ultimo acesso em: 5 de outubro de 2009. 


\section{ANEXO B - Estrutura organizacional da ONU}

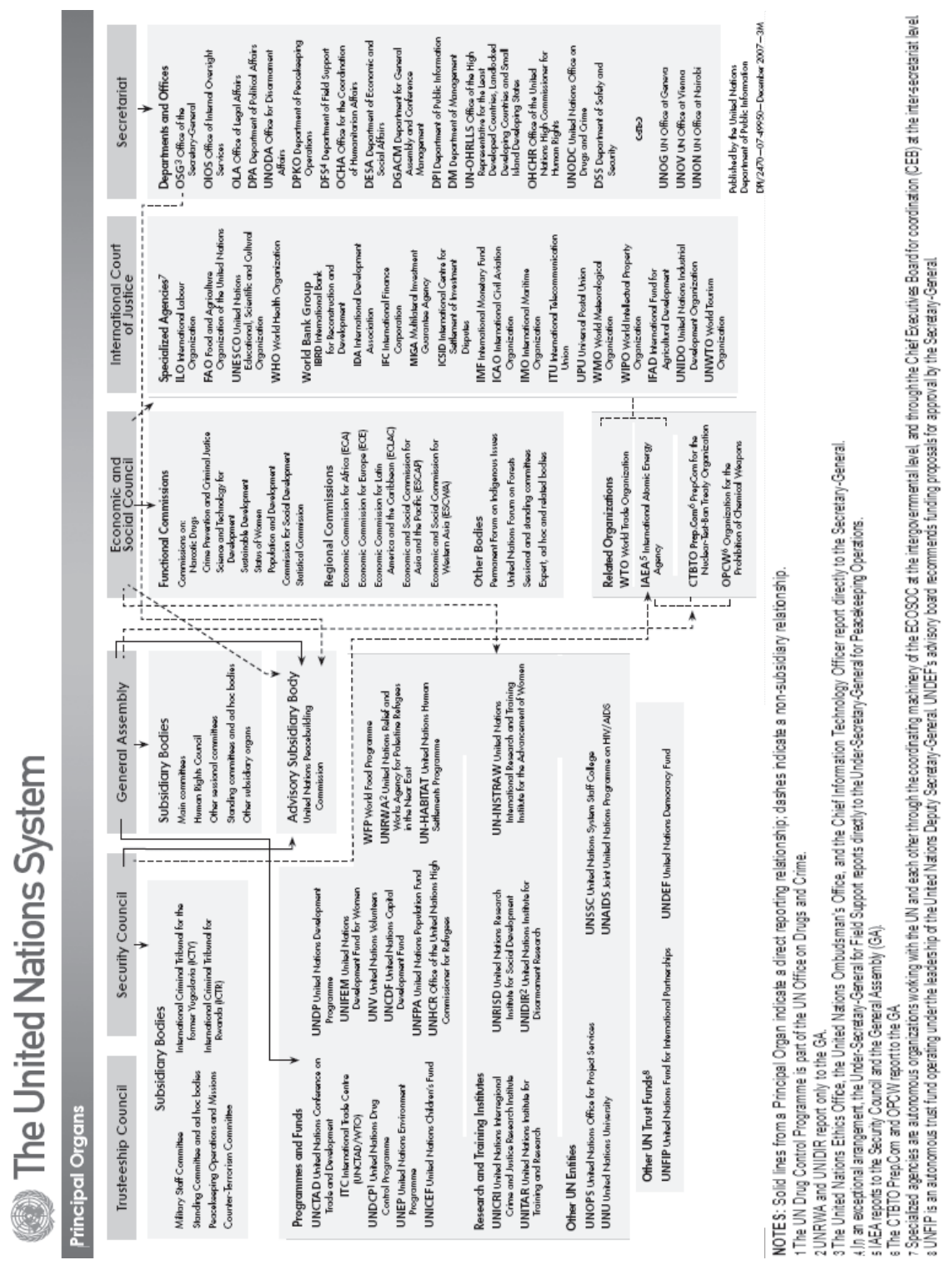

FONTE: ONU. The United Nations System. Disponível no site: <http://www.un.org/aboutun/chart_en.pdf >. Acesso em: 07 set. 2009 


\section{ANEXO C - Estados-membros da ONU por período de adesão}

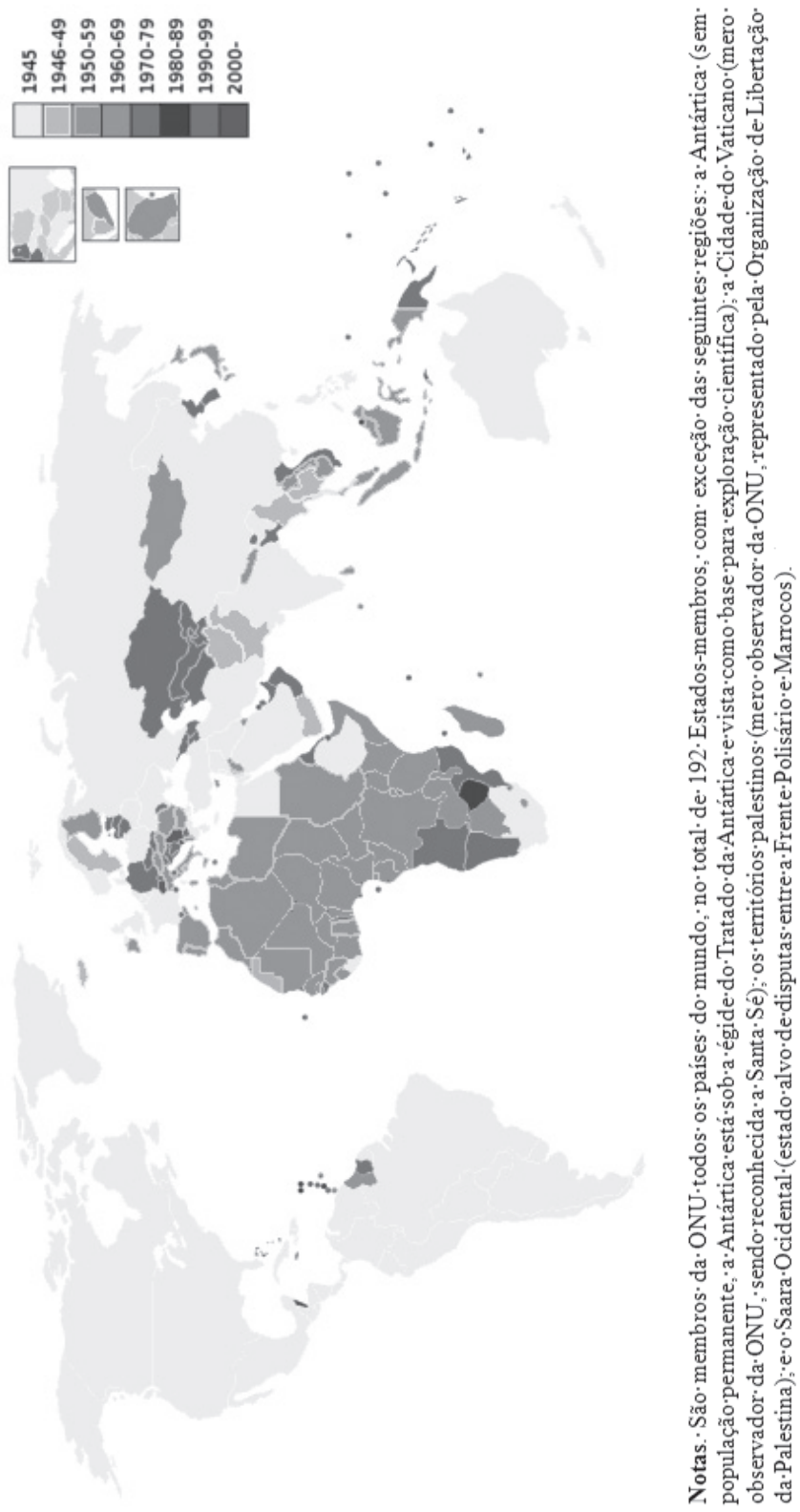

FONTE: ONU. Members States of the UM. Disponível no site: <http://en.wikipedia.org/ wiki/File:United_Nations_member_countries_world_map.PNG $>$, baseado nos dados do site: <http://www.un.org/en/members/index.shtml>. Acesso em: 07 set. 2009. 
ANEXO D - Os principais instrumentos de DHS fundamentais e seus órgãos de fiscalização no sistema universal da ONU

\section{CHARTER OF THE UNITED NATIONS}

THE INTERNATIONAL BILL OF HUMAN RIGHTS

\section{Universal Declaration of Human Rights 1948}

International Covenant on Economic, Social and Cultural Rights 1966 International Covenant on Civil and Political Rights 1966

Optional Protocol to the International Covenant on Civil and Political Rights

Second Optional Protocol to the International Covenant on Civil and Political Rights, aiming at the abolition of the death penalty

THE CORE INTERNATIONAL HUMAN RIGHTS INSTRUMENTS and their monitoring bodies

There are nine core international human rights treaties. Each of these treaties has established a committee of experts to monitor implementation of the treaty provisions by its States parties. Some of the treaties are supplemented by optional protocols dealing with specific concerns.

\begin{tabular}{|c|c|c|c|}
\hline & & Date & $\begin{array}{c}\text { Monitoring } \\
\text { Body }\end{array}$ \\
\hline ICERD & $\begin{array}{l}\text { International Convention on the } \\
\text { Elimination of All Forms of Racial } \\
\text { Discrimination }\end{array}$ & $\begin{array}{c}21 \\
\text { Dec } \\
1965\end{array}$ & CERD \\
\hline ICCPR & $\begin{array}{l}\text { International Covenant on Civil and } \\
\text { Political Rights }\end{array}$ & $\begin{array}{c}16 \\
\text { Dec } \\
1966\end{array}$ & CCPR \\
\hline ICESCR & $\begin{array}{l}\text { International Covenant on Economic, } \\
\text { Social and Cultural Rights }\end{array}$ & $\begin{array}{c}16 \\
\text { Dec } \\
1966\end{array}$ & CESCR \\
\hline CEDAW & $\begin{array}{l}\text { Convention on the Elimination of All } \\
\text { Forms of Discrimination against Women }\end{array}$ & $\begin{array}{c}18 \\
\text { Dec } \\
1979\end{array}$ & CEDAW \\
\hline CAT & $\begin{array}{l}\text { Convention against Torture and Other } \\
\text { Cruel, Inhuman or Degrading Treatment } \\
\text { or Punishment }\end{array}$ & $\begin{array}{c}10 \\
\text { Dec } \\
1984\end{array}$ & CAT \\
\hline CRC & Convention on the Rights of the Child & $\begin{array}{l}20 \\
\text { Nov } \\
1989\end{array}$ & CRC \\
\hline
\end{tabular}




\begin{tabular}{|c|c|c|c|}
\hline ICRMW & $\begin{array}{l}\text { International Convention on the } \\
\text { Protection of the Rights of All Migrant } \\
\text { Workers and Members of Their Families } \\
\text { International Convention for the } \\
\text { Protection of All Persons from Enforced } \\
\text { Disappearance }\end{array}$ & $\begin{array}{c}18 \\
\text { Dec } \\
1990 \\
20 \\
\text { Dec } \\
2006\end{array}$ & CMW \\
\hline CRPD & $\begin{array}{l}\text { Convention on the Rights of Persons } \\
\text { with Disabilities }\end{array}$ & $\begin{array}{c}13 \\
\text { Dec } \\
2006\end{array}$ & CRPD \\
\hline ICESCR - OP & $\begin{array}{l}\text { Optional Protocol of the Covenant on } \\
\text { Economic, Social and Cultural Rights }\end{array}$ & $\begin{array}{c}10 \\
\text { Dec } \\
2008\end{array}$ & CESCR \\
\hline ICCPR-OP1 & $\begin{array}{l}\text { Optional Protocol to the International } \\
\text { Covenant on Civil and Political Rights }\end{array}$ & $\begin{array}{c}16 \\
\text { Dec } \\
1966\end{array}$ & HRC \\
\hline ICCPR-OP2 & $\begin{array}{l}\text { Second Optional Protocol to the } \\
\text { International Covenant on Civil and } \\
\text { Political Rights, aiming at the abolition } \\
\text { of the death penalty }\end{array}$ & $\begin{array}{c}15 \\
\text { Dec } \\
1989\end{array}$ & HRC \\
\hline OP-CEDAW & $\begin{array}{l}\text { Optional Protocol to the Convention } \\
\text { on the Elimination of Discrimination } \\
\text { against Women }\end{array}$ & $\begin{array}{c}10 \\
\text { Dec } \\
1999\end{array}$ & CEDAW \\
\hline OP-CRC-AC & $\begin{array}{l}\text { Optional protocol to the Convention } \\
\text { on the Rights of the Child on the } \\
\text { involvement of children in armed } \\
\text { conflict }\end{array}$ & $\begin{array}{l}25 \\
\text { May } \\
2000\end{array}$ & CRC \\
\hline OP-CRC-SC & $\begin{array}{l}\text { Optional protocol to the Convention } \\
\text { on the Rights of the Child on the sale } \\
\text { of children, child prostitution and child } \\
\text { pornography }\end{array}$ & $\begin{array}{l}25 \\
\text { May } \\
2000\end{array}$ & CRC \\
\hline OP-CAT & $\begin{array}{l}\text { Optional Protocol to the Convention } \\
\text { against Torture and Other Cruel, } \\
\text { Inhuman or Degrading Treatment or } \\
\text { Punishment }\end{array}$ & $\begin{array}{c}18 \\
\text { Dec } \\
2002\end{array}$ & CAT \\
\hline OP-CRPD & $\begin{array}{l}\text { Optional Protocol to the Convention on } \\
\text { the Rights of Persons with Disabilities }\end{array}$ & $\begin{array}{c}12 \\
\text { Dec } \\
2006\end{array}$ & CRPD \\
\hline
\end{tabular}

FONTE: ComDHsNU. The Core International Human Rights Instruments and their Monitoring Bodies. Disponível no site: $<$ http://www2.ohchr.org/english/law/index.htm $>$. Acesso em: 07 set. 2009. 


\section{ANEXO E - Instrumentos universais de DHS sobre a égide da ONU}

\section{UNIVERSAL HUMAN RIGHTS INSTRUMENTS}

In addition to the International Bill of Rights and the core human rights treaties, there are many other universal instruments relating to human rights. A non-exhaustive selection is listed below. The legal status of these instruments varies: declarations, principles, guidelines, standard rules and recommendations have no binding legal effect, but such instruments have an undeniable moral force and provide practical guidance to States in their conduct; covenants, statutes, protocols and conventions are legally-binding for those States that ratify or accede to them. Information on the status of ratification of selected instruments is available here. Printer-friendly versions of these instruments may be downloaded from the CD-ROM Compilation of Universal Instruments accessible online here.

\section{WORLD CONFERENCE ON HUMAN RIGHTS AND MILLENNIUM ASSEMBLY}

- Vienna Declaration and Programme of Action

- United Nations Millennium Declaration

\section{THE RIGHT OF SELF-DETERMINATION}

- United Nations Declaration on the Granting of Independence to Colonial Countries and Peoples

- General Assembly resolution 1803 (XVII) of 14 December 1962, "Permanent sovereignty over natural resources"

- International Convention against the Recruitment, Use, Financing and Training of Mercenaries

\section{RIGHTS OF INDIGENOUS PEOPLES AND MINORITIES}

- Declaration on the Rights of Indigenous Peoples

- Indigenous and Tribal Peoples Convention, 1989 (No. 169)

- Declaration on the Rights of Persons Belonging to National or Ethnic, Religious and Linguistic Minorities 


\section{PREVENTION OF DISCRIMINATION}

- $\quad$ Equal Remuneration Convention, 1951 (No. 100)

- Discrimination (Employment and Occupation) Convention, 1958 (No. 111)

- International Convention on the Elimination of all Forms of Racial Discrimination (ICERD)

- Declaration on Race and Racial Prejudice

- Convention against Discrimination in Education

- Protocol Instituting a Conciliation and Good Offices Commission to be responsible for seeking a settlement of any disputes which may arise between States Parties to the Convention against Discrimination in Education

- Declaration on the Elimination of All Forms of Intolerance and of Discrimination Based on Religion or Belief

- World Conference against Racism, 2001 (Durban Declaration and Programme of Action)

\section{RIGHTS OF WOMEN}

- Convention on the Elimination of All Forms of Discrimination against Women (CEDAW)

- Optional Protocol to the Convention on the Elimination of All Forms of Discrimination against Women (CEDAW-OP)

- Declaration on the Protection of Women and Children in Emergency and Armed Conflict

- Declaration on the Elimination of Violence against Women

\section{RIGHTS OF THE CHILD}

- Convention on the Rights of the Child (CRC)

- Optional Protocol to the Convention on the Rights of the Child on the sale of children, child prostitution and child pornography (CRC-OPSC)

- Optional Protocol to the Convention on the Rights of the Child on the involvement of children in armed conflict (CRC-OPAC)

- Minimum Age Convention, 1973 (No. 138)

- Worst Forms of Child Labour Convention, 1999 (No. 182)

- $\quad$ RIGHTS OF OLDER PERSONS

- United Nations Principles for Older Persons

\section{RIGHTS OF PERSONS WITH DISABILITIES}

- Declaration on the Rights of Mentally Retarded Persons

- Declaration on the Rights of Disabled Persons

- Principles for the protection of persons with mental illness and the improvement of mental health care 
- Standard Rules on the Equalization of Opportunities for Persons with Disabilities

HUMAN RIGHTS IN THE ADMINISTRATION OF JUSTICE: PROTECTION OF PERSONS SUBJECTED TO DETENTION OR IMPRISONMENT

- Standard Minimum Rules for the Treatment of Prisoners

- Basic Principles for the Treatment of Prisoners

- Body of Principles for the Protection of All Persons under Any Form of Detention or Imprisonment

- United Nations Rules for the Protection of Juveniles Deprived of their Liberty

- Declaration on the Protection of All Persons from Being Subjected to Torture and Other Cruel, Inhuman or Degrading Treatment or Punishment

- Convention against Torture and Other Cruel, Inhuman or Degrading Treatment or Punishment (CAT)

- Optional Protocol to the Convention against Torture and Other Cruel, Inhuman or Degrading Treatment or Punishment (OPCAT)

- Principles of Medical Ethics relevant to the Role of Health Personnel, particularly Physicians, in the Protection of Prisoners and Detainees against Torture and Other Cruel, Inhuman or Degrading Treatment or Punishment

- Principles on the Effective Investigation and Documentation of Torture and Other Cruel, Inhuman or Degrading Treatment or Punishment

- Safeguards guaranteeing protection of the rights of those facing the death penalty

- Code of Conduct for Law Enforcement Officials

- Basic Principles on the Use of Force and Firearms by Law Enforcement Officials

- United Nations Standard Minimum Rules for Non-custodial Measures (The Tokyo Rules)

- United Nations Standard Minimum Rules for the Administration of Juvenile Justice (The Beijing Rules)

- Guidelines for Action on Children in the Criminal Justice System

- United Nations Guidelines for the Prevention of Juvenile Delinquency (The Riyadh Guidelines)

- Declaration of Basic Principles of Justice for Victims of Crime and Abuse of Power

- Basic Principles on the Independence of the Judiciary

- Basic Principles on the Role of Lawyers

- Guidelines on the Role of Prosecutors 
- Principles on the Effective Prevention and Investigation of Extra-legal, Arbitrary and Summary Executions

- Declaration on the Protection of All Persons from Enforced Disappearance

- Basic Principles and Guidelines on the Right to a Remedy and Reparation

- International Convention for the Protection of All Persons from Enforced Disappearance (not yet into force)

\section{SOCIAL WELFARE, PROGRESS AND DEVELOPMENT}

- Declaration on Social Progress and Development

- Universal Declaration on the Eradication of Hunger and Malnutrition

- Declaration on the Use of Scientific and Technological Progress in the Interests of Peace and for the Benefit of Mankind

- Declaration on the Right of Peoples to Peace

- Declaration on the Right to Development

- Universal Declaration on the Human Genome and Human Rights

- Universal Declaration on Cultural Diversity

\section{PROMOTION AND PROTECTION OF HUMAN RIGHTS}

- Principles relating to the status of national institutions (The Paris Principles)

- Declaration on the Right and Responsibility of Individuals, Groups and Organs of Society to Promote and Protect Universally Recognized Human Rights and Fundamental Freedoms

\section{MARRIAGE}

- Convention on Consent to Marriage, Minimum Age for Marriage and Registration of Marriages

- Recommendation on Consent to Marriage, Minimum Age for Marriage and Registration of Marriages

\section{RIGHT TO HEALTH}

- Declaration of Commitment on HIV/AIDS

\section{RIGHT TO WORK AND TO FAIR CONDITIONS OF EMPLOYMENT}

- Employment Policy Convention, 1964 (No. 122)

\section{FREEDOM OF ASSOCIATION}

- Freedom of Association and Protection of the Right to Organise Convention, 1948 (No. 87)

- $\quad$ Right to Organise and Collective Bargaining Convention, 1949 (No. 98) 


\section{SLAVERY, SLAVERY-LIKE PRACTICES AND FORCED LABOUR}

- Slavery Convention

- $\quad$ Protocol amending the Slavery Convention signed at Geneva on 25 September 1926

- Supplementary Convention on the Abolition of Slavery, the Slave Trade, and Institutions and Practices Similar to Slavery

- $\quad$ Forced Labour Convention, 1930 (No. 29)

- $\quad$ Abolition of Forced Labour Convention, 1957 (No. 105)

- Convention for the Suppression of the Traffic in Persons and of the Exploitation of the Prostitution of Others

- Protocol to Prevent, Suppress and Punish Trafficking in Persons, Especially Women and Children, supplementing the United Nations Convention against Transnational Organized Crime

\section{RIGHTS OF MIGRANTS}

- International Convention on the Protection of the Rights of All Migrant Workers and Members of Their Families (ICPMW)

- Protocol against the Smuggling of Migrants by Land, Sea and Air, supplementing the United Nations Convention against Transnational Organized Crime

\section{NATIONALITY, STATELESSNESS, ASYLUM AND REFUGEES}

- Convention on the Reduction of Statelessness

- Convention relating to the Status of Stateless Persons

- Convention relating to the Status of Refugees

- Protocol relating to the Status of Refugees

- Declaration on the Human Rights of Individuals Who are not Nationals of the Country in which They Live

\section{WAR CRIMES AND CRIMES AGAINST HUMANITY, INCLUDING GENOCIDE}

- Convention on the Prevention and Punishment of the Crime of Genocide

- Convention on the Non-Applicability of Statutory Limitations to War Crimes and Crimes against Humanity

- Principles of international co-operation in the detection, arrest, extradition and punishment of persons guilty of war crimes and crimes against humanity

- Statute of the International Tribunal for the Former Yugoslavia

- $\quad$ Statute of the International Tribunal for Rwanda

- $\quad$ Rome Statute of the International Criminal Court 


\section{HUMANITARIAN LAW}

- Geneva Convention relative to the Treatment of Prisoners of War

- Geneva Convention relative to the Protection of Civilian Persons in Time of War

- Protocol Additional to the Geneva Conventions of 12 August 1949, and relating to the Protection of Victims of International Armed Conflicts (Protocol I)

- Protocol Additional to the Geneva Conventions of 12 August 1949, and relating to the Protection of Victims of Non-International Armed Conflicts (Protocol II)

\section{Also available:}

- Ratifications and Reservations

- Status of ratifications of human rights treaties

- CD Compilation of International instruments - Universal instruments

- Conventions, Declarations and Other Instruments Found in General Assembly Resolutions (since 1946)

FONTE: ComDHsNU. Universal Human Rights Instruments. Disponível no site: $<$ http:// www2.ohchr.org/english/law/index.htm>. Acesso em: 07 set. 2009. 


\section{ANEXO F - Estrutura da Corte Internacional de Justiça (CIJ)}

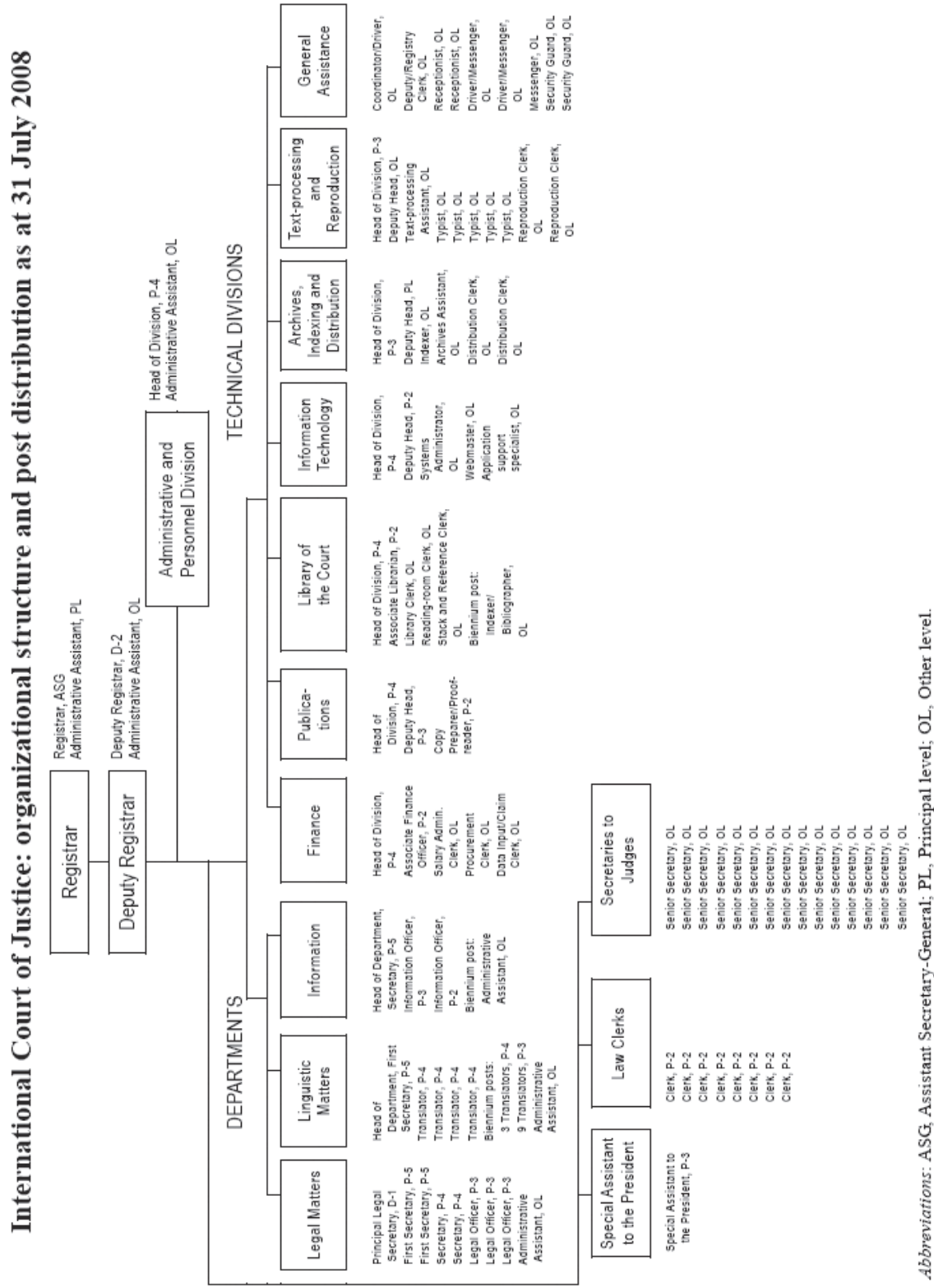

FONTE: CIJ. International Court of Justice: organizational structure and post distribution as at 31 July 2008. Disponivel no site: <http://www.icj-cij.org/court/en/reports/report_2007-2008. pdf $>$. Acesso em: 07 set. 2009. 


\section{ANEXO G - ESTATÍSTICAS DE PETIÇÕES INDIVIDUAIS PERANTE O} CRHNU

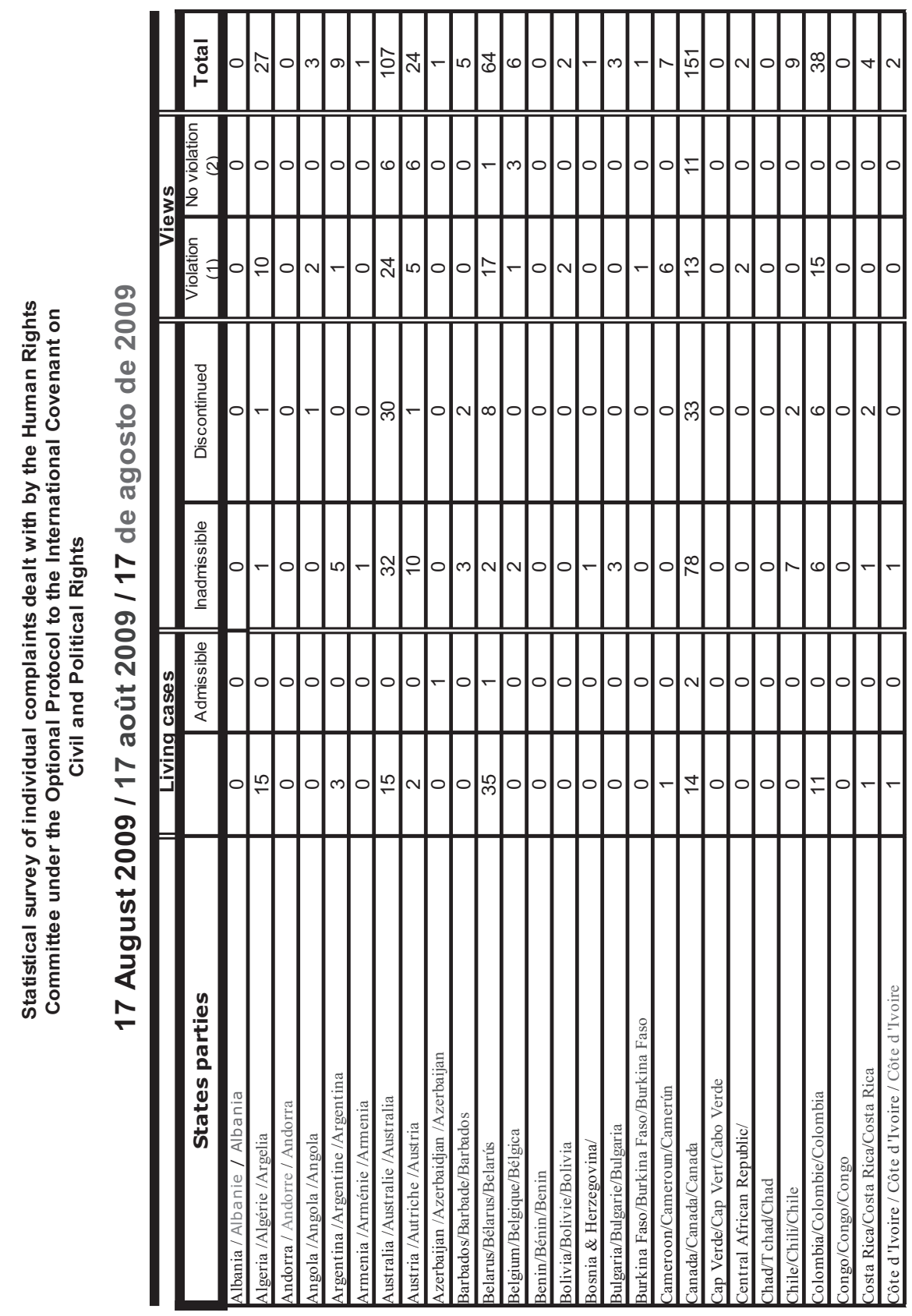




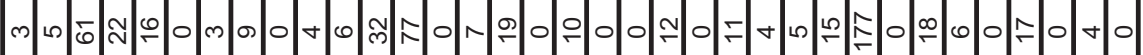

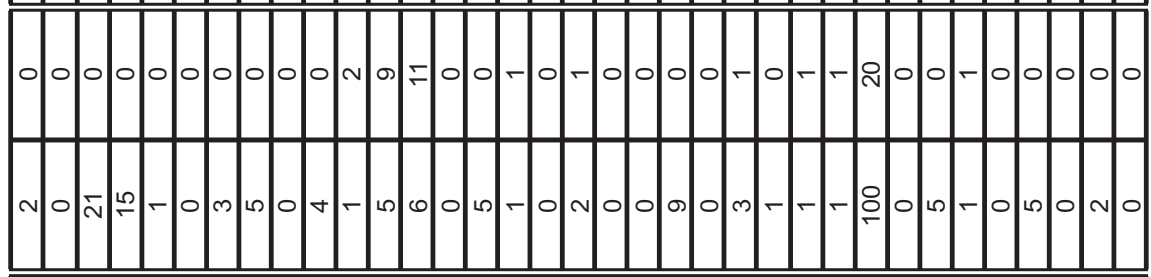

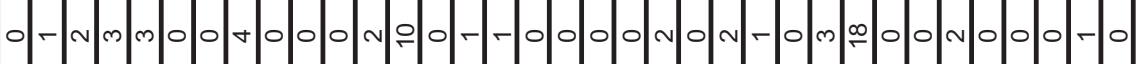

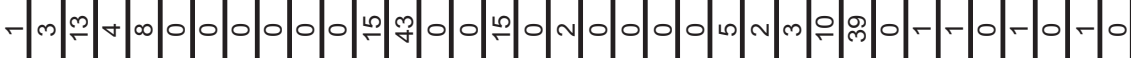

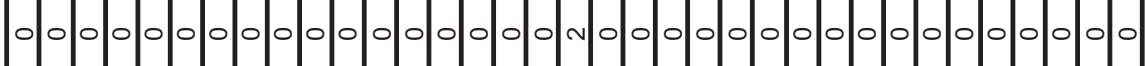

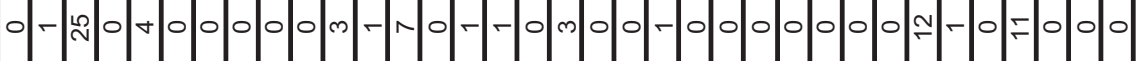

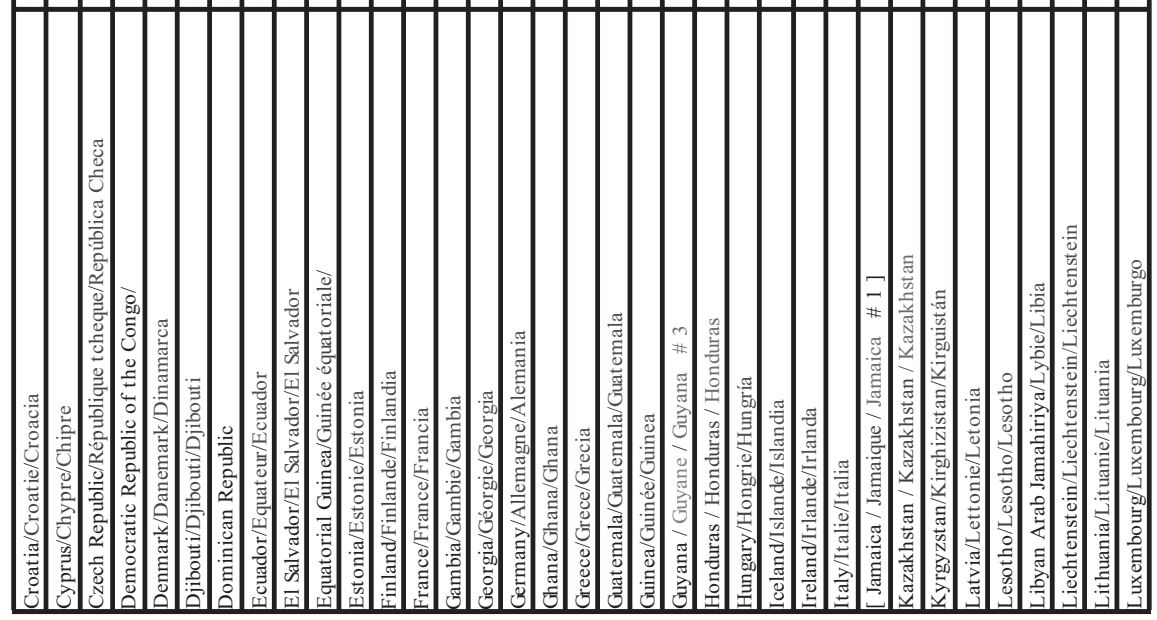




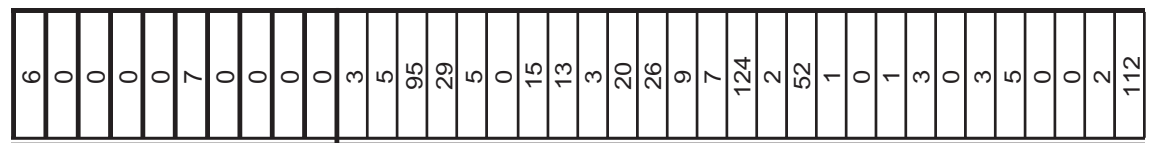

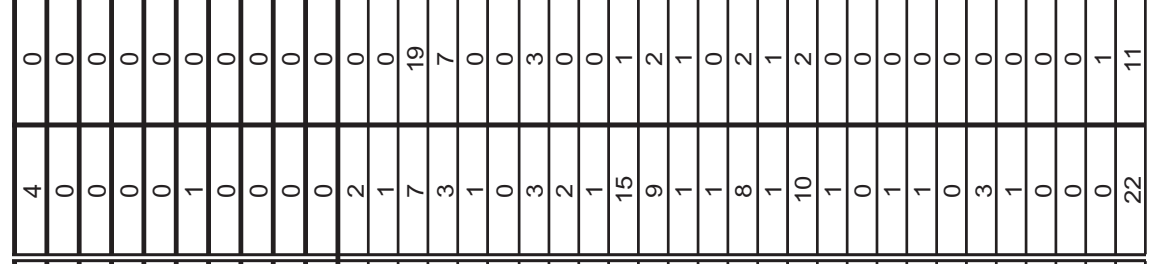

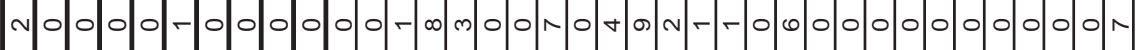
\begin{tabular}{|l}
0.0 \\
0
\end{tabular}

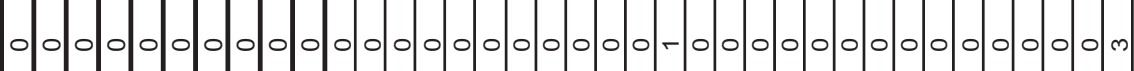

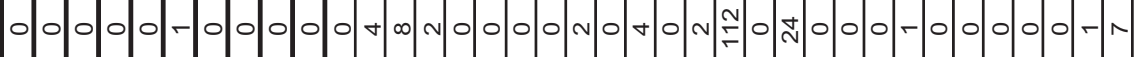

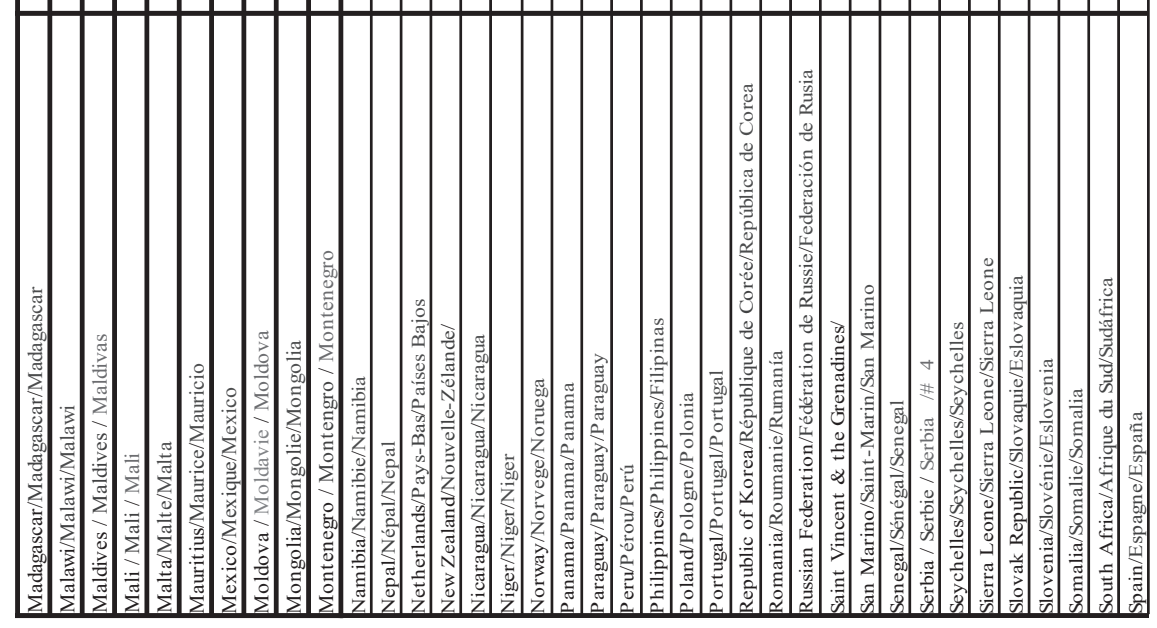




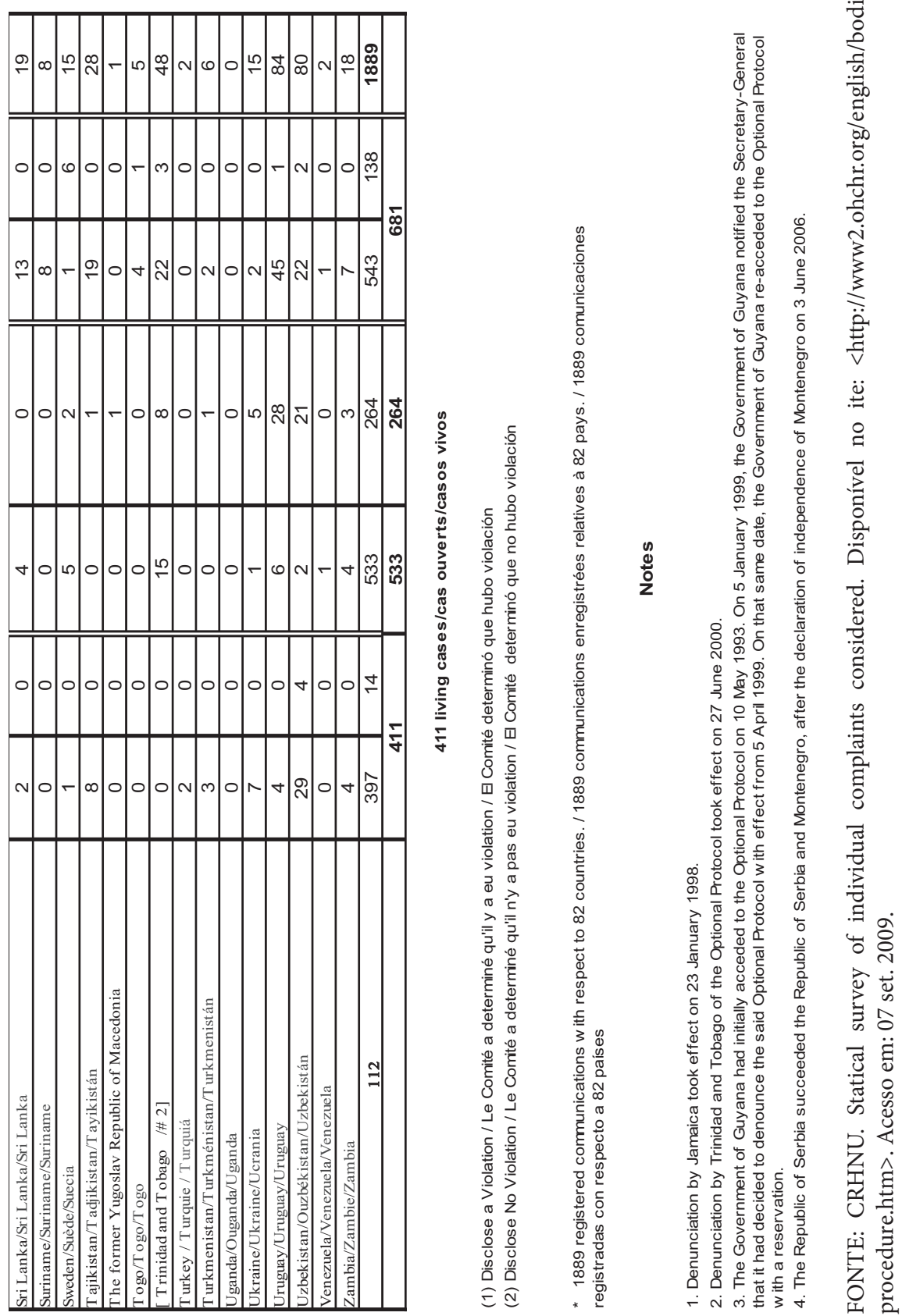




\section{ANEXO H - Primeiro protocolo adicional da Convenção Internacional de Direitos Civis e Políticos (PIDCP)}

\section{OPTIONAL PROTOCOL TO THE INTERNATIONAL COVENANT ON CIVIL AND POLITICAL RIGHTS}

Adopted and opened for signature, ratification and accession by General Assembly resolution 2200A (XXI) of 16 December 1966 entry into force 23 March 1976, in accordance with Article 9

\section{The States Parties to the present Protocol,}

Considering that in order further to achieve the purposes of the International Covenant on Civil and Political Rights (hereinafter referred to as the Covenant) and the implemenation of its provisions it would be appropriate to enable the Human Rights Committee set up in part IV of the Covenant (hereinafter referred to as the Committee) to receive and consider, as provided in the present Protocol, communications from individuals claiming to be victims of violations of any of the rights set forth in the Covenant.

Have agreed as follows:

Article 1

A State Party to the Covenant that becomes a Party to the present Protocol recognizes the competence of the Committee to receive and consider communications from individuals subject to its jurisdiction who claim to be victims of a violation by that State Party of any of the rights set forth in the Covenant. No communication shall be received by the Committee if it concerns a State Party to the Covenant which is not a Party to the present Protocol.

Article 2

Subject to the provisions of article 1, individuals who claim that any of their rights enumerated in the Covenant have been violated and who have exhausted all available domestic remedies may submit a written communication to the Committee for consideration.

Article 3

The Committee shall consider inadmissible any communciation under the present Protocol which is anonymous, or which it considers to be an abuse 
of the right of submission of such communications or to be incompatible with the provisions of the Covenant.

\section{Article 4}

1. Subject to the provisions of article 3, the Committee shall bring any communications submitted to it under the present Protocol to the attention of the State Party to the present Protocol alleged to be violating any provision of the Covenant.

2. Within six months, the receiving State shall submit to the Committee written explanations or statements clarifying the matter and the remedy, if any, that may have been taken by that State.

\section{Article 5}

1. The Committee shall consider communications received under the present Protocol in the light of all written information made available to it by the individual and by the State Party concerned.

2. The Committee shall not consider any communication from an individual unless it has ascertained that:

(a) The same matter is not being examined under another procedure of international investigation or settlement;

(b) The individual has exhausted all available domestic remedies. This shall not be the rule where the application of the remedies is unreasonably prolonged.

3. The Committee shall hold closed meetings when examining communications under the present Protocol.

4. The Committee shall forward its views to the State Party concerned and to the individual.

Article 6

The Committee shall include in its annual report under article 45 of the Covenant a summary of its activities under the present Protocol.

Article 7

Pending the achievement of the objectives of resolution 1514(XV) adopted by the General Assembly of the United Nations on 14 December 1960 con- 
cerning the Declaration on the Granting of Independence to Colonial Countries and Peoples, the provisions of the present Protocol shall in no way limit the right of petition granted to these peoples by the Charter of the United Nations and other international conventions and instruments under the United Nations and its specialized agencies.

\section{Article 8}

1. The present Protocol is open for signature by any State which has signed the Covenant.

2. The present Protocol is subject to ratification by any State which has ratified or acceded to the Covenant. Instruments of ratification shall be deposited with the Secretary-General of the United Nations.

3. The present Protocol shall be open to accession by any State which has ratified or acceded to the Covenant.

4. Accession shall be effected by the deposit of an instrument of accession with the Secretary-General of the United Nations.

5. The Secretary-General of the United Nations shall inform all States which have signed the present Protocol or acceded to it of the deposit of each instrument of ratification or accession.

Article 9

1. Subject to the entry into force of the Covenant, the present Protocol shall enter into force three months after the date of the deposit with the Secretary-General of the United Nations of the tenth instrument of ratification or instrument of accession.

2. For each State ratifying the present Protocol or acceding to it after the deposit of the tenth instrument of ratification or instrument of accession, the present Protocol shall enter into force three months after the date of the deposit of its own instrument of ratification or instrument of accession.

Article 10

The provisions of the present Protocol shall extend to all parts of federal States without any limitations or exceptions. 
Article 11

1. Any State Party to the present Protocol may propose an amendment and file it with the Secretary-General of the United Nations. The Secretary-General shall thereupon communicate any proposed amendments to the States Parties to the present Protocol with a request that they notify him whether they favour a conference of States Parties for the purpose of considering and voting upon the proposal. In the event that at least one third of the States Parties favours such a conference, the Secretary-General shall convene the conference under the auspices of the United Nations. Any amendment adopted by a majority of the States Parties present and voting at the conference shall be submitted to the General Assembly of the United Nations for approval.

2. Amendments shall come into force when they have been approved by the General Assembly of the United Nations and accepted by a two-thirds majority of the States Parties to the present Protocol in accordance with their respective constitutional processes.

3. When amendments come into force, they shall be binding on those States Parties which have accepted them, other States Parties still being bound by the provisions of the present Protocol and any earlier amendment which they have accepted.

\section{Article 12}

1. Any State Party may denounce the present Protocol at any time by written notification addressed to the Secretary-General of the United Nations. Denunciation shall take effect three months after the date of receipt of the notification by the Secretary-General.

2. Denunciation shall be without prejudice to the continued application of the provisions of the present Protocol to any communication submitted under article 2 before the effective date of denunciation.

\section{Article 13}

Irrespective of the notifications made under article 8, paragraph 5, of the present Protocol, the Secretary-General of the United Nations shall inform 
all States referred to in article 48, paragraph I, of the Covenant of the following particulars:

(a) Signatures, ratifications and accessions under article 8;

(b) The date of the entry into force of the present Protocol under article 9 and the date of the entry into force of any amendments under article 11;

(c) Denunciations under article 12 .

Article 14

1. The present Protocol, of which the Chinese, English, French, Russian and Spanish texts are equally authentic, shall be deposited in the archives of the United Nations.

2. The Secretary-General of the United Nations shall transmit certified copies of the present Protocol to all States referred to in article 48 of the Covenant.

FONTE: ComDHsNU. Optional Protocol to the International Covenant on Civil and Political Rights. Disponível no site: <http://www2.ohchr.org/english/law/ccpr-one.htm>. Acesso em: 07 set. 2009.

\section{ANEXO I - Modelo padrão de petição individual perante o CEDMNU MODEL FORM FOR SUBMISSION OF COMMUNICATIONS TO THE COMMITTEE ON THE ELIMINATION OF DISCRIMINATION AGAINST WOMEN UNDER THE OPTIONAL PROTOCOL OF THE CONVENTION}

The Optional Protocol to the Convention on the Elimination of All Forms of Discrimination against Women entered into force on 22 December 2000. It entitles the Committee on the Elimination of Discrimination against Women, a body of 23 independent experts, to receive and consider communications (petitions) from, or on behalf of, individuals or a group of individuals who claim to be victims ofviolations of the rights protected by the Convention.

To be considered by the Committee, a communication:

- must be in writing;

- may not be anonymous;

- must refer to a State which is a party to both the Convention on the Elimination of All Forms of 
Discrimination against Women and the Optional Protocol;

- must be submitted by, or on behalf of, an individual or a group of individuals under the jurisdiction of a State which is a party to the Convention and the Optional Protocol. In cases where a communication is submitted on behalf of an individual or a group of individuals, their consent is necessary unless the person submitting the communication can justify acting on their behalf without such consent.

A communication will not normally be considered by the Committee:

- unless all available domestic remedies have been exhausted;

- where the same matter is being or has already been examined by the Committee or another international procedure;

- if it concerns an alleged violation occurring before the entry into force of the Optional Protocol for the State.

In order for a communication to be considered the victim or victims must agree to disclose her/their identity to the State against which the violation is alleged. The communication, if admissible, will be brought confidentially to the attention of the State party concerned.

If you wish to submit a communication, please follow the guidelines below as closely as possible. Also, please submit any relevant information which becomes available after you have submitted this form.

Further information on the Convention on the Elimination of All Forms of Discrimination against Women and its Optional Protocol, as well as the rules of procedure of the Committee can be found at:

http://www.un.org/womenwatch/daw/cedaw/index.html 


\section{Guidelines for submission}

The following questionnaire provides a guideline for those who wish to submit a communication for consideration by the Committee on the Elimination of Discrimination against Women under the Optional Protocol to the Convention on the Elimination of All Forms of Discrimination against Women. Please provide as much information as available in response to the items listed below.

\section{Send your communication to:}

Committee on the Elimination of Discrimination against Women c/o Division for the Advancement of Women, Department of Economic and Social Affairs United Nations Secretariat

2 United Nations Plaza

DC-2/12th Floor

New York, NY 10017

United States of America

Fax: 1-212-963-3463

1. Information concerning the author(s) of the communication

- Family name

- First name

- Date and place of birth

- Nationality/citizenship

- Passport/identity card number (if available)

- Sex

- Marital status/children

- Profession

- Ethnic background, religious affiliation, social group (if relevant)

- Present address

- Mailing address for confidential correspondence (if other than present address)

- Fax/telephone/e-mail

- Indicate whether you are submitting the communication as: 
- Alleged victim(s). If there is a group of individuals alleged to be victims, rovide basic information about each individual.

- On behalf of the alleged victim(s). Provide evidence showing the consent of the victim(s), or reasons that justify submitting the communication without such consent.

2. Information concerning the alleged victim(s) (if other than the author)

- Family name

- First name

- Date and place of birth

- Nationality/citizenship

- Passport/identity card number (if available)

- Sex

- Marital status/children

- Profession

- Ethnic background, religious affiliation, social group (if relevant)

- Present address

- Mailing address for confidential correspondence (if other than present address)

- Fax/telephone/e-mail

3. Information on the State party concerned

- Name of the State party (country)

4. Nature of the alleged violation(s)

Provide detailed information to substantiate your claim, including:

- Description of alleged violation(s) and alleged perpetrator(s)

- Date(s)

- Place(s)

- Provisions of the Convention on the Elimination of All Forms of Discrimination against Women that were allegedly violated. If the communication refers to more than one provision, describe each issue separately. 
5. Steps taken to exhaust domestic remedies

Describe the action taken to exhaust domestic remedies; for example, attempts to obtain legal, administrative, legislative, policy or programme remedies, including:

- Type(s) of remedy sought

- Date(s)

- $\operatorname{Place}(\mathrm{s})$

- Who initiated the action

- Which authority or body was addressed

- Name of court hearing the case (if any)

- If domestic remedies have not been exhausted, explain why.

Please note : Enclose copies of all relevant documentation.

6. Other international procedures

Has the same matter already been examined or is it being examined under another procedure of international investigation or settlement? If yes, explain:

- Type of procedure(s)

- $\operatorname{Date}(\mathrm{s})$

- Place(s)

- Results (if any)

Please note: Enclose copies of all relevant documentation.

7. Date and signature

Date/place:

Signature of author(s) and/or victim(s):

8. List of documents attached (do not send originals, only copies)

FONTE: CEDMNU. Model Comunication Form. Disponível no site: <http://www.un.org/ womenwatch/daw/cedaw/opmodelform.html>. Acesso em: 07 set. 2009. 


\section{ANEXO J - Protocolo facultativo à Convenção sobre a eliminação de todas as formas de discriminação contra mulheres de 1979}

Optional Protocol to the Convention on the Elimination of All Forms of Discrimination against Women The States Parties to the present Protocol, Noting that the Charter of the United Nations reaffirms faith in fundamental human rights, in the dignity and worth of the human person and in the equal rights of men and women, Also noting that the Universal Declaration of Human Rights5 proclaims that all human beings are born free and equal in dignity and rights and that everyone is entitled to all the rights and freedoms set forth therein, without distinction of any kind, including distinction based on sex, Recalling that the International Covenants on Human Rights6 and other international human rights instruments prohibit discrimination on the basis of sex, Also recalling the Convention on the Elimination of All Forms of Discrimination against Women4 ("the Convention"), in which the States Parties thereto condemn discrimination against women in all its forms and agree to pursue by all appropriate means and without delay a policy of eliminating discrimination against women, Reaffirming their determination to ensure the full and equal enjoyment by women of all human rights and fundamental freedoms and to take effective action to prevent violations of these rights and freedoms, Have agreed as follows:

Article 1

A State Party to the present Protocol ("State Party") recognizes the competence of the Committee on the Elimination of Discrimination against Women ("the Committee") to receive and consider communications submitted in accordance with article 2 .

Article 2

Communications may be submitted by or on behalf of individuals or groups of individuals, under the jurisdiction of a State Party, claiming to be victims of a violation of any of the rights set forth in the Convention by that State Party. Where a communication is submitted on behalf of individuals or groups of individuals, this shall be with their consent unless the author can justify acting on their behalf without such consent. 
Article 3

Communications shall be in writing and shall not be anonymous. No communication shall be received by the Committee if it concerns a State Party to the Convention that is not a party to the present Protocol.

\section{Article 4}

1. The Committee shall not consider a communication unless it has ascertained that all available domestic remedies have been exhausted unless the application of such remedies is unreasonably prolonged or unlikely to bring effective relief.

2. The Committee shall declare a communication inadmissible where:

(a) The same matter has already been examined by the Committee or has been or is being examined under another procedure of international investigation or settlement;

(b) It is incompatible with the provisions of the Convention;

(c) It is manifestly ill-founded or not sufficiently substantiated;

(d) It is an abuse of the right to submit a communication;

(e) The facts that are the subject of the communication occurred prior to the entry into force of the present Protocol for the State Party concerned unless those facts continued after that date.

\section{Article 5}

1. At any time after the receipt of a communication and before a determination on the merits has been reached, the Committee may transmit to the State Party concerned for its urgent consideration a request that the State Party take such interim measures as may be necessary to avoid possible irreparable damage to the victim or victims of the alleged violation.

2. Where the Committee exercises its discretion under paragraph 1 of the present article, this does not imply a determination on admissibility or on the merits of the communication. 
Article 6

1. Unless the Committee considers a communication inadmissible without reference to the State Party concerned, and provided that the individual or individuals consent to the disclosure of their identity to that State Party, the Committee shall bring any communication submitted to it under the present Protocol confidentially to the attention of the State Party concerned.

2. Within six months, the receiving State Party shall submit to the Committee written explanations or statements clarifying the matter and the remedy, if any, that may have been provided by that State Party.

\section{Article 7}

1. The Committee shall consider communications received under the present Protocol in the light of all information made available to it by or on behalf of individuals or groups of individuals and by the State Party concerned, provided that this information is transmitted to the parties concerned.

2. The Committee shall hold closed meetings when examining communications under the present Protocol.

3. After examining a communication, the Committee shall transmit its views on the communication, together with its recommendations, if any, to the parties concerned.

4. The State Party shall give due consideration to the views of the Committee, together with its recommendations, if any, and shall submit to the Committee, within six months, a written response, including information on any action taken in the light of the views and recommendations of the Committee.

5. The Committee may invite the State Party to submit further information about any measures the State Party has taken in response to its views or recommendations, if any, including as deemed appropriate by the Committee, in the State Party's subsequent reports under article 18 of the Convention.

Article 8

1. If the Committee receives reliable information indicating grave or systematic violations by a State Party of rights set forth in the Convention, the Committee shall invite that State Party to cooperate in the examination of the information and to this end to submit observations with regard to the information concerned. 
2. Taking into account any observations that may have been submitted by the State Party concerned as well as any other reliable information available to it, the Committee may designate one or more of its members to conduct an inquiry and to report urgently to the Committee. Where warranted and with the consent of the State Party, the inquiry may include a visit to its territory.

3. After examining the findings of such an inquiry, the Committee shall transmit these findings to the State Party concerned together with any comments and recommendations.

4. The State Party concerned shall, within six months of receiving the findings, comments and recommendations transmitted by the Committee, submit its observations to the Committee.

5. Such an inquiry shall be conducted confidentially and the cooperation of the State Party shall be sought at all stages of the proceedings.

Article 9

1. The Committee may invite the State Party concerned to include in its report under article 18 of the Convention details of any measures taken in response to an inquiry conducted under article 8 of the present Protocol.

2. The Committee may, if necessary, after the end of the period of six months referred to in article 8.4, invite the State Party concerned to inform it of the measures taken in response to such an inquiry.

Article 10

1. Each State Party may, at the time of signature or ratification of the present Protocol or accession thereto, declare that it does not recognize the competence of the Committee provided for in articles 8 and 9.

2. Any State Party having made a declaration in accordance with paragraph 1 of the present article may, at any time, withdraw this declaration by notification to the Secretary-General.

Article 11

A State Party shall take all appropriate steps to ensure that individuals under its jurisdiction are not subjected to ill treatment or intimidation as a consequence of communicating with the Committee pursuant to the present Protocol. 
Article 12

The Committee shall include in its annual report under article 21 of the Convention a summary of its activities under the present Protocol.

Article 13

Each State Party undertakes to make widely known and to give publicity to the Convention and the present Protocol and to facilitate access to information about the views and recommendations of the Committee, in particular, on matters involving that State Party.

Article 14

The Committee shall develop its own rules of procedure to be followed when exercising the functions conferred on it by the present Protocol.

Article 15

1. The present Protocol shall be open for signature by any State that has signed, ratified or acceded to the Convention.

2. The present Protocol shall be subject to ratification by any State that has ratified or acceded to the Convention. Instruments of ratification shall be deposited with the Secretary-General of the United Nations.

3. The present Protocol shall be open to accession by any State that has ratified or acceded to the Convention.

4. Accession shall be effected by the deposit of an instrument of accession with the Secretary-General of the United Nations.

Article 16

1. The present Protocol shall enter into force three months after the date of the deposit with the Secretary-General of the United Nations of the tenth instrument of ratification or accession.

2. For each State ratifying the present Protocol or acceding to it after its entry into force, the present Protocol shall enter into force three months after the date of the deposit of its own instrument of ratification or accession. 
Article 17

No reservations to the present Protocol shall be permitted.

\section{Article 18}

1. Any State Party may propose an amendment to the present Protocol and file it with the Secretary-General of the United Nations. The Secretary-General shall thereupon communicate any proposed amendments to the States Parties with a request that they notify her or him whether they favour a conference of States Parties for the purpose of considering and voting on the proposal. In the event that at least one third of the States Parties favour such a conference, the Secretary-General shall convene the conference under the auspices of the United Nations. Any amendment adopted by a majority of the States Parties present and voting at the conference shall be submitted to the General Assembly of the United Nations for approval.

2. Amendments shall come into force when they have been approved by the General Assembly of the United Nations and accepted by a two-thirds majority of the States Parties to the present Protocol in accordance with their respective constitutional processes.

3. When amendments come into force, they shall be binding on those States Parties that have accepted them, other States Parties still being bound by the provisions of the present Protocol and any earlier amendments that they have accepted.

\section{Article 19}

1. Any State Party may denounce the present Protocol at any time by written notification addressed to the Secretary-General of the United Nations. Denunciation shall take effect six months after the date of receipt of the notification by the Secretary-General.

2. Denunciation shall be without prejudice to the continued application of the provisions of the present Protocol to any communication submitted under article 2 or any inquiry initiated under article 8 before the effective date of denunciation. 
Article 20

The Secretary-General of the United Nations shall inform all States of:

(a) Signatures, ratifications and accessions under the present Protocol;

(b) The date of entry into force of the present Protocol and of any amendment under article 18;

(c) Any denunciation under article 19.

Article 21

1. The present Protocol, of which the Arabic, Chinese, English, French, Russian and Spanish texts are equally authentic, shall be deposited in the archives of the United Nations.

2. The Secretary-General of the United Nations shall transmit certified copies of the present Protocol to all States referred to in article 25 of the Convention.

FONTE: CEDMNU. Optional Protocol to the Convention on the Elimination of All Forms of Discrimination against Women. Disponvível no site: <http://www.un.org/womenwatch/ daw/cedaw/protocol/text.htm>. Acesso em: 07 set. 2009. 


\section{ANEXO K - Estatísticas do CTNU}

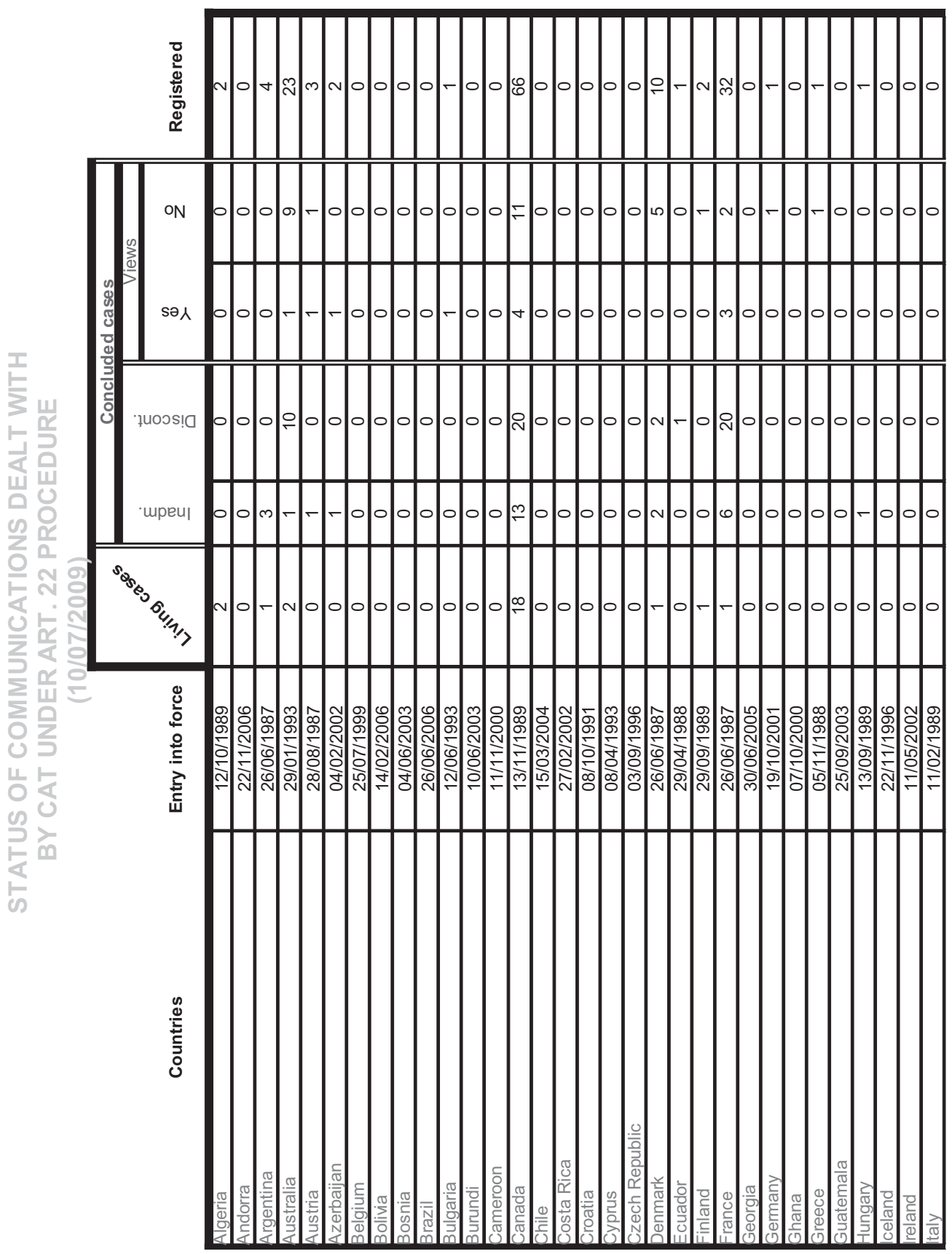



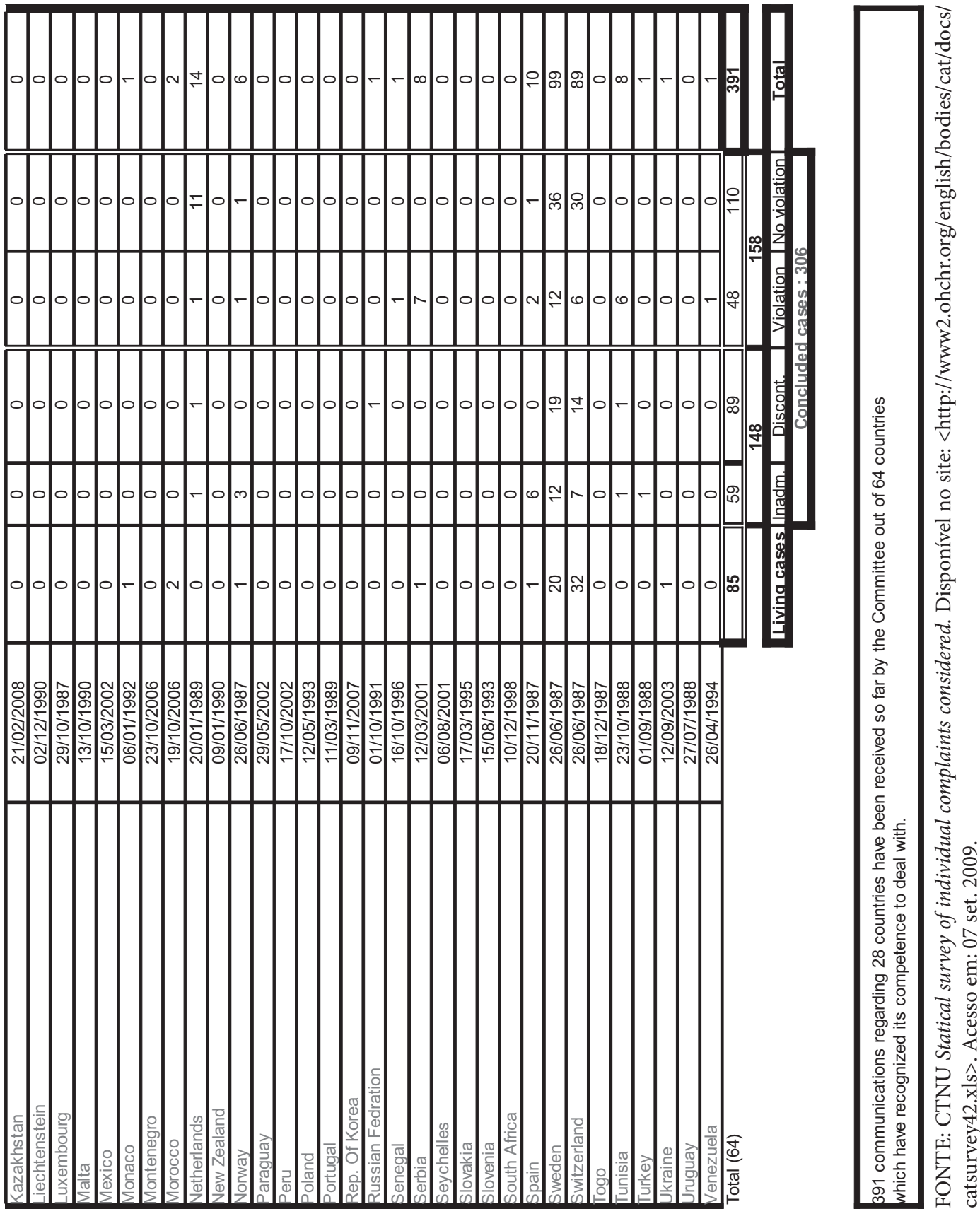

ర్రి:

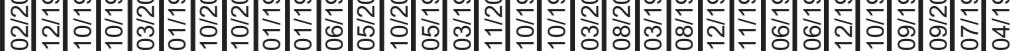

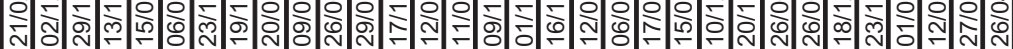

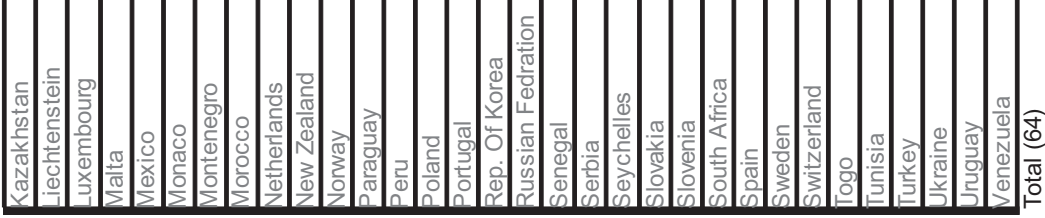




\section{ANEXO L - Art. 22 da Convenção contra tortura}

Article 22

1. A State Party to this Convention may at any time declare under this article that it recognizes the competence of the Committee to receive and consider communications from or on behalf of individuals subject to its jurisdiction who claim to be victims of a violation by a State Party of the provisions of the Convention. No communication shall be received by the Committee if it concerns a State Party which has not made such a declaration.

2. The Committee shall consider inadmissible any communication under this article which is anonymous or which it considers to be an abuse of the right of submission of such communications or to be incompatible with the provisions of this Convention.

3. Subject to the provisions of paragraph 2, the Committee shall bring any communications submitted to it under this article to the attention of the State Party to this Convention which has made a declaration under paragraph I and is alleged to be violating any provisions of the Convention. Within six months, the receiving State shall submit to the Committee written explanations or statements clarifying the matter and the remedy, if any, that may have been taken by that State.

4. The Committee shall consider communications received under this article in the light of all information made available to it by or on behalf of the individual and by the State Party concerned. 5. The Committee shall not consider any communications from an individual under this article unless it has ascertained that:

(a) The same matter has not been, and is not being, examined under another procedure of international investigation or settlement;

(b) The individual has exhausted all available domestic remedies; this shall not be the rule where the application of the remedies is unreasonably prolonged or is unlikely to bring effective reliefto the person who is the victim of the violation of this Convention.

5. The Committee shall hold closed meetings when examining communications under this article. 
6. The Committee shall forward its views to the State Party concerned and to the individual.

7. The provisions of this article shall come into force when five States Parties to this Convention have made declarations under paragraph 1 of this article. Such declarations shall be deposited by the States Parties with the SecretaryGeneral of the United Nations, who shall transmit copies thereof to the other States Parties. A declaration may be withdrawn at any time by notification to the Secretary-General. Such a withdrawal shall not prejudice the consideration of any matter which is the subject of a communication already transmitted under this article; no further communication by or on behalf of an individual shall be received under this article after the notification of withdrawal of the declaration has been received by the SecretaryGeneral, unless the State Party has made a new declaration.

FONTE: CTNU. Article 22 of the Convention against Torture and Other Cruel, Inhuman or Degrading Treatment or Punishment. Disponível no site: <http://www2.ohchr.org/ english/law/cat.htm>. Acesso em: 07 set. 2009. 


\section{ANEXO M - Estatísticas do CEDRNU}

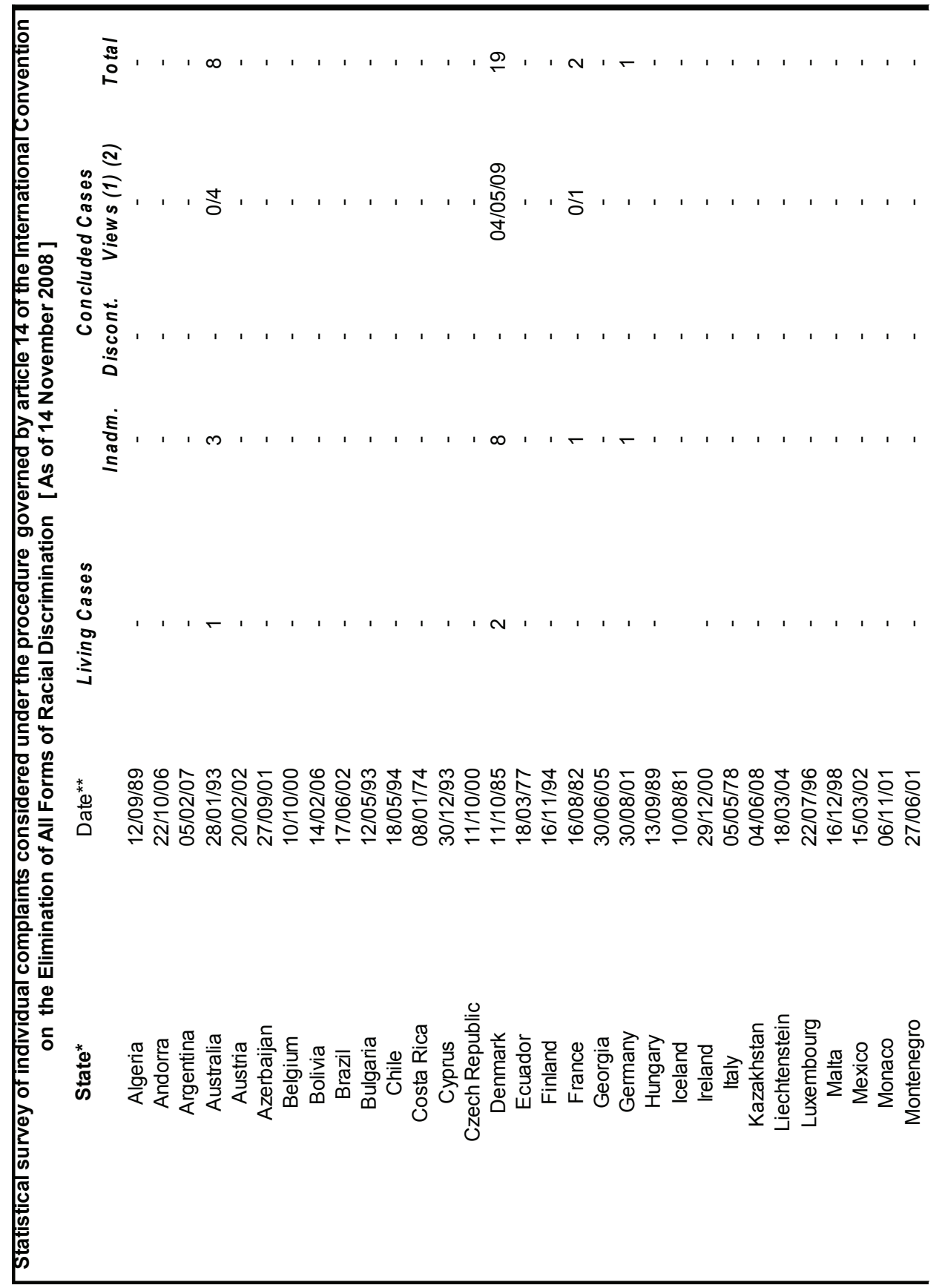




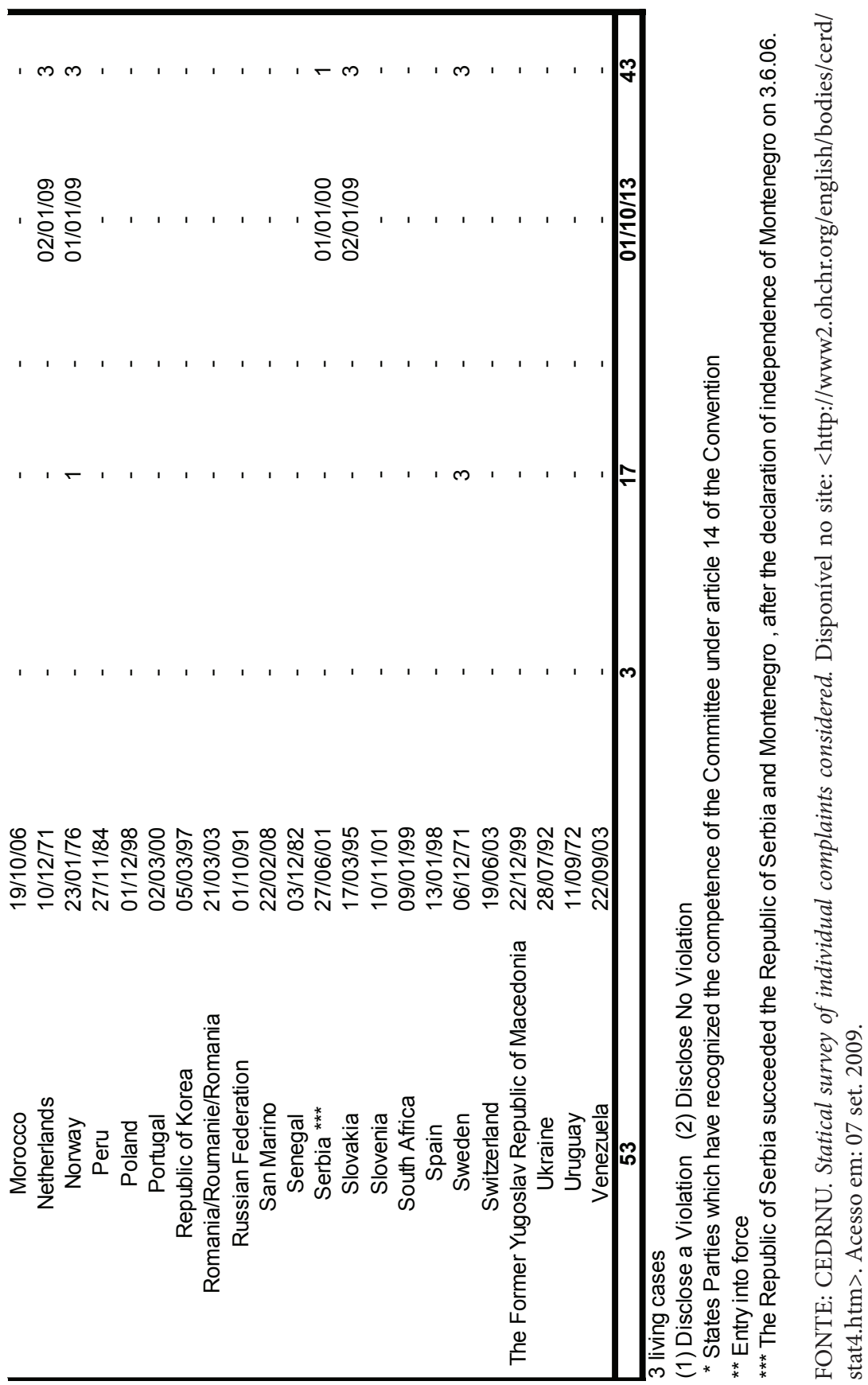




\section{ANEXON-Art. 14 da Convenção sobre a eliminação da discriminação racial}

Article 14

1. A State Party may at any time declare that it recognizes the competence of the Committee to receive and consider communications from individuals or groups of individuals within its jurisdiction claiming to be victims of a violation by that State Party of any of the rights set forth in this Convention. No communication shall be received by the Committee if it concerns a State Party which has not made such a declaration.

2. Any State Party which makes a declaration as provided for in paragraph I of this article may establish or indicate a body within its national legal order which shall be competent to receive and consider petitions from individuals and groups of individuals within its jurisdiction who claim to be victims of a violation of any of the rights set forth in this Convention and who have exhausted other available local remedies.

3. A declaration made in accordance with paragraph 1 of this article and the name of any body established or indicated in accordance with paragraph 2 of this article shall be deposited by the State Party concerned with the Secretary-General of the United Nations, who shall transmit copies thereof to the other States Parties. A declaration may be withdrawn at any time by notification to the Secretary-General, but such a withdrawal shall not affect communications pending before the Committee.

4. A register of petitions shall be kept by the body established or indicated in accordance with paragraph 2 of this article, and certified copies of the register shall be filed annually through appropriate channels with the Secretary-General on the understanding that the contents shall not be publicly disclosed.

5. In the event of failure to obtain satisfaction from the body established or indicated in accordance with paragraph 2 of this article, the petitioner shall have the right to communicate the matter to the Committee within six months.

6.

(a) The Committee shall confidentially bring any communication referred to it to the attention of the State Party alleged to be 
violating any provision of this Convention, but the identity of the individual or groups of individuals concerned shall not be revealed without his or their express consent. The Committee shall not receive anonymous communications;

(b) Within three months, the receiving State shall submit to the Committee written explanations or statements clarifying the matter and the remedy, if any, that may have been taken by that State.

7.

(a) The Committee shall consider communications in the light of all information made available to it by the State Party concerned and by the petitioner. The Committee shall not consider any communication from a petitioner unless it has ascertained that the petitioner has exhausted all available domestic remedies. However, this shall not be the rule where the application of the remedies is unreasonably prolonged;

(b) The Committee shall forward its suggestions and recommendations, if any, to the State Party concerned and to the petitioner.

8. The Committee shall include in its annual report a summary of such communications and, where appropriate, a summary of the explanations and statements of the States Parties concerned and of its own suggestions and recommendations.

9. The Committee shall be competent to exercise the functions provided for in this article only when at least ten States Parties to this Convention are bound by declarations in accordance with paragraph I of this article.

FONTE: CEDRNU. Article 14 of the International Convention on the Elimination of All Forms of Racial Discrimination. Disponível no site: <http://www2.ohchr.org/english/law/ cerd.htm>. Acesso em: 07 set. 2009. 


\section{ANEXO 0 - Protocolo adicional à convenção sobre direito das pessoas com deficiência}

\section{Optional Protocol to the Convention on the Rights of Persons with Disabilities}

The States Parties to the present Protocol have agreed as follows:

Article 1

1. A State Party to the present Protocol ("State Party") recognizes the competence of the Committee on the Rights of Persons with Disabilities ("the Committee") to receive and consider communications from or on behalf of individuals or groups of individuals subject to its jurisdiction who claim to be victims of a violation by that State Party of the provisions of the Convention.

2. No communication shall be received by the Committee if it concerns a State Party to the Convention that is not a party to the present Protocol.

Article 2

The Committee shall consider a communication inadmissible when:

(a) The communication is anonymous;

(b) The communication constitutes an abuse of the right of submission of such communications or is incompatible with the provisions of the Convention;

(c) The same matter has already been examined by the Committee or has been or is being examined under another procedure of international investigation or settlement;

(d) All available domestic remedies have not been exhausted. This shall not be the rule where the application of the remedies is unreasonably prolonged or unlikely to bring effective relief;

(e) It is manifestly ill-founded or not sufficiently substantiated; or when

(f) The facts that are the subject of the communication occurred prior to the entry into force of the present Protocol for the State Party concerned unless those facts continued after that date. 
Article 3

Subject to the provisions of article 2 of the present Protocol, the Committee shall bring any communications submitted to it confidentially to the attention of the State Party. Within six months, the receiving State shall submit to the Committee written explanations or statements clarifying the matter and the remedy, if any, that may have been taken by that State.

Article 4

1. At any time after the receipt of a communication and before a determination on the merits has been reached, the Committee may transmit to the State Party concerned for its urgent consideration a request that the State Party take such interim measures as may be necessary to avoid possible irreparable damage to the victim or victims of the alleged violation.

2. Where the Committee exercises its discretion under paragraph 1 of this article, this does not imply a determination on admissibility or on the merits of the communication.

Article 5

The Committee shall hold closed meetings when examining communications under the present Protocol. After examining a communication, the Committee shall forward its suggestions and recommendations, if any, to the State Party concerned and to the petitioner.

Article 6

1. If the Committee receives reliable information indicating grave or systematic violations by a State Party of rights set forth in the Convention, the Committee shall invite that State Party to cooperate in the examination of the information and to this end submit observations with regard to the information concerned.

2. Taking into account any observations that may have been submitted by the State Party concerned as well as any other reliable information available to it, the Committee may designate one or more of its members to conduct an inquiry and to report urgently to the Committee. Where warranted and with the consent of the State Party, the inquiry may include a visit to its territory. 
3. After examining the findings of such an inquiry, the Committee shall transmit these findings to the State Party concerned together with any comments and recommendations.

4. The State Party concerned shall, within six months of receiving the findings, comments and recommendations transmitted by the Committee, submit its observations to the Committee.

5. Such an inquiry shall be conducted confidentially and the cooperation of the State Party shall be sought at all stages of the proceedings.

\section{Article 7}

1. The Committee may invite the State Party concerned to include in its report under article 35 of the Convention details of any measures taken in response to an inquiry conducted under article 6 of the present Protocol.

2. The Committee may, if necessary, after the end of the period of six months referred to in article 6.4, invite the State Party concerned to inform it of the measures taken in response to such an inquiry.

Article 8

Each State Party may, at the time of signature or ratification of the present Protocol or accession thereto, declare that it does not recognize the competence of the Committee provided for in articles 6 and 7.

Article 9

The Secretary-General of the United Nations shall be the depositary of the present Protocol.

Article 10

The present Protocol shall be open for signature by signatory States and regional integration organizations of the Convention at United Nations Headquarters in New York as of 30 March 2007.

Article 11

The present Protocol shall be subject to ratification by signatory States of this Protocol which have ratified or acceded to the Convention. It shall be sub- 
ject to formal confirmation by signatory regional integration organizations of this Protocol which have formally confirmed or acceded to the Convention. It shall be open for accession by any State or regional integration organization which has ratified, formally confirmed or acceded to the Convention and which has not signed the Protocol.

Article 12

1. "Regional integration organization" shall mean an organization constituted by sovereign States of a given region, to which its member States have transferred competence in respect of matters governed by the Convention and this Protocol. Such organizations shall declare, in their instruments of formal confirmation or accession, the extent of their competence with respect to matters governed by the Convention and this Protocol. Subsequently, they shall inform the depositary of any substantial modification in the extent of their competence.

2. References to "States Parties" in the present Protocol shall apply to such organizations within the limits of their competence.

3. For the purposes of article 13, paragraph 1, and article 15, paragraph 2, any instrument deposited by a regional integration organization shall not be counted.

4. Regional integration organizations, in matters within their competence, may exercise their right to vote in the meeting of States Parties, with a number of votes equal to the number of their member States that are Parties to this Protocol. Such an organization shall not exercise its right to vote if any of its member States exercises its right, and vice versa.

Article 13

1. Subject to the entry into force of the Convention, the present Protocol shall enter into force on the thirtieth day after the deposit of the tenth instrument of ratification or accession.

2. For each State or regional integration organization ratifying, formally confirming or acceding to the Protocol after the deposit of the tenth such instrument, the Protocol shall enter into force on the thirtieth day after the deposit of its own such instrument. 


\section{Article 14}

1. Reservations incompatible with the object and purpose of the present Protocol shall not be permitted.

2. Reservations may be withdrawn at any time.

\section{Article 15}

1. Any State Party may propose an amendment to the present Protocol and submit it to the Secretary-General of the United Nations. The Secretary-General shall communicate any proposed amendments to States Parties, with a request to be notified whether they favour a meeting of States Parties for the purpose of considering and deciding upon the proposals. In the event that, within four months from the date of such communication, at least one third of the States Parties favour such a meeting, the Secretary-General shall convene the meeting under the auspices of the United Nations. Any amendment adopted by a majority of two thirds of the States Parties present and voting shall be submitted by the Secretary-General to the General Assembly for approval and thereafter to all States Parties for acceptance.

2. An amendment adopted and approved in accordance with paragraph 1 of this article shall enter into force on the thirtieth day after the number of instruments of acceptance deposited reaches two thirds of the number of States Parties at the date of adoption of the amendment. Thereafter, the amendment shall enter into force for any State Party on the thirtieth day following the deposit of its own instrument of acceptance. An amendment shall be binding only on those States Parties which have accepted it.

\section{Article 16}

A State Party may denounce the present Protocol by written notification to the Secretary-General of the United Nations. The denunciation shall become effective one year after the date of receipt of the notification by the Secretary-General.

Article 17

The text of the present Protocol shall be made available in accessible formats. 
Article 18

The Arabic, Chinese, English, French, Russian and Spanish texts of the present Protocol shall be equally authentic.

In witness thereof the undersigned plenipotentiaries, being duly authorized thereto by their respective Governments, have signed the present Protocol.

FONTE: CDPDNU. Optional Protocol to the Convention on the Rights of Persons with Disabilities. Disponível no site: <http://www2.ohchr.org/english/law/disabilities-op.htm>. Acesso em: 07 set. 2009.

\section{ANEXO P - ART. 77 da Convenção dos trabalhadores migrantes de 1990}

Article 77

1. A State Party to the present Convention may at any time declare under the present article that it recognizes the competence of the Committee to receive and consider communications from or on behalf of individuals subject to its jurisdiction who claim that their individual rights as established by the present Convention have been violated by that State Party. No communication shall be received by the Committee if it concerns a State Party that has not made such a declaration.

2. The Committee shall consider inadmissible any communication under the present article which is anonymous or which it considers to be an abuse of the right of submission of such communications or to be incompatible with the provisions of the present Convention.

3. The Committee shall not consider any communication from an individual under the present article unless it has ascertained that:

(a) The same matter has not been, and is not being, examined under another procedure of international investigation or settlement;

(b) The individual has exhausted all available domestic remedies; this shall not be the rule where, in the view of the Committee, the application of the remedies is unreasonably prolonged or is unlikely to bring effective relief to that individual. 
4. Subject to the provisions of paragraph 2 of the present article, the Committee shall bring any communications submitted to it under this article to the attention of the State Party to the present Convention that has made a declaration under paragraph 1 and is alleged to be violating any provisions of the Convention. Within six months, the receiving State shall submit to the Committee written explanations or statements clarifying the matter and the remedy, if any, that may have been taken by that State.

5. The Committee shall consider communications received under the present article in the light of all information made available to it by or on behalf of the individual and by the State Party concerned.

6. The Committee shall hold closed meetings when examining communications under the present article.

7. The Committee shall forward its views to the State Party concerned and to the individual.

8. The provisions of the present article shall come into force when ten States Parties to the present Convention have made declarations under paragraph 1 of the present article. Such declarations shall be deposited by the States Parties with the Secretary-General of the United Nations, who shall transmit copies thereof to the other States Parties. A declaration may be withdrawn at any time by notification to the Secretary-General. Such a withdrawal shall not prejudice the consideration of any matter that is the subject of a communication already transmitted under the present article; no further communication by or on behalf of an individual shall be received under the present article after the notification of withdrawal of the declaration has been received by the SecretaryGeneral, unless the State Party has made a new declaration.

FONTE: CTMNU. Article 77 of the International Convention on the Protection of the Rights of All Migrant Workers and Members of Their Families. Disponível no site: <http:// www2.ohchr.org/english/law/cmw.htm >. Acesso em: 07 set. 2009. 


\section{ANEXO Q - Modelo padrão de petição individual perante os CRHNU, CTNU, CEDRNU}

Several bodies dealing with communications have developed model questionnaires to facilitate their examination of reported violations of human rights and these have been made available to persons wishing to report cases of alleged violations. It should, however, be noted that communications are considered even when they are not submitted in the form of a questionnaire.

Whatever the reporting format, the precise address of the body to which a reported case(s) is(are) sent for examination should appear at the very beginning of the comunnication so as to ensure its easy and immediate channeling to the addressee.

Mail: Petitions Team

Office oftheHighCommissionerforHumanRightsUnitedNationsOfficeatGeneva 1211 Geneva 10,SwitzerlandFax:+41229179022 (particularlyforurgentmatters) E-mail:tb-petitions@ohchr.org

\section{MODEL COMPLAINT FORM}

For communications under:

- Optional Protocol to the International Covenant on Civil and Political Rights

- Convention against Torture, or

- International Convention on the Elimination of Racial Discrimination

Please indicate which of the above procedures you are invoking: .........

Date:

\section{Information on the complainant:}

Name: ........ First name(s):

Nationality: Date and place of birth:

Address for correspondence on this complaint:

Submitting the communication:

on the author's own behalf:

on behalf of another person: 
[ If the complaint is being submitted on behalf of another person:]

Please provide the following personal details of that other person

Name: ........ First name(s):

Nationality: ........ Date and place of birth:

Address or current whereabouts:

If you are acting with the knowledge and consent of that person, please provide that person's authorization

for you to bring this complaint ...........

$\mathrm{Or}$

If you are not so authorized, please explain the nature of your relationship with that person:

and detail why you consider it appropriate to bring this complaint on his or her behalf:

\section{State concerned/Articles violated}

Name of the State that is either a party to the Optional Protocol (in the case of a complaint to the Human

Rights Committee) or has made the relevant declaration (in the case of complaints to the Committee against

Torture or the Committee on the Elimination of Racial Discrimination):

Articles of the Covenant or Convention alleged to have been violated:

\section{Exhaustion of domestic remedies/Application to other international procedures}

Steps taken by or on behalf of the alleged victims to obtain redress within the State concerned for the

alleged violation - detail which procedures have been pursued, including recourse to the courts and other

public authorities, which claims you have made, at which times, and with which outcomes:

If you have not exhausted these remedies on the basis that their application would be unduly

prolonged, that they would not be effective, that they are not available to you, or for any other

reason, please explain your reasons in detail:

Have you submitted the same matter for examination under another procedure of international investigation

or settlement (e.g. the Inter-American Commission on Human Rights, the European Court of Human

Rights, or the African Commission on Human and Peoples' Rights)? 
If so, detail which procedure(s) have been, or are being, pursued, which claims you have made, at

which times, and with which outcomes:

\section{Facts of the complaint}

Detail, in chronological order, the facts and circumstances of the alleged violations. Include all matters

which may be relevant to the assessment and consideration of your particular case. Please explain how you

consider that the facts and circumstances described violate your rights.

Author's signature:

[The blanks under the various sections of this model communication simply indicate where your responses

are required. You should take as much space as you need to set out your responses.]

V. Checklist of supporting documentation (copies, not originals, to be enclosed with your

complaint):

- Written authorization to act (if you are bringing the complaint on behalf of another person and are

not otherwise justifying the absence of specific authorization):

- Decisions of domestic courts and authorities on your claim (a copy of the relevant national

legislation is also helpful):

- Complaints to and decisions by any other procedure of international investigation or settlement:

- Any documentation or other corroborating evidence you possess that substantiates your

description in Part IV of the facts of your claim and/or your argument that the facts described amount to a

violation of your rights:

If you do not enclose this information and it needs to be sought specifically from you, or if accompanying

documentation is not provided in the working languages of the Secretariat, the consideration of your complaint may be delayed.

FONTE: ComDHsNU. Model Complaint Form. Disponível no site: <http://www2.ohchr. org/english/bodies/docs/annex1.pdf >. Acesso em: 07 set. 2009. 


\section{ANEXO R - Sobre a União da Europa Ocidental (UEO) \\ Western European Union (WEU)}

The glossary is being updated given the recent signing of the Treaty of Lisbon.

Set up in 1948 by the Treaty of Brussels, the WEU is a European organisation for the purposes of cooperation on defence and security. It consists of 28 countries with four different statuses: Member States, Associate Members, Observers and Associate Partners. Of the EU-15 countries, ten are full Member States, while the remaining five - Austria, Denmark, Finland, Ireland and Sweden - have observer status. The six Associate Members are the Czech Republic, Hungary, Iceland, Norway, Poland and Turkey, and there are seven Associate Partners: Bulgaria, Estonia, Latvia, Lithuania, Romania, Slovakia and Slovenia.

In the Treaty of Amsterdam the WEU was defined as an integral part of the development of the Union because it gave the EU operational capability in the field of defence. However, the paragraph concerned was deleted by the Treaty of Nice. The WEU did indeed play a major role in the first Petersberg tasks, such as the police detachment in Mostar or cooperation with the police in Albania. However, it now seems to have abandoned that role in favour of developing the Union's own structures and capabilities in the sphere of the European security and defence policy (ESDP). The transfer of the WEU's operational capabilities to the Union attests to this. The WEU's subsidiary bodies, the Security Studies Institute and the Satellite Centre, were hived off to the Union on 1 January 2002. The Treaty of Nice also deleted from the Treaty on European Union a number of provisions concerning relations between the WEU and the Union.

Collective defence, a primary responsibility of the WEU, now falls within the North Atlantic Treaty Organisation's (NATO) sphere of competence.

See:

Collective defence

Common foreign and security policy (CFSP)

European security and defence identity

European Security and Defence Policy

(ESDP)

\section{NATO (North Atlantic Treaty Organisation)}

'New-look' NATO

Petersberg tasks

FONTE: UEO. Western European Union. Disponíel no site: <http://europa.eu/scadplus/ glossary/western_european_union_en.htm>. Acesso em: 07 set. 2009. 


\section{ANEXO S - Estados Membros da União Européia Ocidental (2007)}

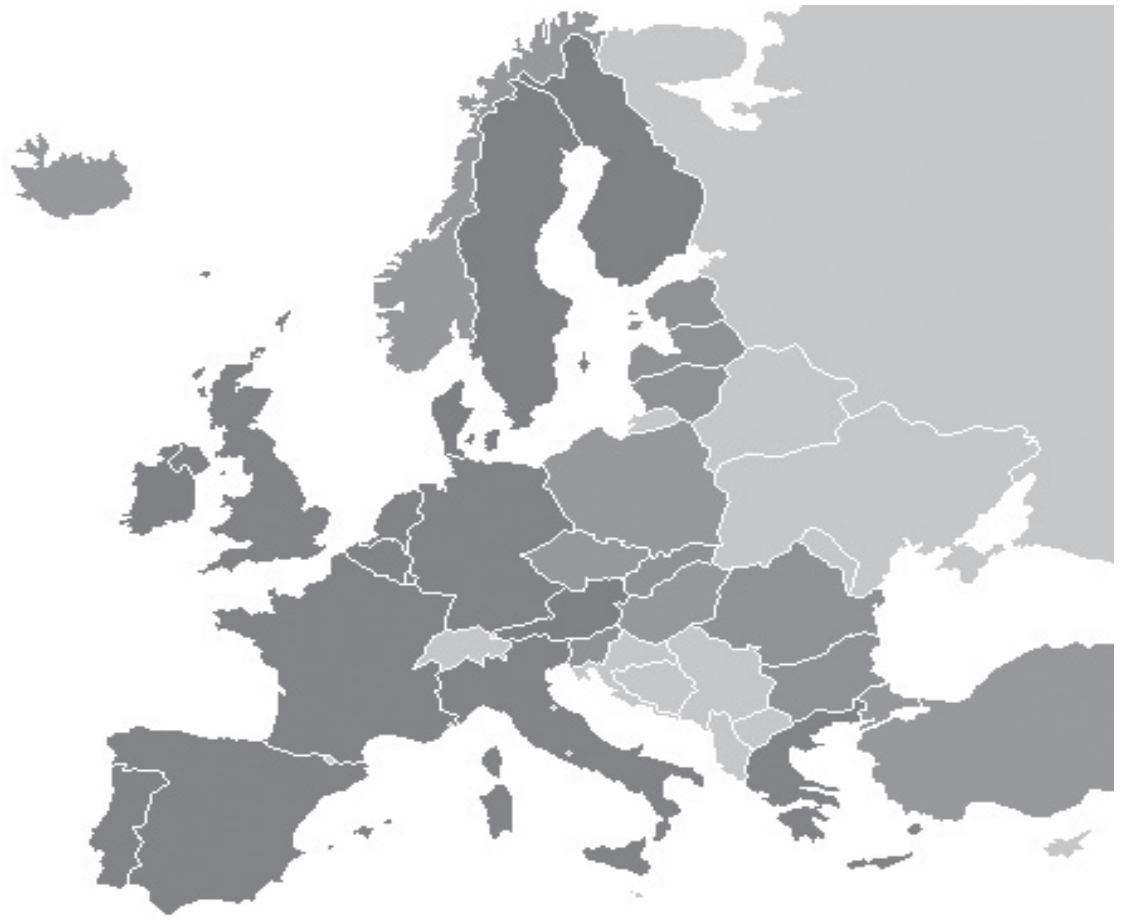

\section{Western European Union}

Members

Associate members

Observers

Associate partners

FONTE: UEO. Western Europena Union. Disponível no site: <http://en.wikipedia.org/wiki/ File:WEU_Map.svg >. Acesso em: 07 set. 2009. 


\title{
ANEXO T - Estatísticas do Tribunal de Justiça das Comunidades Européias
}

\author{
Actividade geral do Tribunal de Justiça \\ Processos entrados, findos, pendentes (2004-2008) (1)
}

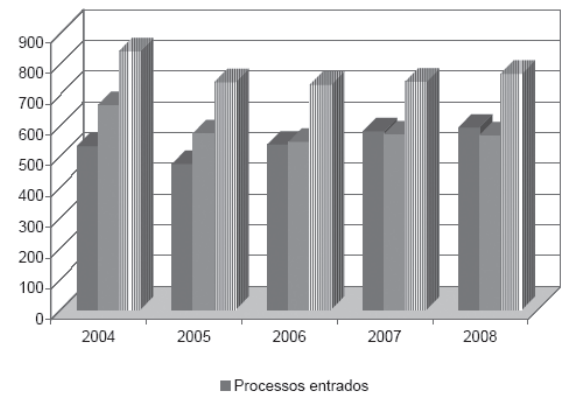

Processos findos

\begin{tabular}{|c|c|c|c|c|c|}
\hline \multicolumn{6}{|c|}{ m Processos pendentes } \\
\hline & 2004 & 2005 & 2006 & 2007 & 2008 \\
\hline Processos entrados & 531 & 474 & 537 & 580 & 592 \\
\hline Processos findos & 665 & 574 & 546 & 570 & 567 \\
\hline Processos pendentes & 840 & 740 & 731 & 741 & 767 \\
\hline
\end{tabular}

1 Os números referidos (números brutos) indicam o número total de processos independentemente das apensações por conexão (um número de processo $=$ um processo).

Processos entrados

2. Tipos de processos (2004-2008) (1) (2)

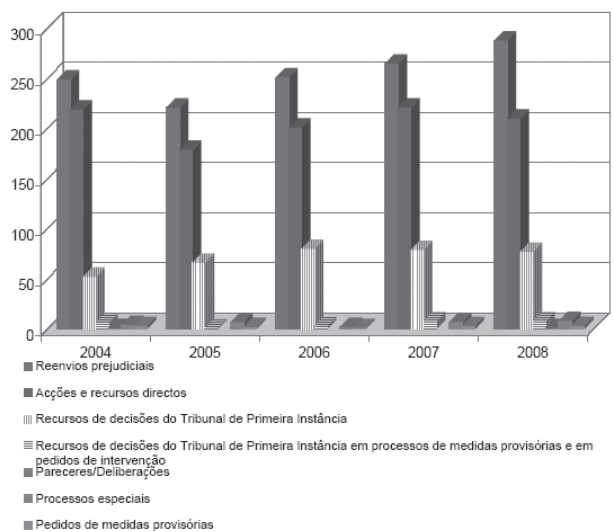

Pedidos de medidas provisórias

' Os números referidos (números brutos) indicam o número total de processos independentemente das apensaçōes por conexão (um número de processo $=$ um processo)

'São considerados eprocessos especiaisn: a fixação das despesas (artigo $74^{\circ} \mathrm{do}$ Regulamento de Processo); o apoio judiciário (artigo $76^{\circ}$ do Regulamento de Processo); a oposição a um acórdäo (artigo $94^{\circ}$ do Regulamento de Processo); a oposição de terceiros (artigo $97^{\circ}$ do Regulamento de (artigo 10 into Process un acordà (artigo Regulamento de Processo), a análise de uma proposta do primeiro advogado-geral de reapreciaçäo de uma decisaao do Tribunal de Primeira Instância (artigo 62. do Estatuto do Tribunal de Justiça); a penhora (Protocolo relativo aos Privilégios e Imunidades); os processos em matéria de imunidades

FONTE: UE. Relatório Anual de 2008. Disponível no site: <http://curia.europa.eu/jcms/ upload/docs/application/pdf/2009-03/ra08_pt_cj_stat.pdf>, p. 85-86. Acesso em: 07 set. 2009. 


\section{ANEXO U - Processo na Corte Européia de primeira instância}

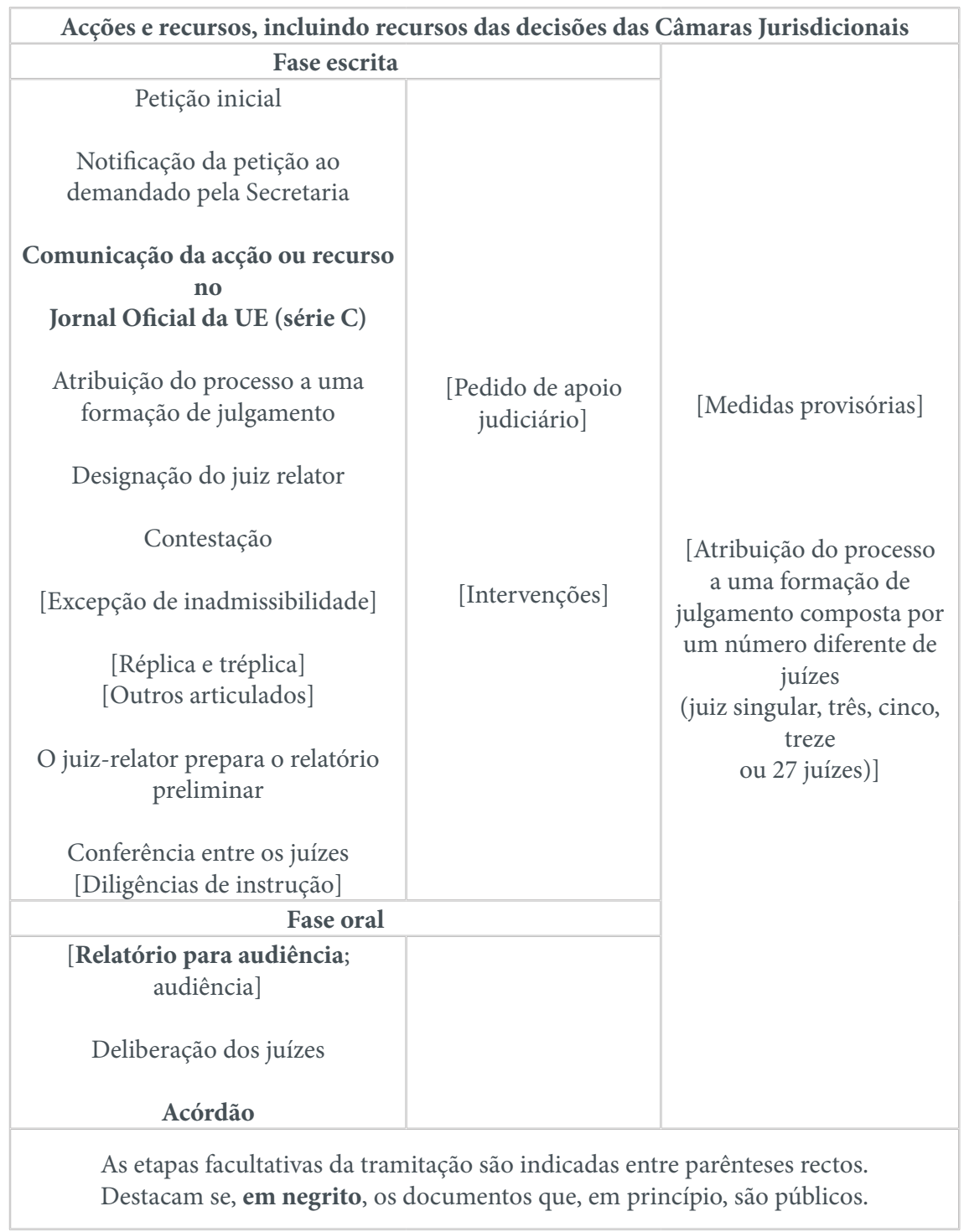

FONTE: UE. Esquema do Processo. Disponível no site: <http://curia.europa.eu/jcms/jcms/ Jo2_7033/apresentacao\#compet>. Acesso em: 07 set. 2009. 


\section{ANEXO V- Estados-membros da União Européia (UE)}

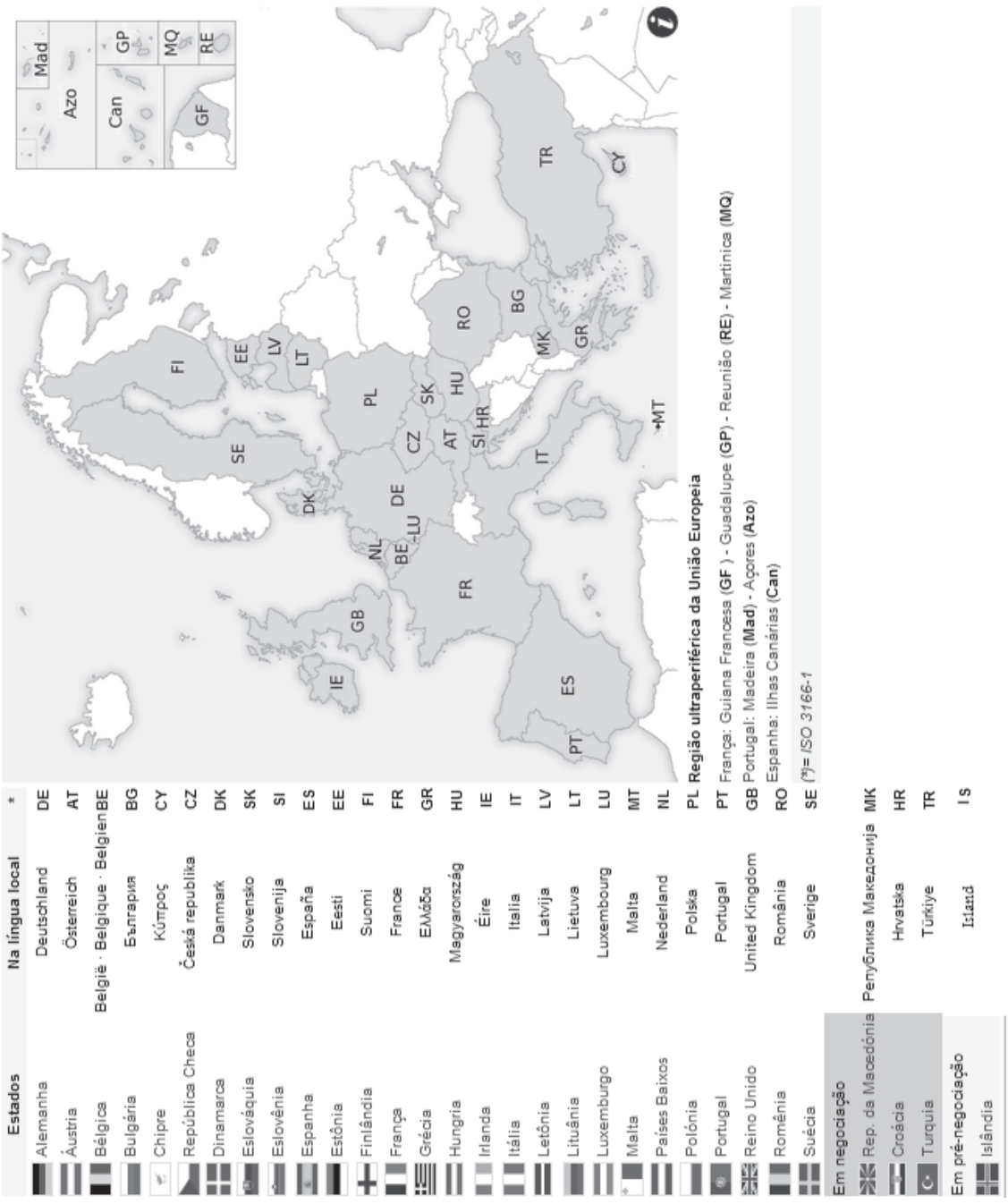

FONTE: UE. Estados-membros da União Européia. Disponível no site: <http://pt.wikipedia. org/wiki/Uni\%C3\%A3o_Europeia\#Territ.C3.B3rio.2FEstados-membros>. Acesso em: 07 set. 2009. 


\section{ANEXO X - Finanças da União Européia (EU)}

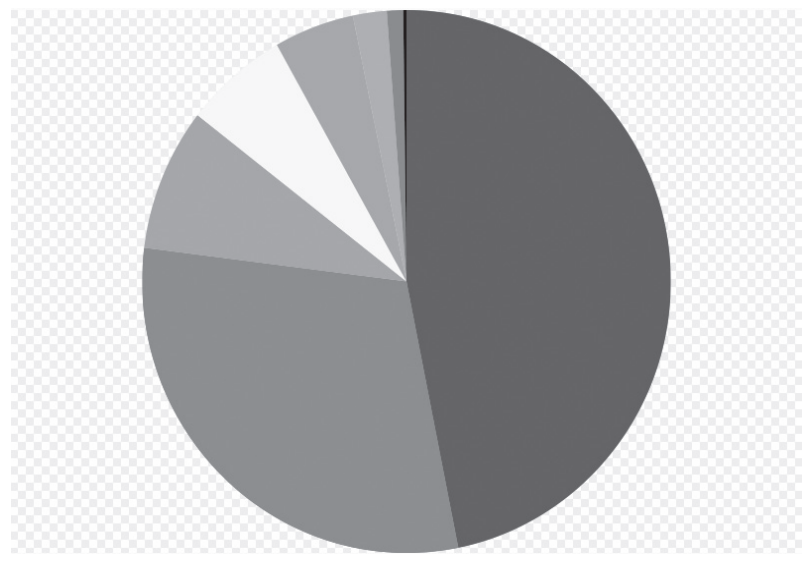

EU budget 2006 - Total expenditure. Budget numbers gotten from page 8 of this, which was accessed from European Commission > Financial Programming andtBudget $>$ Documents

Total EU expenditure in millions of euros for 2006. Figure includes EU25, non-EU, earmarked and other.

Agriculture: 49798.8 (approx 46.7\%)

Structural Actions: 32399.3 (approx 30.4\%)

Internal Policies: 9013.7 (approx 8.5\%)

Administration: 6699.7 (approx 6.3\%)

External Actions: 5186.2 (approx 4.9\%)

Pre-Accession Strategy: 2276.7 (approx 2.1\%)

Compensations: 1073.5 (approx 1.0\%)

Reserves: 127.6 (approx 0.1\%)

Total expenditure $=106,575.5$

FONTE: UE. EU budget 2006 - Total expenditure. Disponível no site: <http://en.wikipedia. org/wiki/File:EU_Budget_2006_-_Total_expenditure.svg $>$; baseado nos dados do site: $<$ http://www.ec.europa.eu/budget/documents/budget_current_year-1_en.htm>. Acesso em: 07 set. 2009. 


\section{ANEXO Y- Linha dos Tratados da UE}

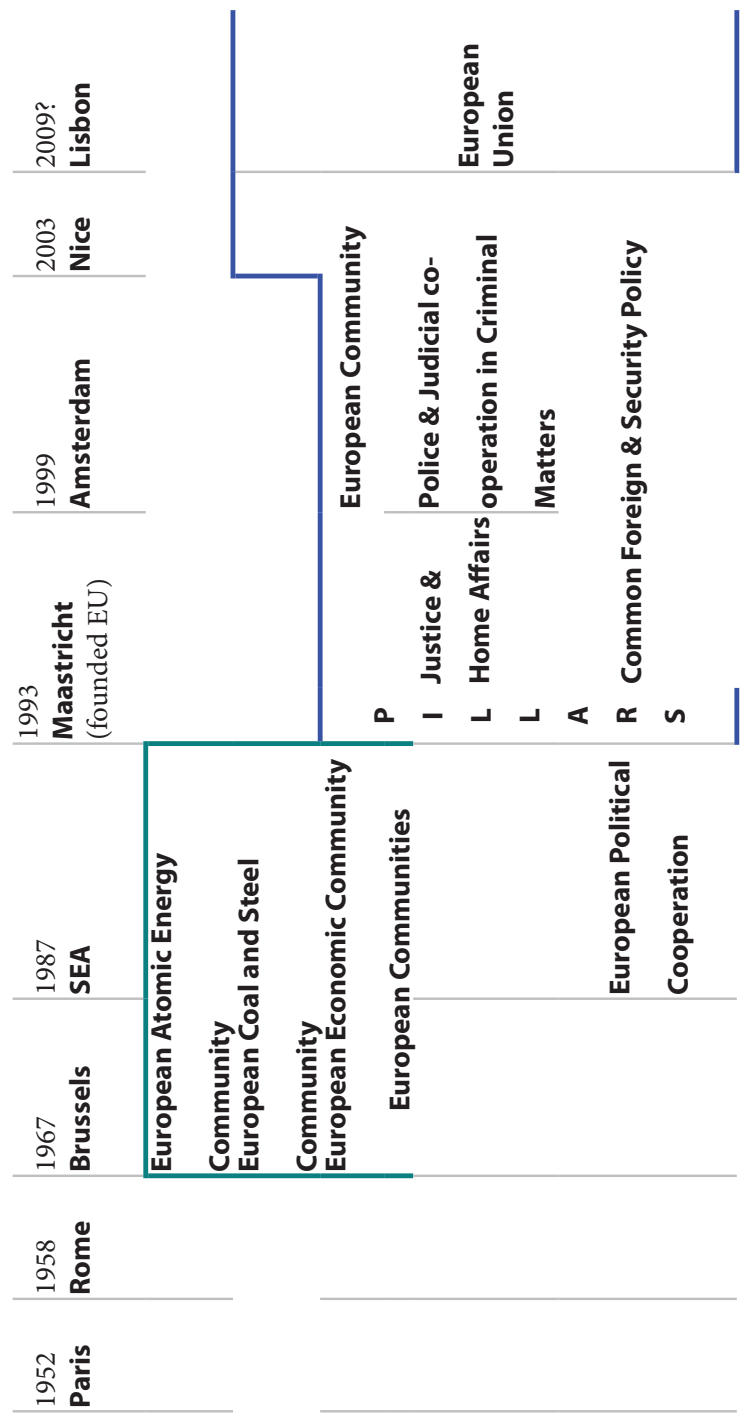

㐫

FONTE: UE. Treaties of the European Union. Dispnível no seguinte site: <http://en.wikipedia. org/wiki/Treaties_of_the_European_Union>. Acesso em: 07 set. 2009. 


\section{ANEXO W - Composição do Conselho da Europa (início de 2009)}

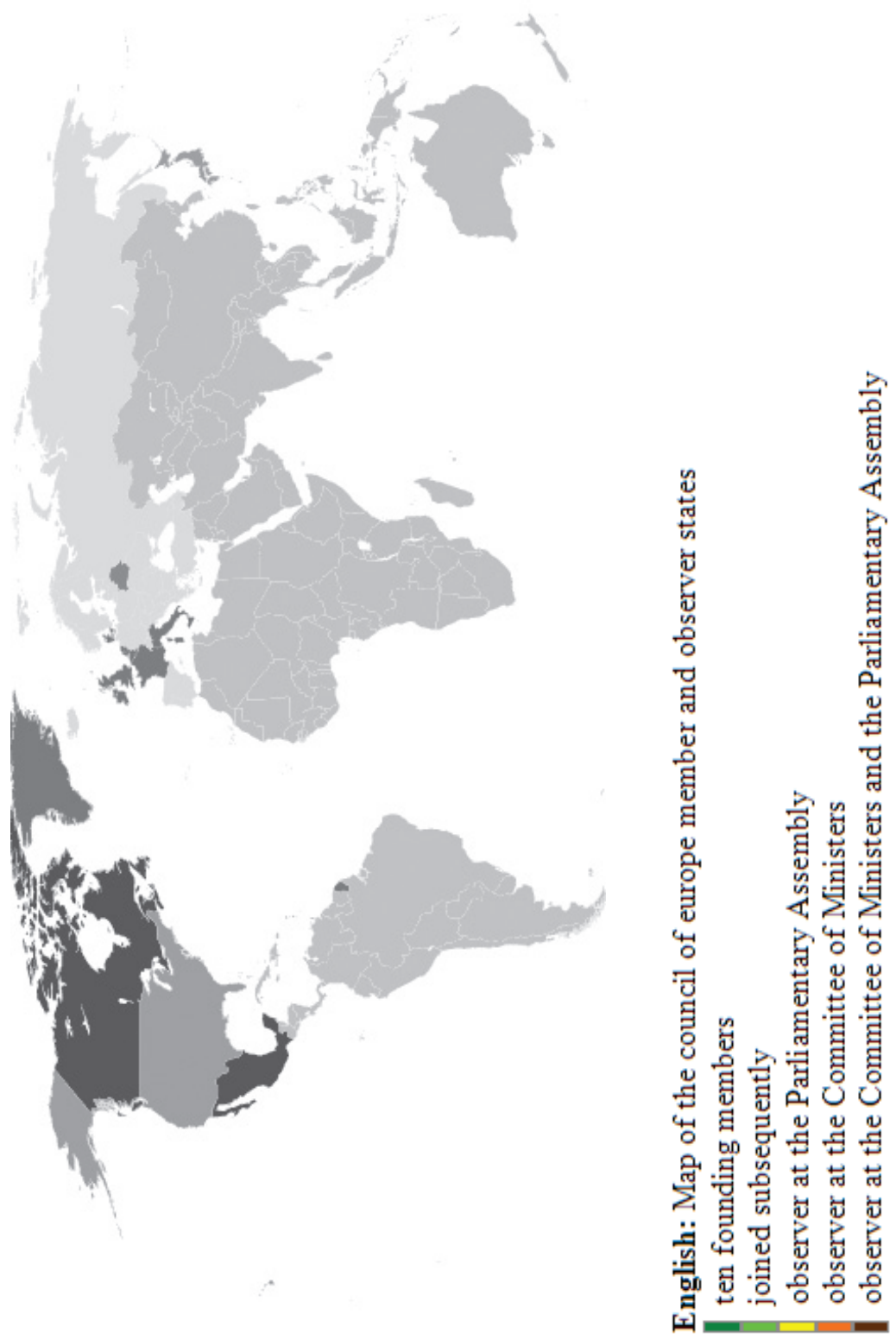

FONTE: CoE. Map of the Council of Europe member and observer states. Disponível no site: $<$ http://en.wikipedia.org/wiki/File:Council_of_europe_map.svg>. Acesso em: 07 set. 2009. 


\title{
ANEXO Z - Quadro simplificado das assinaturas e ratificações dos Tratados de Dhs (Convenção Européia e Protocolos) da CtEDHs
}

\author{
Simplified Chart of signatures and ratifications \\ Treaties coming from the subject-matter: \\ Human Rights (Convention and Protocols only)
}

Status as of: $8 / 9 / 2009$

\begin{tabular}{|c|c|c|c|c|c|c|c|c|c|}
\hline States / Treaties CETS Nos. & 005 & 009 & 046 & 114 & 117 & 177 & 187 & 194 & 204 \\
\hline Albania & $\mathrm{P}$ & $\mathrm{P}$ & $\mathrm{P}$ & $\mathrm{P}$ & $\mathrm{P}$ & $\mathrm{P}$ & $\mathrm{P}$ & $\mathrm{P}$ & \\
\hline Andorra & $\mathrm{P}$ & $P$ & $P$ & $\mathrm{P}$ & $\mathrm{P}$ & $\mathrm{P}$ & $P$ & $P$ & \\
\hline Armenia & $\mathrm{P}$ & $\mathrm{P}$ & $\mathrm{P}$ & $P$ & $\mathrm{P}$ & $\mathrm{P}$ & S & $\mathrm{P}$ & \\
\hline Austria & $\mathrm{P}$ & $\mathrm{P}$ & $\mathrm{P}$ & $\mathrm{P}$ & $\mathrm{P}$ & $\mathrm{S}$ & $P$ & $\mathrm{P}$ & $\mathrm{S}$ \\
\hline Azerbaijan & $\mathrm{P}$ & $\mathrm{P}$ & $\mathrm{P}$ & $\mathrm{P}$ & $\mathrm{P}$ & S & & $\mathrm{P}$ & \\
\hline Belgium & $P$ & $\mathrm{P}$ & $P$ & $\mathrm{P}$ & $\mathrm{s}$ & $\mathrm{s}$ & $\mathrm{P}$ & $\mathrm{P}$ & \\
\hline Bosnia and Herzegovina & $\mathrm{P}$ & $\mathrm{P}$ & $\mathrm{P}$ & $\mathrm{P}$ & $\mathrm{P}$ & $\mathrm{P}$ & $\mathrm{P}$ & $\mathrm{P}$ & \\
\hline Bulgaria & $\mathrm{P}$ & $\mathrm{P}$ & $P$ & $P$ & $\mathrm{P}$ & & $\mathrm{P}$ & $\mathrm{P}$ & \\
\hline Croatia & $\mathrm{P}$ & $P$ & $\mathrm{P}$ & $\mathrm{P}$ & $\mathrm{P}$ & $\mathrm{P}$ & $P$ & $\mathrm{P}$ & \\
\hline Cyprus & $\mathrm{P}$ & $\mathrm{P}$ & $\mathrm{P}$ & $\mathrm{P}$ & $\mathrm{P}$ & $\mathrm{P}$ & $\mathrm{P}$ & $\mathrm{P}$ & \\
\hline Czech Republic & $\mathrm{P}$ & $\mathrm{P}$ & $\mathrm{P}$ & $\mathrm{P}$ & $\mathrm{P}$ & $\mathrm{S}$ & $\mathrm{P}$ & $\mathrm{P}$ & \\
\hline Denmark & $\mathrm{P}$ & $\mathrm{P}$ & $\mathrm{P}$ & $\mathrm{P}$ & $\mathrm{P}$ & & $\mathrm{P}$ & $\mathrm{P}$ & $\mathrm{P}$ \\
\hline Estonia & $\mathrm{P}$ & $\mathrm{P}$ & $\mathrm{P}$ & $\mathrm{P}$ & $\mathrm{P}$ & $\mathrm{s}$ & $\mathrm{P}$ & $\mathrm{P}$ & \\
\hline Finland & $\mathrm{P}$ & $\mathrm{P}$ & $\mathrm{P}$ & $\mathrm{P}$ & $\mathrm{P}$ & $\mathrm{P}$ & $\mathrm{P}$ & $\mathrm{P}$ & \\
\hline France & $P$ & $\mathrm{P}$ & $\mathrm{P}$ & $\mathrm{P}$ & $\mathrm{P}$ & & $\mathrm{P}$ & $\mathrm{P}$ & $\mathrm{s}$ \\
\hline Georgia & $\mathrm{P}$ & $\mathrm{P}$ & $\mathrm{P}$ & $\mathrm{P}$ & $\mathrm{P}$ & $\mathrm{P}$ & $\mathrm{P}$ & $\mathrm{P}$ & $\mathrm{P}$ \\
\hline Germany & $\mathrm{P}$ & $\mathrm{P}$ & $\mathrm{P}$ & $\mathrm{P}$ & $\mathrm{S}$ & S & $\mathrm{P}$ & $\mathrm{P}$ & \\
\hline Greece & $\mathrm{P}$ & $\mathrm{P}$ & & $\mathrm{P}$ & $\mathrm{P}$ & $\mathrm{s}$ & $\mathrm{P}$ & $\mathrm{P}$ & \\
\hline Hungary & $\mathrm{P}$ & $\mathrm{P}$ & $\mathrm{P}$ & $\mathrm{P}$ & $\mathrm{P}$ & $\mathrm{S}$ & $\mathrm{P}$ & $\mathrm{P}$ & \\
\hline Iceland & $\mathrm{P}$ & $P$ & $P$ & $P$ & $\mathrm{P}$ & $\mathrm{s}$ & $P$ & $\mathrm{P}$ & $\mathrm{P}$ \\
\hline Ireland & $\mathrm{P}$ & $\mathrm{P}$ & $\mathrm{P}$ & $\mathrm{P}$ & $\mathrm{P}$ & $\mathrm{S}$ & $\mathrm{P}$ & $\mathrm{P}$ & $\mathrm{P}$ \\
\hline Italy & $\mathrm{P}$ & $\mathrm{P}$ & $\mathrm{P}$ & $\mathrm{P}$ & $\mathrm{P}$ & s & $\mathrm{P}$ & $\mathrm{P}$ & \\
\hline Latvia & $\mathrm{P}$ & $\mathrm{P}$ & $\mathrm{P}$ & $\mathrm{P}$ & $\mathrm{P}$ & $S$ & S & $\mathrm{P}$ & \\
\hline Liechtenstein & $\mathrm{P}$ & $\mathrm{P}$ & $\mathrm{P}$ & $\mathrm{P}$ & $\mathrm{P}$ & $\mathrm{s}$ & $\mathrm{P}$ & $\mathrm{P}$ & \\
\hline Lithuania & $P$ & $P$ & $P$ & $P$ & $\mathrm{P}$ & & $P$ & $\mathrm{P}$ & \\
\hline Luxembourg & $\mathrm{P}$ & $\mathrm{P}$ & $\mathrm{P}$ & $\mathrm{P}$ & $\mathrm{P}$ & $\mathrm{P}$ & $\mathrm{P}$ & $\mathrm{P}$ & $\mathrm{S}$ \\
\hline Malta & $\mathrm{P}$ & $\mathrm{P}$ & $\mathrm{P}$ & $\mathrm{P}$ & $\mathrm{P}$ & & $\mathrm{P}$ & $\mathrm{P}$ & \\
\hline Moldova & $\mathrm{P}$ & $\mathrm{P}$ & $\mathrm{P}$ & $\mathrm{P}$ & $\mathrm{P}$ & $S$ & $\mathrm{P}$ & $P$ & \\
\hline Monaco & $P$ & $\mathrm{~s}$ & $\mathrm{P}$ & $P$ & $P$ & & $P$ & $P$ & $P$ \\
\hline Montenegro & $P$ & $P$ & $P$ & $P$ & $\mathrm{P}$ & $P$ & $\mathrm{P}$ & $\mathrm{P}$ & \\
\hline Netherlands & $\mathrm{P}$ & $\mathrm{P}$ & $\mathrm{P}$ & $P$ & $\mathrm{~S}$ & $\mathrm{P}$ & $P$ & $\mathrm{P}$ & \\
\hline Norway & $P$ & $P$ & $P$ & $P$ & $\mathrm{P}$ & $\mathrm{s}$ & $\mathrm{P}$ & $\mathrm{P}$ & $P$ \\
\hline Poland & $\mathrm{P}$ & $\mathrm{P}$ & $\mathrm{P}$ & $\mathrm{P}$ & $\mathrm{P}$ & & $\mathrm{S}$ & $\mathrm{P}$ & \\
\hline Portugal & $\mathrm{P}$ & $\mathrm{P}$ & $P$ & $P$ & $\mathrm{P}$ & $\mathrm{s}$ & $\mathrm{P}$ & $\mathrm{P}$ & \\
\hline Romania & $P$ & $\mathrm{P}$ & $\mathrm{P}$ & $\mathrm{P}$ & $\mathrm{P}$ & $\mathrm{P}$ & $\mathrm{P}$ & $\mathrm{P}$ & \\
\hline Russia & $P$ & $\mathrm{P}$ & $\mathrm{P}$ & $\mathrm{s}$ & $\mathrm{P}$ & S & & S & \\
\hline San Marino & $\mathrm{P}$ & $\mathrm{P}$ & $\mathrm{P}$ & $\mathrm{P}$ & $\mathrm{P}$ & $\mathrm{P}$ & $\mathrm{P}$ & $\mathrm{P}$ & $S$ \\
\hline Serbia & $\mathrm{P}$ & $\mathrm{P}$ & $P$ & $\mathrm{P}$ & $\mathrm{P}$ & $\mathrm{P}$ & $\mathrm{P}$ & $P$ & \\
\hline Slovakia & $P$ & $P$ & $P$ & $P$ & $\mathrm{P}$ & $\mathrm{s}$ & $\mathrm{P}$ & $P$ & \\
\hline Slovenia & $P$ & $P$ & $P$ & $P$ & $P$ & $\mathrm{~s}$ & $P$ & $P$ & $P$ \\
\hline Spain & $P$ & $P$ & S & $P$ & $\mathrm{~S}$ & $\mathrm{P}$ & S & $P$ & $\mathrm{~s}$ \\
\hline Sweden & $P$ & $\mathrm{P}$ & $\mathrm{P}$ & $P$ & $\mathrm{P}$ & & $\mathrm{P}$ & $\mathrm{P}$ & \\
\hline Switzerland & $P$ & $\mathrm{~s}$ & & $\mathrm{P}$ & $\mathrm{P}$ & & $\mathrm{P}$ & $P$ & \\
\hline the former Yugoslav Republic of Macedonia & $P$ & $P$ & $P$ & $P$ & $\mathrm{P}$ & $\mathrm{P}$ & $P$ & $\mathrm{P}$ & $\mathrm{s}$ \\
\hline Turkey & $P$ & $P$ & S & $\mathrm{P}$ & S & S & $\mathrm{P}$ & $\mathrm{P}$ & \\
\hline Ukraine & $P$ & $\mathrm{P}$ & $\mathrm{P}$ & $\mathrm{P}$ & $\mathrm{P}$ & $\mathrm{P}$ & $\mathrm{P}$ & $\mathrm{P}$ & \\
\hline United Kingdom & $P$ & $\mathrm{P}$ & $\mathrm{S}$ & $\mathrm{P}$ & & & $P$ & $\mathrm{P}$ & \\
\hline
\end{tabular}

Notes: S : Signatory - P : Party - D : Denunciation Source : Treaty Office on <http:// conventions.coe.int> 
CETS No.: 005 - Convention for the Protection of Human Rights and Fundamental Freedoms

CETS No.: 009 - Protocol to the Convention for the Protection of Human Rights and Fundamental Freedoms

CETS No.: 046Protocol No. 4 to the Convention for the Protection of Human Rights and Fundamental Freedoms, securing certain rights and freedoms other than those already included in the Convention and in the first Protocol thereto CETS No.: 117 - Protocol No. 7 to the Convention for the Protection of Human Rights and Fundamental Freedoms

CETS No.: 177 - Protocol No. 12 to the Convention for the Protection of Human Rights and Fundamental Freedoms

CETS No.: 187 - Protocol No. 13 to the Convention for the Protection of Human Rights and Fundamental Freedoms, concerning the abolition of the death penalty in all circumstances

CETS No.: 194 - Protocol No. 14 to the Convention for the Protection of Human Rights and Fundamental Freedoms, amending the control system of the Convention

CETS No.: 204 - Protocol No. 14bis to the Convention for the Protection of Human Rights and Fundamental Freedoms

FONTE: CtEDHs. Simplified Chart of signatures and ratifications. Disponível no site: $<$ http:// conventions.coe.int/Treaty/Commun/ListeTableauCourt.asp?MA=3\&CM=16\&CL=ENG $>$. Acesso em: 07 set. 2009. 


\section{ANEXO AA- Estatística da CtEDHs}

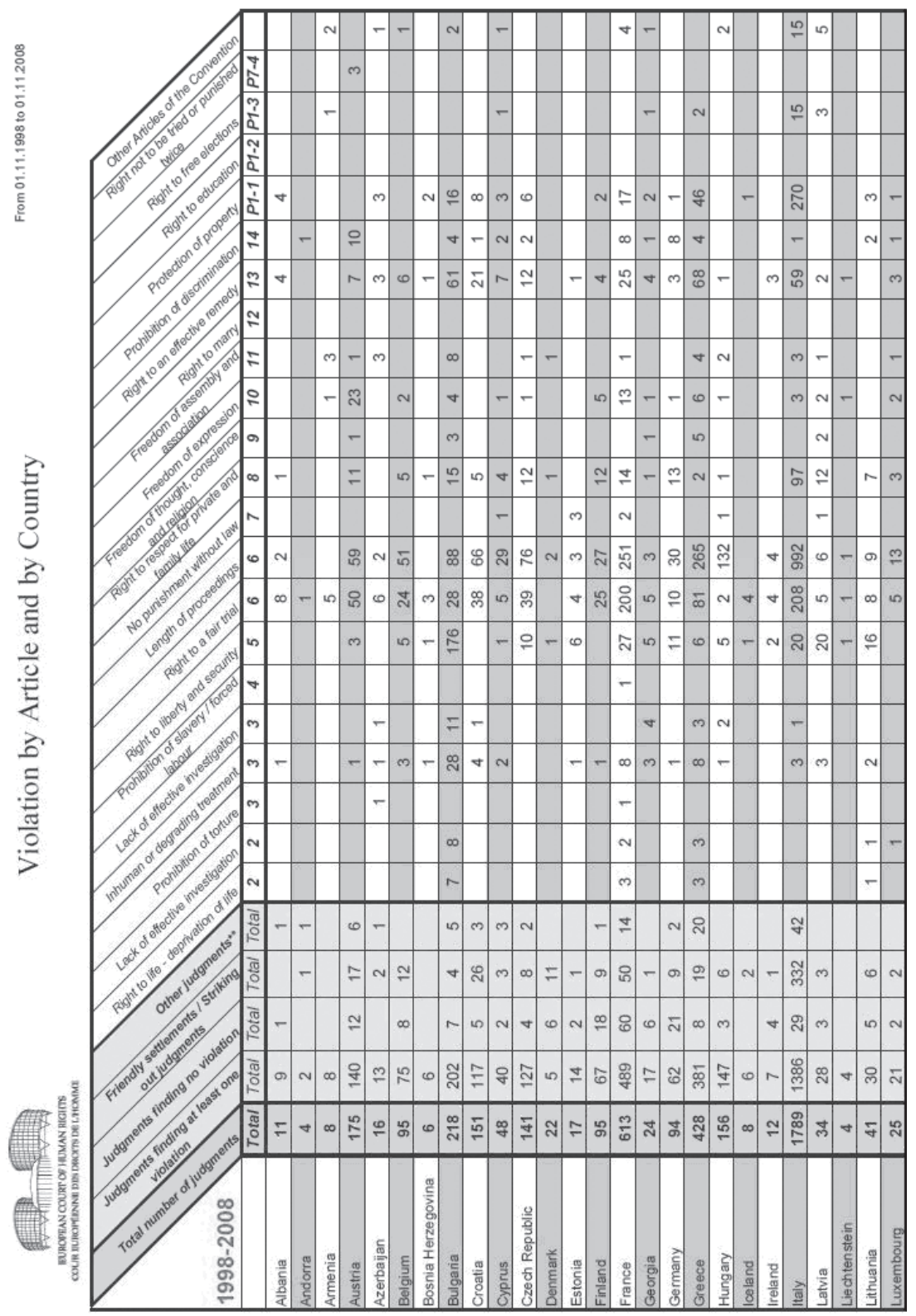




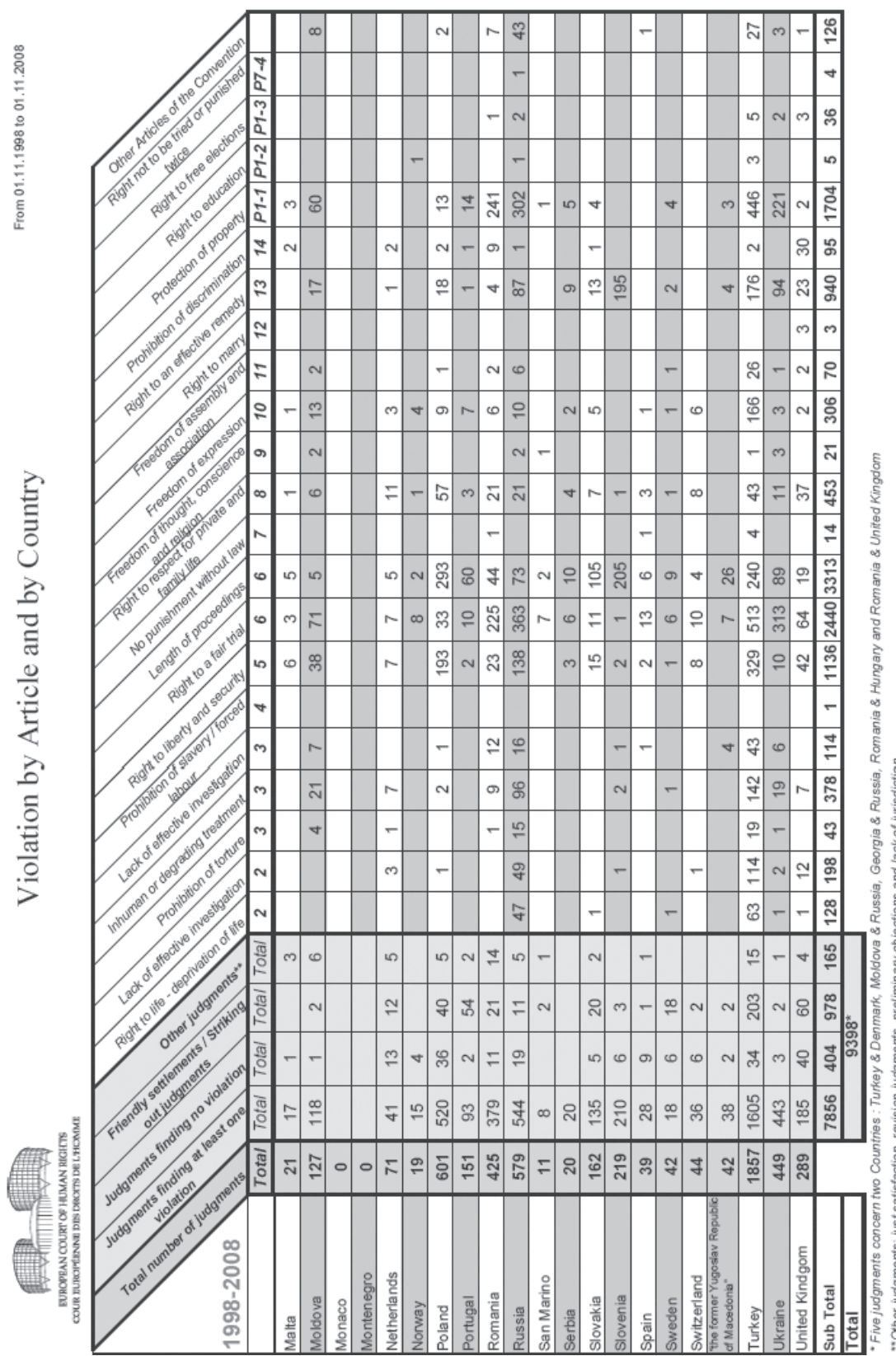

FONTE: CtEDHs. European Court of Human Rights - Some Facts and Figures. Disponível no site: <http://www.echr.coe.int/NR/rdonlyres/ACD46A0F-615A-48B9-89D6-8480AFCC29FD/0/ FactsAndFigures_EN.pdf>.p. 12-13. Acesso em: 07 set. 2009. 


\section{ANEXO BB - Esquema processual de um caso perante a CtEDHs}

\section{Case-processing flow chart}

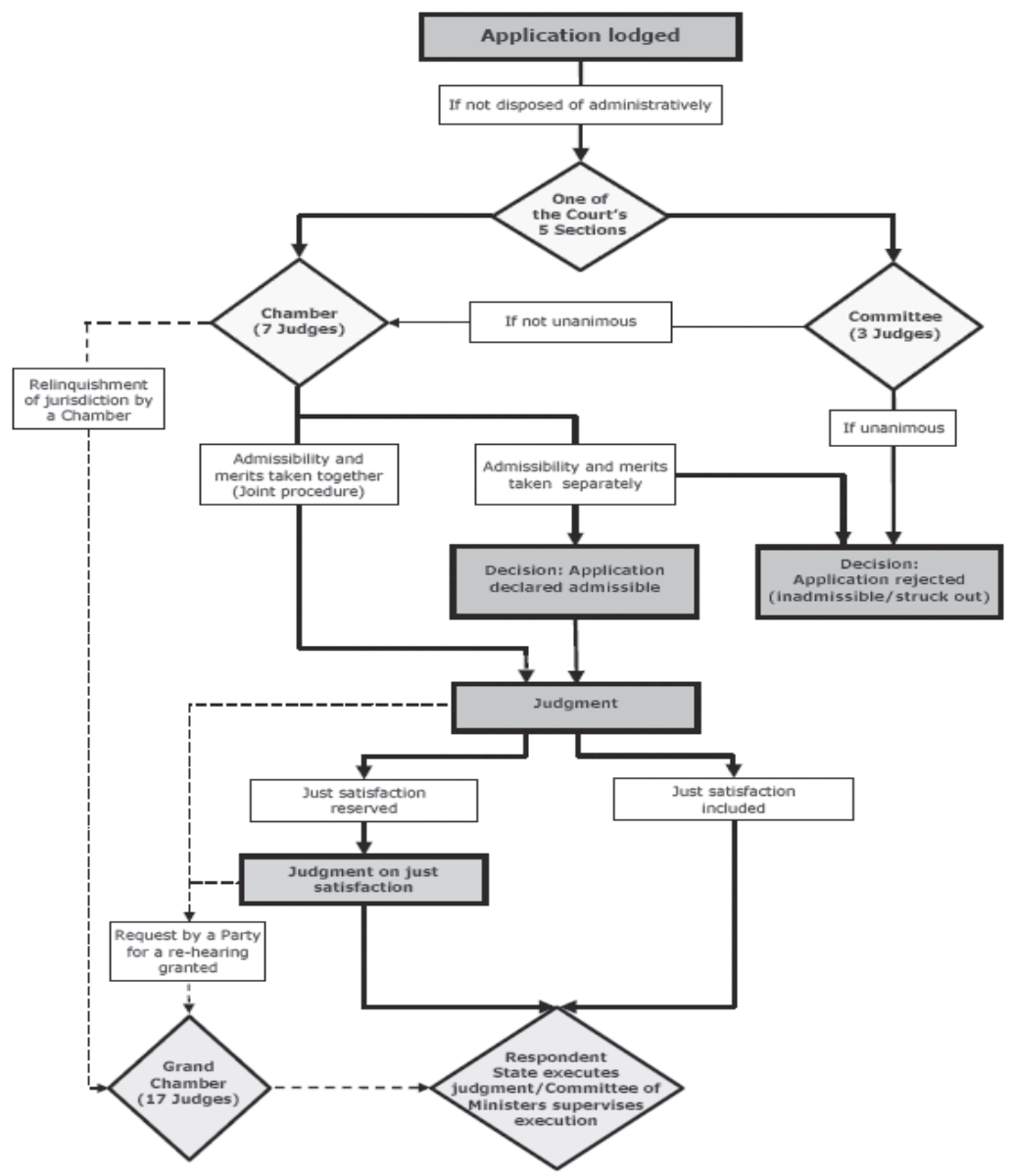

This flowchart indicates the progress of a case through the different judicial formations. In the interests of readability, it does not include certain stages in the procedure - such as communication of an application to the respondent State, consideration of a re-hearing request by the Panel of the Grand Chamber and friendly settlement negotiations.

FONTE: CtEDHs. Court of Human Rights - Some Facts and Figures. Disponível no site: <http:// www.echr.coe.int/NR/rdonlyres/ACD46A0F-615A-48B9-89D6-8480AFCC29FD/0/ FactsAndFigures_EN.pdf >. p. 2. Acesso em: 07 set. 2009. 


\section{ANEXO CC- Estatísticas da CtEDHs}

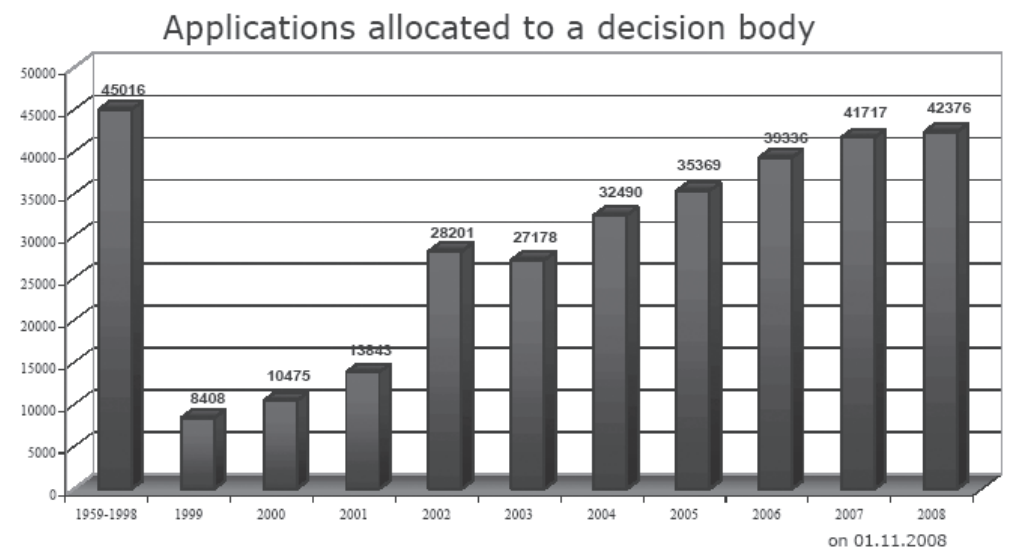

Applications which are allocated to a decision body are those for which the Court has received a correctly completed form, accompanied by copies of relevant documents. These applications will be examined by a Committee or by a Chamber of the Court. These figures do not include applications which are at the pre-judicial stage (incomplete case file).

\section{Pending allocated cases}

On 1 November 2008 approximately 95900 applications were pending before a decision body.
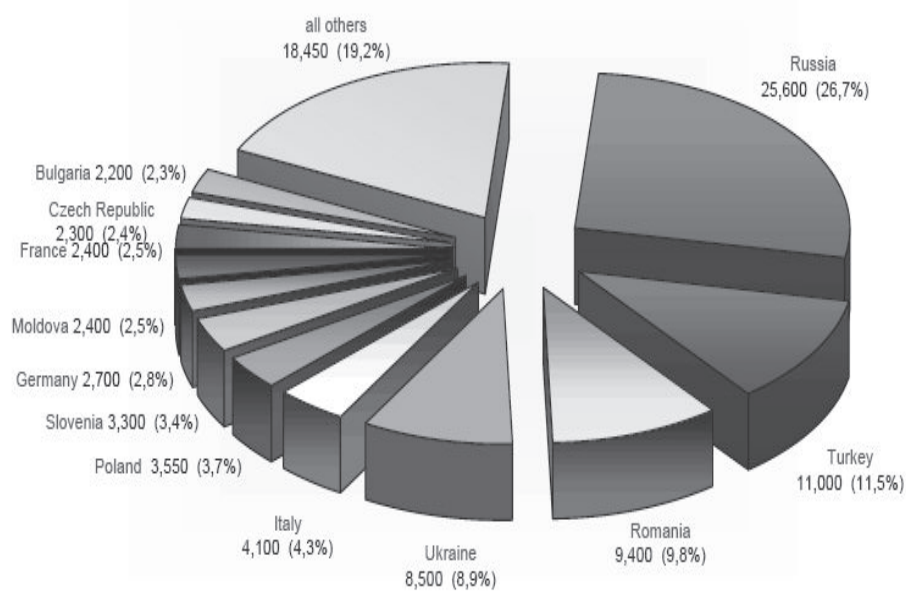

FONTE: CtEDHs. Court of Human Rights - Some Facts and Figures. Disponível no site: <http:// www.echr.coe.int/NR/rdonlyres/ACD46A0F-615A-48B9-89D6-8480AFCC29FD/0/ FactsAndFigures_EN.pdf>.p. 4. Acesso em: 07 set. 2009. 


\section{Judgments delivered by the Court}

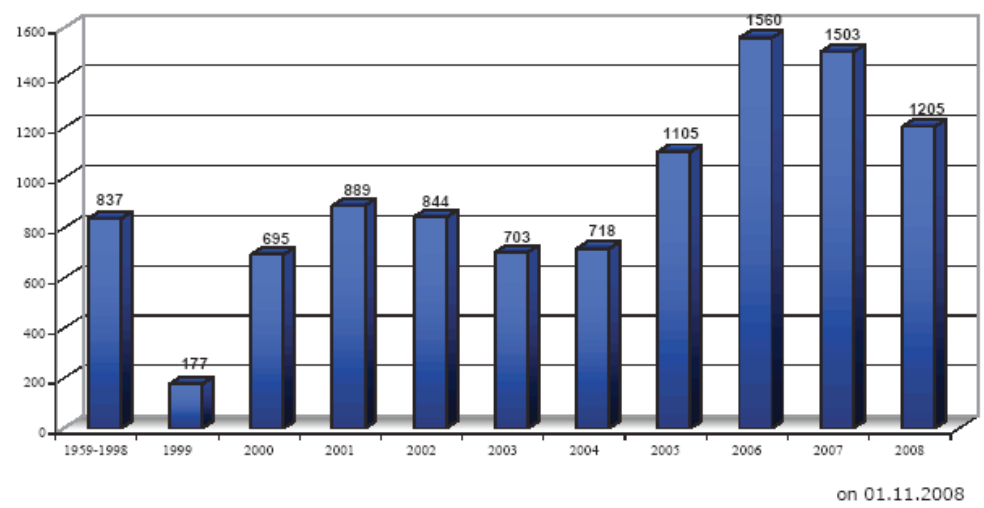

More than half the judgments delivered by the Court between 1998 and 2008 concerned four of the Council of Europe's 47 member States: Turkey (1,857 judgments), Italy $(1,789$ judgments), France (613 judgments) and Poland (601 judgments). Of the total number of judgments it has delivered since the 1998 reform, in over $83 \%$ of cases the Court has found at least one violation of the Convention by the respondent State.

\section{Violation judgments by country

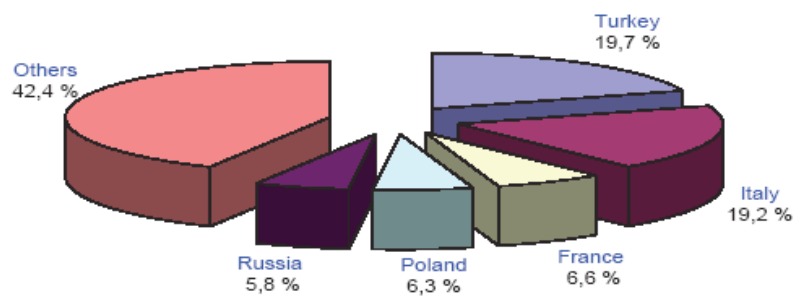

More than half the Court's judgments between 1998 and 2008 have concerned four of the Council of Europe's 47 member States: Turkey (1857 judgments), Italy (1789 judgments), France (613 judgments) and Poland (601 judgments). In more than $83 \%$ of all judgments it has delivered since the 1998 reform, the Court has found at least one violation of the Convention by the respondent State. 


\title{
Subject-matter of the Court's judgments 1998-2008
}

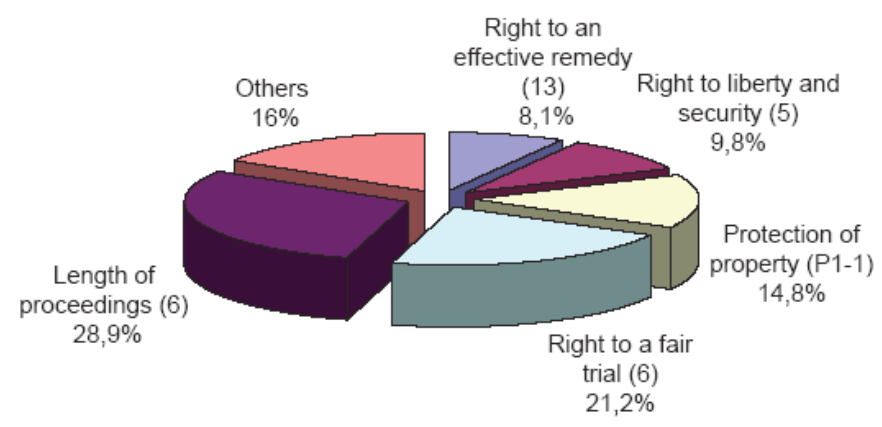

\begin{abstract}
More than half of the judgments in which the Court has found a violation between 1998 and 2008 have included a violation of Article 6, whether on account of the unfairness or the length of proceedings. Furthermore, $65 \%$ of violations found by the Court concern Article 6 (right to a fair hearing) and Article 1 of Protocol No. 1 (protection of property). Lastly, more than $7 \%$ of violations found by the Court concern the right to life or the prohibition of torture and inhuman or degrading treatment (Articles 2 and 3 of the Convention).
\end{abstract}

FONTE: CtEDHs. Court of Human Rights - Some Facts and Figures. Disopnível no site: <http:// www.echr.coe.int/NR/rdonlyres/ACD46A0F-615A-48B9-89D6-8480AFCC29FD/0/ FactsAndFigures_EN.pdf>.p. 5-6. Acesso em: 07 set. 2009.

\section{ANEXO DD- Acordo Europeu relativo a participação de pessoas na CtEDHs}

European Agreement relating to Persons Participating in Proceedings of the European Court of Human Rights

Strasbourg, 5.III.1996

The member States of the Council of Europe, signatories hereto, Having regard to the Convention for the Protection of Human Rights and Fundamental Freedoms, signed at Rome on 4 November 1950 (hereinafter referred to as "the Convention");

Recalling the European Agreement relating to Persons Participating in Proceedings of the European Commission and Court of Human Rights, signed at London on 6 May 1969; 
Having regard to Protocol No. 11 to the Convention, restructuring the control machinery established thereby, signed at Strasbourg on 11 May 1994 (hereinafter referred to as "Protocol No. 11 to the Convention"), which establishes a permanent European Court of Human Rights (hereinafter referred to as "the Court") to replace the European Commission and Court of Human Rights;

Considering, in the light of this development, that it is advisable for the better fulfilment of the purposes of the Convention that persons taking part in proceedings before the Court be accorded certain immunities and facilities by a new Agreement, the European Agreement relating to Persons Participating in Proceedings of the European Court of Human Rights (hereinafter referred to as "this Agreement"),

Have agreed as follows:

Article 1

The persons to whom this Agreement applies are:

any persons taking part in proceedings instituted before the Court as parties, their representatives and advisers;

witnesses and experts called upon by the Court and other persons invited by the President of the Court to take part in proceedings.

For the purposes of this Agreement, the term "Court" shall include committees, chambers, a panel of the Grand Chamber, the Grand Chamber and the judges. The term "taking part in proceedings" shall include making communications with a view to a complaint against a State Party to the Convention.

If in the course of the exercise by the Committee of Ministers of its functions under Article 46, paragraph 2, of the Convention, any person mentioned in paragraph 1 above is called upon to appear before, or to submit written statements to the Committee of Ministers, the provisions of this Agreement shall apply in relation to him. 
Article 2

The persons referred to in paragraph 1 of Article 1 of this Agreement shall have immunity from legal process in respect of oral or written statements made, or documents or other evidence submitted by them before or to the Court.

This immunity does not apply to communication outside the Court of any such statements, documents or evidence submitted to the Court.

Article 3

The Contracting Parties shall respect the right of the persons referred to in paragraph 1 of Article 1 of this Agreement to correspond freely with the Court.

As regards persons under detention, the exercise of this right shall in particular imply that:

a. their correspondence shall be despatched and delivered without undue delay and without alteration;

b. such persons shall not be subject to disciplinary measures in any form on account of any communication sent through the proper channels to the Court;

c. such persons shall have the right to correspond, and consult out of hearing of other persons, with a lawyer qualified to appear before the courts of the country where they are detained in regard to an application to the Court, or any proceedings resulting therefrom.

In application of the preceding paragraphs, there shall be no interference by a public authority except such as is in accordance with the law and is necessary in a democratic society in the interests of national security, for the detection or prosecution of a criminal offence or for the protection of health.

Article 4

The Contracting Parties undertake not to hinder the free movement and travel, for the purpose of attending and returning from proceedings before the Court, of persons referred to in paragraph 1 of Article 1 of this Agreement. 
No restrictions shall be placed on their movement and travel other than such as are in accordance with the law and necessary in a democratic society in the interests of national security or public safety, for the maintenance of ordre public, for the prevention of crime, for the protection of health or morals, or for the protection of the rights and freedoms of others.

Such persons shall not, in countries of transit and in the country where the proceedings take place, be prosecuted or detained or be subjected to any other restriction of their personal liberty in respect of acts or convictions prior to the commencement of the journey.

Any Contracting Party may, at the time of signature, ratification, acceptance or approval of this Agreement, declare that the provisions of this paragraph will not apply to its own nationals. Such a declaration may be withdrawn at any time by means of a notification addressed to the Secretary General of the Council of Europe.

The Contracting Parties undertake to re-admit on his return to their territory any such person who commenced his journey in the said territory.

The provisions of paragraphs 1 and 2 of this Article shall cease to apply when the person concerned has had, for a period of fifteen consecutive days from the date when his presence is no longer required by the Court, the opportunity of returning to the country from which his journey commenced.

Where there is any conflict between the obligations of a Contracting Party resulting from paragraph 2 of this Article and those resulting from a Council of Europe convention or from an extradition treaty or other treaty concerning mutual assistance in criminal matters with other Contracting Parties, the provisions of paragraph 2 of this Article shall prevail.

Article 5

Immunities and facilities are accorded to the persons referred to in paragraph 1 of Article 1 of this Agreement solely in order to ensure for them the freedom 
of speech and the independence necessary for the discharge of their functions, tasks or duties, or the exercise of their rights in relation to the Court.

The Court shall alone be competent to waive, in whole or in part, the immunity provided for in paragraph 1 of Article 2 of this Agreement; it has not only the right but the duty to waive immunity in any case where, in its opinion, such immunity would impede the course of justice and waiver in whole or in part would not prejudice the purpose defined in paragraph 1 of this Article.

The immunity may be waived by the Court, either ex officio or at the request of any Contracting Party or of any person concerned.

Decisions waiving immunity or refusing the waiver shall be accompanied by a statement of reasons.

If a Contracting Party certifies that waiver of the immunity provided for in paragraph 1 of Article 2 of this Agreement is necessary for the purpose of proceedings in respect of an offence against national security, the Court shall waive immunity to the extent specified in the certificate.

In the event of the discovery of a fact which might, by its nature, have a decisive influence and which at the time of the decision refusing waiver of immunity was unknown to the author of the request, the latter may make a new request to the Court.

Article 6

Nothing in this Agreement shall be construed as limiting or derogating from any of the obligations assumed by the Contracting Parties under the Convention or its protocols.

Article 7

This Agreement shall be open for signature by the member States of the Council of Europe, which may express their consent to be bound by: 
a. signature without reservation as to ratification, acceptance or approval; or

b. signature, subject to ratification, acceptance or approval, followed by ratification, acceptance or approval.

a. Instruments of ratification, acceptance or approval shall be deposited with the Secretary General of the Council of Europe.

Article 8

This Agreement shall enter into force on the first day of the month following the expiration of a period of one month after the date on which ten member States of the Council of Europe have expressed their consent to be bound by the Agreement in accordance with the provisions of Article 7 or on the date of entry into force of Protocol No. 11 to the Convention, whichever is the later.

In respect of any member State which subsequently expresses its consent to be bound by it, this Agreement shall enter into force on the first day of the month following the expiration of a period of one month after the date of such signature or of the deposit of the instrument of ratification, acceptance or approval.

Article 9

Any Contracting State may, when depositing its instrument of ratification, acceptance or approval or at any later date, by declaration addressed to the Secretary General of the Council of Europe, extend this Agreement to any territory or territories specified in the declaration and for whose international relations it is responsible or on whose behalf it is authorised to give undertakings.

This Agreement shall enter into force for any territory or territories specified in a declaration made pursuant to paragraph 1 on the first day of the month following the expiration of one month after the date of receipt of the declaration by the Secretary General.

Any declaration made pursuant to paragraph 1 may, in respect of any territory mentioned in such declaration, be withdrawn according to the procedure laid down for denunciation in Article 10 of this Agreement. 
Article 10

This Agreement shall remain in force indefinitely.

Any Contracting Party may, insofar as it is concerned, denounce this Agreement by means of a notification addressed to the Secretary General of the Council of Europe.

Such denunciation shall take effect six months after the date of receipt by the Secretary General of such notification. Such denunciation shall not have the effect of releasing the Contracting Parties concerned from any obligation which may have arisen under this Agreement in relation to any person referred to in paragraph 1 of Article 1.

Article 11

The Secretary General of the Council of Europe shall notify the member States of the Council of:

any signature;

the deposit of any instrument of ratification, acceptance or approval;

any date of entry into force of this Agreement in accordance with Articles

8 and 9 thereof;

any other act, notification or communication relating to this Agreement.

In witness whereof the undersigned, being duly authorised thereto, have signed this Agreement.

Done at Strasbourg, this 5th day of March 1996, in English and French, both texts being equally authentic, in a single copy which shall be deposited in the archives of the Council of Europe. The Secretary General of the Council of Europe shall transmit certified copies to each member State of the Council of Europe.

FONTE: CtEDHs. European Agreement relating to Persons Participating in Proceedings of the European Court of Human Rights. Disponível no site: <http://conventions.coe.int/Treaty/ EN/Treaties/Html/161.htm>. Acesso em: 07 set. 2009. 


\section{ANEXO EE - Relatório explicativo do Acordo Europeu relativo a participação de pessoas na CtEDHs}

Explanatory Report

\section{Introduction}

1. With the adoption by the Committee of Ministers on 20 April 1994, and subsequent signature by all member States of the Council of Europe, of Protocol No. 11 to the Convention for the Protection of Human Rights and Fundamental Freedoms (hereinafter referred to as "the Convention" (1)), the Committee of Ministers authorised, in January and September 1995, the amendment and subsequently the replacement of the European Agreement relating to persons participating in proceedings of the European Commission and Court of Human Rights, signed at London on 6 May 1969 (hereinafter referred to as "the 1969 Agreement").

2. It was considered more appropriate to replace rather than amend the 1969 Agreement in that Protocol No. 11 to the Convention restructures fundamentally the Convention's control machinery, especially by replacing the European Commission and Court of Human Rights with a new permanent Court. The 1969 Agreement remains in force and applicable to proceedings of the Commission and the Court under the present system. The new Agreement applies exclusively to proceedings before the Court as established by Protocol No. 11 to the Convention.

3. The present Agreement repeats the text of the 1969 Agreement with the alterations necessitated by the deletion of all references to the Commission as well as obsolete provisions of the former text of the Convention (see, in this connection, the travaux préparatoires of the 1969 Agreement, document H (69) 15). In addition, a few grammatical corrections have been made in the French version of the new text.

4. The new text was prepared between the months of March and September 1995 by the Committee of Experts for the Improvement of Procedures for the Protection of Human Rights (DH-PR), a subordinate body of the Steering Committee for Human Rights (CDDH).

5. This draft agreement prepared by the DH-PR and subsequently finalised by the $\mathrm{CDDH}$ - after due consultation with the Presidents of the European Com- 
mission and Court of Human Rights - was submitted to the Committee of Ministers, which adopted the text at the 556th meeting of the Ministers' Deputies on 9 February 1996. It was opened for signature by member states of the Council of Europe on 5 March 1996.

\section{Commentary on the provisions of the Agreement}

Article 1

6. The text of Article 1, paragraph 1, is a simplified and shortened version of Article 1, paragraph 1, of the 1969 Agreement; it applies to Articles 33 and 34 of the Convention. It is drafted in such a way as to ensure, inter alia, that the present Agreement applies to "third-party interventions" under Article 36 of the Convention as well as to any persons taking part in proceedings by virtue of this provision.

7. Paragraph 2 of Article 1 is based on that of the same provision in the 1969 Agreement, taking due account of changes made to the Convention by Protocol No. 11. This paragraph encompasses the work of judges who carry out their duties under the terms of the Convention or of the rules of the Court, as the case may be. Complaints include both inter-state cases and individual applications.

8. Whereas paragraph 3 of Article 1 of the 1969 Agreement related to the former Article 32 of the Convention (cases for decision by the Committee of Ministers), in the present text of paragraph 3 of Article 1 the words "Article 32 of" are deleted. Although the Committee of Ministers has no judicial or quasi-judicial role to play under any of the proceedings established by Protocol No. 11 to the Convention, reference to the Committee of Ministers remains useful in case any party is requested to take part in proceedings under Article 46 of the Convention.

Articles 2 to 6

9. The text of Articles 2 to 6 is virtually identical to that of Articles 2 to 6 of the 1969 Agreement. Reference to the Commission is deleted and replaced where necessary. As concerns correspondence with detained persons, the text of Article 3, paragraph 2.a, has been altered so as to take into account the judgment 
of the European Court of Human Rights in the Campbell case, judgment of 25 March 1992, Series A, volume 233, especially paragraphs 62 and 63.

Also, the text of Article 6 mentions the protocols to the Convention; this addition reflects developments after the adoption of the Convention in 1950. Obviously, the Agreement will extend only to protocols which States have ratified.

Articles 7 to 11

10. These Articles are based on similar provisions to those in the 1969 Agreement (Articles 7 to 11) and contain final clauses which are in conformity with the usual final clauses.

The text of Article 9, which relates to territories for whose international relations a State is responsible, has been somewhat modified in order for it to correspond more closely to similar provisions in the Convention and its protocols.

This Agreement will enter into force only after ten member States of the Council of Europe have expressed their consent to be bound by it or on the date of entry into force of Protocol No. 11 to the Convention, whichever is the later.

Note : (1) Unless otherwise stated, article references are to the articles of the Convention as amended by Protocol No. 11 .

FONTE: CtEDHs. Explanatory Report. Disponível no site <http://conventions.coe.int/ Treaty/EN/Reports/HTML/161.htm>. Acesso em: 07 set. 2009. 


\section{ANEXO FF - Formulário para petição individual perante a CtEDHs}

Application pack

Documentation for persons wishing to apply to the European Court of Human Rights

The Application Form should be printed out, completed and sent by post addressed to the Registrar of the European Court of Human Rights at the following address

We would draw your attention to the fact that applications to the Court may be sent only by post, even if they have been faxed beforehand.

European Court of Human Rights

Council of Europe

67075 Strasbourg-Cedex

France

Tel: +33 (0)3 88412018

Fax: $+33(0) 388412730$

Voir notice Numéro de dossier / See Notes File-number

Ver Nota Explicativa Número de queixa POR

\section{COUR EUROPÉENNE DES DROITS DE L'HOMME / EUROPEAN COURT OF HUMAN RIGHTS / TRIBUNAL EUROPEU DOS DIREITOS DO HOMEM}

Conseil de l'Europe - Council of Europe - Conselho da Europa Strasbourg, France - Estrasburgo, França

\section{REQUÊTE / APPLICATION/QUEIXA}

présentée en application de l'article 34 de la Convention européenne des Droits de l'Homme,

ainsi que des articles 45 et 47 du Règlement de la Cour / under Article 34 of the European Convention on Human Rights

and Rules 45 and 47 of the Rules of Court / apresentada nos termos do artigo $34^{\circ}$ da Convenção Europeia dos Direitos do Homem e dos artigos $45^{\circ}$ e $47^{\circ}$ do Regulamento do Tribunal 


\section{LES PARTIES/ THE PARTIES/ AS PARTES}

\section{A. LE REQUÉRANT / LA REQUÉRANTE / THE APPLICANT/O /A REQUERENTE}

(Renseignements à fournir concernant le / la requérant(e) et son / sa représentant(e) éventuel(le))

(Fill in the following details of the applicant and the representative, if any) (Informações a dar relativas ao/à requerente e ao/à seu/sua eventual representante) 1. Nom de famille 2. Prénom (s)

Surname / Apelido(s) First name (s) / Nome(s)

Sexe: masculin / féminin Sex: male / female Sexo: masculino / feminino

3. Nationalité 4. Profession

Nationality / Nacionalidade Occupation / Profissão

5. Date et lieu de naissance

Date and place of birth / Data e local de nascimento

6. Domicile

Permanent address / Domicílio

7. Tel. $\mathrm{N}^{\circ}$

8. Adresse actuelle (si différente de 6.)

Present address (if different from 6.) / Morada actual (se diferente de 6.)

9. Nom et prénom du / de la représentant(e) 1

Name of representative* / Apelido(s) e nome(s) do / da representante

10. Profession du / de la représentant $(e)$

Occupation of representative / Profissão do / da representante

11. Adresse du / de la représentant(e)

Address of representative / Morada do / da representante

12. Tel. $\mathrm{N}^{\circ}$ Fax $\mathrm{N}^{\circ}$

\section{B. LA HAUTE PARTIE CONTRACTANTE / THE HIGH CONTRACTING PARTY/ A ALTA PARTE CONTRATANTE}

(Indiquer ci-après le nom de l'Etat / des Etats contre le(s) quel(s) la requête est dirigée)

(Fill in the name of the State(s) against which the application is directed)

(Indicar aqui o(s) Estado(s) contra o(s) qual(quais) se dirige a queixa) 
13.

1 Si le / la requérant(e) est représenté(e), joindre une procuration signée par le / la requérant(e) en faveur du / de la représentant(e).

A form of authority signed by the applicant should be submitted if a representative is appointed.

Se o / a requerente está representado/a, juntar uma procuração assinada pelo/a requerente em favor do / da representante.

\section{EXPOSÉ DES FAITS / STATEMENT OF THE FACTS / EXPOSIÇÃO DOS FACTOS}

(Voir $\$ 19$ (b) de la notice) / (See $\$ 19$ (b) of the Notes) / (Ver $n^{\circ} 19$ (b) da Nota Explicativa)

14.

Si nécessaire, continuer sur une feuille séparée / Continue on a separate sheet if necessary / Se necessário, continue em folha separada

\section{EXPOSÉ DE LA OU DES VIOLATION(S) DE LA CONVENTION ET I OU DES PROTOCOLES ALLÉGUÉE(S), AINSI QUE DES ARGUMENTS À L'APPUI STATEMENT OF ALLEGED VIOLATION(S) OF THE CONVENTION AND / OR PROTOCOLS AND OF RELEVANT ARGUMENTS / EXPOSIÇÃO DA(S) VIOLAÇÃO(ÕES) DA CONVENÇÃO ALEGADA(S), ASSIM COMO DOS ARGUMENTOS EM QUE SE BASEIA}

(Voir $\$ 19$ (c) de la notice) / (See $\$ 19$ (c) of the Notes) / (Ver $n^{\circ} 19$ (c) da Nota Explicativa)

15. 


\section{EXPOSÉ RELATIF AUX PRESCRIPTIONS DE L'ARTICLE 35 § 1 DE LA CONVENTION / STATEMENT RELATIVE TO ARTICLE 35 \& 1 OF THE CONVENTION / EXPOSIÇÃO RELATIVA AOS REQUISITOS DO ARTIGO $35^{\circ} \S 1$ DA CONVENÇÃO}

(Voir $\$ 19$ (d) de la notice. Donner pour chaque grief, et au besoin sur une feuille séparée, les renseignements demandés sous les points 16 à 18 ci-après)

(See $\$ 19$ (d) of the Notes. If necessary, give the details mentioned below under points 16 to 18 on a separate sheet for each separate complaint)

(Ver $n^{\circ} 19$ (d) da Nota Explicativa. Se necessário, faça constar os dados solicitados nos números 16 a 18 numa folha separada, para cada uma das queixas)

16. Décision interne définitive (date et nature de la décision, organe - judiciaire ou autre - l'ayant rendue)

Final decision (date, court or authority and nature of decision)

Decisão interna definitiva (data e natureza da decisão, órgão - judicial ou outro - que a tenha pronunciado)

17. Autres décisions (énumérées dans l'ordre chronologique en indiquant, pour chaque décision, sa date, sa nature et l'organe - judiciaire ou autre - l'ayant rendue) Other decisions (list in chronological order, giving date, court or authority and nature of decision for each of them)

Outras decisões (enumeradas por ordem cronológica, indicando a sua data, a sua natureza e o órgão - judicial ou outro - que as tenha pronunciado)

18. Dispos(i)ez-vous d'un recours que vous n'avez pas exercé? Si oui, lequel et pour quel motif n'a-t-il pas été exercé?

Is there or was there any other appeal or other remedy available to you which you have not used? If so, explain why you have not used it.

Dispunha o / a requerente de um outro recurso que não tenha exercido? Em caso afirmativo, indique qual e porque motivo não foi exercido.

Si nécessaire, continuer sur une feuille séparée / Continue on a separate sheet if necessary / Se necessário, continue em folha separada 


\section{EXPOSÉ DE L'OBJET DE LA REQUÊTE / STATEMENT OF THE OBJECT OF THE APPLICATION / EXPOSIÇÃO DO OBJECTO DA QUEIXA}

(Voir $\$ 19$ (e) de la notice) / (See $\$ 19$ (e) of the Notes) / (Ver no 19 (e) da Nota Explicativa)

19.

\section{AUTRES INSTANCES INTERNATIONALES TRAITANT OU AYANT TRAITÉ}

L'AFFAIRE / STATEMENT CONCERNING OTHER INTERNATIONAL PROCEEDINGS / OUTRAS INSTÂNCIAS INTERNACIONAIS QUE CONHEÇAM OU TIVERAM CONHECIMENTO DESTE CASO

(Voir $\$ 19$ (f) de la notice) / (See $\$ 19(f)$ of the Notes) / (Ver $n^{\circ} 19(f)$ da Nota Explicativa)

20. Avez-vous soumis à une autre instance internationale d'enquête ou de règlement les griefs énoncés dans la présente requête? Si oui, fournir des indications détaillées à ce sujet.

Have you submitted the above complaints to any other procedure of international investigation or settlement? If so, give full details.

Foram as queixas contidas neste pedido submetidas a uma outra instância internacional? Em caso afirmativo, fornecer informação detalhada a esse respeito.

\section{PIÈCES ANNEXÉES (PAS D'ORIGINAUX, UNIQUEMENT DES COPIES ;}

PRIÈRE DE N'UTILISER NI AGRAFE, NI ADHÉSIF, NI LIEN D'AUCUNE SORTE) I LIST OF DOCUMENTS (NO ORIGINAL DOCUMENTS, ONLY PHOTOCOPIES,DO NOT STAPLE, TAPE OR BIND DOCUMENTS) / DOCUMENTOS ANEXOS À QUEIXA (APENAS CÓPIAS E NÃO OS ORIGINAIS POR FAVOR NÃO UTILIZAR AGRAFOS, FITA-COLA OU OUTRA FORMA DE UNIR.)

(Voir $\$ 19$ (g) de la notice. Joindre copie de toutes les décisions mentionnées sous ch. IV et VI ci-dessus. Se procurer, au besoin, les copiesnécessaires, et, en cas 
d'impossibilité, expliquer pourquoi celles-ci ne peuvent pas être obtenues. Ces documents ne vous seront pas retournés.)

(See $\$ 19(g)$ of the Notes. Include copies of all decisions referred to in Parts IV and VI above. If you do not have copies, you should obtain them. If you cannot obtain them, explain why not. No documents will be returned to you.)

(Ver $n^{\circ} 19$ (g) da Nota Explicativa.. Deve juntar cópia de todas as decisões mencionadas nas secções IV e VI deste formulário. No caso de não dispor de cópias, deverá fazê-las. Se não puder obtê-las, explique os motivos. Nenhum documento lhe será devolvido.)

21.

a).

b).

c).

\section{DÉCLARATION ET SIGNATURE / DECLARATION AND SIGNATURE / DECLARAÇÃO E ASSINATURA}

(Voir $\$ 19$ (h) de la notice) / (See $\$ 19$ (h) of the Notes) / (Ver $n^{\circ} 19$ (h) da Nota Explicativa)

Je déclare en toute conscience et loyauté que les renseignements qui figurent sur la présente formule de requête sont exacts. / I hereby declare that, to the best of my knowledge and belief, the information I have given in the present application form is correct. / Declaro por minha consciência e honra que todos os dados fornecidos neste formulário de queixa são exactos.

Lieu / Place / Lugar

Date / Date / Data.

(Signature du / de la requérant(e) ou du / de la représentant(e))

(Signature of the applicant or of the representative)

(Assinatura do/da requerente ou do/da seu/sua representante) 


\section{NOT AEXPLICATIVA}

destinada às pessoas que pretendam queixar-se ao

\section{TRIBUNAL EUROPEU DOS DIREITOS DO HOMEM}

\section{QUAIS SÃO AS QUEIXAS QUE O TRIBUNAL PODE EXAMINAR ?}

1. O Tribunal Europeu dos Direitos do Homem é um tribunal internacional que tem competência para examinar queixas provenientes de pessoas que se considerem vítimas de violação de um dos direitos previstos na Convenção Europeia dos Direitos do Homem. Esta Convenção é um tratado internacional que vincula um número relativamente elevado de Estados, os quais se comprometeram a respeitar um certo número de direitos fundamentais. Tais direitos estão previstos na Convenção e nos Protocolos nº 1, 4, 6, 7, 12 e 13, que alguns Estados também ratificaram. Antes de tudo, deve examinar os textos referidos, que encontrará em anexo.

2. Se se considerar pessoal e directamente vítima de uma violação de um ou vários destes direitos fundamentais, cometida por um dos Estados visados, pode queixar-se ao Tribunal Europeu.

3. O Tribunal Europeu pode apenas examinar queixas relativas a um ou a vários dos direitos enumerados na Convenção e nos Protocolos. O Tribunal Europeu não é um tribunal de recurso que possa anular ou modificar as decisões proferidas pelas jurisdições nacionais, nem tem competência para intervir directamente, em seu favor, junto das autoridades contra as quais se queixa.

4. O Tribunal Europeu pode apenas examinar queixas dirigidas contra um dos Estados que tenham ratificado a Convenção ou o Protocolo que garanta o direito em causa. O Tribunal Europeu não pode examinar queixas que digam respeito a factos anteriores à data em que o Estado em causa tenha ratificado estes instrumentos. As datas de ratificação vêm indicadas na presente

5. Só poderá recorrer ao Tribunal Europeu a propósito de actos praticados por uma autoridade pública (legislativa, administrativa, judicial, etc.) de um destes Estados. O Tribunal Europeu não pode examinar queixas dirigidas contra particulares ou instituições privadas.

6. Nos termos do artigo $35^{\circ} n^{\circ} 1$ da Convenção, o Tribunal Europeu só poderá ser solicitado depois do esgotamento das vias de recurso internas e no prazo 
de seis meses a contar da data da decisão interna definitiva. As queixas que não respeitem estas condições de admissibilidade não poderão ser examinadas pelo Tribunal Europeu.

7. A regra do esgotamento das vias de recurso internas significa que as pessoas que desejem dirigir-se ao Tribunal Europeu devem previamente tentar obter perante os tribunais nacionais uma decisão sobre a situação de que se queixam, recorrendo até à mais alta instância competente. Se não interpôs todos os recursos disponíveis, deverá demonstrar que os recursos em causa não eram eficazes.

8. Ao interpor os referidos recursos, deverá ter cumprido as regras processuais aplicáveis, nomeadamente os prazos previstos na lei. Se, por exemplo, o seu recurso foi indeferido porque o interpôs fora do prazo legal ou porque não respeitou qualquer outra regra processual ou de competência, o Tribunal Europeu não poderá examinar a sua queixa.

9. No entanto, se se queixar de uma decisão judicial, nomeadamente de uma sentença de condenação, não lhe é exigido que tente obter a revisão do processo, depois de ter interposto todos os recursos judiciais ordinários. Também não é necessário interpor um recurso extrajudicial ou pedir um perdão ou uma amnistia. Além disso, as petições (ao Parlamento, a um chefe de Estado ou de Governo, a um ministro ou ao Provedor de Justiça) não constituem recursos que devam ser exercidos.

10. Depois da mais alta instância nacional competente ter proferido a sua decisão, tem um prazo de seis meses para se dirigir ao Tribunal Europeu. Este prazo conta-se a partir da notificação, pessoal ou do seu advogado, da decisão final, proferida em relação aos recursos ordinários e não a partir de decisão posterior que rejeite um eventual pedido de revisão do processo, a interposição de um recurso extrajudicial, um pedido de perdão ou de amnistia, ou, por exemplo, uma petição.

11. O prazo de seis meses é interrompido com o envio da primeira carta ao Tribunal Europeu expondo claramente, mesmo que de maneira sumária, o objecto da queixa que pretende apresentar, ou pelo envio do formulário de queixa preenchido. Um simples pedido de informações não é suficiente para interromper o prazo de seis meses. 12. A título meramente informativo, mais de $90 \%$ das queixas examinadas pelo Tribunal Europeu são declaradas inadmissíveis por não respeitarem uma das condições de admissibilidade anteriormente descritas. 


\section{COMO SE DEVE DIRIGIR AO TRIBUNAL ?}

13. As línguas oficiais do Tribunal Europeu são o francês e o inglês mas, se preferir, pode escrever para o Secretariado na língua oficial de um dos Estados que ratificaram a Convenção. Durante a fase inicial do processo, poderá receber cartas do Tribunal Europeu nessa mesma língua. Deverá no entanto estar consciente de que numa fase posterior do processo, isto é, se o Tribunal Europeu decidir solicitar ao Governo a apresentação de observações escritas sobre as suas alegações, toda a correspondência que lhe será enviada pelo Tribunal Europeu será redigida em francês ou em inglês, e as observações posteriores a submeter por si ou pelo seu representante deverão em princípio ser igualmente em francês ou inglês.

14. A queixa só pode ser apresentada via postal (e não por telefone). Se apresentar a queixa por correio electrónico ou por fax, deverá obrigatoriamente confirmá-la via postal. Será inútil deslocar-se pessoalmente a Estrasburgo para expor o seu caso verbalmente.

15. Toda a correspondência relativa à sua queixa deve ser enviada para a seguinte

morada:

Exmo. Senhor Secretário do

Tribunal Europeu dos Direitos do Homem

Conselho da Europa

F - 67075 STRASBOURG CEDEX.

Por favor não utilize agrafos, fita-cola ou qualquer outra forma de unir as cartas ou os documentos destinados ao Tribunal Europeu. Todas as páginas devem ser numeradas por ordem.

16. Após a recepção da sua primeira carta ou do formulário de queixa, o secretariado do Tribunal Europeu responder-lhe-á informando-o da abertura de um processo em seu nome (ao qual será atribuído um número que deverá ser mencionado em toda a correspondência ulterior) e fornecendo-lhe um conjunto de etiquetas com um código de barras que deverá colar na correspondência que endereçar ao Tribunal Europeu. Poderão posteriormente ser-lhe pedidos outros documentos, informações ou explicações complementares relativos à sua queixa. O secretariado não pode contudo prestar informações sobre as disposições legais 
em vigor no Estado contra o qual é apresentada a queixa nem prestar consulta jurídica sobre a aplicação ou interpretação do direito interno.

17. Deverá, no seu interesse, ser diligente na resposta à correspondência enviada pelo secretariado do Tribunal Europeu. Qualquer atraso ou ausência de resposta da sua parte são susceptíveis de ser considerados como uma manifestação do seu desinteresse no prosseguimento da instrução do processo.

18. Se considerar que as queixas que pretende formular dizem respeito a um dos direitos garantidos pela Convenção ou por um dos Protocolos e que as condições acima descritas se encontram preenchidas, deverá preencher o formulário de queixa de maneira detalhada e legível e enviá-lo o mais rapidamente possível, juntamente com os documentos pertinentes, em todo o caso no prazo de oito semanas após a data da primeira carta enviada pelo secretariado do Tribunal Europeu. Se o formulário de queixa não for enviado no prazo de oito semanas, a data que será tida em conta para verificar o respeito do prazo de seis meses estipulado no artigo 35 no 1 (ver parágrafos 6 e 10) será a data do envio do formulário de queixa preenchido, e não a data do envio da sua primeira carta ao Tribunal Europeu. Além disso, se o formulário de queixa não for enviado ao secretariado do Tribunal Europeu no prazo de seis meses após a data em que o formulário lhe foi remetido, tal será considerado como uma manifestação do desinteresse da sua parte no prosseguimento da instrução do processo, que será destruído.

19. Quando preencher o formulário de queixa queira por favor:

a) indicar os elementos de identificação das partes (parte I do formulário). Se a queixa for apresentada em nome de vários requerentes, utilize uma folha em separado para cada um deles. Se tiver um representante, junte uma procuração (ou tantas procurações, quantos os representantes);

b) expor de forma clara e concisa os factos pelos quais se queixa (parte II do formulário). Procure descrever os factos pela sua ordem, indicando as datas exactas. Se as suas alegações se referirem a situações distintas (por exemplo, diferentes processos judiciais), descreva uma situação de cada vez;

c) explicar, o mais claramente possível, quais são as queixas que pretende formular tendo em consideração a Convenção (Parte III 
do formulário). Indique qual ou quais as disposições da Convenção em causa e explique porque considera que os factos por si descritos na parte II do formulário tiveram como consequência a violação dessas disposições;

d) indicar as informações e as datas que sejam susceptíveis de demonstrar que os prazos estipulados e a regra do esgotamento das vias de recurso internas foram cumpridos (parte IV do formulário). Utilize uma folha em separado para cada situação descrita;

e) indicar, resumidamente, quais as suas pretensões relativamente ao processo no

Tribunal Europeu (parte V do formulário);

f) indicar se as queixas contidas neste formulário foram submetidas a uma outra instância internacional (parte VI do formulário). Em caso afirmativo, queira fornecer informações detalhadas a esse respeito, nomeadamente o nome da instituição a que recorreu, as datas e os pormenores dos processos instruídos e das decisões proferidas. Junte ao formulário uma cópia das decisões e de todos os documentos pertinentes;

g) juntar ao formulário uma lista de todas as decisões judiciais ou outras por si mencionadas na parte IV e VI, bem como uma lista de todos os demais documentos que queira submeter à apreciação do Tribunal Europeu como meio de prova (acta da audiência, auto de inquirição de testemunhas, etc.). Se ainda não o tiver feito, junte ao formulário de queixa uma cópia integral dos mencionados documentos. Nenhum documento lhe será devolvido. É portanto do seu interesse enviar unicamente cópias e

não os originais dos documentos.

h) assinar o formulário. Se este for assinado apenas pelo seu representante, deverá ser acompanhado de uma procuração devidamente preenchida (salvo se a procuração tiver já sido enviada ao secretariado do Tribunal Europeu). 
20. Regra geral, todas as informações contidas nos documentos por si enviados ao secretariado do Tribunal Europeu, nomeadamente os elementos de identificação das pessoas em causa, serão acessíveis ao público. Estas informações poderão constar do HUDOC, base de dados do Tribunal Europeu acessível via internet, se o Tribunal Europeu as tiver mencionado na exposição de factos contida na comunicação da queixa ao Estado visado, na decisão sobre a sua admissibilidade, na decisão de arquivamento ou no acórdão. Se não desejar que a sua identidade seja revelada, deverá precisá-lo e expor as razões que justifiquem uma tal derrogação à regra geral de publicidade do processo. $\mathrm{O}$ Tribunal Europeu pode autorizar $\mathrm{O}$ anonimato em casos excepcionais e devidamente motivados.

21. Para a apresentação inicial da queixa, não é necessário ser representado e o seu eventual representante não terá de ser obrigatoriamente um advogado. Se desejar dirigir-se ao Tribunal Europeu através de um advogado ou de outro representante, será necessário juntar ao formulário de queixa uma procuração. $\mathrm{O}$ representante legal de uma pessoa colectiva (sociedade comercial, associação, etc.) ou de um grupo de particulares deverá fazer prova do seu direito estatutário ou legal de representação.

22. O Tribunal Europeu não concede assistência judiciária para o ajudar a pagar um advogado que o assista na redacção da queixa inicial. Numa fase posterior do processo, se a queixa for comunicada ao Governo em causa para observações escritas, o requerente poderá eventualmente obter a assistência judiciária, se não dispuser de meios suficientes para remunerar um advogado e se o Tribunal Europeu julgar que a concessão da assistência judiciária é necessária para a boa marcha do processo.

23. A instrução do processo é gratuita. O processo é escrito, pelo menos na sua fase preliminar. Não é, pois, necessário que se apresente na sede do Tribunal Europeu. Será sistematicamente informado de todas as decisões proferidas pelo Tribunal. 


\section{TRIBUNAL EUROPEU DOS DIREITOS DO HOMEM}

\section{P R O C U R A Ç Ã 01}

(Artigo $36^{\circ}$ do Regulamento do Tribunal)

Eu, abaixo-assinada/o

(nome e morada da/o queixosa/o)

dou pela presente poderes a

(nome e morada da/o representante)

para me representar no processo perante o Tribunal Europeu dos Direitos do Homem e em todos os processos susceptíveis de intervir no âmbito da Convenção Europeia dos Direitos do Homem, relacionados com a queixa que introduzi, nos termos do artigo $34^{\circ}$ da Convenção, contra

(Governo respondente)

no dia .

(data da carta de introdução da queixa)

(local e data)

(assinatura da/o queixosa/o)

Pela presente, aceito esta nomeação

(assinatura da/o representante)

1. Este formulário deverá ser preenchido e assinado pelos queixosos que pretendam ser representados perante o Tribunal Europeu, e pela/o advogada/o que os represente ou qualquer outra pessoa nomeada para este efeito.

FONTE: CtEDHs. Apply to the Court - Application pack. Disponível no site: <http://www. echr.coe.int/ECHR/EN/Header/Applicants/Apply+to+the+Court/Application+pack/> Acesso em: 07 set. 2009. 


\section{ANEXO GG - Explicações práticas para apresentação de petições individuais por carta e por e-mail}

\section{PRACTICE DIRECTION1}

\section{INSTITUTION OF PROCEEDINGS2}

(individual applications under Article 34 of the Convention)

\section{General}

1. An application under Article 34 of the Convention must be submitted in writing. No application may be made by phone.

2. An application must be sent to the following address:

The Registrar

European Court of Human Rights

Council of Europe

F - 67075 STRASBOURG CEDEX.

3. An application should normally be made on the form 3 referred to in Rule 47 $\$ 1$ of the Rules of Court and be accompanied by the documents and decisions mentioned in Rule $47 \$ 1(\mathrm{~h})$.

Where an applicant introduces his application in a letter, such letter must set out, at least in summary form, the subject matter of the application in order to interrupt the running of the six-month rule contained in Article $35 \$ 1$ of the Convention.

4. If an application has not been submitted on the official form or an introductory letter does not contain all the information referred to in Rule 47, the applicant may be required to submit a duly completed form. It must be despatched within eight weeks from the date of the Registry's letter requesting the applicant to complete and return the form.

Failure to comply with this time-limit will have implications for the date of introduction of the application and may therefore affect the applicant's compliance with the six-month rule contained in Article $35 \$ 1$ of the Convention.

5. Applicants may file an application by sending it by facsimile ("fax")4. However, they must despatch the signed original by post within eight weeks from the date of the Registry's letter referred to in paragraph 4 above.

6. Where, within six months of being asked to do so, an applicant has not returned a duly completed application form, the file will be destroyed. 
1. Issued by the President of the Court in accordance with Rule 32 of the Rules of Court on

1 November 2003 and amended on 22 September 2008.

2. This practice direction supplements Rules 45 and 47 of the Rules of Court.

3. The relevant form can be downloaded from the Court's website (www.echr.coe. int).

4. Fax no. +00 33 (0)3 884127 30; other facsimile numbers can be found on the Court's website (www.echr.coe.int).

7. On receipt of the first communication setting out the subject-matter of the case, the Registry will open a file, whose number must be mentioned in all subsequent correspondence. Applicants will be informed thereof by letter. They may also be asked for further information or documents.

8.

(a) An applicant should be diligent in conducting correspondence with the Court's Registry.

(b) A delay in replying or failure to reply may be regarded as a sign that the applicant is no longer interested in pursuing his application.

9. Failure to provide further information at the Registry's request (see paragraph 8) may result in the application being declared inadmissible or struck out of the Court's list of cases.

\section{Form and contents}

10. An application should be written legibly and, preferably, typed.

11. Where, exceptionally, an application exceeds 10 pages (excluding annexes listing documents), an applicant must also file a short summary.

12. Where applicants produce documents in support of the application, they should not submit original copies. The documents should be listed in order by date, numbered consecutively and given a concise description (e.g. letter, order, judgment, appeal, etc.).

13. An applicant who already has an application pending before the Court must inform the Registry accordingly, stating the application number. 
14.

(a) Where an applicant does not wish to have his or her identity disclosed, he or she should state the reasons for his or her request in writing, pursuant to Rule $47 \S 3$.

(b) The applicant should also state whether, in the event of anonymity being authorised by the President of the Chamber, he or she wishes to be designated by his or her initials or by a single letter (e.g. "X", "Y”, “Z”, etc.).

FONTE: CtEDHs. Practice Direction - Institution of Proceddings. Disponível no site: $<$ http:// www.echr.coe.int/NR/rdonlyres/9F0B9646-3806-4814-A7CF-345304DCCDB2/0/ PracticeDirectionsInstitutionOfProceedingsMarch2009.pdf >. Acesso em: 07 set. 2009.

\section{PRACTICE DIRECTION1}

\section{SECURED ELECTRONIC FILING}

\section{Scope of application}

1. The Governments of the Contracting States which have opted for the Court's system of secured electronic filing shall send all their written communications with the Court by uploading them on the secured Internet site set up for that purpose and shall accept written communications sent to them by the Registry of the Court by downloading them from that site, with the following exceptions:

a) All written communications in relation to a request for interim measures under Rule 39 of the Rules of Court shall be sent simultaneously by two means: through the secured site and by fax;

b) Attachments, such as plans, manuals, etc. which may not be comprehensively viewed in an electronic format may be filed by post;

c) The Court's Registry may request that a paper document or attachment be submitted by post.

2. If the Government have filed a document by post or fax, they shall, as soon as possible, file electronically a notice of filing by post or fax, describing the document sent, stating the date of dispatch and setting forth the reasons why electronic filing was not possible. 


\section{Technical requirements}

3. The Government shall possess the necessary technical equipment and follow the user manual sent to them by the Court's Registry.

\section{Format and naming convention}

4. A document filed electronically shall be in PDF format, preferably in searchable PDF.

5. Unsigned letters and written pleadings shall not be accepted. Signed documents to be filed electronically shall be generated by scanning the original paper copy. The Government shall keep the original paper copy in their files.

6. The name of a document filed electronically shall be prefixed by the application number, followed by the name of the applicant as spelled in the Latin script by the Registry of the Court and contain an indication of the contents of the document 2 .

1. Issued by the President of the Court in accordance with Rule 32 of the Rules of Court on 22 September 2008.

2. The following is an example: 65051/01 Karagyozov Observ Adm Merits.

\section{Relevant date with regard to time limits}

7. The date on which the Government have successfully uploaded a document on the secured site shall be considered as the date of dispatch within the meaning of Rule $38 \$ 2$ of the Rules of Court or the date of filing for the purposes of Rule $73 \S 1$ of the Rules of Court.

8. To facilitate keeping track of the correspondence exchanged, every day shortly before midnight the secured server generates automatically an electronic mail message listing the documents that have been filed electronically within the past 24 hours.

\section{Different versions of one and the same document}

9. The secured electronic site shall not permit the modification, replacement or deletion of an uploaded document. If the need arises for the Government to modify a document they have uploaded, they shall create a new document named differently (for example, by adding the word "modified" in the document name). This opportunity should only be used where genuinely necessary and should not be used to correct minor errors. 
10. Where the Government have filed more than one version of the same document, only the document filed in time shall be taken into consideration. Where more than one version has been filed in time, the latest version shall be taken into consideration, unless the President of the Chamber decides otherwise.

FONTE: CtEDHs. Practice Direction - Secured Eletronic Filing. Disponível no site: <http:// www.echr.coe.int/NR/rdonlyres/C3F78149-F39D-48E9-B348-99C86FFDD273/0/ SecuredDocumentsDecember2008.pdf > Acesso em: 07 set. 2009.

\section{PRACTICE DIRECTION1}

\section{WRITTEN PLEADINGS}

\section{Filing of pleadings}

\section{General}

1. A pleading must be filed with the Registry within the time-limit fixed in accordance with Rule 38 and in the manner described in paragraph 2 of that Rule.

2. The date on which a pleading or other document is received at the Court.s Registry will be recorded on that document by a receipt stamp.

3. All pleadings, as well as all documents annexed thereto, should be submitted to the Court.s Registry in 3 copies sent by post with 1 copy sent, if possible, by fax.

4. Secret documents should be filed by registered post.

5. Unsolicited pleadings shall not be admitted to the case file unless the President of the Chamber decides otherwise (see Rule $38 \$ 1$ ).

\section{Filing by facsimile}

6. A party may file pleadings or other documents with the Court by sending them by facsimile (.fax.)2.

7. The name of the person signing a pleading must also be printed on it so that he or she can be identified.

\section{Form and contents}

\section{Form}

8. A pleading should include: 
(a) the application number and the name of the case;

(b) a title indicating the nature of the content (e.g. observations on admissibility [and the merits]; reply to the Government.s/ the applicant.s observations on admissibility [and the merits]; observations on the merits; additional observations on admissibility [and the merits]; memorial etc.).

1. Issued by the President of the Court in accordance with Rule 32 of the Rules of Court on 1 November 2003.

2. Fax no. +0033 (0)3 884127 30; other facsimile numbers can be found on the Court.s website (www.echr.coe.int).

9. A pleading should normally in addition

(a) be on A4 paper having a margin of not less than $3.5 \mathrm{~cm}$ wide;

(b) be wholly legible and, preferably, typed;

(c) have all numbers expressed as figures;

(d) have pages numbered consecutively;

(e) be divided into numbered paragraphs;

(f) be divided into chapters and/or headings corresponding to the form and style of the Court.s decisions and judgments (.Facts. / .Domestic law [and practice]. / .Complaints. / .Law.; the latter chapter should be followed by headings entitled .Preliminary objection on ....; .Alleged violation of Article ...., as the case may be);

(g) place any answer to a question by the Court or to the other party.s arguments under a separate heading;

(h) give a reference to every document or piece of evidence mentioned in the pleading and annexed thereto.

10. If a pleading exceeds 30 pages, a short summary should also be filed with it.

11. Where a party produces documents and/or other exhibits together with a pleading,every piece of evidence should be listed in a separate annex.

\section{Contents}

12. The parties. pleadings following communication of the application should include: 
(a) any comments they wish to make on the facts of the case; however,

(i) if a party does not contest the facts as set out in the statement of facts prepared by the Registry, it should limit its observations to a brief statement to that effect;

(ii) if a party contests only part of the facts as set out by the Registry, or wishes to supplement them, it should limit its observations to those specific points;

(iii) if a party objects to the facts or part of the facts as presented by the other party, it should state clearly which facts are uncontested and limit its observations to the points in dispute;

(b) legal arguments relating first to admissibility and, secondly, to the merits of the case; however,

(i) if specific questions on a factual or legal point were put to a party, it should, without prejudice to Rule 55, limit its arguments to such questions;

(ii) if a pleading replies to arguments of the other party, submissions should refer to the specific arguments in the order prescribed above.

13.

(a) The parties. pleadings following the admission of the application should include:

(i) a short statement confirming a party.s position on the facts of the case as established in the decision on admissibility;

(ii) legal arguments relating to the merits of the case;

(iii) a reply to any specific questions on a factual or legal point put by the Court.

(b) An applicant party submitting claims for just satisfaction at the same time should do so in the manner described in the practice direction on filing just satisfaction claims.1

14. In view of the confidentiality of friendly-settlement proceedings (see Article $38 \$ 2$ of the Convention and Rule $62 \$ 2$ ), all submissions and documents filed within the framework of the attempt to secure a friendly settlement should be submitted separately from the written pleadings. 
15. No reference to offers, concessions or other statements submitted in connection with the friendly settlement may be made in the pleadings filed in the contentious proceedings.

\section{Time-limits}

\section{General}

16. It is the responsibility of each party to ensure that pleadings and any accompanying documents or evidence are delivered to the Court.s Registry in time.

\section{Extension of time-limits}

17. A time-limit set under Rule 38 may be extended on request from a party.

18. A party seeking an extension of the time allowed for submission of a pleading must make a request as soon as it has become aware of the circumstances justifying such an extension and, in any event, before the expiry of the time-limit. It should state the reason for the delay.

19. If an extension is granted, it shall apply to all parties for which the relevant time-limit is running, including those which have not asked for it.

1. Not yet issued, for the time being see Rule 60 .

\section{Failure to comply with requirements for pleadings}

20. Where a pleading has not been filed in accordance with the requirements set out in paragraphs 8-15 of this practice direction, the President of the Chamber may request the party concerned to resubmit the pleading in compliance with those requirements.

21. A failure to satisfy the conditions listed above may result in the pleading being considered not to have been properly lodged (see Rule $38 \$ 1$ of the Rules of Court).

FONTE: CtEDHs. Practice Direction - Writen Pleading. Disponível no site: <http:// www.echr.coe.int/NR/rdonlyres/F3BB90F1-E7D7-43BB-8D64-DE6FC54BE779/0/ PracticeDirectionsWrittenPleadingsMarch2005.pdf>. Acesso em: 07 set. 2009. 


\section{ANEXO HH - Estrutura organizacional da OEA}

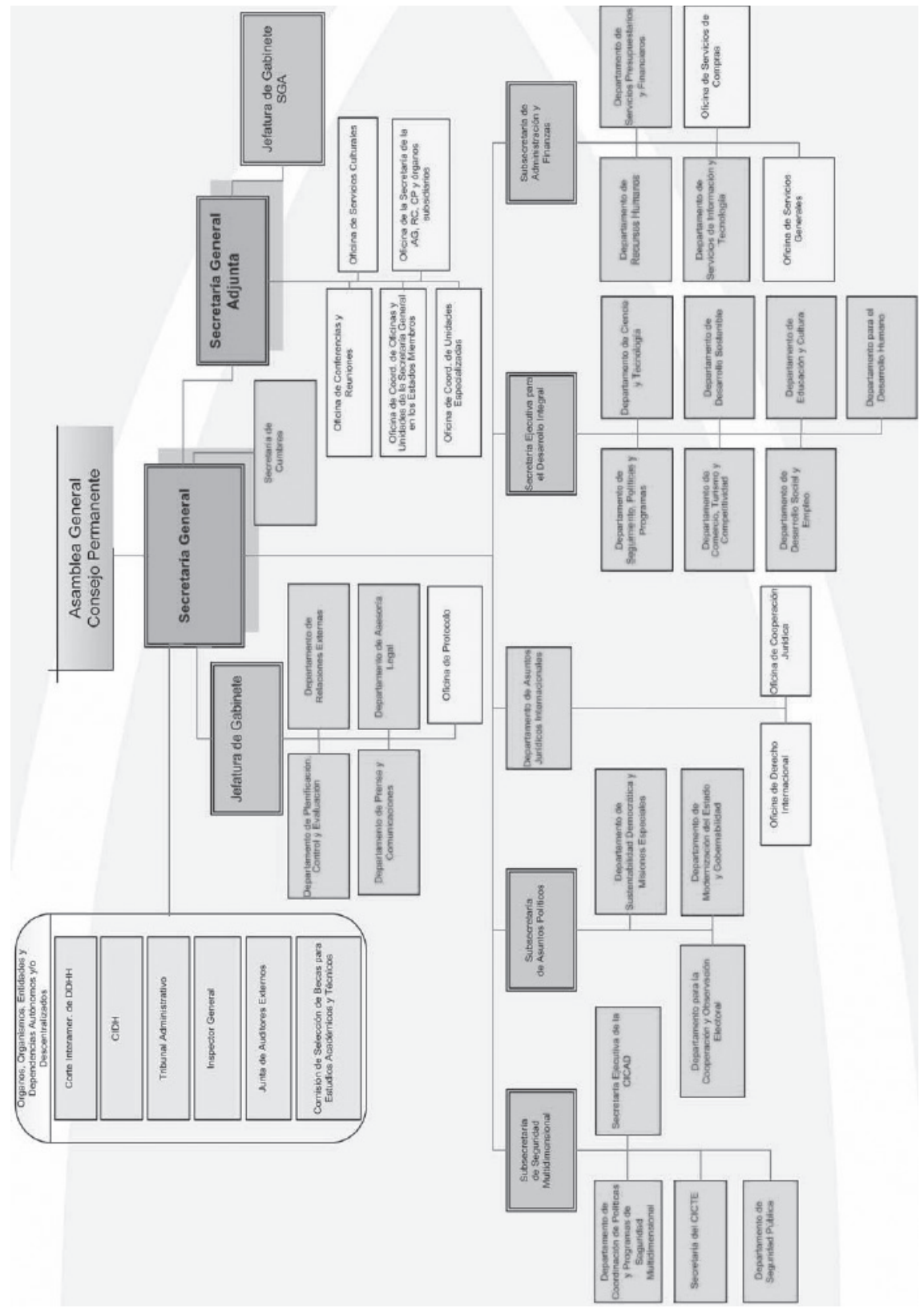

FONTE: OEA/ORGANOGRAMA, disponível em: <http://scm.oas.org/pdfs/2008/AG04093p. pdf>. Acesso: em 10 mar. 2008. Acesso em: 07 set. 2009. 
ANEXO II - Estados Americanos nas Organizações Regionais

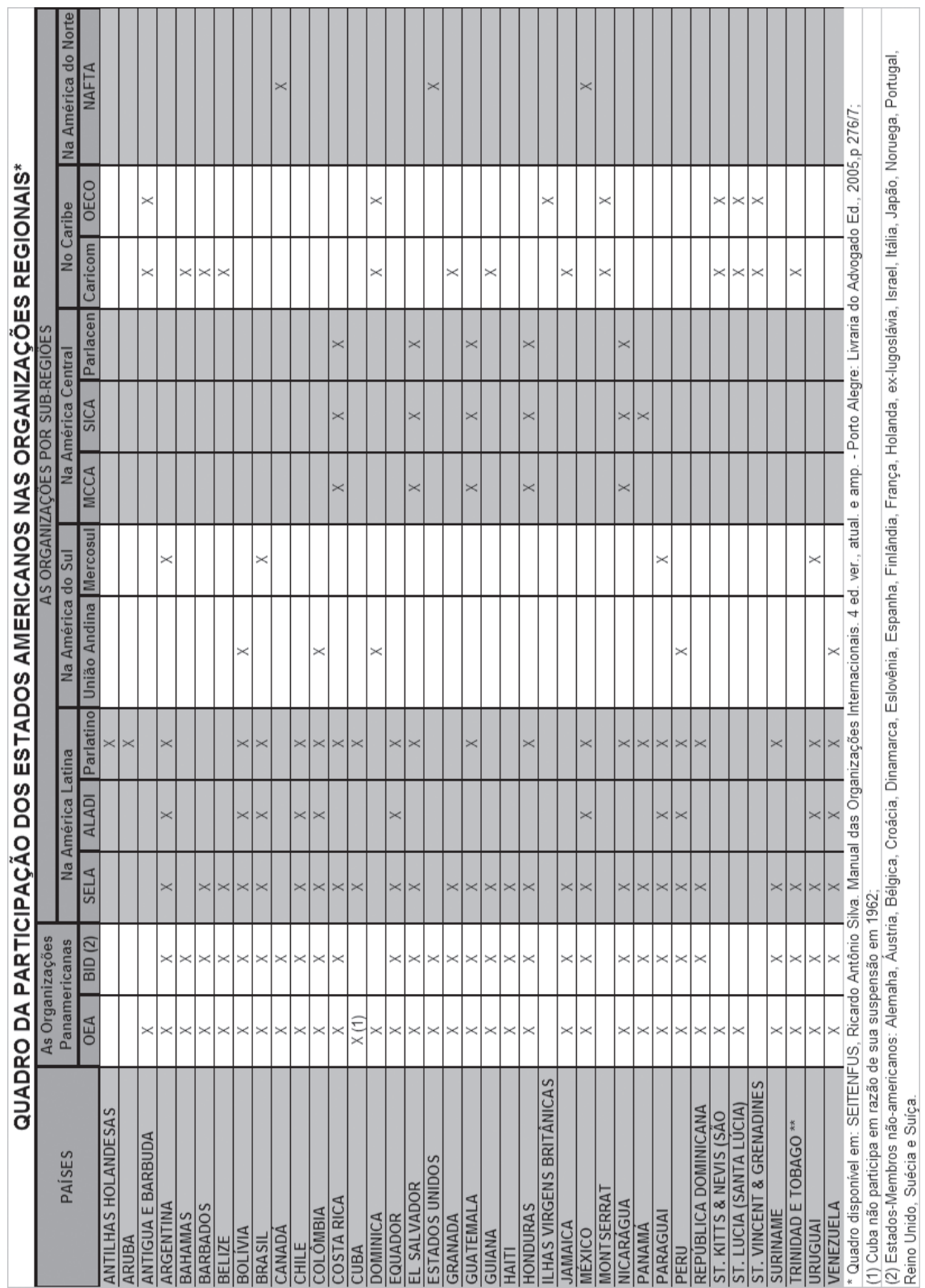

FONTE: SEITENFUS, Ricardo Antônio Silva. Manual das Organizações Internacionais. 4ed. ver., atual. e amp. - Porto Alegre: Livraria do Advogado Ed., 2005, p. 276/7. 


\section{ANEXO JJ - Movimento de constitucionalização dos DHs}

Movimento de constitucionalização pode ser verificado nas seguintes Constituições:

1. art. 75 (22) da Constituição de 1994 da Argentina, cf. o site:<http://www. casarosada.gov.ar/images/stories/ley_24430.pdf >;

2. $\quad$ art. 5 da Constituição de 2005 do Chile, cf. o site: <http://www.gobiernodechile.cl/viewEstado.aspx?idArticulo=22481 $>$;

3. o art. 93 e 94 da Constituição de 1991 da Colômbia, cf. o site: <http://pdba. georgetown.edu/constitutions/colombia/col91.html>;

4. o $\$ 3$ do art. 5 da CFB de 1988, cf. o site: <http://www.planalto.gov.br/ccivil_03/Constituicao/Constituiçao.htm>;

5. o art. 15 da Constituição de 1982 de Honduras, cf. o site: <http://www.congreso.gob.hn/constituciones/CONSTITUCION\%201982\%20DECRETO\%20 131-82.pdf>;

6. o art. 46 da Constituição de 1985 da Guatemala, cf. o site: <http://pdba.georgetown.edu/Constitutions/Guate/guate85.html >;

7. o art. 46 da Constituição de 1987 da Nicarágua, cf. o site: <http://pdba.georgetown.edu/Constitutions/Nica/nica87.html>;

8. os arts. 142 e 145 da Constituição de 1992 do Paraguai, cf. o site: <http://www. senado.gov.py/leyes/?pagina=ley_resultado\&id=2865 $>$;

9. os arts. 32, 55, 205 e disposição final 4 da Constituição de 1993 do Peru, cf o site: <http://www2.congreso.gob.pe/congreso/constitucion.doc >;

10. os arts. 19 a 31 da Constituição de 1999 da Venezuela, cf. o site: <http://www. gobiernoenlinea.ve/legislacion-view/sharedfiles/ConstitucionRBV1999. pdf $>$.

FONTE: Sites do governo com Constituições Federais. Acesso em: 09/04/2009. 
ANEXO KK - A adesão do Brasil aos Tratados de DHs

\begin{tabular}{|c|c|c|c|}
\hline \multirow[b]{2}{*}{ Título } & \multirow[b]{2}{*}{ Data } & \multicolumn{2}{|c|}{ Promulgação } \\
\hline & & $\begin{array}{l}\text { Decreto } \\
\text { no }\end{array}$ & Data \\
\hline Convenção sobre a Escravatura & $25 / 09 / 1926$ & 66 & $14 / 07 / 1965$ \\
\hline $\begin{array}{l}\text { Convenção sobre o Instituto Indigenista } \\
\text { Interamericano }\end{array}$ & $24 / 02 / 1940$ & 36098 & 19/08/1954 \\
\hline $\begin{array}{l}\text { Acordo Relativo a Concessão de um } \\
\text { Título de Viagem para Refugiados } \\
\text { que Estejam sob Jurisdição do Comitê } \\
\text { Intergovernamental de Refugiados }\end{array}$ & $15 / 10 / 1946$ & 38018 & 07/10/1955 \\
\hline $\begin{array}{l}\text { Convenção Interamericana sobre a } \\
\text { Concessão dos Direitos Civis à Mulher }\end{array}$ & $02 / 05 / 1948$ & 31643 & $23 / 10 / 1952$ \\
\hline $\begin{array}{l}\text { Convenção Interamericana sobre a } \\
\text { Concessão dos Direitos Políticos à } \\
\text { Mulher }\end{array}$ & $02 / 05 / 1948$ & 28011 & $19 / 04 / 1950$ \\
\hline $\begin{array}{l}\text { Convenção para a Prevenção do Crime } \\
\text { de Genocídio }\end{array}$ & 09/12/1948 & 30822 & $06 / 05 / 1952$ \\
\hline $\begin{array}{l}\text { Declaração Universal dos Direitos } \\
\text { Humanos }\end{array}$ & $10 / 12 / 1948$ & & \\
\hline $\begin{array}{l}\text { Convenção para a Melhoria da Sorte dos } \\
\text { Feridos e Enfermos dos Exércitos em } \\
\text { Campanha (I) }\end{array}$ & 12/08/1949 & 42121 & 21/08/1957 \\
\hline $\begin{array}{l}\text { Convenção para a Melhoria da Sorte } \\
\text { dos Feridos, Enfermos e Náufragos das } \\
\text { Forças Armadas no Mar (II) }\end{array}$ & 12/08/1949 & 42121 & 21/08/1957 \\
\hline $\begin{array}{l}\text { Convenção Relativa ao Tratamento dos } \\
\text { Prisioneiros de Guerra (III) }\end{array}$ & 12/08/1949 & 42121 & 21/08/1957 \\
\hline $\begin{array}{l}\text { Convenção Relativa à Proteção dos Civis } \\
\text { em Tempo de Guerra (IV) }\end{array}$ & 12/08/1949 & 42121 & 21/08/1957 \\
\hline $\begin{array}{l}\text { Convenção Relativa ao Estatuto dos } \\
\text { Refugiados }\end{array}$ & $02 / 07 / 1951$ & 50215 & 28/01/1961 \\
\hline $\begin{array}{l}\text { Convenção sobre os Direitos Políticos } \\
\text { da Mulher }\end{array}$ & $31 / 03 / 1953$ & 52476 & $12 / 09 / 1963$ \\
\hline $\begin{array}{l}\text { Convenção relativa à Escravatura, } \\
\text { assinada em Genebra a } 25 \text { de setembro } \\
\text { de } 1926 \text { e emendada pelo Protocolo } \\
\text { aberto à assinatura ou à aceitação na } \\
\text { Sede das Nações Unidas }\end{array}$ & 07/12/1953 & 58563 & $01 / 06 / 1966$ \\
\hline $\begin{array}{l}\text { Convenção Suplementar sobre a } \\
\text { Abolição da Escravatura, do Tráfico de } \\
\text { Escravos e das Instituições e Práticas } \\
\text { Análogas à Escravatura }\end{array}$ & 07/09/1956 & 58563 & $01 / 06 / 1966$ \\
\hline
\end{tabular}




\begin{tabular}{|c|c|c|c|}
\hline \multirow[b]{2}{*}{ Título } & \multirow[b]{2}{*}{ Data } & \multicolumn{2}{|c|}{ Promulgação } \\
\hline & & $\begin{array}{l}\text { Decreto } \\
\text { no }\end{array}$ & Data \\
\hline $\begin{array}{l}\text { Convenção Internacional sobre a } \\
\text { Eliminação de Todas as Formas de } \\
\text { Discriminação Racial }\end{array}$ & 07/03/1966 & 65810 & 08/12/1969 \\
\hline $\begin{array}{l}\text { Protocolo Facultativo ao Pacto de } \\
\text { Direitos Civis e Políticos }\end{array}$ & 16/12/1966 & & \\
\hline $\begin{array}{l}\text { Pacto Internacional sobre Direitos Civis } \\
\text { e Políticos }\end{array}$ & 19/12/1966 & 592 & 06/07/1992 \\
\hline $\begin{array}{l}\text { Pacto Internacional sobre Direitos } \\
\text { Econômicos, Sociais e Culturais }\end{array}$ & 19/12/1966 & 591 & 06/07/1992 \\
\hline $\begin{array}{l}\text { Protocolo sobre o Estatuto dos } \\
\text { Refugiados }\end{array}$ & $31 / 01 / 1967$ & 70946 & 07/08/1972 \\
\hline $\begin{array}{l}\text { Convenção Americana sobre Direitos } \\
\text { Humanos (Pacto de São José) }\end{array}$ & 22/11/1969 & 678 & $06 / 11 / 1992$ \\
\hline $\begin{array}{l}\text { Convenção sobre a Eliminação de Todas } \\
\text { as Formas de Discriminação Contra as } \\
\text { Mulheres }\end{array}$ & 18/12/1979 & $4377(*)$ & $13 / 09 / 2002$ \\
\hline $\begin{array}{l}\text { Convenção Contra a Tortura e outros } \\
\text { Tratamentos ou Penas Cruéis, } \\
\text { Desumanos ou Degradantes }\end{array}$ & $10 / 12 / 1984$ & 40 & 15/02/1991 \\
\hline $\begin{array}{l}\text { Convenção Interamericana para } \\
\text { Prevenir e Punir a Tortura }\end{array}$ & 09/12/1985 & 98386 & 09/11/1989 \\
\hline $\begin{array}{l}\text { Protocolo Adicional à Convenção } \\
\text { Americana sobre Direitos Humanos em } \\
\text { Matéria de Direitos Econômicos, Sociais } \\
\text { e Culturais (Protocolo de San Salvador) }\end{array}$ & $17 / 11 / 1988$ & 3321 & $30 / 12 / 1999$ \\
\hline $\begin{array}{l}\text { Convenção no } 169 \text { da Organização } \\
\text { Internacional do Trabalho - OIT sobre } \\
\text { Povos Indígenas e Tribais }\end{array}$ & 27/06/1989 & 5051 & $19 / 04 / 2004$ \\
\hline Convenção sobre os Direitos da Criança & 20/11/1989 & 99710 & $21 / 11 / 1990$ \\
\hline $\begin{array}{l}\text { Protocolo à Convenção Americana sobre } \\
\text { Direitos Humanos Relativo à Abolição } \\
\text { da Pena de Morte }\end{array}$ & $08 / 06 / 1990$ & 2754 & $27 / 08 / 1998$ \\
\hline $\begin{array}{l}\text { Acordo Constitutivo do Fundo para o } \\
\text { Desenvolvimento dos Povos Indígenas } \\
\text { da América Latina e do Caribe }\end{array}$ & 24/07/1992 & 3108 & $30 / 06 / 1999$ \\
\hline $\begin{array}{l}\text { Conferência Mundial sobre Direitos } \\
\text { Humanos (Declaração e Programa de } \\
\text { Ação) }\end{array}$ & 25/6/1993 & & \\
\hline $\begin{array}{l}\text { Convenção Interamericana sobre Tráfico } \\
\text { Internacional de Menores }\end{array}$ & 18/03/1994 & 2740 & $20 / 08 / 1998$ \\
\hline
\end{tabular}




\begin{tabular}{|c|c|c|c|}
\hline \multirow[b]{2}{*}{ Título } & \multirow[b]{2}{*}{ Data } & \multicolumn{2}{|c|}{ Promulgação } \\
\hline & & $\begin{array}{c}\text { Decreto } \\
\text { no }\end{array}$ & Data \\
\hline $\begin{array}{l}\text { Convenção Interamericana para } \\
\text { Prevenir, Punir e Erradicar a Violência } \\
\text { contra a Mulher }\end{array}$ & 09/06/1994 & 1973 & 01/08/1996 \\
\hline $\begin{array}{l}\text { Convenção Interamericana para a } \\
\text { Eliminação de Todas as Formas de } \\
\text { Discriminação contra as Pessoas } \\
\text { Portadoras de Deficiência }\end{array}$ & 07/06/1999 & 3956 & $08 / 10 / 2001$ \\
\hline $\begin{array}{l}\text { Protocolo Facultativo à Convenção para } \\
\text { a Eliminação de Todas as Formas de } \\
\text { Discriminação contra as Mulheres }\end{array}$ & 06/10/1999 & 4316 & $30 / 07 / 2002$ \\
\hline \begin{tabular}{|l|} 
Declaração de Reconhecimento da \\
Competência Obrigatória da Corte \\
Interamericana de Direitos Humanos
\end{tabular} & & 4463 & $08 / 11 / 2002$ \\
\hline $\begin{array}{l}\text { Declaração Facultativa à Convenção } \\
\text { Internacional sobre a Eliminação de } \\
\text { Todas as Formas de Discriminação } \\
\text { Racial }\end{array}$ & & 4738 & $12 / 06 / 2003$ \\
\hline $\begin{array}{l}\text { Protocolo Facultativo à Convenção } \\
\text { sobre os Direitos da Criança relativo ao } \\
\text { envolvimento de crianças em conflitos } \\
\text { armados }\end{array}$ & $25 / 05 / 2000$ & 5006 & $08 / 03 / 2004$ \\
\hline $\begin{array}{l}\text { Protocolo Facultativo à Convenção } \\
\text { sobre os Direitos da Criança referente } \\
\text { à venda de crianças, à prostituição } \\
\text { infantil e à pornografia infantil }\end{array}$ & $25 / 05 / 2000$ & 5007 & $08 / 03 / 2004$ \\
\hline $\begin{array}{l}\text { Protocolo Facultativo à Convenção } \\
\text { contra a Tortura e outros Tratamentos } \\
\text { ou Penas Cruéis,Desumanos ou } \\
\text { Degradantes }\end{array}$ & $18 / 12 / 2002$ & 6.085 & $19 / 4 / 2007$ \\
\hline
\end{tabular}

(*) O Decreto n $^{\circ} 4.377$, de 13/09/2002 revogou o Decreto no 86.460, de 20/03/1984.

FONTE: MRE/DAI. Disponível no site: <http://www2.mre.gov.br/dai/dhumanos.htm>. Acesso em: 07 set. 2009. 


\section{ANEXO LL - Proposta de protocolo à Convenção Americana}

\section{PROJETO DE PROTOCOLO FACULTATIVO DA CONVENÇÃO AMERICANA SOBRE DIREITOS HUMANOS}

\section{PREÂMBULO}

Os Estados Partes deste Protocolo, CONSIDERANDO:

Que toda pessoa deve ter pleno direito à justiça, como enuncia a Declaração Americana dos Direitos e Deveres do Homem em seu artigo XVIII ao estabelecer que "toda pessoa pode recorrer aos tribunais para fazer respeitar seus direitos";

Que o artigo 44 da Convenção Americana sobre Direitos Humanos estabelece que "qualquer pessoa ou grupo de pessoas, ou entidade não-governamental legalmente reconhecida em um ou mais Estados membros da Organização, pode apresentar à Comissão petições que contenham denúncias ou queixas de violação desta Convenção por um Estado Parte";

Que a Convenção Americana sobre Direitos Humanos estabelece, em seu artigo 8 , o direito das pessoas às garantias judiciais e, em seu artigo 24, o direito à igualdade de proteção, sem discriminação, perante a lei, pelo qual os indivíduos devem poder aceder sem restrição à proteção judicial oferecida pela Corte Interamericana de Direitos Humanos, que deve garantir esses direitos de forma contundente e em sua própria jurisdição;

Que a Corte Interamericana de Direitos Humanos e a Comissão Interamericana de Direitos Humanos promoveram recentemente modificações em seus regulamentos que favorecem um aumento em seu trabalho a favor da proteção dos direitos humanos, em especial outorgando o locus standi in judicio às vítimas de violações dos direitos humanos perante a Corte Interamericana de Direitos Humanos; e

TENDO PRESENTE que os Estados Partes da Convenção Americana sobre Direitos Humanos se comprometem a respeitar e garantir os direitos e liberdades nela consagrados a toda pessoa, sem qualquer discriminação, inclusive a proteção judicial internacional e o acesso à mesma sem qualquer restrição,

CONVIERAM em assinar o seguinte 


\section{PROTOCOLO FACULTATIVO À CONVENÇÃO AMERICANA SOBRE DIREITOS HUMANOS}

\section{Artigo 1}

A vítima, seus familiares ou seus representantes têm o direito de levar diretamente um caso à Corte Interamericana de Direitos Humanos depois de concluído o processo perante a Comissão Interamericana de Direitos Humanos. Para isso terão o prazo de três meses contados a partir do vencimento do prazo estabelecido pelo artigo 51 da Convenção Americana sobre Direitos Humanos.

\section{Artigo 2}

Este Protocolo Facultativo aplicar-se-á a fatos ocorridos depois de sua entrada em vigor.

\section{Artigo 3}

Este Protocolo Facultativo não admite reservas.

\section{Artigo 4}

Este Protocolo Facultativo fica aberto à assinatura e à ratificação ou adesão de todo Estado Parte da Convenção Americana sobre Direitos Humanos. A ratificação deste Protocolo ou a adesão ao mesmo serão efetuadas mediante o depósito de um instrumento de ratificação ou adesão na Secretaria-Geral da Organização dos Estados Americanos.

\section{Artigo 5}

Em conformidade com o artigo 77, parágrafo 2, da Convenção Americana sobre Direitos Humanos, este Protocolo entrará em vigor, para os Estados que o ratificarem ou a ele aderirem, a partir do depósito do instrumento correspondente de ratificação ou adesão na Secretaria-Geral da Organização dos Estados Americanos.

\section{Artigo 6}

1. Os Estados Partes poderão denunciar este Protocolo a qualquer momento mediante notificação escrita dirigida à Secretário-Geral da Organização dos Estados Americanos. A denúncia surtirá efeito seis meses a partir da data em que a Secretaria-Geral receber a notificação. 
2. A denúncia será feita sem prejuízo de que as disposições deste Protocolo continuem sendo aplicadas a qualquer caso apresentado perante a Corte Interamericana de Direitos Humanos, por força do artigo 1, antes da data de vigência da denúncia.

FONTE: OEA/AG. Projeto de Protocolo Facultativo da Convenção Americana sobre Direitos Humanos. Disponível no site: <http://scm.oas.org/DOC_SEARCH_ENGINE/ PORTUGUESE/hist_01/ag01643p06.doc>. Acesso em: 07 set. 2009.

\section{ANEXO MM - Atas das reuniões de Experts de 5/6 fev e 8/9 fev/2000 ACTA DE LA III REUNION D TRABAJO DE EXPERTOS SOBRE EL FORTALECIMENTODELSISTEMA INTERAMERICANODEPROTECCION DE LOS DERECHOS HUMANOS (FEBRERO DE 2000)}

5 y 6 de febrero de 2000

\section{RECOMENDACIONES}

\section{PARTICIPACION DE LOS INDIVIDUOS EM EL PROCEDIMENTO ANTE} LA CORTE

Los participantes expresaron su deseo de uma mayor participaciónd e los individus em el procedimiento ante la Corte, em particular em actos tales como la presentación y decargo de pruebas y formulación de alegatos. Senalaron que esto podría lograrse, de inicio, medinte uma reforma reglamentaria, antes de que se considere um proyecto de Protocolo Adciional em este momento. Sin embargo, expresaron su preocupación por la necesidad imperiosa de mayores recusos fnancieros del sistema para asegurar dicha participación de los indivíduos. 


\section{ACTA DE LA IV REUNION DE TRABAJO DE EXPERTOS SOBRE EL FORTALECIMIENTO DEL SISTEMA INTERAMERICANO DE PROTECCION DE LOS DERECHOS HUMANOS (FEBRERO DE 2000)}

8 y 9 de febrero de 2000

\section{RECOMENDACIONES}

\section{PARTICIPATION DE LOS INDIVIDUOS EM EL PROCEDIMIENTO ANTE LA CORTE}

Los presntes expresaron su dseo de uma participación más amplia, efectiva autônoma de los indivíduos em el procedimiento ante la Corte, em particular em actos tales como la presentación y descargo de pruebas y formulación de alegatos. Senalaron que esto puede lograrse, deinicio, mediante uma reforma reglametnaria, antes de que se considere um Protocolo a la Convención al respecto.

Además, observaron el papel que tienen los indivíduos ante la Comisión em el procedimeiento em cuanto al eentual envio de casos a la Corte, a efectos de que sean consultaods al respecto.

FONTE: ROBLES, Manuel E. Ventura. El acceso directo de la víctima a la Corte Interamericana de Derechos Humanos: um ideal y uma llucha de Antonio A. Cançado Trindade. In: Os rumos do Direito Internacional dos direitos humanos: ensaios em homenagem ao professor Antônio Augusto Cançado Trindade/Renato Zebini Ribeiro Leão, coord. - Porto Alegre: Sergio Antonio Fabris Ed. 2005, p. 228/9. 


\title{
ANEXO NN - Estudo sobre o acesso das pessoas à CtIDHs
}

\author{
OEA/Ser.P \\ AG/RES. 1833 (XXXI-O/01) \\ 5 junio 2001 \\ Original: español
}

\section{RESOLUCIÓN \\ ESTUDIO SOBRE EL ACCESO DE LAS PERSONAS A LA CORTE INTERAMERICANA DE DERECHOS HUMANOS}

(Aprobada en la cuarta sesión plenaria, celebrada el 5 de junio de 2001)

\section{LA ASAMBLEA GENERAL,}

VISTOS:

El informe del Consejo Permanente sobre la evaluación y el perfeccionamiento del sistema interamericano de protección y promoción de los derechos humanos, presentado en cumplimiento de la resolución AG/RES. 1701 (XXX-O/00) (CP/doc. /01);

La Declaración y el Plan de Acción de la Tercera Cumbre de las Américas, celebrada en Canadá, en abril de 2001;

La propuesta del Gobierno de Costa Rica (CP/doc.3405/01) "Proyecto de Protocolo Facultativo a la Convención Americana sobre los Derechos Humanos" (AG/doc.629/01);

Las recientes reformas reglamentarias de la Comisión Interamericana de Derechos Humanos y de la Corte Interamericana de Derechos Humanos respecto al acceso de las personas al sistema interamericano de derechos humanos;

CONSIDERANDO que los Jefes de Estado y de Gobierno en el Plan de Acción de la Tercera Cumbre de las Américas, decidieron continuar promoviendo medidas concretas para fortalecer y perfeccionar el sistema interamericano de derechos humanos, en particular, el funcionamiento de la Corte Interamericana de Derechos Humanos y la Comisión Interamericana de Derechos Humanos, 
encomendando, entre otros temas, facilitar el acceso de las personas al mecanismo interamericano de protección de los derechos humanos;

TENIENDO PRESENTE que el derecho internacional de los derechos humanos tiene como característica intrínseca que la persona es sujeto del derecho internacional; y

CONSIDERANDO que el diálogo sobre el fortalecimiento del sistema interamericano de derechos humanos logró grandes avances en la identificación de áreas que requieren de un mayor estudio, en aras de desarrollar un sistema de derechos humanos sólido y eficaz que evolucione teniendo como única finalidad la protección del individuo y la salvaguardia de sus derechos fundamentales,

RESUELVE:

1. Encomendar al Consejo Permanente que inicie el estudio del acceso de la víctima a la Corte Interamericana de Derechos Humanos (ius standi) y su puesta en práctica.

2. Encomendar al Consejo Permanente que, en la consideración del estudio mencionado en el párrafo anterior, tome en cuenta dentro de los referentes el estudio realizado por el Gobierno de Costa Rica (AG/CP/doc.629/01), así como las recientes reformas reglamentarias de la Corte y de la Comisión y Interamericanas de Derechos Humanos respecto al acceso de las personas al sistema interamericano de derechos humanos.

3. Solicitar al Consejo Permanente que contemple iniciar la consideración de dicho estudio, con el apoyo de la Corte Interamericana de Derechos Humanos, la Comisión Interamericana de Derechos Humanos y la Sociedad Civil, durante el segundo semestre de 2001, a fin de remitirlo, lo antes posible, a los Estados Parte de la Convención Americana de Derechos Humanos para su consideración durante el trigésimo segundo período ordinario de sesiones de la Asamblea General.

4. 4. Solicitar al Consejo Permanente que informe sobre la ejecución de esta resolución a la Asamblea General en su trigésimo segundo período ordinario de sesiones.

FONTE: OEA/AG RES 1833. Disponível no site: <http://www.oas.org/Assembly2001/ documentosS/Reso-Arti\%20aprovados/Ag-res1833.htm>. Acesso em: 07 set. 2009. 


\section{ANEXO 00 - Estudo sobre 0 acesso das pessoas à CtIDHs}

AG/RES. 1895 (XXXII-O/02)

\section{ESTUDIO SOBRE EL ACCESO DE LAS PERSONAS A LA CORTE INTERAMERICANA DE DERECHOS HUMANOS}

(Aprobada en la cuarta sesión plenaria celebrada el 4 de junio de 2002)

\section{LA ASAMBLEA GENERAL, VISTOS:}

El "Informe: Bases Para un Proyecto de Protocolo a la Convención Americana sobre Derechos Humanos, para fortalecer su mecanismo de Protección (Tomo II)", publicación presentada por la Corte Interamericana de Derechos Humanos en mayo del 2002;

La Declaración y el Plan de Acción de la Tercera Cumbre de las Américas, celebrada en la Ciudad de Québec, Canadá en abril de 2001;

La propuesta del Gobierno de Costa Rica, "Proyecto de Protocolo Facultativo a la Convención Americana sobre Derechos Humanos" (AG/CP/doc.629/01);

Las reformas de los Reglamentos de la Comisión Interamericana de Derechos Humanos y la Corte Interamericana de Derechos Humanos respecto al acceso de las personas al sistema interamericano de derechos humanos;

CONSIDERANDO que los Jefes de Estado y de Gobierno, en el Plan de Acción de la Tercera Cumbre de las Américas, decidieron continuar promoviendo medidas concretas para fortalecer y perfeccionar el sistema interamericano de derechos humanos, en particular el funcionamiento de la Corte Interamericana de Derechos Humanos y la Comisión Interamericana de Derechos Humanos, concentrándose en la facilitación del acceso de las personas al sistema;

TENIENDO PRESENTE que el derecho internacional de los derechos humanos tiene como característica intrínseca que la persona es sujeto del derecho internacional; $y$

CONSIDERANDO que el diálogo sobre el fortalecimiento del sistema interamericano de derechos humanos logró grandes avances en la identificación de áreas que requieren mayor estudio, en aras de desarrollar un sistema de derechos humanos sólido y eficaz que evolucione teniendo como última finalidad la protección del individuo y la salvaguardia de sus derechos fundamentales, 


\section{RESUELVE:}

1. Encomendar al Consejo Permanente que continúe la consideración del tema “ acceso de la víctima a la Corte Interamericana de Derechos Humanos (ius standi) y su puesta en práctica”, teniendo en cuenta el informe de la Corte Interamericana de Derechos Humanos, la propuesta del gobierno de Costa Rica, así como las reformas reglamentarias de la Corte y de la Comisión.

2. Solicitar al Consejo Permanente que invite a la Corte Interamericana de Derechos Humanos, la Comisión Interamericana de Derechos Humanos y la sociedad civil a participar en la consideración de este tema, durante el segundo semestre de 2002, con el objeto de someter un informe al trigésimo tercer período ordinario de sesiones de la Asamblea General.

3. Solicitar al Consejo Permanente que informe sobre la ejecución de esta resolución a la Asamblea General en su trigésimo tercer período ordinario de sesiones.

FONTE: OEA/AG RES. 1895. Disponível no site: <http://www.oas.org/juridico/spanish/ ag02/agres_1895.htm>. Acesso em: 07 set. 2009.

\section{ANEXO PP - Formulário de apresentação de petição individual perante a ComIDHs}

\section{FORMULARIO}

\section{INSTRUCCIONES}

El formulario debe ser llenado de la manera más completa posible, e incluyendo toda la información disponible con relación a un hecho en particular que constituya una o más violaciones a los derechos humanos por parte de Estados miembros de la OEA. La redacción de las respuestas debe ser sencilla y directa. En caso de que la información solicitada no esté a su alcance o no exista, debe señalar "información no disponible” o "no se aplica”, según corresponda. Si necesita más espacio para completar un punto del formulario, por favor anexe una hoja. El formulario puede completarse también en la página web de la Comisión: www.cidh.org. 
Una vez completo, el formulario debe enviarse al Secretario Ejecutivo de la CIDH por:

- Correo a la siguiente dirección postal:

\section{Comisión Interamericana de Derechos Humanos}

1889 F Street, N. W.

Washington, D.C. 20006

USA

- Fax al siguiente número: 1-202-458-3992.

- Correo electrónico a la siguiente dirección: cidhoea@oas.org

Tenga presente que si envía el formulario de manera electrónica, se le solicitará luego que ratifique la denuncia enviándola por correo o facsímil con su firma.

\section{I. PERSONA, GRUPO DE PERSONAS U ORGANIZACIÓN QUE PRESENTAN LA PETICIÓN}

Nombre:

(en caso de tratarse de una entidad no gubernamental, incluir el nombre de su representante o representantes legales)

Dirección postal:.

(NOTA: La Comisión no podrá tramitar su denuncia si no contiene una dirección postal)

Teléfono:

Fax:

Correo

Electrónico:

¿Desea usted que la CIDH mantenga su identidad como peticionario en reserva durante el procedimiento?

Sí........No.

\section{NOMBRE DE LA PERSONA O PERSONAS AFECTADAS POR LAS VIOLACIONES DE DERECHOS HUMANOS}

Nombre:

Dirección postal: 
Teléfono:

Fax:

Correo electrónico:

En caso de que la víctima haya fallecido, identifique también a sus familiares cercanos:

2III. ESTADO MIEMBRO DE LA OEA CONTRA EL CUAL SE PRESENTA LA DENUNCIA

\section{HECHOS DENUNCIADOS}

Relate los hechos de manera completa y detallada. Especifique el lugar y la fecha en que ocurrieron las violaciones alegadas.

Pruebas disponibles

Indique los documentos que puedan probar las violaciones denunciadas (por ejemplo, expedientes judiciales, informes forenses, fotografías, filmaciones, etc.). Si los documentos están en su poder, por favor adjunte una copia. NO ADJUNTE ORIGINALES (No es necesario que las copias estén certificadas).

Identifique a los testigos de las violaciones denunciadas. Si esas personas han declarado ante las autoridades judiciales, remita de ser posible copia del testimonio correspondiente o señale si es posible remitirlo en el futuro. Indique si es necesario que la identidad de los testigos sea mantenida en reserva. 
Identifique a las personas y/o autoridades responsables por los hechos denunciados.

V. DERECHOS HUMANOS VIOLADOS (En caso de ser posible, especifique las normas de la Convención Americana o las de otros instrumentos aplicables que considere violadas)

2VI. RECURSOS JUDICIALES DESTINADOS A REPARAR LAS CONSECUENCIAS DE LOS HECHOS DENUNCIADOS

Detalle las gestiones realizadas por la víctima o el peticionario ante los jueces, los tribunales u otras autoridades. Señale si no le ha sido posible iniciar o agotar este tipo de gestiones debido a que (1) no existe en la legislación interna del Estado el debido proceso legal para la protección del derecho violado; (2) no se le ha permitido el acceso a los recursos de la jurisdicción interna, o haya sido impedido de agotarlos; (3) hay retardo injustificado en la decisión sobre los mencionados recursos.

Señale si hubo una investigación judicial y cuándo comenzó. Si ha finalizado, indique cuándo y su resultado. Si no ha finalizado indique las causas.

En caso de que los recursos judiciales hayan finalizado, señale la fecha en la cual la víctima fue notificada de la decisión final. 
2VII. INDIQUESIHAY ALGÚN PELIGRO PARA LA VIDA, LA INTEGRIDAD O LA SALUD DE LA VÍCTIMA. EXPLIQUE SI HA PEDIDO AYUDA A LAS AUTORIDADES, Y CUÁL FUE LA RESPUESTA.

VIII. INDIQUE SI EL RECLAMO CONTENIDO EN SU PETICIÓN HA SIDO PRESENTADO ANTE EL COMITÉ DE DERECHOS HUMANOS DE LAS NACIONES UNIDAS U OTRO ÓRGANO INTERNACIONAL

FIRMA

FECHA

FONTE: ComIDH/MANUAL pp. 18-23. Disponível no site: <https://www.cidh.oas.org/ cidh_apps/manual_pdf/MANUAL2002_S.pdf>. Acesso em: 07 set. 2009.

\section{ANEXO QQ - ATUAL REGULAMENTO DA CtIDHs}

\section{ATUAL REGULAMENTO DA CORTE INTERAMERICANA DE DIREITOS HUMANOS}

\section{DISPOSIÇÕES PRELIMINARES}

\section{Artigo 1. Objetivo}

1. O presente Regulamento tem como objetivo regular a organização e o procedimento da Corte Interamericana de Direitos Humanos.

2. A Corte poderá adotar outros regulamentos que sejam necessários para o cumprimento de suas funções.

3. Na falta de disposição deste Regulamento ou em caso de dúvida sobre sua interpretação, a Corte decidirá. 


\section{Artigo 2. Definições}

Para os efeitos deste Regulamento:

1. o termo "Agente" significa a pessoa designada por um Estado para representá-lo perante a Corte Interamericana de Direitos Humanos;

2. o termo "Agente Assistente" significa a pessoa designada por um Estado para assistir o Agente no exercício de suas funções e substituí-lo em suas ausências temporárias;

3. o termo "amicus curiae" significa o terceiro alheio ao litígio e ao processo que apresenta à Corte fundamentos acerca dos fatos contidos na demanda ou formula considerações jurídicas sobre a matéria do processo, por meio de um documento ou de uma alegação em audiência.

4. a expressão “Assembléia Geral” significa a Assembléia Geral da Organização dos Estados Americanos;

5. o termo "Comissão" significa a Comissão Interamericana de Direitos Humanos;

6. a expressão “Comissão Permanente” significa a Comissão Permanente da Corte Interamericana de Direitos Humanos;

7. a expressão "Conselho Permanente" significa o Conselho Permanente da Organização dos Estados Americanos;

8. o termo “Convenção” significa a Convenção Americana sobre Direitos Humanos (Pacto de San José da Costa Rica);

9. o termo "Corte" significa a Corte Interamericana de Direitos Humanos;

10. o termo "Delegados" significa as pessoas designadas pela Comissão para representá-la perante a Corte;

11. a expressão "denunciante original” significa a pessoa, grupo de pessoas ou entidade não-governamental que tenha apresentado a denúncia original perante a Comissão, nos termos do artigo 44 da Convenção;

12. o termo "dia" será entendido como dia corrido;

13. a expressão "Estados Partes" significa aqueles Estados que ratificaram ou aderiram à Convenção;

14. a expressão "Estados membros" significa aqueles Estados que são membros da Organização dos Estados Americanos;

15. o termo "Estatuto" significa o Estatuto da Corte, aprovado pela Assembléia Geral da Organização dos Estados Americanos no dia 31 de outubro de 1979 (AG/RES 448 [IX-0/79]), com suas emendas; 
16. o termo "familiares" significa os familiares imediatos, ou seja, ascendentes e descendentes em linha direta, irmãos, cônjuges ou companheiros, ou aqueles determinados pela Corte conforme o caso;

17. a expressão "Relatório da Comissão" significa o relatório previsto no artigo 50 da Convenção;

18. o termo "Juiz" significa os juízes que integram a Corte em cada caso;

19. a expressão “Juiz Titular” significa qualquer juiz eleito de acordo com os artigos 53 e 54 da Convenção;

20. a expressão "Juiz Interino" significa qualquer juiz nomeado de acordo com os artigos 6.3 e 19.4 do Estatuto;

21. a expressão "Juiz ad hoc" significa qualquer juiz nomeado de acordo com o artigo 55 da Convenção;

22. o termo "mês" entender-se-á como mês calendário;

23. a abreviatura "OEA" significa a Organização dos Estados Americanos;

24. a expressão "partes no caso" significa a vítima ou a suposta vítima, o Estado e, somente para fins processuais, a Comissão;

25. o termo "perito" significa a pessoa que, por possuir determinados conhecimentos científicos, artísticos, técnicos ou práticos, informa ao julgador sobre pontos do litígio na medida em que se relacionam com seu notório conhecimento ou experiência.

26. o termo "Presidente" significa o Presidente da Corte;

27. a expressão "suposta vítima" significa a pessoa da qual se alega terem sido violados os direitos protegidos na Convenção;

28. o termo "Secretaria" significa a Secretaria da Corte;

29. o termo "Secretário" significa o Secretário da Corte;

30. a expressão "Secretário Adjunto" significa o Secretário Adjunto da Corte;

31. 3 Assim adicionado pela Corte durante seu Octagésimo Segundo Período Ordinário de Sessões, na sessão celebrada no dia 29 de janeiro de 2009.

32. 31. a expressão "Secretário-Geral" significa o Secretário-Geral da OEA;

33. 32. o termo "Vice-Presidente" significa o Vice-Presidente da Corte;

34. 33. o termo "vítima" significa a pessoa cujos direitos foram violados de acordo com a sentença proferida pela Corte. 


\section{TÍTULO I - DA ORGANIZAÇÃO E DO FUNCIONAMENTO DA CORTE Capítulo I - DA PRESIDÊNCIA E DA VICE-PRESIDÊNCIA}

\section{Artigo 3. Eleição do Presidente e do Vice-Presidente}

1. O Presidente e o Vice-Presidente são eleitos pela Corte por um período de dois anos no exercício de suas funções, podendo ser reeleitos. Seu mandato começa no primeiro dia da primeira sessão do ano correspondente. A eleição será realizada no último período ordinário de sessões celebrado pela Corte no ano anterior.

2. As eleições as quais se refere o presente artigo serão realizadas por votação secreta dos Juízes Titulares presentes e serão proclamados eleitos os candidatos que obtenham quatro ou mais votos. Se nenhum juiz obtiver essa votação, proceder-se-á a uma nova votação para decidir, por maioria de votos, entre os dois juízes que tiverem recebido mais votos. Em caso de empate, este será decidido em favor do juiz que tiver precedência, de acordo com o artigo 13 do Estatuto.

\section{Artigo 4. Atribuições do Presidente}

1. São atribuições do Presidente:

a) representar a Corte;

b) presidir as sessões da Corte e submeter à sua consideração as matérias que constem na ordem do dia;

c) dirigir e promover os trabalhos da Corte;

d) decidir as questões de ordem que sejam suscitadas nas sessões da Corte. Se um dos juízes assim o solicitar, a questão de ordem será submetida à decisão da maioria;

e) apresentar um relatório semestral à Corte sobre as funções que cumpriu no exercício da presidência durante o período a que o mesmo se refere;

f) as demais atribuições que lhe competem de acordo com o Estatuto ou com o presente Regulamento, assim como as que forem incumbidas pela Corte. 
2. O Presidente pode delegar, para casos específicos, a representação a que se refere o parágrafo 1.a. deste artigo, ao Vice-Presidente ou a qualquer um dos juízes ou, se necessário, ao Secretário ou ao Secretário Adjunto.

3. Se o Presidente é nacional de uma das partes no caso submetido à Corte ou então, por circunstâncias excepcionais, se assim o considerar conveniente, cederá o exercício da Presidência em relação a esse caso. Aplica-se a mesma regra ao Vice-Presidente ou a qualquer juiz chamado a exercer as funções do Presidente.

\section{Artigo 5. Atribuições do Vice-Presidente}

1. O Vice-Presidente supre as ausências temporárias do Presidente e o substitui em caso de ausência definitiva. Nesse último caso, a Corte elegerá um Vice-Presidente para o resto do período. O mesmo procedimento será aplicado a qualquer outro caso de ausência absoluta do Vice-Presidente.

2. No caso de ausência do Presidente e do Vice-Presidente, suas funções serão desempenhadas pelos outros juízes, na ordem de precedência estabelecida no artigo 13 do Estatuto.

\section{Artigo 6. Comissões}

1. A Comissão Permanente será integrada pelo Presidente, pelo Vice-Presidente e pelos outros juízes que o Presidente considere conveniente designar, de acordo com as necessidades da Corte. A Comissão Permanente assistirá o Presidente no exercício de suas funções.

2. A Corte poderá designar outras comissões para assuntos específicos. Em casos de urgência, se a Corte não estiver reunida, poderão ser designadas pelo Presidente.

3. As comissões serão regidas pelas disposições do presente Regulamento, quando aplicáveis. 


\section{Capitulo II - DA SECRETARIA}

\section{Artigo 7. Eleição do Secretário}

1. A Corte elegerá seu Secretário. O Secretário deverá possuir os conhecimentos jurídicos requeridos para o cargo, conhecer os idiomas de trabalho da Corte e ter a experiência necessária para o exercício de suas funções.

2. O Secretário será eleito por um período de cinco anos e poderá ser reeleito. Poderá ser removido em qualquer momento mediante decisão da Corte. Para eleger e remover o Secretário é necessária uma maioria, de não menos de quatro juízes, em votação secreta, observado o quorum da Corte.

\section{Artigo 8. Secretário Adjunto}

1. O Secretário Adjunto será designado em conformidade com o previsto no Estatuto, mediante proposta do Secretário da Corte. Assistirá o Secretário no exercício de suas funções e suprirá suas ausências temporárias.

2. No caso de que o Secretário e o Secretário Adjunto estiverem impossibilitados de exercer suas funções, o Presidente poderá designar um Secretário interino.

3. Em caso de ausência temporária do Secretário e do Secretário Adjunto da sede da Corte, o Secretário poderá designar um advogado da Secretaria como encarregado desta.

\section{Artigo 9. Juramento}

1. O Secretário e o Secretário Adjunto prestarão juramento ou declaração solene, perante o Presidente, sobre o fiel cumprimento de suas funções e sobre o sigilo que se obrigam a manter a respeito dos fatos de que tomem conhecimento no exercício de suas funções.

2. Os membros da Secretaria, mesmo que chamados a desempenhar funções interinas ou transitórias, deverão, ao tomar posse do cargo, prestar juramento ou declaração solene perante o Presidente em relação ao fiel cumprimento de suas funções e sobre o sigilo que se obrigam a manter a respeito dos fatos de que tomem conhecimento no exercício de suas funções. Se o Presidente não estiver presente na sede da Corte, o Secretário ou o Secretário Adjunto tomará o juramento. 
3. De todo juramento será lavrada uma ata, a qual o juramentado e quem houver tomado o juramento assinarão.

\section{Artigo 10. Atribuições do Secretário}

São atribuições do Secretário:

a. notificar as sentenças, opiniões consultivas, resoluções e demais decisões da Corte;

b. lavrar as atas das sessões da Corte;

c. assistir às reuniões que a Corte realize dentro ou fora da sede;

d. dar trâmite à correspondência da Corte;

e. dirigir a administração da Corte, de acordo com as instruções do Presidente;

f. preparar os projetos de programas de trabalho, regulamentos e orçamentos da Corte;

g. planejar, dirigir e coordenar o trabalho do pessoal da Corte;

h. executar as tarefas de que seja incumbido pela Corte ou pelo Presidente;

i. as demais atribuições estabelecidas no Estatuto ou neste Regulamento.

\section{Capítulo III - DO FUNCIONAMENTO DA CORTE}

\section{Artigo 11. Sessões ordinárias}

A Corte realizará os períodos ordinários de sessões que sejam necessários durante o ano para o pleno exercício de suas funções, nas datas que a Corte fixar em sua sessão ordinária imediatamente anterior. O Presidente, em consulta com a Corte, poderá mudar as datas desses períodos quando assim requeiram circunstâncias excepcionais. 


\section{Artigo 12. Sessões extraordinárias}

As sessões extraordinárias serão convocadas por iniciativa do próprio Presidente ou a pedido da maioria dos juízes.

\section{Artigo 13. Sessões fora da sede4}

A Corte poderá reunir-se em qualquer Estado membro que considerar conveniente para a maioria de seus membros e com prévia aquiescência do Estado respectivo.

\section{Artigo 14. Quorum}

O quorum para as deliberações da Corte é de cinco juízes.

\section{Artigo 15. Audiências, deliberações e decisões}

1. A Corte celebrará audiências quando estimar pertinente. Estas serão públicas, salvo quando o Tribunal considerar oportuno que sejam privadas.

2. A Corte deliberará em privado e suas deliberações permanecerão secretas. Delas somente participarão os juízes, embora também possam estar presentes o Secretário e o Secretário Adjunto, ou quem os substituir, bem como o pessoal de Secretaria necessário. Ninguém mais poderá ser admitido, a não ser mediante decisão especial da Corte e após prévio juramento ou declaração solene.

3. Toda questão que deva ser submetida a votação será formulada em termos precisos em um dos idiomas de trabalho. O respectivo texto será traduzido pela Secretaria aos outros idiomas de trabalho e distribuído antes da votação, à petição de qualquer um dos juízes.

4. O transcurso das audiências e deliberações da Corte constará em gravações de áudio.

\section{Artigo 16. Decisões e votações}

1. O Presidente submeterá os assuntos a votação, item por item. O voto de cada juiz será afirmativo ou negativo, não sendo admitidas abstenções.

2. Os votos serão emitidos na ordem inversa ao sistema da precedência estabelecido no artigo 13 do Estatuto.

3. As decisões da Corte serão adotadas por maioria dos juízes presentes no momento da votação. 
4. Em caso de empate, o voto do Presidente decidirá.

\section{Artigo 17. Continuidade das funções dos juízes}

1. Os juízes cujo mandato houver expirado continuarão a conhecer dos casos de que hajam tomado conhecimento e que se encontrem em fase de sentença. Contudo, em caso de falecimento, renúncia, impedimento, escusa ou inabilitação, proceder-se-á à substituição do juiz de que se trate pelo juiz que tenha sido eleito para substituí-lo, se esse for o caso, ou pelo juiz que tenha precedência entre os novos juízes eleitos na oportunidade do término do mandato daquele que deve ser substituído.

2. Tudo que seja relacionado às reparações e às custas, assim como à supervisão do cumprimento das sentenças da Corte, compete aos juízes que a integrarem nessa fase do processo, a menos que já se tenha realizado uma audiência pública, em cujo caso conhecerão da matéria os juízes que estiveram presentes nessa audiência.

3. Tudo que seja relacionado às medidas provisórias compete à Corte em funções, integrada pelos Juízes Titulares.

\section{Artigo 18. Juízes Interinos}

Os Juízes Interinos terão os mesmos direitos e atribuições dos Juízes Titulares, salvo as limitações expressamente estabelecidas.

\section{Artigo 19. Juizes ad hoc}

1. Ocorrendo um dos casos previstos nos artigos 55.2 e 55.3, da Convenção e 10.2 e 10.3 do Estatuto, o Presidente, por meio da Secretaria, informará aos Estados mencionados nos referidos artigos sobre a possibilidade de designação de um Juiz ad hoc dentro dos 30 dias seguintes à notificação da demanda.

2. Quando parecer que dois ou mais Estados têm um interesse comum, o Presidente informá-los-á sobre a possibilidade de designar em conjunto um Juiz ad hoc, na forma prevista no artigo 10 do Estatuto. Se esses Estados, dentro dos trinta dias seguintes à última notificação da demanda não houverem comuni- 
cado seu acordo à Corte, cada um dos Estados poderá apresentar, dentro dos 15 dias seguintes, o seu candidato. Decorrido esse prazo e tendo sido apresentados vários candidatos, o Presidente procederá à escolha, mediante sorteio, de um Juiz ad hoc comum, a qual comunicará aos interessados.

3. Se os Estados interessados não fazem uso de seus direitos, nos prazos assinalados nos parágrafos precedentes, considerar-se-á que renunciaram ao seu exercício.

4. O Secretário comunicará às demais partes no caso a designação de Juízes ad hoc.

5. O Juiz ad hoc prestará juramento na primeira sessão dedicada ao exame do caso para o qual houver sido designado.

6. Os Juízes ad hoc perceberão emolumentos nas mesmas condições previstas para os Juízes Titulares.

\section{Artigo 20. Impedimentos, escusas e inabilitação}

1. Os impedimentos, as escusas e a inabilitação dos juízes reger-se-ão pelo disposto no artigo 19 do Estatuto.

2. Os impedimentos e escusas deverão ser alegados antes da realização da primeira audiência pública referente ao caso. Contudo, se a causa de impedimento ou escusa ocorrer ou for conhecida apenas posteriormente, a mesma poderá ser invocada perante a Corte na primeira oportunidade, para que esta tome decisão imediata.

3. Quando, por qualquer causa, um juiz não se fizer presente em alguma das audiências ou em outros atos do processo, a Corte poderá decidir por sua inabilitação para continuar a conhecer do caso, levando em consideração todas as circunstâncias que, a seu juízo, sejam relevantes.

\section{TÍTULO II - DO PROCESSO}

\section{Capítulo I - REGRAS GERAIS}

\section{Artigo 21. Idiomas oficiais}

1. Os idiomas oficiais da Corte são os da OEA, ou seja, o espanhol, o inglês, o português, e o francês. 
2. Os idiomas de trabalho serão os que a Corte adote anualmente. Contudo, para um caso determinado, também se poderá adotar como idioma de trabalho o de uma das partes, sempre que seja oficial.

3. Ao início do exame de cada caso, determinar-se-ão os idiomas de trabalho, a não ser que continuem sendo utilizados os mesmos idiomas que a Corte utilizava previamente.

4. A Corte poderá autorizar qualquer pessoa que compareça perante a mesma a se expressar em seu próprio idioma, se não tiver suficiente conhecimento dos idiomas de trabalho, mas em tal caso adotará as medidas necessárias para assegurar a presença de um intérprete que traduza a declaração para os idiomas de trabalho. Esse intérprete deverá prestar juramento ou declaração solene sobre o fiel cumprimento dos deveres do cargo e sobre o sigilo a respeito dos fatos de que tome conhecimento no exercício de suas funções.

5. Em todos os casos, dar-se-á fé ao texto autêntico.

\section{Artigo 22. Representação dos Estados}

1. Os Estados que sejam partes em um caso estarão representados por Agentes, os quais, por sua vez, poderão ser assistidos por quaisquer pessoas por ele eleitas.

2. Quando um Estado substituir o ou os Agentes terá que comunicar a Corte. A substituição terá efeito desde que seja notificada a Corte em sua sede.

3. Poderão ser credenciados Agentes Assistentes, os quais assistirão os Agentes no exercício de suas funções e suprirão ausências temporárias dos mesmos.

4. Ao indicar os Agentes, o Estado interessado deverá informar o endereço no qual serão tidas como oficialmente recebidas as comunicações pertinentes.

\section{Artigo 23. Representação da Comissão}

A Comissão será representada pelos Delegados que designar para tal fim. Esses Delegados poderão fazer-se assistir por quaisquer pessoas de sua escolha. 


\section{Artigo 24. Participação das supostas vítimas}

1. Depois de admitida a demanda, as supostas vítimas ou seus representantes devidamente credenciados poderão apresentar suas petições, argumentos e provas de forma autônoma durante todo o processo.

2. Se existir pluralidade de supostas vítimas ou representantes devidamente credenciados, deverá ser designado um interveniente comum, que será o único autorizado para a apresentação de petições, argumentos e provas no curso do processo, incluindo nas audiências públicas.

3. No caso de eventual discordância, a Corte decidirá sobre o pertinente.

\section{Artigo 25. Cooperação dos Estados}

1. Os Estados Partes em um caso têm o dever de cooperar para que sejam devidamente realizadas todas aquelas notificações, comunicações ou citações enviadas a pessoas sobre as quais exerçam jurisdição, bem como o dever de facilitar a execução de

2. A mesma regra é aplicável a toda diligência que a Corte resolva efetuar ou ordenar no território do Estado parte no caso. 3. Quando a execução de quaisquer diligências a que se referem os parágrafos precedentes requerer a cooperação de qualquer outro Estado, o Presidente dirigir-se-á ao respectivo governo para solicitar as facilidades necessárias.

\section{Artigo 26. Medidas Provisórias}

1. Em qualquer fase do processo, sempre que se tratar de casos de extrema gravidade e urgência e quando for necessário para evitar prejuízos irreparáveis às pessoas, a Corte, ex officio ou a pedido de qualquer das partes, poderá ordenar as medidas provisórias que considerar pertinentes, nos termos do artigo 63.2 da Convenção.

2. Tratando-se de assuntos ainda não submetidos à sua consideração, a Corte poderá atuar por solicitação da Comissão.

3. Nos casos contenciosos que já se encontrem em conhecimento da Corte, as vítimas ou as supostas vítimas, ou seus representantes devidamente credenciados, poderão apresentar diretamente a esta uma petição de medidas provisórias em relação aos referidos casos. 
4. A solicitação pode ser apresentada ao Presidente, a qualquer um dos juízes ou à Secretaria, por qualquer meio de comunicação. De qualquer forma, quem houver recebido a solicitação deverá levá-la ao imediato conhecimento do Presidente.

5. A Corte ou, caso esta não esteja reunida, o Presidente poderá requerer ao Estado, à Comissão ou aos representantes dos beneficiários, quando considerar possível e indispensável, a apresentação de informação sobre um pedido de medidas provisórias, antes de resolver sobre a medida solicitada.

6. Se a Corte não estiver reunida, o Presidente, em consulta com a Comissão Permanente e, se for possível, com os demais juízes, requererá do governo interessado que tome as providências urgentes necessárias a fim de assegurar a eficácia das medidas provisórias que a Corte venha a adotar depois em seu próximo período de sessões.

7. Assim adicionado pela Corte durante seu Octagésimo Segundo Período Ordinário de Sessões, na sessão celebrada no dia 29 de janeiro de 2009.

8. A supervisão das medidas urgentes ou provisórias ordenadas realizar-se-á mediante a apresentação de relatórios estatais e das observações correspondentes aos referidos relatórios por parte dos representantes dos beneficiários. A Comissão Interamericana de Direitos Humanos deverá apresentar observações ao relatório do Estado e às observações dos beneficiários das medidas ou de seus representantes.

9. Nas circunstâncias que estimar pertinentes, a Corte poderá requerer a outras fontes de informação dados relevantes sobre o assunto, que permitam apreciar a gravidade e a urgência da situação e a eficácia das medidas. Para os mesmos efeitos, poderá também requerer as perícias e relatórios que considerar oportunos.

10. 9. A Corte, ou seu Presidente se esta não estiver reunida, poderá convocar as partes a uma audiência pública ou privada sobre as medidas provisórias.

11. 10. A Corte incluirá em seu Relatório Anual à Assembléia Geral uma relação das medidas provisórias que tenha ordenado durante o período do relatório e, quando tais medidas não tenham sido devidamente executadas, formulará as recomendações que considere pertinentes. 


\section{Artigo 27. Apresentação de Escritos}

1. A demanda, sua contestação, o escrito de petições, argumentos e provas e as demais petições dirigidas à Corte poderão ser apresentadas pessoalmente, via courier, facsímile, telex, correio ou qualquer outro meio geralmente utilizado. Em caso de apresentação dos escritos por meios eletrônicos, os originais e a totalidade de seus anexos deverão ser recebidos no Tribunal dentro do prazo máximo improrrogável de 21 dias, contados a partir do dia em que expirou o prazo para o envio dos escritos. Para garantir a autenticidade dos documentos, a Corte contará com um protocolo adequado.

2. O escrito original da demanda, da contestação da demanda, de petições, argumentos e provas (artigo 37 do Regulamento), contestação de exceções preliminares (artigo 38.4 do Regulamento), assim como os respectivos anexos destes, deverão ser acompanhados com três cópias idênticas à original, e recebidos dentro do prazo de 21 dias, conforme disposto no inciso anterior.

3. O Presidente pode, em consulta com a Comissão Permanente, rejeitar qualquer petição das partes que considere manifestamente improcedente, ordenando sua devolução, sem qualquer trâmite, ao interessado.

\section{Artigo 28. Procedimento por não comparecimento ou falta de atuação}

1. Quando uma parte não comparecer ou se abstiver de atuar, a Corte, ex officio, dará continuação ao processo até sua finalização.

2. Quando a parte comparecer tardiamente, ingressará no processo na fase em que o mesmo se encontrar.

\section{Artigo 29. Reunião de casos e de autos}

1. Em qualquer fase do processo, a Corte pode determinar a acumulação de casos conexos quando existir identidade de partes, objeto e base normativa.

2. A Corte também poderá ordenar que as diligências escritas ou orais de diferentes casos, incluindo a apresentação de testemunhas, sejam efetuadas em conjunto.

3. Mediante prévia consulta com os Agentes e Delegados, o Presidente poderá decidir pela instrução conjunta de dois ou mais casos. 


\section{Artigo 30. Decisões}

1. As sentenças e resoluções que ponham fim ao processo são de competência exclusiva da Corte.

2. As demais resoluções serão ditadas pela Corte, se estiver reunida, ou se não estiver, pelo Presidente, salvo disposição em contrário. Toda decisão do Presidente, que não seja de simple trâmite, é recorrível perante a Corte.

3. Contra as sentenças e resoluções da Corte não procede nenhum meio de impugnação.

\section{Artigo 31. Publicação das sentenças e outras decisões}

1. A Corte ordenará a publicação de:

a. suas sentenças e outras decisões, incluindo os votos fundamentados, dissidentes ou concordantes, quando cumprirem os requisitos mencionados no artigo 59.2 do presente Regulamento;

b. as peças do processo, com exclusão daquelas que sejam consideradas irrelevantes ou inconvenientes para esse fim;

c. o transcurso das audiências através do meio tecnológico que corresponda;

d. todo documento que se considere conveniente.

2. As sentenças serão publicadas nos idiomas de trabalho utilizados no caso; os demais documentos serão publicados em seu idioma original.

3. Os documentos depositados na Secretaria da Corte, relativos a casos já sentenciados, estarão à disposição do público, salvo se a Corte tiver decidido de outra maneira.

\section{Artigo 32. Aplicação do artigo 63.1. da Convenção}

A aplicação desse preceito poderá ser invocada em qualquer fase da causa. 


\section{Capítulo II - PROCEDIMENTO ESCRITO}

\section{Artigo 33. Início do processo}

Em conformidade com o artigo 61.1 da Convenção, a apresentação de uma causa será feita perante a Secretaria da Corte, mediante a interposição da demanda nos idiomas de trabalho. Formulada a demanda em apenas um desses idiomas, não se suspenderá o trâmite regulamentar, porém a tradução para os demais idiomas deverá ser apresentada dentro dos trinta dias subsequentes.

\section{Artigo 34. Escrito da demanda}

O escrito da demanda indicará:

1. os pedidos (incluídos os referentes a reparações e custas); as partes no caso; a exposição dos fatos; as resoluções de abertura do procedimento e de admissibilidade da denúncia pela Comissão; as provas oferecidas, com a indicação dos fatos sobre os quais as mesmas versarão; a individualização das testemunhas e peritos e o objeto de suas declarações; os fundamentos do direito e as conclusões pertinentes. Além disso, a Comissão deverá indicar, se possível, o nome e o endereço das supostas vítimas ou de seus representantes devidamente credenciados.

2. os nomes dos Agentes ou dos Delegados.

3. No caso de que esta informação não seja assinalada na demanda, a Comissão será a representante processual das supostas vítimas como garantidora do interesse público sob a Convenção Americana, de modo a evitar a falta de defesa das mesmas. Junto com a demanda, caso seja apresentada pela Comissão, acompanhará o relatório a que se refere o artigo 50 da Convenção.

\section{Artigo 35. Exame preliminar da demanda}

Se no exame preliminar da demanda, o Presidente verificar que os requisitos fundamentais não foram cumpridos, solicitará ao demandante que supra as lacunas dentro de um prazo de 20 dias.

\section{Artigo 36. Notificação da demanda}

1. O Secretário notificará a demanda a:

a. o Presidente e os juízes da Corte;

b. o Estado demandado; 
c. a Comissão, se não for a demandante;

d. a suposta vítima ou seus representantes devidamente credenciados, conforme o caso.

2. O Secretário informará sobre a apresentação da demanda aos outros Estados Partes, ao Conselho Permanente da OEA por intermédio do seu Presidente, e ao Secretário Geral da OEA.

3. Junto com a notificação, o Secretário solicitará aos Estados demandados que designem o ou os respectivos Agentes e, no caso da Comissão, que designe seus Delegados, dentro do prazo de 30 dias. Enquanto os Delegados não forem nomeados, a Comissão será considerada suficientemente representada pelo seu Presidente, para todos os efeitos do caso.

\section{Artigo 37. Escrito de petições, argumentos e provas}

1. Notificada a demanda à suposta vítima ou aos seus representantes devidamente credenciados, estes disporão de um prazo improrrogável de 2 meses, contado a partir do recebimento desse escrito e de seus anexos, para apresentar autonomamente à Corte suas petições, argumentos e provas.

\section{Artigo 38. Exceções Preliminares}

1. As exceções preliminares só poderão ser opostas no escrito de contestação da demanda.

2. Ao opor exceções preliminares, deverão ser expostos os fatos referentes às mesmas, os fundamentos de direito, as conclusões e os documentos que as embasem, bem como o oferecimento dos meios de prova que o autor da exceção pretenda fazer valer.

3. A apresentação de exceções preliminares não exercerá efeito suspensivo sobre o procedimento em relação ao mérito, aos prazos e aos respectivos termos.

4. As partes no caso interessadas em expor razões por escrito sobre as exceções preliminares poderão fazê-lo dentro de um prazo de trinta dias, contado a partir do recebimento da comunicação.

5. Quando considerar indispensável, a Corte poderá convocar uma audiência especial para as exceções preliminares, depois da qual decidirá sobre as mesmas. 
6. A Corte poderá resolver numa única sentença as exceções preliminares e o mérito do caso, em função do princípio de economia processual.

\section{Artigo 39. Contestação à demanda}

1. O demandado contestará por escrito, conjuntamente, a demanda e o escrito de petições, argumentos e provas, dentro do prazo improrrogável de 2 meses contado a partir do recebimento desse último escrito e de seus anexos. A contestação conterá os mesmos requisitos assinalados no artigo 34 deste Regulamento. A referida contestação será comunicada pelo Secretário às pessoas citadas no artigo 36.1 do mesmo.

2. O demandado deverá declarar em sua contestação se aceita os fatos e os pedidos ou se os contradiz, e a Corte poderá considerar como aceitos aqueles fatos que não tenham sido expressamente negados e os pedidos que não tenham sido expressamente controvertidos.

\section{Artigo 40. Outros atos do procedimento escrito}

Contestada a demanda e antes da abertura do procedimento oral, as partes poderão solicitar ao Presidente a realização de outros atos do procedimento escrito. Neste caso, se considerar pertinente, o Presidente fixará os prazos para a apresentação dos respectivos documentos.

\section{Artigo 41. Apresentação de Amicus Curiae}

O escrito de quem deseje atuar como amicus curiae poderá ser apresentado ao Tribunal, junto com seus anexos, em qualquer momento do processo contencioso, desde que dentro dos 15 dias posteriores à celebração da audiência pública. Nos casos em que não for celebrada audiência pública, deverão ser remetidos dentro dos 15 dias posteriores à Resolução correspondente na qual se outorga prazo para o envio de alegações finais e prova documental. O escrito de amicus curiae, junto com seus anexos, será levado de imediato ao conhecimento das partes para sua informação, com prévia consulta à Presidência. 


\section{Capítulo III - PROCEDIMENTO ORAL}

\section{Artigo 42. Abertura}

O Presidente fixará a data de abertura do procedimento oral e indicará as audiências necessárias.

\section{Artigo 43. Direção dos debates}

1. O Presidente dirigirá os debates nas audiências, determinará a ordem segundo a qual usarão da palavra as pessoas autorizadas a nelas intervir e disporá as medidas pertinentes para uma melhor realização das audiências.

2. Em relação ao uso da palavra pelas vítimas ou supostas vítimas, ou seus representantes devidamente credenciados, será observado o estipulado no artigo 24 do presente Regulamento.

\section{Artigo 44. Perguntas durante os debates}

1. Os juízes poderão formular as perguntas que considerarem pertinentes a toda pessoa que compareça perante a Corte.

2. As supostas vítimas, as testemunhas, os peritos e qualquer outra pessoa que a Corte decida ouvir poderão ser interrogados, sob a direção do Presidente, pelas pessoas a que se referem os artigos 22, 23 e 24 deste Regulamento.

3. O Presidente está facultado a resolver quanto à pertinência das perguntas formuladas e a eximir de respondê-las a pessoa à qual foram dirigidas, a menos que a Corte dedida de outra forma. Não serão admitidas perguntas que induzam às respostas.

\section{Artigo 45. Atas das audiências:}

1. De cada audiência, a Secretaria fará constar:

a. o nome dos juízes presentes;

b. o nome das pessoas mencionadas nos artigos 22, 23 e 24 deste Regulamento que estiveram presentes;

c. os nomes e dados pessoais das testemunhas, dos peritos e das demais pessoas que tenham comparecido;

2. A Secretaria gravará as audiências e anexará uma cópia da gravação aos autos do processo. 
3. Os Agentes, os Delegados, as vítimas ou as supostas vítimas, ou seus representantes devidamente credenciados, receberão cópia da gravação da audiência pública posteriormente a esta.

\section{Capítulo IV - DA PROVA}

\section{Artigo 46. Admissão}

1. As provas produzidas pelas partes só serão admitidas se forem propostas na demanda da Comissão, nas petições e argumentos das supostas vítimas, na contestação da demanda e observações às petições e argumentos apresentada pelo Estado e, conforme o caso, no escrito de exceções preliminares e na sua contestação.

2. As provas produzidas perante a Comissão serão incorporadas aos autos do processo, desde que tenham sido recebidas em procedimentos contraditórios, salvo se a Corte considerar indispensável repeti-las.

3. Excepcionalmente, a Corte poderá admitir uma prova se alguma das partes alegar força maior, impedimento grave ou fatos supervenientes em momento distinto dos anteriormente assinalados, desde que se assegure às partes contrárias o direito de defesa.

\section{Artigo 47. Medidas de instrução ex officio}

A Corte poderá, em qualquer fase da causa:

1. Procurar ex officio toda prova que considere útil e necessária. Particularmente, poderá ouvir, na qualidade de suposta vítima, de testemunha, de perito ou por outro título, a qualquer pessoa cuja declaração, testemunho, ou opinião considere pertinente.

2. Requerer das partes o fornecimento de alguma prova que esteja ao alcance das mesmas ou de explicação ou declaração que, em seu entender, possa ser útil.

3. Solicitar a qualquer entidade, escritório, órgão ou autoridade de sua escolha que obtenha informação, que expresse uma opinião ou elabore um relatório ou parecer sobre um determinado tema. Enquanto a Corte não autorizar, os respectivos documentos não serão publicados.

4. Encarregar a um ou a vários de seus membros a realização de qualquer medida de instrução, incluindo audiências, seja na sede da Corte ou fora desta. 
5. No caso de ser impossível proceder nos termos do inciso anterior, os juízes poderão comissionar à Secretaria a realização das diligências de instrução que se requeiram.

\section{Artigo 48. Ônus financeiro da prova}

A parte que propuser uma prova arcará com o ônus financeiro decorrente desta.

\section{Artigo 49. Substituição de declarantes oferecidos}

A parte que tenha proposto a declaração de uma suposta vítima, uma testemunha ou um perito e requer uma substituição, deverá solicitá-la ao Tribunal com a devida fundamentação.

\section{Artigo 50. Citação de supostas vítimas, testemunhas e peritos 27}

1. A Corte determinará a oportunidade para a apresentação, a cargo das partes, das supostas vítimas, testemunhas e peritos que considere necessário ouvir. Outrossim, ao citar as supostas vítimas, a testemunha e o perito, a Corte indicará o objeto da declaração, do testemunho ou da perícia. O Tribunal poderá designar peritos e admitir aqueles que, nesta qualidade, sejam propostos pelas partes, e valorará seus ditames tomando em conta quem ofereceu sua designação.

2. A parte que oferece uma prova de supostas vítimas, testemunhas ou peritos encarregar-se-á de seu comparecimento perante o Tribunal.

3. A Corte poderá requerer que determinadas supostas vítimas, testemunhas e peritos oferecidos pelas partes prestem suas declarações, testemunhos ou ditames por meio de declaração rendida perante notario público (affidavift). Uma vez recebida a declaração rendida perante notario público (affidavit), esta será remitida à ou às outras partes para que apresentem suas observações. 


\section{Artigo 51. Juramento ou declaração solene das testemunhas e peritos}

1. Depois de verificada sua identidade e antes de declarar, toda testemunha prestará juramento ou fará uma declaração solene, em que afirmará que dirá a verdade, toda a verdade e nada mais que a verdade.

2. Depois de verificada sua identidade e antes de desempenhar sua tarefa, todo perito prestará juramento ou fará uma declaração solene, em que afirmará que exercerá as suas funções com toda a honra e com toda consciência.

3. O juramento ou declaração a que se refere este artigo será cumprido perante a Corte ou perante o Presidente ou outro juiz que atuar por delegação da mesma.

\section{Artigo 52. Impugnação de testemunhas}

1. A testemunha poderá ser impugnada por qualquer parte dentro dos 10 dias seguintes ao recebimento da lista definitiva na qual se confirma o oferecimento de tal declaração.

2. O valor das declarações e das impugnações das partes sobre as mesmas será objeto de apreciação da Corte.

\section{Artigo 53. Recusa de peritos}

1. As causas de impedimento para os juízes previstas no artigo 19.1 do Estatuto serão aplicáveis aos peritos.

2. A impugnação deverá ser proposta dentro dos 10 dias subseqüentes ao recebimento da lista definitiva na qual se confirma o oferecimento de tal ditame.

3. Se o perito impugnado discordar da causa invocada, a decisão caberá à Corte a respeito. Contudo, não estando reunida a Corte, o Presidente, em consulta com a Comissão Permanente, poderá ordenar a apresentação da prova, dando conhecimento à Corte, a qual resolverá definitivamente sobre o valor da mesma.

4. Quando for necessário designar um novo perito, caberá à Corte decidir a respeito. Contudo, se houver urgência na apresentação da prova, o Presidente, em consulta com a Comissão Permanente, fará tal designação, dando conhecimento à Corte, que decidirá definitivamente sobre o valor da prova. 


\section{Artigo 54. Proteção de supostas vítimas, testemunhas e peritos}

Os Estados não poderão processar as supostas vítimas, as testemunhas e os peritos, nem exercer represálias contra os mesmos ou seus familiares, em virtude de suas declarações ou laudos apresentados à Corte.

\section{Artigo 55. Não comparecimento ou falso testemunho}

A Corte levará ao conhecimento do Estado que exerce jurisdição sobre a testemunha os casos em que as pessoas convocadas a comparecer ou declarar não compareceram ou se recusem a depor, sem motivo legítimo, ou que, segundo o parecer da própria Corte, tenham violado o juramento ou declaração solene, para os fins previstos na legislação nacional correspondente.

\section{Capítulo V - ENCERRAMENTO ANTECIPADO DO PROCESSO}

\section{Artigo 56. Desistência do caso}

1. Quando a parte demandante notificar a Corte de sua desistência, esta decidirá, ouvida a opinião das outras partes no caso, se cabe ou não a desistência e, em consequência, se procede a cancelar e declarar encerrado o assunto.

2. Se o demandado comunicar à Corte seu acatamento às pretensões da parte demandante e às das supostas vítimas, ou seus representantes, a Corte, ouvido o parecer das partes no caso, resolverá sobre a procedência do acatamento e seus efeitos jurídicos. Nesse contexto, a Corte determinará, se for o caso, as reparações e as custas correspondentes.

\section{Artigo 57. Solução amistosa}

Quando as partes no caso perante a Corte comunicarem a esta a existência de uma solução amistosa, de um acordo ou de outro fato capaz de dar solução ao litígio, a Corte poderá declarar encerrado o processo.

\section{Artigo 58. Prosseguimento do exame do caso}

A Corte, levando em conta as responsabilidades que lhe cabem em matéria de proteção dos direitos humanos, poderá decidir pelo prosseguimento do exame do caso, mesmo em presença das situações indicadas nos artigos precedentes. 


\section{Capítulo VI - DAS SENTENÇAS}

\section{Artigo 59. Conteúdo das sentenças}

1. A sentença conterá:

a. o nome do Presidente e dos demais juízes que a proferiram, do Secretário e do Secretário Adjunto;

b. a identificação das partes e seus representantes;

c. uma relação dos atos do procedimento;

d. a determinação dos fatos;

e. as conclusões das partes;

f. os fundamentos de direito;

g. a decisão sobre o caso;

h. o pronunciamento sobre as reparações e as custas, se procede;

i. o resultado da votação;

j. a indicação sobre o texto que dá fé.

2. Todo juiz que houver participado no exame de um caso tem direito a acrescer à sentença seu voto fundamentado, concordante ou dissidente. Esses votos deverão ser apresentados dentro do prazo fixado pelo Presidente, para que possam ser conhecidos pelos juízes antes da notificação da sentença. Os mencionados votos só poderão referirse à matéria tratada nas sentenças.

\section{Artigo 60. Sentença de reparações}

1. Quando na sentença sobre o mérito do caso não se houver decidido especificamente sobre reparações, a Corte determinará a oportunidade para sua posterior decisão e indicará o procedimento.

2. Se a Corte for informada de que as partes no processo chegaram a um acordo em relação ao cumprimento da sentença sobre o mérito, verificará que o acordo seja conforme a Convenção e disporá o que couber sobre a matéria.

\section{Artigo 61. Pronunciamento e comunicação da sentença}

1. Chegado o momento da sentença, a Corte deliberará em privado e aprovará a sentença, a qual será notificada às partes pela Secretaria.

2. Enquanto não se houver notificado a sentença às partes, os textos, os argumentos e os votos permanecerão em segredo. 
3. As sentenças serão assinadas por todos os juízes que participaram da votação e pelo Secretário. Contudo, será válida a sentença assinada pela maioria dos juízes e pelo Secretário.

4. Os votos fundamentados, dissidentes ou concordantes serão assinados pelos juízes que os sustentem e pelo Secretário.

5. As sentenças serão concluídas com uma ordem de comunicação e execução assinada pelo Presidente e pelo Secretário e selada por este.

6. Os originais das sentenças ficarão depositados nos arquivos da Corte. O Secretário entregará cópias certificadas aos Estados Partes, às partes no caso, ao Conselho Permanente por intermédio do seu Presidente, ao Secretário Geral da OEA, e a qualquer outra pessoa interessada que o solicitar.

\section{Artigo 62. Pedido de interpretação de sentença}

1. O pedido de interpretação a que se refere o artigo 67 da Convenção poderá ser formulado em relação às sentenças de mérito ou de reparações e se apresentará na Secretaria da Corte, cabendo nela indicar com precisão as questões relativas ao sentido ou ao alcance da sentença cuja interpretação é solicitada.

2. O Secretário comunicará o pedido de interpretação às partes do caso e as convidará a apresentar por escrito as razões que considerem pertinentes, dentro do prazo fixado pelo Presidente.

3. Para fins de exame do pedido de interpretação, a Corte reunir-se-á, se for possível, com a mesma composição com a qual emitiu a sentença de que se trate. Não obstante, em caso de falecimento, renúncia, impedimento, escusa ou inabilitação, proceder-se-á à substituição do juiz que corresponder, nos termos do artigo 17 deste Regulamento.

4. O pedido de interpretação não exercerá efeito suspensivo sobre a execução da sentença.

5. A Corte determinará o procedimento a ser seguido e decidirá mediante sentença.

\section{Artigo 63. Supervisão de Cumprimento de Sentenças e outras decisões do Tribunal 35}

1. A supervisão das sentenças e das demais decisões da Corte realizar-se-á mediante a apresentação de relatórios estatais e das correspondentes observações a esses relatórios por parte das vítimas ou de seus representantes legais. A Co- 
missão deverá apresentar observações ao relatório do Estado e às observações das vítimas ou de seus representantes.

2. A Corte poderá requerer a outras fontes de informação dados relevantes sobre o caso, que permitam apreciar o cumprimento. Para os mesmos efeitos poderá também requerer as perícias e relatórios que considere oportunos.

3. Quando considere pertinente, o Tribunal poderá convocar as partes a uma audiência para supervisar o cumprimento de suas decisões.

4. Uma vez que o Tribunal conte com a informação pertinente, determinará o estado do cumprimento do decidido e emitirá as resoluções que estime pertinentes.

\section{TÍTULO III - DOS PARECERES CONSULTIVOS}

\section{Artigo 64. Interpretação da Convenção}

1. As solicitações de parecer consultivo previstas no artigo 64.1 da Convenção deverão formular com precisão as perguntas específicas em relação às quais pretende-se obter o parecer da Corte.

2. As solicitações de parecer consultivo apresentadas por um Estado membro ou pela Comissão deverão indicar, adicionalmente, as disposições cuja interpretação é solicitada, as considerações que dão origem à consulta e o nome e endereço do Agente ou dos Delegados.

3. Se o pedido de parecer consultivo é de outro órgão da OEA diferente da Comissão, o pedido deverá precisar, além do indicado no parágrafo anterior, como a consulta se refere à sua esfera de competência.

\section{Artigo 65. Interpretação de outros tratados}

1. Se a solicitação referir-se à interpretação de outros tratados concernentes à proteção dos direitos humanos nos Estados americanos, tal como previsto no artigo 64.1 da Convenção, deverá identificar o tratado e suas respectivas partes, formular as perguntas específicas em relação às quais é solicitada o parecer da Corte e incluir as considerações que dão origem à consulta.

2. Se a solicitação emanar de um dos órgãos da OEA, deverá explicar como a consulta se refere à sua esfera de competência. 


\section{Artigo 66. Interpretação de leis internas}

1. A solicitação de parecer consultivo formulada em conformidade com o artigo 64.2 da Convenção deverá indicar: a. as disposições de direito interno, bem como as da Convenção ou de outros tratados concernentes à proteção dos direitos humanos, que são objeto da consulta;

b. as perguntas específicas sobre as quais se pretende obter o parecer da Corte;

c. o nome e endereço do Agente do solicitante.

2. O pedido será acompanhado de cópia das disposições internas a que se refere a consulta.

\section{Artigo 67. Procedimento}

1. Uma vez recebida um pedido de parecer consultivo, o Secretário enviará cópia deste a todos os Estados membros, à Comissão, ao Conselho Permanente da OEA por intermédio do seu Presidente, ao Secretário Geral da OEA e aos órgãos da mesma a cuja esfera de competência se refira o tema da consulta, se pertinente.

2. O Presidente fixará um prazo para que os interessados enviem suas observações por escrito.

3. O Presidente poderá convidar ou autorizar qualquer pessoa interessada para que apresente sua opinião por escrito sobre os itens submetidos a consulta. Se o pedido referirse ao disposto no artigo 64.2 da Convenção, poderá fazê-lo mediante consulta prévia com o Agente.

4. Uma vez concluído o procedimento escrito, a Corte decidirá quanto à conveniência ou não de realizar o procedimento oral e fixará a audiência, a menos que delegue esta última tarefa ao Presidente. No caso do previsto no artigo 64.2 da Convenção, será realizada uma consulta prévia ao Agente.

\section{Artigo 68. Aplicação analógica}

A Corte aplicará ao trâmite dos pareceres consultivos as disposições do Título II deste Regulamento, na medida em que as julgar compatíveis. 
Artigo 69. Emissão e conteúdo dos pareceres consultivos 1. A emissão dos pareceres consultivos será regida pelo disposto no artigo 61 deste Regulamento.

1. Os pareceres consultivos conterão:

a. o nome do Presidente e dos demais juízes que as emitirem, do Secretário e do Secretário Adjunto;

b. os assuntos submetidos à Corte;

c. uma relação dos atos do procedimento;

d. os fundamentos de direito;

e. o parecer da Corte;

f. a indicação do texto que dá fé.

2. Todo juiz que houver participado da emissão de um parecer consultivo tem direito a acrescer-lhe seu voto fundamentado, dissidente ou concordante. Esses votos deverão ser apresentados no prazo fixado pelo Presidente para que possam ser conhecidos pelos juízes antes da comunicação do parecer consultivo. Para efeito de sua publicação, aplicar-se-á o disposto no artigo 31.1.a deste Regulamento.

3. Os pareceres consultivos poderão ser lidas em público.

\section{TÍTULO IV - DISPOSIÇÕES FINAIS E TRANSITÓRIAS}

\section{Artigo 70. Emendas ao Regulamento}

O presente Regulamento poderá ser emendado pelo voto da maioria absoluta dos Juízes Titulares da Corte e revoga, a partir da sua entrada em vigor, as normas regulamentares anteriores que a ele se oponham 36.

\section{Artigo 71. Início da vigência}

O presente Regulamento, cujos textos em espanhol e inglês são igualmente autênticos, entrará em vigor em 24 de março 200937.

\section{Artigo 72. Aplicação38}

1. As disposições modificadas ou adicionadas a este Regulamento que se relacionem com o trâmite de casos perante a Corte, serão de aplicação imediata e integral a todos os litígios ou solicitações de parecer submetidos ao seu co- 
nhecimento posteriormente à data de entrada em vigor das reformas correspondentes.

2. Os casos em curso continuarão tramitando conforme este regulamento, com exceção de aqueles casos em que se tenha convocado a audiência no momento de entrada em vigor do presente Regulamento, os quais seguirão tramitando conforme as disposições do Regulamento anterior.

Dado na sede da Corte Interamericana de Direitos Humanos em San José da Costa Rica no dia 29 de Janeiro de 2009.

*Aprovado pela Corte no seu XLIX Período Ordinário de Sessões celebrado de 16 a 25 de novembro de 2001 e reformado parcialmente pela Corte em seu LXXXII Período Ordinário de Sessões, celebrado de 19 a 31 de janeiro de 2009

Observação: enquadramento das partes relevantes quanto a participação individual perante a CtIDHs e destaque em verde para as disposições adicionadas em 2009 ao Regulamento.

FONTE: OEA. Regulamento da CtIDHs. Disponível no site: <http://www.cidh.oas.org/ Basicos/Portugues/w.Regulamento.Corte.port.pdf $>$. Acesso em setembro de 2009. 


\section{ANEXO RR - Países-partes do Estatuto de ROMA}
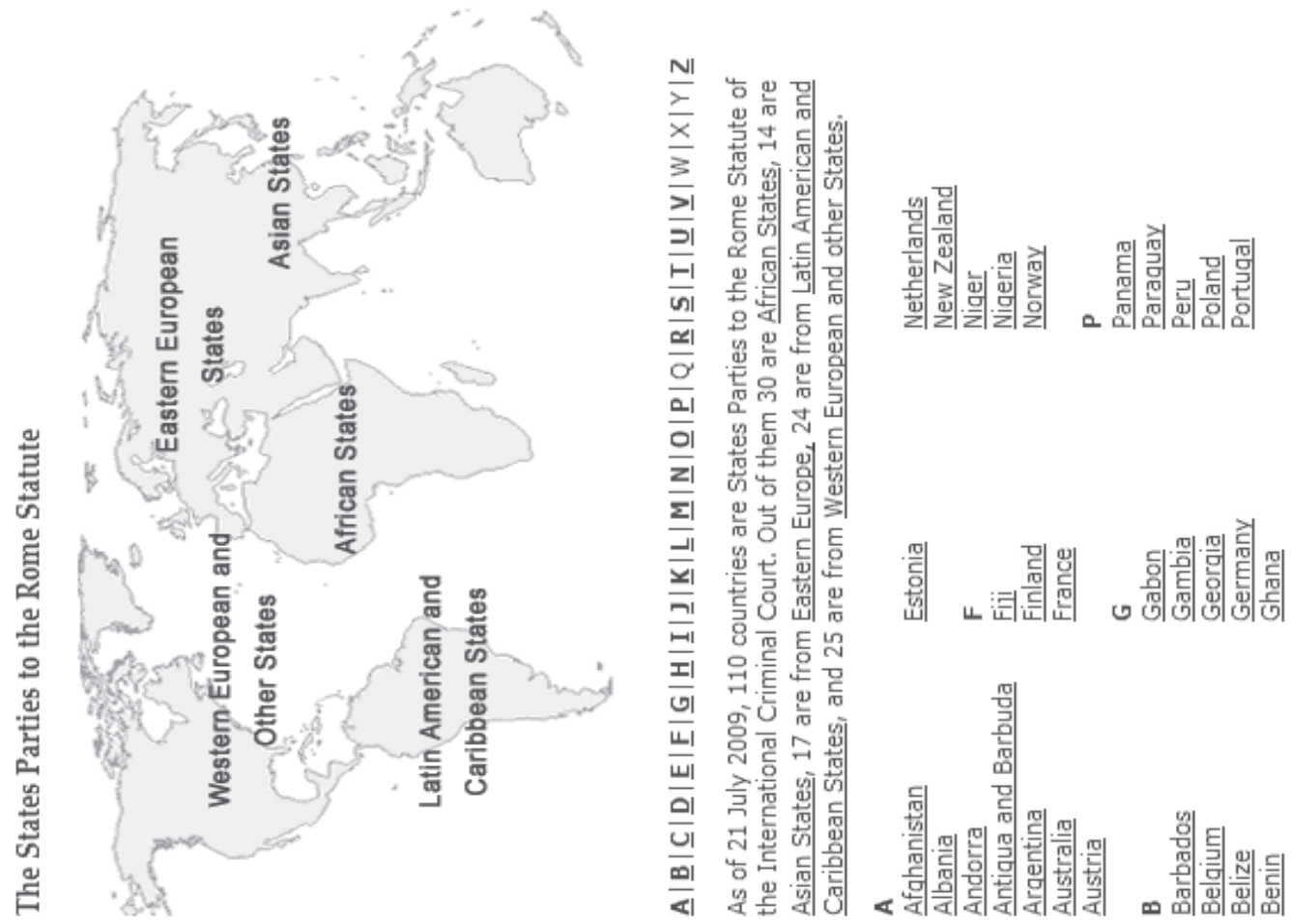


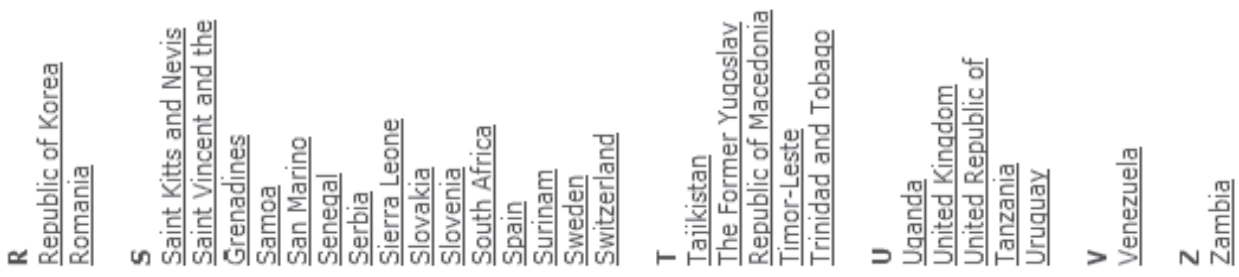

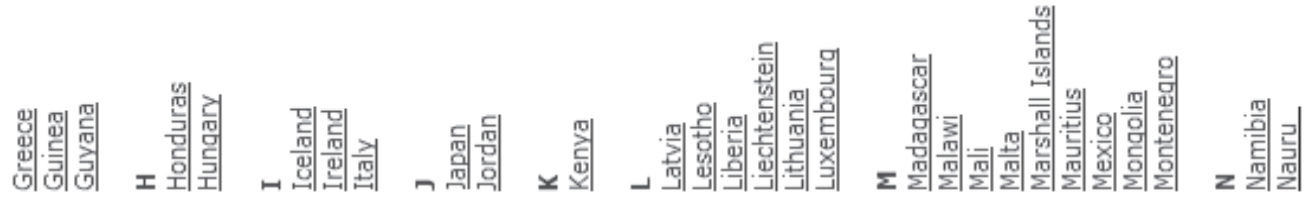

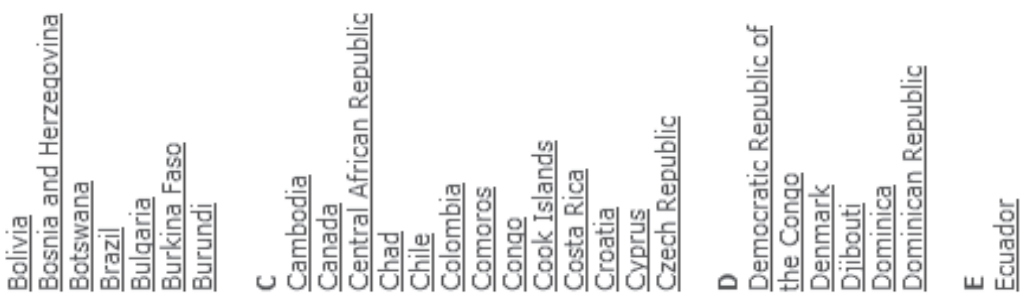

FONTE: TPI. The States Parties to the Rome Statute. Disponivel no site: <http://www.icccpi.int/Menus/ASP/states+parties/>. Acesso em: 07 set. 2009. 


\section{ANEXO SS - Definições dos crimes julgados pelo TPI}

Art. 5.1 do TPI: “[...]Nos termos do presente Estatuto, o Tribunal terá competência para julgar os seguintes crimes: a) O crime de genocídio; b) Os crimes contra a Humanidade; c) Os crimes de guerra; d) O crime de agressão.5.2 - O Tribunal poderá exercer a sua competência em relação ao crime de agressão desde que, nos termos dos artigos $121 .^{\circ}$ e $123 .^{\circ}$, seja aprovada uma disposição em que se defina o crime e se enunciem as condições em que o Tribunal terá competência relativamente a este crime. Tal disposição deve ser compatível com as disposições pertinentes da Carta das Nações Unidas.”

Art. 6 do ETPI,: “[...] um dos atos enumerados a seguir, cometidos com a intenção de destruir, no todo ou em parte, um grupo nacional, étnico, racial ou religioso, tais como: a) homicídio de membros do grupo; b) ofensa grave à integridade física ou mental de membros do grupo; c) sujeição intencional do grupo a condições de existência capazes de provocar sua destruição física, total ou parcial; d) medidas destinada as impedir os nascimentos no seio do grupo;e) transferência forçada de crianças de um grupo para outro [...]”

Art. 7.1 do ETPI: “[...] entende-se por crime contra a humanidade, qualquer um dos atos seguintes, quando cometido no quadro de uma ataque generalizado ou sistemático, contra qualquer população civil, havendo conhecimento desse ataque: a) homicídio; b) extermínio; c) escravidão; d) deportação ou transferência forçada de uma população; e) prisão ou outra forma de privação grave de liberdade física, em violação das normas fundamentais de direito internacional; f ) tortura; g) estupro, escravidão sexual, prostituição forçada, gravidez forçada, esterilização forçada ou qualquer outra forma de violência no campo sexual de gravidade comparável; h) perseguição de um grupo ou coletividade que possa ser identificada, por motivos políticos, raciais, nacionais, étnicos, culturais, religiosos ou de gênero, tal como definido no $\$ 3^{\circ}$, ou em função de outros critérios universalmente reconhecidos como inaceitáveis no direito internacional, relacionados com qualquer ato referido neste parágrafo ou com qualquer crime de competência da Corte; i) desaparecimento forçado de pessoas; $j$ ) crime e apartheid; $k$ ) outros atos desumanos de caráter semelhante, que causem intencionalmente grande sofrimento, ou afetem gravemente a integridade física ou saúde física ou mental.” 
Art. 8.2 do ETPI: "2.Para efeitos do presente Estatuto, entende-se por "crimes de guerra”: a) violações graves às Convenções de Genebra de 12 de agosto de 1949, a saber, qualquer um dos seguintes atos, dirigidos contra pessoas ou bens protegidos nos termos da Convenção de Genebra que for pertinente: [...] b) outras violações graves das leis e costumes aplicáveis em conflitos armado internacionais no âmbito do direito internacional, a saber, qualquer um dos seguintes atos: [...] c) em caso de conflito armado eu não seja de índole internacional, as violações graves do art. $3^{\circ}$ comum às quatro Convenções de Genebra de 12 de agosto de 1949, a saber, qualquer um dos atos que a seguir se indicam, cometidos contra pessoas que não participem diretamente nas hostilidades, incluindo os membros das forças armadas que tenham deposto armas e os que tenham ficado impedidos de continuar combater devido a doença, lesões, prisão ou qualquer outro motivo: [...] d) A alínea c do $\$ 2$ do presente artigo aplica-se aos conflitos armados que não tenham caráter internacional e, por conseguinte, não se aplica a situações de distúrbio e de tensão internas, tais como motins, atos de violência esporádicos ou isolados ou outros de caráter semelhante; e) as outras violações graves das leis e costumes aplicáveis aos conflitos armados que não têm caráter internacional, no quadro do direito internacional, a saber, qualquer um dos seguintes atos: [...]f) a alínea e do $\$ 2$ do presente artigo aplicar-se-á aos conflitos armados que não tenham caráter internacional, por conseguinte, não se aplicará a situações de distúrbio e de tensão internas, tais como motins, atos de violência esporádicos ou isolados ou outros de caráter semelhante; aplicar-se-á, ainda, a conflitos armados que tenham lugar no território de um Estado, quando exista um conflito armado prolongado entre as autoridades governamentais e grupos armados organizados ou entre esses grupos."

FONTE: TPI. Estatuto de Roma. Disponível no site: <http://www.gddc.pt/direitos-humanos/ textos-internacionais-dh/tidhuniversais/tpi-estatuto-roma.html>. Acesso em: 07 set. 2009. 


\section{ANEXO TT - Estrutura do TPI}
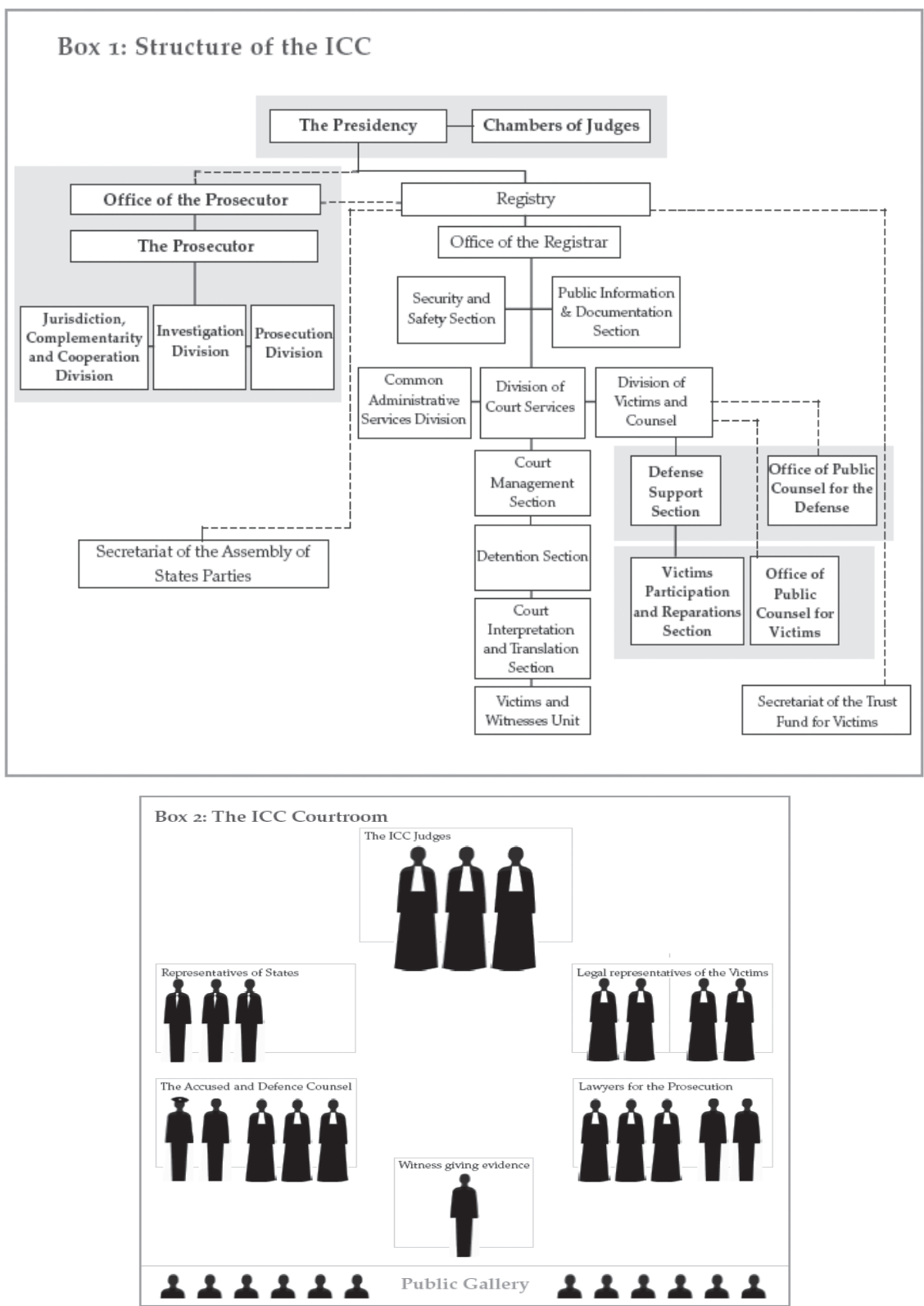

FONTE: TPI. Structure of the ICC /The ICC Courtroom. Disponível no site: <http://www. icc-cpi.int/NR/rdonlyres/04DDAEA9-6023-492F-AE24-53CF9C9F6D92/144111/VPRS_ Booklet_En.pdf>.p. 6-7. Acesso em: 07 set. 2009. 


\section{ANEXO UU - Processo perante o TPI}

\section{Box 4: Stages of proceedings}

\begin{tabular}{|l|l|}
\hline $\begin{array}{l}\text { Preliminary } \\
\text { Examination } \\
\text { Stage }\end{array}$ & $\begin{array}{l}\text { Situation in which crimes } \\
\text { under the ICCs jurisdiction } \\
\text { appear to have been } \\
\text { committed is referred to the } \\
\text { ICC Prosecutor by a State Party } \\
\text { or the UN Security Council. }\end{array}$ \\
\hline
\end{tabular}

ICC Prosecutor examines

If ICC Prosecutor considers there is a reasonable bas is to proceed, he initiates an investigation.

\section{ICC Prosecutor conducts investigation.}

Pre-Trial Stage (Pre-Trial Chamber)

\section{Trial Stage}

(Trial Chamber)

Appeal Stage (Appeals Chamber)

Commencement of a trial

Judgement

Reparations proceedings sentence information received.

Situation in which information about alleged crimes under the ICCs jurisdiction is sent to the ICC Prosecutor, who may seek to start proceedings on his own initiative (proprio motu).

ICC Prosecutor examines information received.

If ICC Prosecutor considers that there is a reasonable basis to initiate an investigation, he requests authorisation from the Pre-Trial Chamber.

Pre-Trial Chamber authorises an investigation.

ICC Prosecutor conducts investigation.

Pre-Trial Chamber issues warrant of arrest/summons to appear

Person sought by the Court is arrested/surrenders

First appearance of an arrested or surrended person

Confirmation of charges hearing

Decision on conviction or acquittal, and sentencing

Appeal against decision of acquittal or conviction or against

Decision on appeal

Revision

FONTE: TPI. Stages of proceedings. Disponível no site: <http://www.icc-cpi.int/NR/ rdonlyres/04DDAEA9-6023-492F-AE24-53CF9C9F6D92/144111/VPRS_Booklet_ En.pdf>. p. 11. Acesso em: 07 set. 2009. 


\section{ANEXO V V - Diagrama de diferenciação entre vítima do caso e vitima da situação}

1. Have ICC proceedings begun?

If yes

2. Does the applicant want to participate during the situation phase (preliminairy examination phase) If yes If no

3. Is the applicant a victim of the situation?

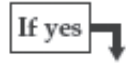

The Judges will consider whether the applicant is entitled to participate in relation to the situation If yes

4. Has the ICC issued Arrest Warrants? If yes

5. Does the victim want to participate during the Pre-Trial and Trial phases (and any Appeal following trial) If yes

The Judges will consider whether the applicant is a victim of the case

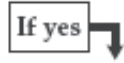

Box 8: Diagram on victim of the situation and victim of the case

6. The Judges will consider whether the victim is entitled to participate in relation to the case

FONTE:TPI.Diagram on victim of the situation and victim of the case. Disponível no site: $<$ http:// www.icc-cpi.int/NR/rdonlyres/04DDAEA9-6023-492F-AE24-53CF9C9F6D92/144111/ VPRS_Booklet_En.pdf>.p. 18. Acesso em: 07 set. 2009. 


\section{ANEXO XX - Processo da petição da vítima perante o TPI}

\section{Box 10: ICC-Victims' application process}

Victims are informed about their rights and how to apply to participate in ICC proceedings

Victims obtain and complete application forms with the assistance of individuals or organisations trained by the ICC

Victims submit their applications to the VPRS at the Headquarters or a Field Office

VPRS receives an application and provides the applicant with a reference number to the contact address provided or to the legal representative, if the applicant has appointed one

VPRS files the application with the Chamber of Judges.

Judges review and decide if the application is succesful or rejected and the applicant is notified

If succesful, applicant receives information, including about legal representation. If rejected applicant is allowed to apply again later in the proceedings

FONTE: TPI. ICC - Victim's Apliccation Process. Disponível no site: <http://www.icc-cpi. int/NR/rdonlyres/04DDAEA9-6023-492F-AE24-53CF9C9F6D92/144111/VPRS_Booklet_ En.pdf>. p. 24. Acesso em: 07 set. 2009. 


\title{
ANEXO YY - Modelo padrão de petição individual para reparação de vitimas perante $O$ TPI
}

\author{
Cour \\ Pénale \\ Internationale \\ International \\ Criminal \\ Court \\ STANDARD APPLICATION FORM TO PARTICIPATE IN PROCEEDINGS \\ BEFORE THE INTERNATIONAL CRIMINAL COURT \\ FOR INDIVIDUAL VICTIMS AND PERSONS ACTING ON THEIR BEHALF
}

\section{FORM PARTICIPATION-1}

Please complete this Application Form if you believe you have suffered harm as a result of a crime under the jurisdiction of the International Criminal Court (ICC) and wish to participate in the proceedings before the ICC by putting forward your observations, views or concerns, or if you are acting on behalf of such a person.

The purpose of this Application Form is to collect information to help a Chamber of Judges in the ICC decide whether you are entitled to participate in proceedings before the Court. Your completion of this Application Form will not automatically lead to your participation in the proceedings before the ICC.

The information provided in the Application Form will be forwarded to a Chamber of Judges in the ICC which will

Who should use this Application Form?

A victim who is seeking to participate in proceedings before the ICC

For the purposes of the ICC, a victim is a person who has suffered harm as a result of the commission of a crime within the jurisdiction of the Court.

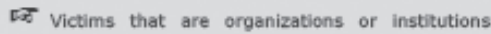
should use FORM PARTICIPATION-2.

A person acting on behalf of a victim Where a victim is a child, or has a disability that prevents the victim from acting on her or his own behalf, someone else may make an application on their behalf. Where a victim is deceased, someone else may consider your application. Please be advised that criminal proceedings take time and it may be some time before the Court makes decisions on your application.

Please review the accompanying Booklet before completing the Application Form as it will help you fill it in correctly. The Booklet contains explanations regarding:

- What the International Criminal Court is

- The purpose of this Application Form and what will happen to it

- Instructions on how to complete each section of the Application Form. Please note that each Part of this Application Form corresponds to the same Part of the Booklet.

also make the application. In addition, a person may make the application with the consent of a victim. In any of above circumstances, the person making the application should complete Part B.

A person assisting a victim

Where a victim or a person acting on behalf of a victim is filling in this Application Form, they may be assisted in filling in the Application Form by another person. This would be the case, for example, if either the victim or the person acting on behalf of the victim is unable to read or to write. Where a person assists in filling in this Application Form, she or he should complete Part I.

Please note that one Application Form should be filled in per applicant. 


\section{NOTE}

This Application Form and the process of applying are free of charge. The ICC, as a matter of practice, does not charge any fee at any stage of the application process.

\section{Instructions:}

Please take into account the following instructions when completing this Application Form:

- Please fill in this Application Form to the extent possible.

- Please type or write your answers clearly.

- Please attach answers to the questions on a separate sheet of paper if you need more space.

- You must sign your Application Form, or add your thumbprint or other mark where indicated at the end of Part $\mathrm{J}$.

- Please also put initials of the applicant in the box located at the bottom of each page of this Application Form as well as any other documents accompanying it. This will help prevent pages of the Application Form from being lost.

- Please provide photocopies of documents requested to the extent possible. If you do not have the documentation requested your application will still be considered. If possible, please staple all the pages of the Application Form and the accompanying documents. Do not send original documents at this time, but please take good care of original documents, which the Court may request at a later stage.

If you seek help in filling in this Application Form, you may contact the ICC or an ICC Field Office which will put you in touch with someone near you to help you fill in this Application Form.

\section{Note regarding disclosure of information:}

The information contained in your Application Form may be forwarded to the Defence and the Prosecutor. In addition, part or all of the information may be made available to the general public in the course of proceedings. If you do not wish for part or all of the information in the form to be disclosed or made public for reasons related to your security or wellbeing, you should tick the relevant boxes in Part $H$ of the Application Form and provide the information requested. The Chamber of Judges will decide on the request, and their decision will be communicated to you.

The Application Form should be sent directly to one of the following addresses:

\section{ICC HEADQUARTERS}

International Criminal Court

Victims Participation and Reparations Section (VPRS)

P.O. Box 19519, 2500 CM The Hague

The Netherlands

Fax: + 31705159100

Email: vprsapplications@icc-cpi.int

\section{ICC FIELD OFFICES}

\section{ICC Field Office in Kampala}

Victims Participation and Reparations Section (VPRS) P.O. Box 72735 - Kampala

Telephone: + 256772706062

\section{ICC Field office in Kinshasa}

Victims Participation and Reparations Section (VPRS) Telephone: + 243998011426 r + 243998011403 


\section{PART A}

PERSONAL INFORMATION ABOUT THE VICTIM. See Part $A$ of the Booklet.

Have you already submitted an application for participation or reparations to the ICC?

|Yes | No

If yes, when?

Day $\square$ Month $\square$

Year

If you have a registration number, please indicate it:

VPRS-

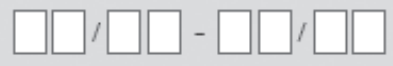

1. Surname(s):

2. Other name(s):

3. Please provide the folloving information as far as relevant:

Father's name:

Mother's name:

Name of next of kin or, if you are under 18 years old, guardian:

4. Sex: Female Male

5. Age or, if not known, approximate age:

or date of birth, or if not known, approximate date of birth:

Day $\longrightarrow$ Month $\square$

Year

6. Place of birth:

7. Nationality (ies):

8. What is your tribe/ethnic group?

Initials of applicant

NOTE: This Application Form and the process of applyinc are free of charge. 

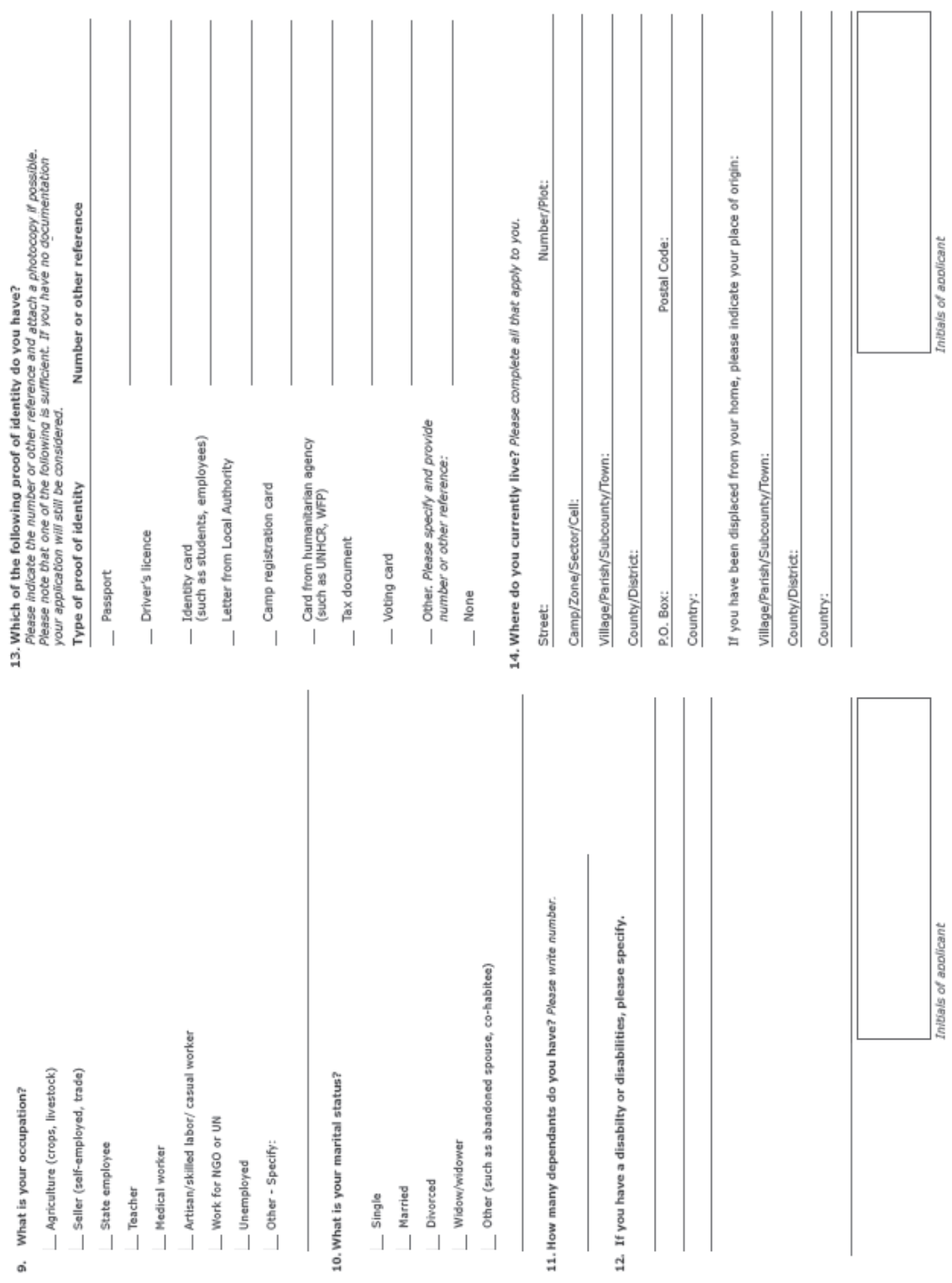

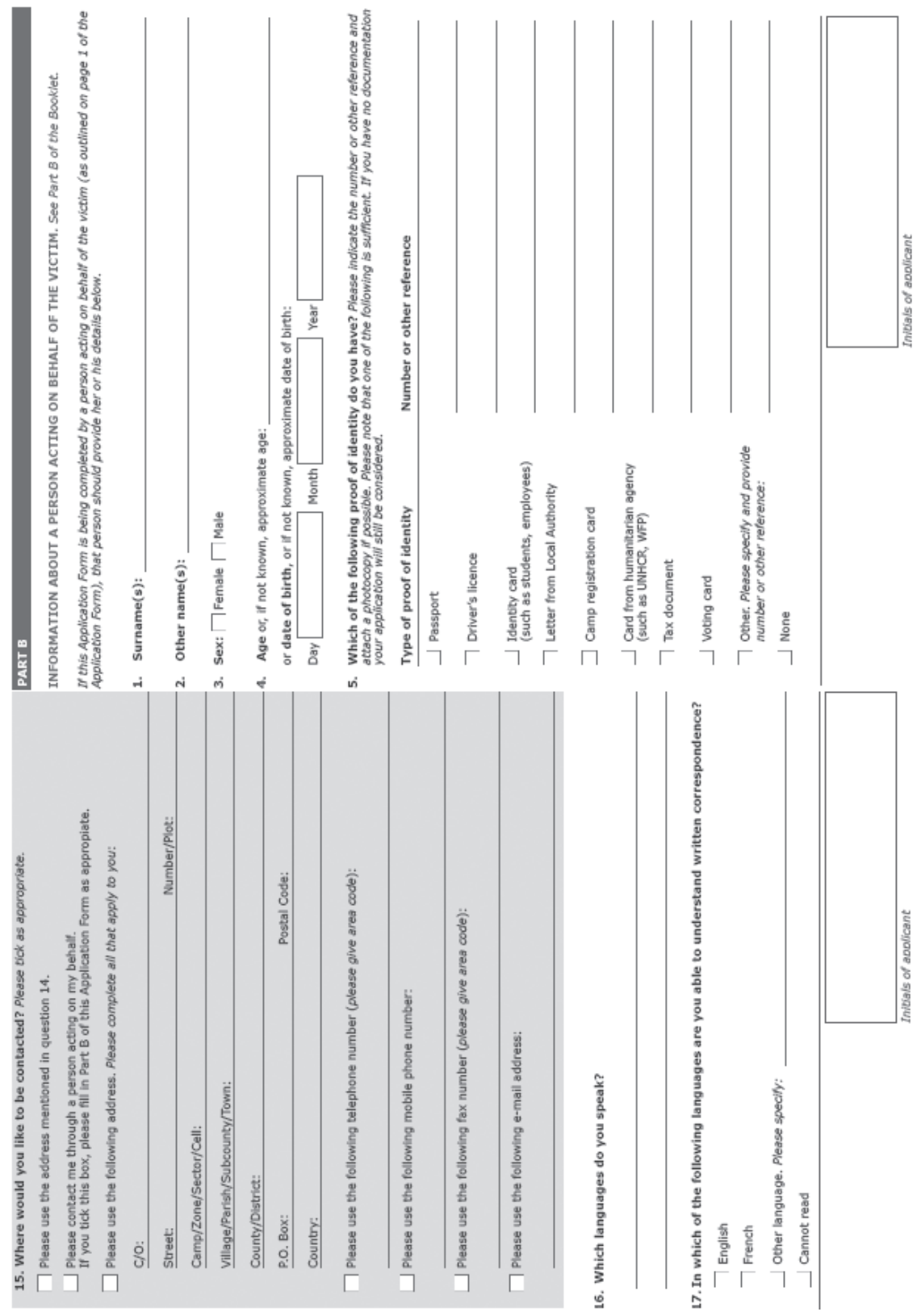

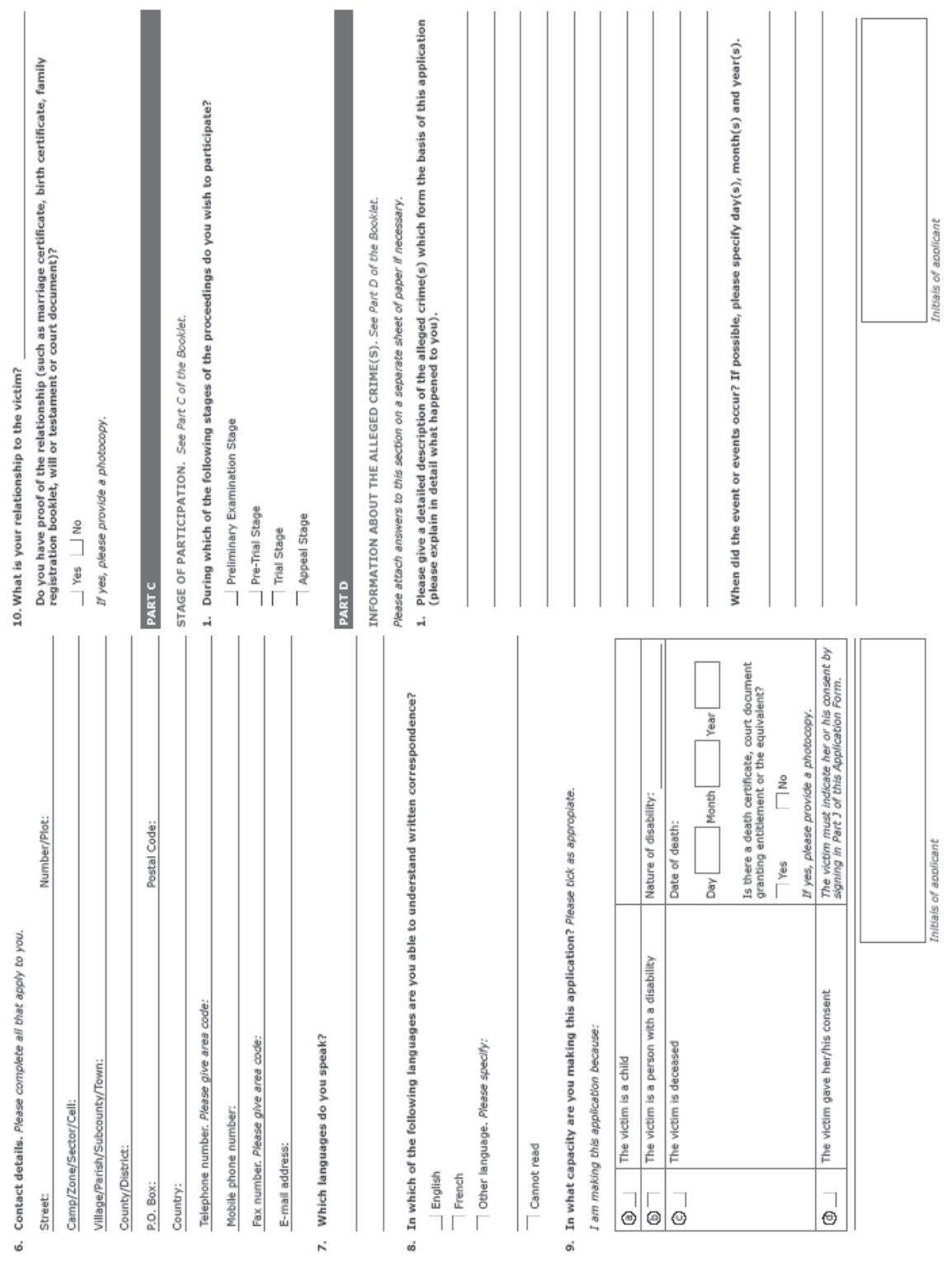


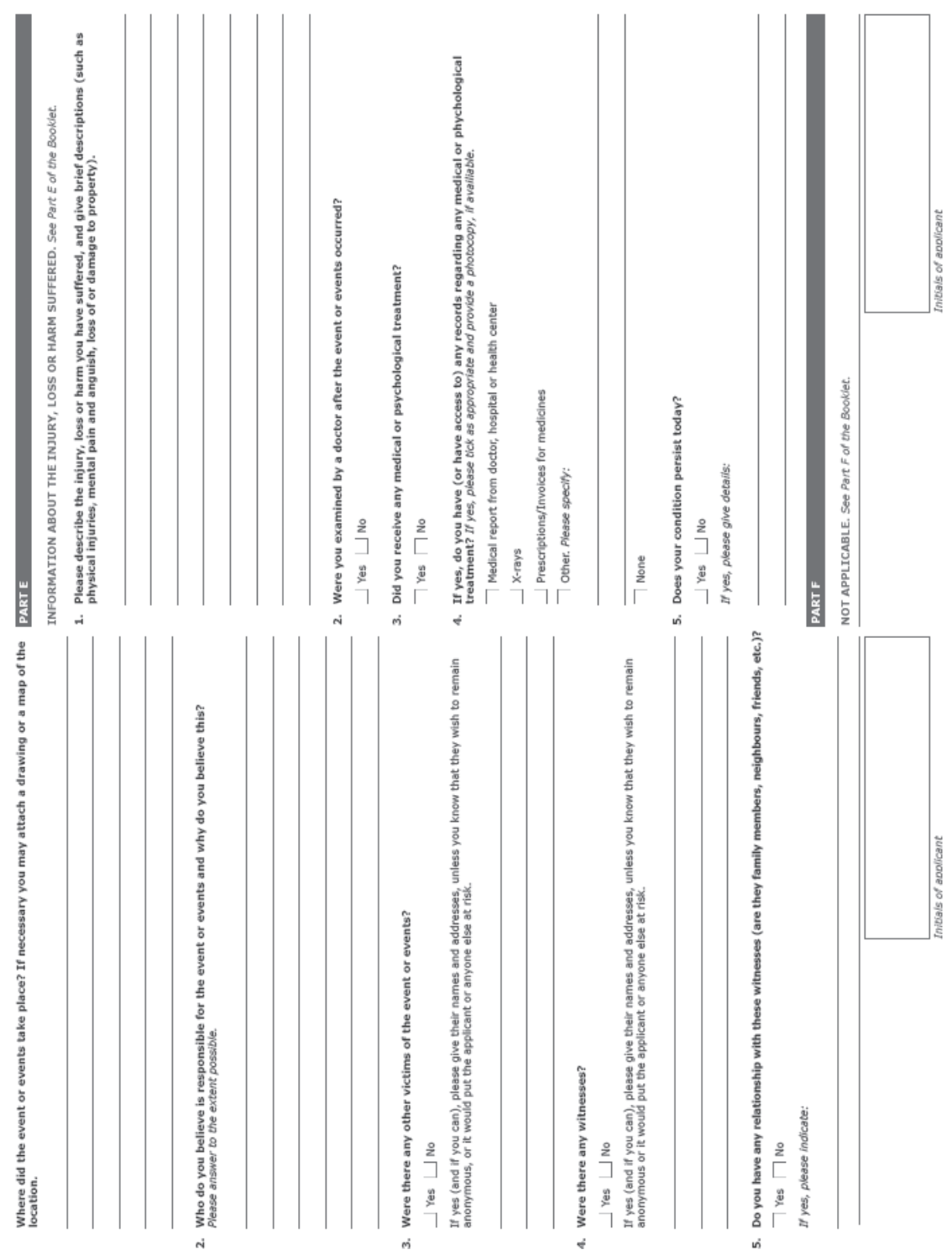




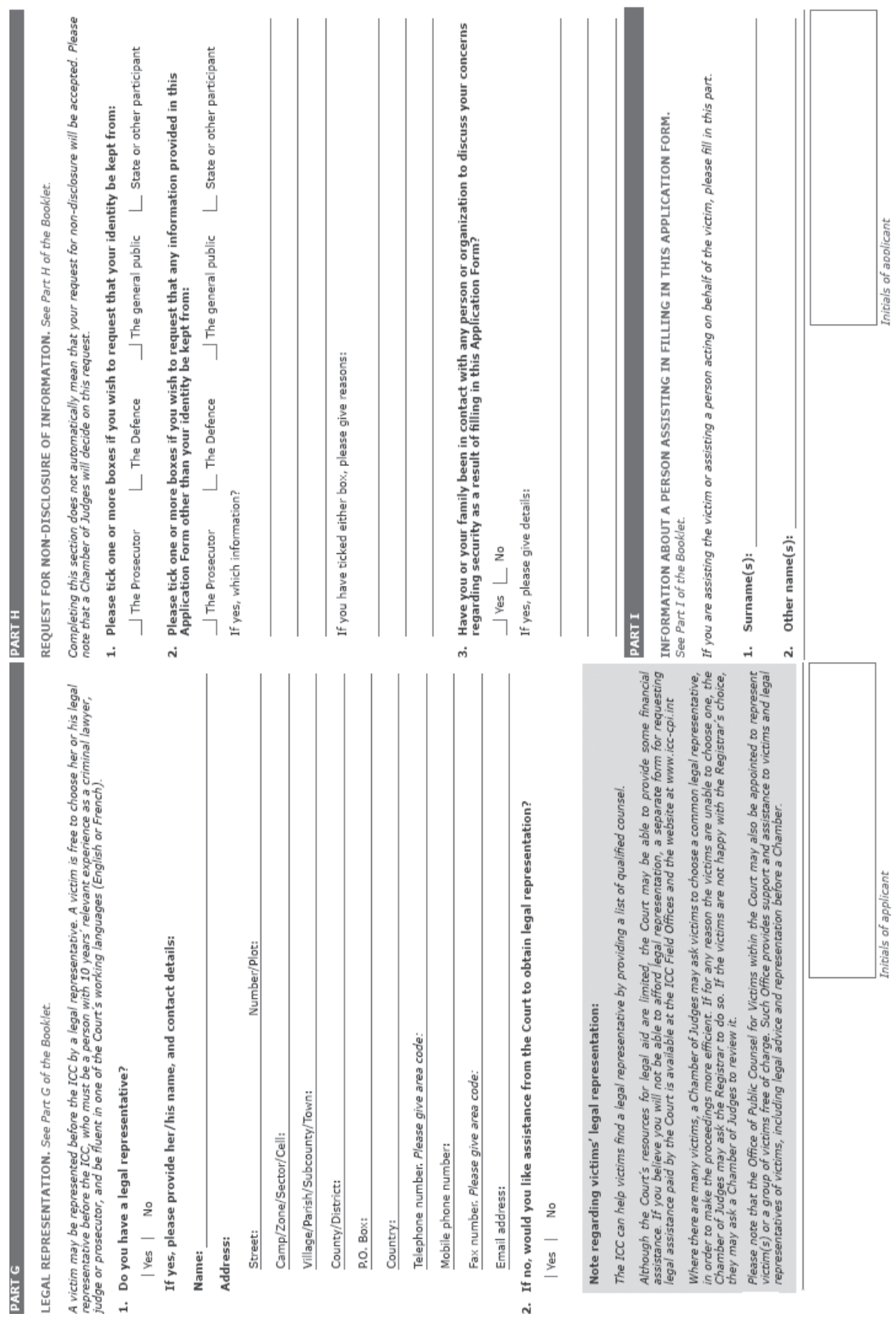




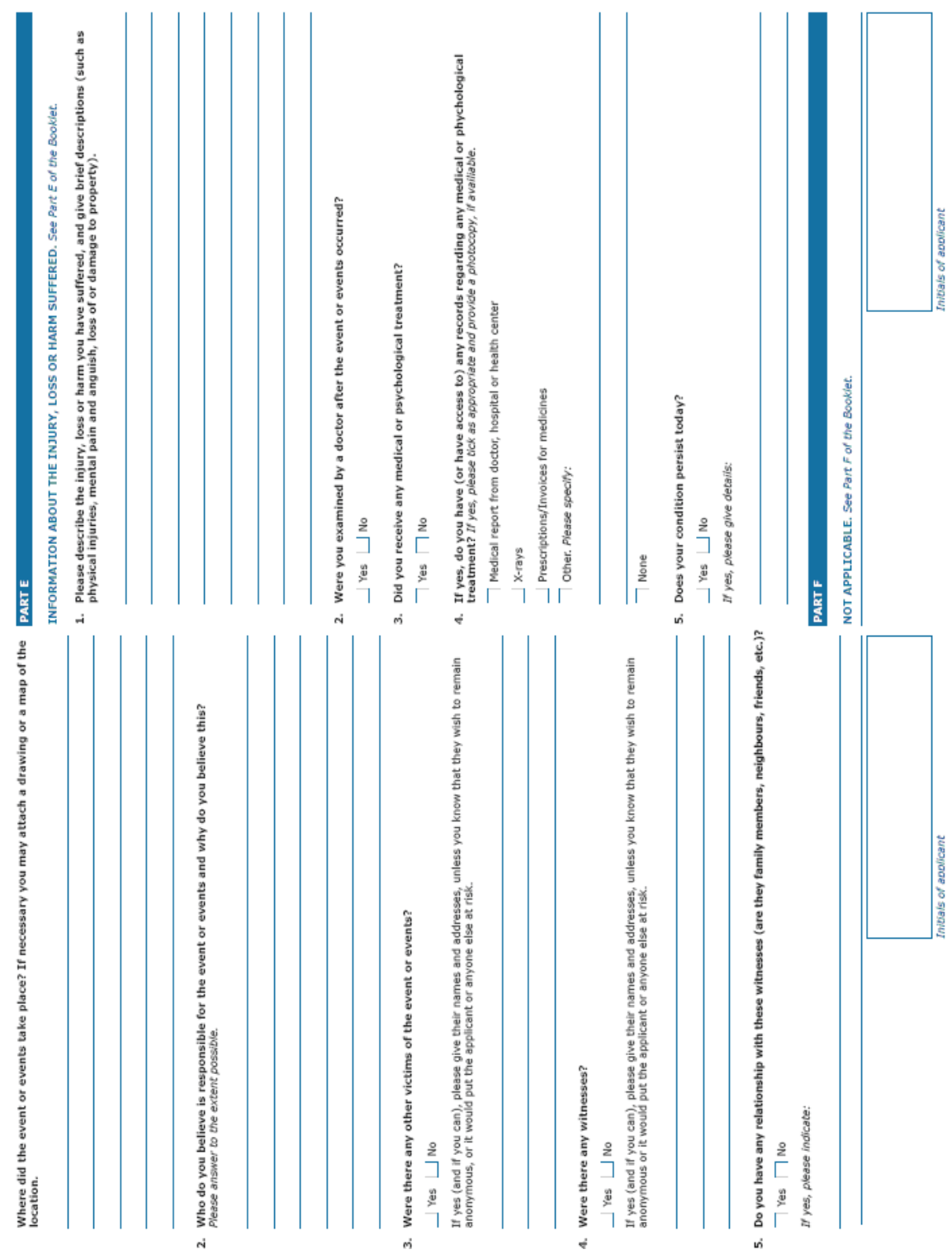



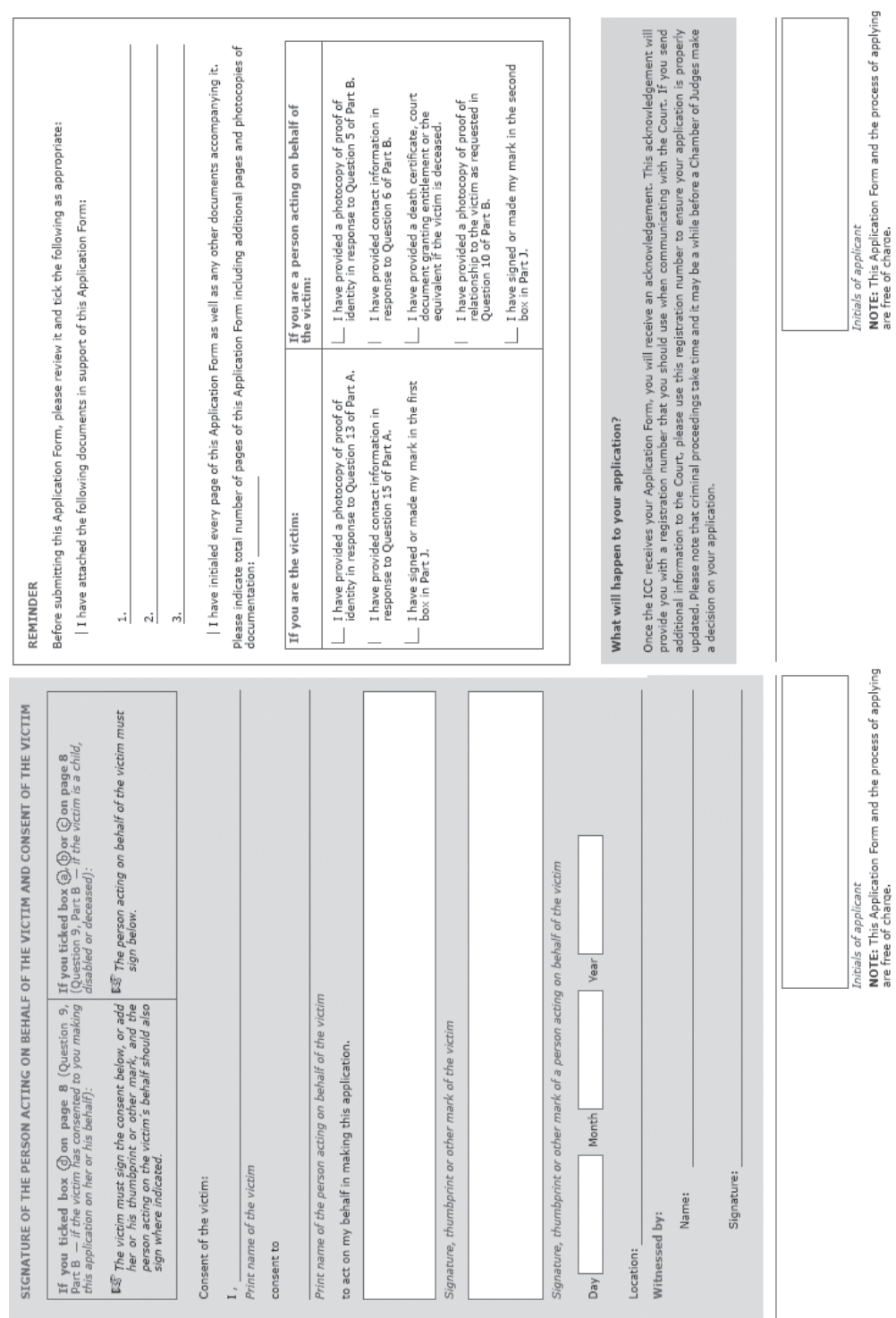

FONTE: TPI. Application form to participate in proceedings before the ICC for individual victims and persons acting on their behalf, cf o site: <http://www2.icc-cpi.int/NR/ rdonlyres/5C713EAC-AAE0-46A9-A6F3-CB019284D740/144100/FormParticipation1_ en1.pdf>. p. 2-17.

Para maiores informações de como preencher o formulário vide A guide for the Participation of Victims in the proceedings of the court, cf site: <http://www2.icc-cpi.int/ NR/rdonlyres/04DDAEA9-6023-492F-AE24-53CF9C9F6D92/144111/VPRS_Booklet_ En.pdf>. P. 29-43. Acesso em: 07 set. 2009. 


\section{APÊNDICE A - Estatísticas da ComIDHs}

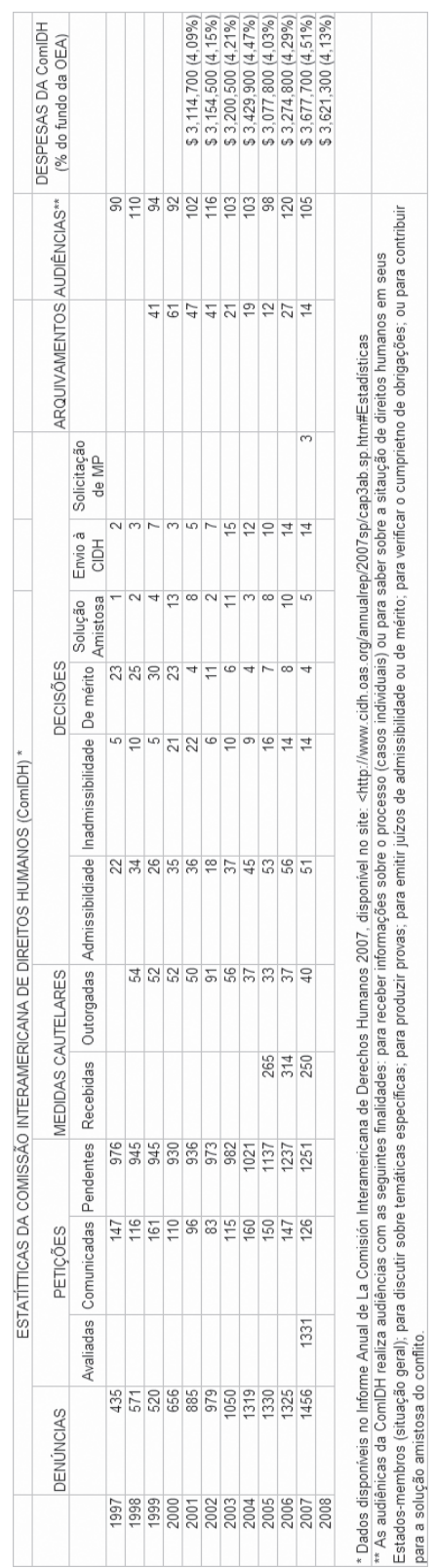

FONTE: Tabela elaborada com base nos dados do Informe Anual de La Comisión Interamericana de Derechos Humanos 2007, disponível no site: <http://www.cidh.oas.org/ annualrep/2007sp/cap3ab.sp.htm\#Estadísticas>. Acesso em: 07 set. 2009. 


\section{APÊNCICE B - Estatísticas da CtIDHs}

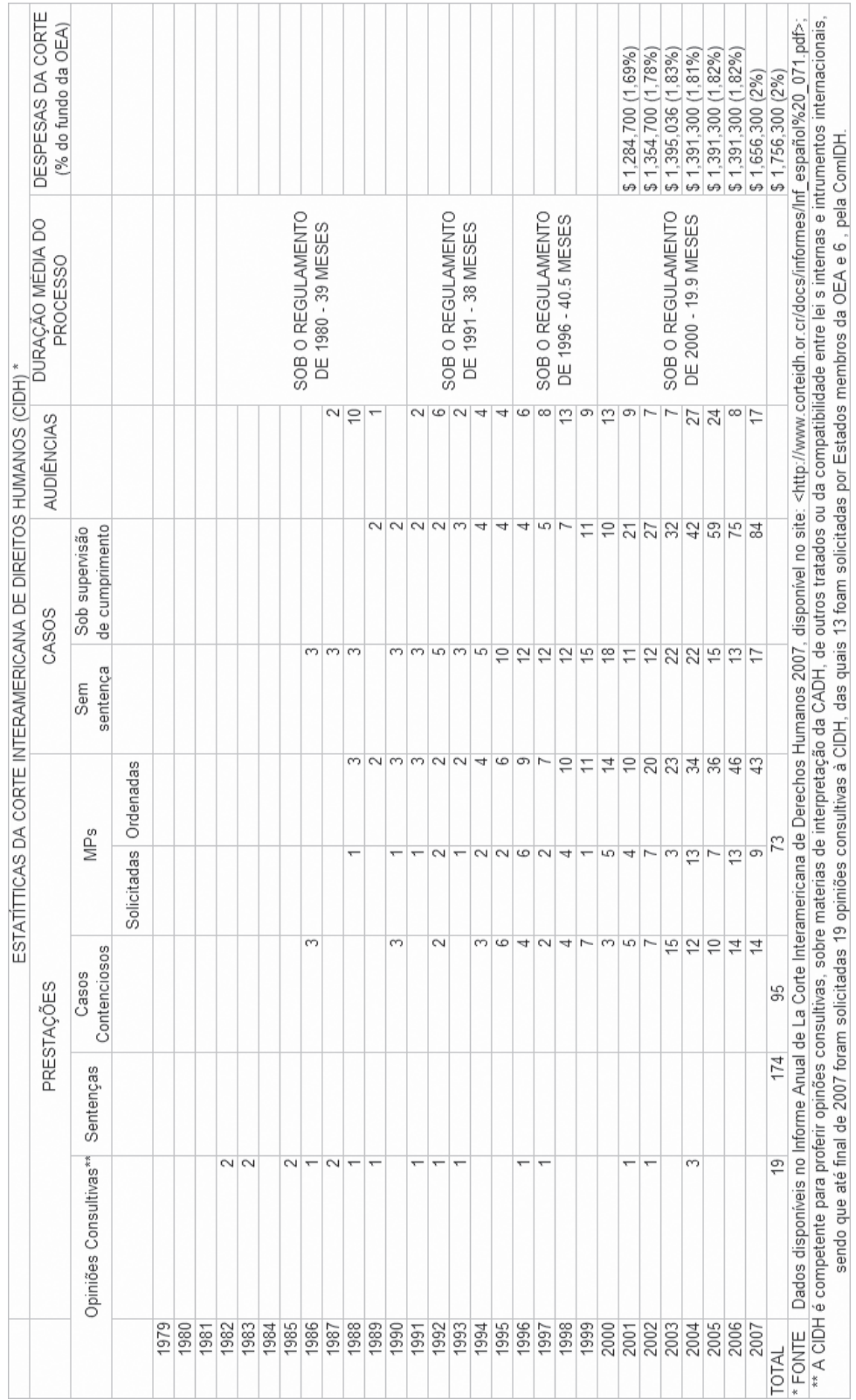

FONTE: CtIDHs. Tabela elaborada com base nos dados do Informe Anual de La Corte Interamericana de Derechos Humanos 2007, disponível no site: <http://www.corteidh.or.cr/ docs/informes/Inf_español\%20_071.pdf>. Acesso em: 07 set. 2009. 


\section{APÊNDICE C - Adesão dos países americanos aos instrumentos internacionais}

\begin{tabular}{|c|c|c|c|c|c|c|c|c|c|c|c|c|c|}
\hline 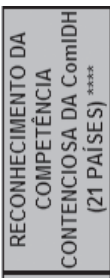 & 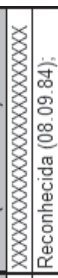 & 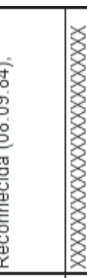 & |人 & \begin{tabular}{l|l} 
\\
$x$ \\
$>$
\end{tabular} & 度 & 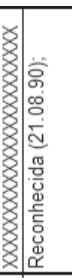 & 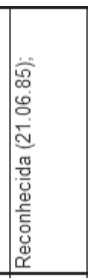 & 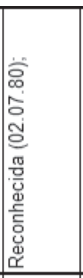 & 秉条 & 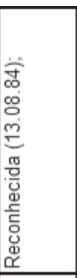 & 条 & 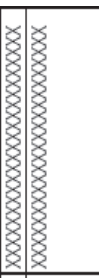 & 屬 \\
\hline 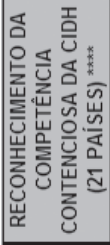 & 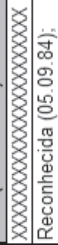 & 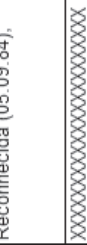 & 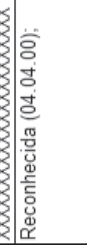 & 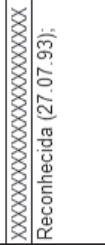 & 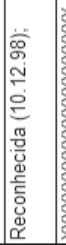 & 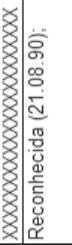 & 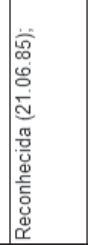 & 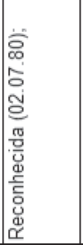 & 赵度 & 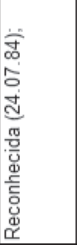 & 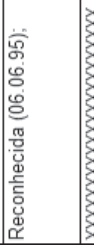 & 要 & 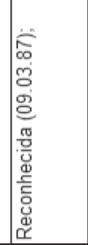 \\
\hline 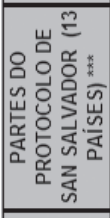 & 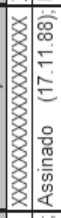 & 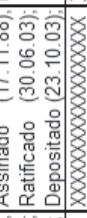 & 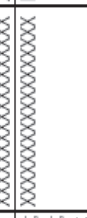 & 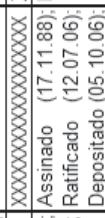 & 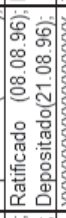 & 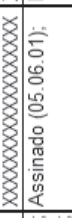 & 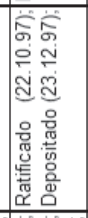 & 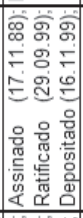 & 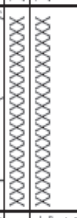 & 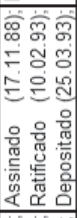 & 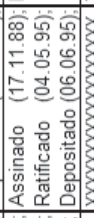 & 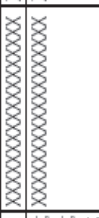 & 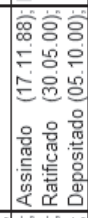 \\
\hline 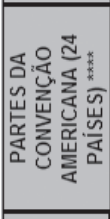 & 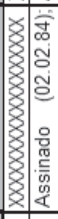 & 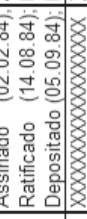 & 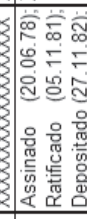 & 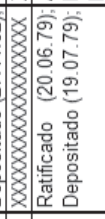 & 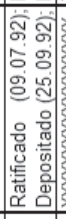 & ช & 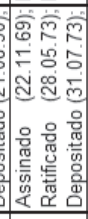 & 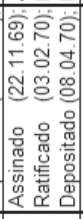 & 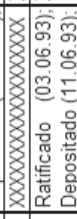 & 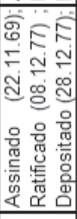 & 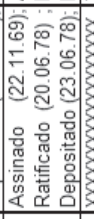 & 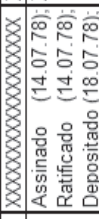 & 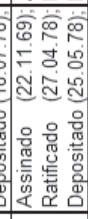 \\
\hline 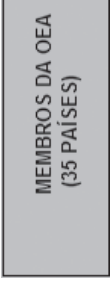 & 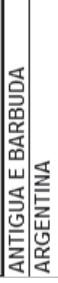 & 養 & 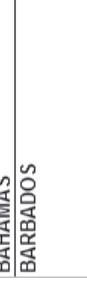 & 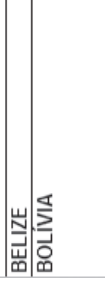 & $\sqrt{5}$ & & 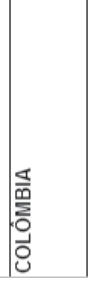 & 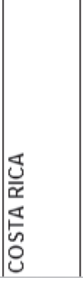 & 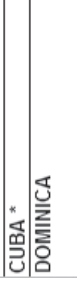 & 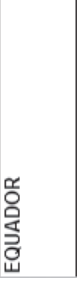 & 焉 & 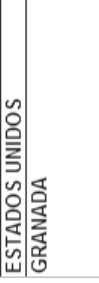 & 崖 \\
\hline
\end{tabular}


Univ. JUS, Brasília, v. 22, n.1, p. 113-406, jan./jun. 2011 O indivíduo na condição de sujeito ativo e passivo do direito internacional ...

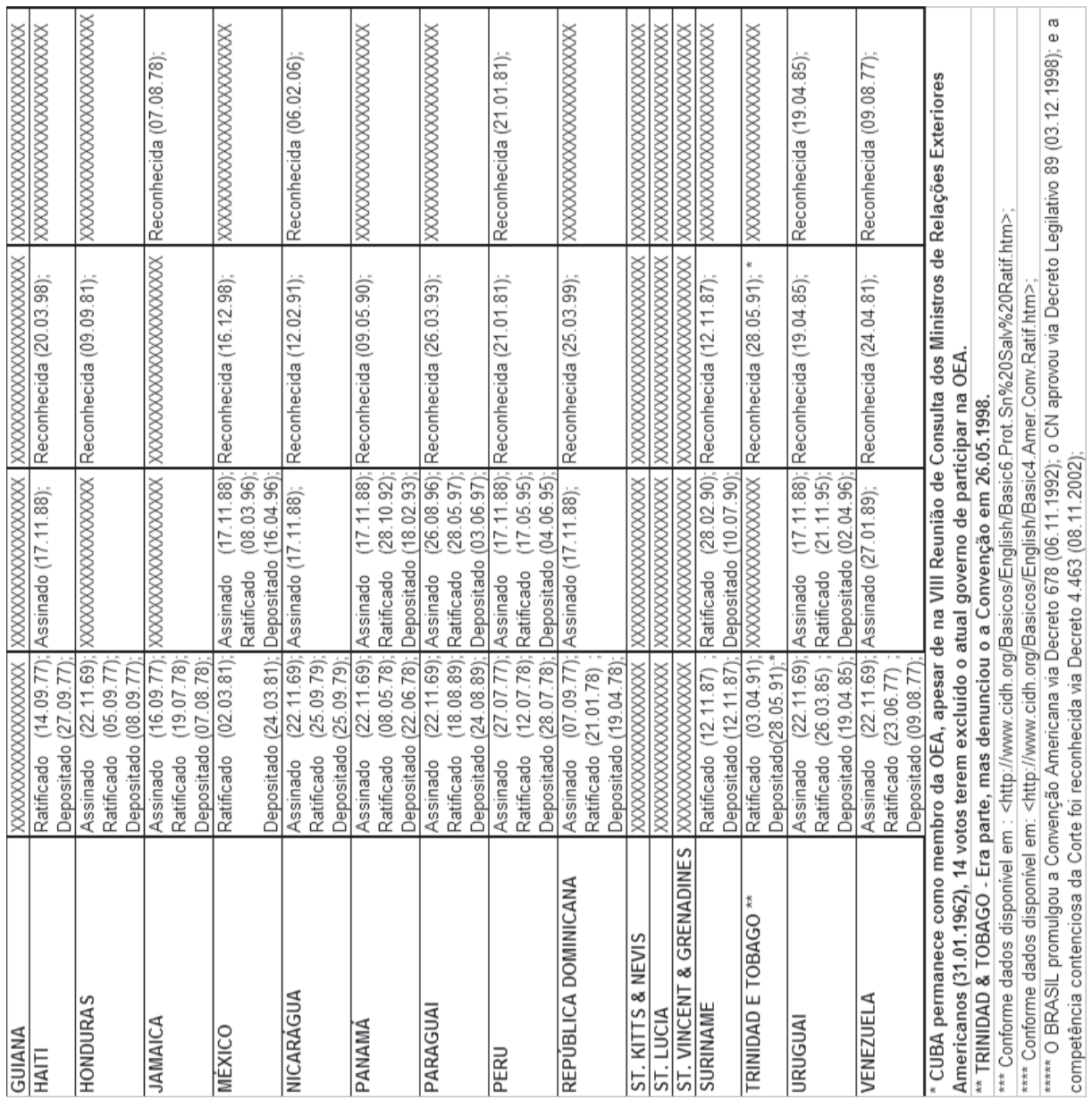

FONTE: Tabela elaborada com base nos dados disponíveis nos seguintes sites: <http:// www.cidh.org/Basicos/English/Basic6.Prot.Sn\%20Salv\%20Ratif.ht>; <http://www.cidh.org/ Basicos/English/Basic4.Amer.Conv.Ratif.htm>. Acesso em: 07 set. 2009. 


\section{APÊNDICE D - Procedimento geral do Sistema Interamericano}

\begin{tabular}{|c|c|}
\hline \multicolumn{2}{|c|}{ SISTEMA INTERAMERICANO } \\
\hline \multicolumn{2}{|c|}{$\begin{array}{c}\text { PROCEDIMENTO GERAL * (Art. 54,106 e } 145 \text { da Carta da OEA; Declaração } \\
\text { Americana; Art. } 20 \text { alínea a do Estatuto; Art. } 32 \text { a } 43 \text { e Art. } 51 \text { a } 54 \text { do Regulamento da } \\
\text { ComIDH) }\end{array}$} \\
\hline \multicolumn{2}{|c|}{ FASE POSTULATÓRIA } \\
\hline \multicolumn{2}{|c|}{$\begin{array}{l}\text { SECRETARIA DA ComIDH }{ }^{* * * *} \text { (Art. } 21 \text { do Estatuto e Art. } 12 \text { a } 14 \text { do Regulamento da } \\
\text { ComIDH) }\end{array}$} \\
\hline $\begin{array}{l}\text { LEGITIMADOS ATIVOS (Art. } 26 \text { 1o do } \\
\text { Regulamento da ComIDH) }\end{array}$ & $\begin{array}{l}\text { Podem protocolar petições: - qq pessoa ou } \\
\text { grupo de pessoas; - qq ONG reconhecida } \\
\text { por membro da OEA; }\end{array}$ \\
\hline $\begin{array}{l}\text { REQUISITOS DE ADMISSIBILIDADE } \\
\text { (Art. } 52 \text { do Regulamento da ComIDH) }\end{array}$ & $\begin{array}{l}\text { Verificar os seguintes requisitos: - } \\
\text { esgotamento dos recursos internos; }\end{array}$ \\
\hline QUESTÕES PRELIMINARES & $\begin{array}{l}\text { A ComIDH pode solicitar: - informações } \\
\text { aos membros da OEA; - pesquisas e } \\
\text { investigações; }\end{array}$ \\
\hline \multicolumn{2}{|c|}{ FASE PROBATÓRIA } \\
\hline $\begin{array}{l}\text { DEVIDO PROCESSO LEGAL (Art. } 55 \text { a } \\
59 \text { do Regulamento da ComIDH) }\end{array}$ & $\begin{array}{l}\text { A ComIDH,para elaborar estudos e } \\
\text { relatórios, pode: - solicitar informações } \\
\text { ao Estado demandado; - fazer pesquisas e } \\
\text { investigações; }\end{array}$ \\
\hline $\begin{array}{l}\text { AMPLA DEFESA (Art. } 20 \text { do Estatuto da } \\
\text { ComIDH) }\end{array}$ & $\begin{array}{l}\text { A ComIDH pode por inciativa própria: - } \\
\text { criar uma Comissão Especial (com anuência } \\
\text { ou convite do país) para observações in loco; }\end{array}$ \\
\hline $\begin{array}{l}\text { ARQUIVO OU PROSSEGUIMENTO } \\
\text { (Art. } 18 \text { do Estatuto da ComIDH) }\end{array}$ & $\begin{array}{l}\text { A ComIDH pode : - arquivar o caso por } \\
\text { alegações insubsistentes; - prosseguir nas } \\
\text { apurações dos fatos; }\end{array}$ \\
\hline \multicolumn{2}{|c|}{ FASE DELIBERATÓRIA } \\
\hline $\begin{array}{l}\text { DELIBERAÇÃO/RESOLUÇÃO (Art. } 53 \\
\text { do Regulamento da ComIDH) }\end{array}$ & $\begin{array}{l}\text { A ComIDH , ao final do processo, deve: - } \\
\text { Adotar uma Resolução; }\end{array}$ \\
\hline RECOMENDAÇÃO (Art. 53 p1 do & A ComIDH pode : - Formular \\
\hline $\begin{array}{l}\text { Regulmento da ComIDH c/c Art. } 20 \text { do } \\
\text { Estatuto da ComIDH) }\end{array}$ & $\begin{array}{l}\text { Recomendações ao Estado; e - Fixar prazo } \\
\text { para seu cumprimento; }\end{array}$ \\
\hline $\begin{array}{l}\text { PUBLICAÇÃO FACULTATIVA (Art. } 53 \\
\text { P4 do Regulamento da ComIDH }\end{array}$ & A ComIDH pode: - Publicar a Resolução; \\
\hline 90 DIAS PARA RECONSIDERAÇÃO & $\begin{array}{l}\text { O Estado, pode solicitar a reconsideração } \\
\text { das recomendações do relatório, se houver } \\
\text { novos fatos ou argumentos de direito; }\end{array}$ \\
\hline $\begin{array}{c}\text { NOVO PRAZO PARA CUMPRIMENTO } \\
\text { DA DECISÃO }\end{array}$ & $\begin{array}{l}\text { A ComIDH pode: - Estabelecer novo prazo } \\
\text { para o Estado cumprir a decisão; }\end{array}$ \\
\hline $\begin{array}{l}\text { PUBLICAÇÃO OBRIGATÓRIA (Art. } 54 \\
\text { do Regulamento da ComIDH) }\end{array}$ & $\begin{array}{l}\text { Se o Estado não cumprir no novo prazo, a } \\
\text { ComIDH publicará a decisão; }\end{array}$ \\
\hline
\end{tabular}


INSTÂNCIA POLÍTICA

DECISÃO FINAL/RECOMENDAÇÕES A Assembléia Gera da OEA: - determinará DA AG DA OEA (Art. 63 do Regulamento que os Estados tomem medidas para reparar da ComIDH) as vítimas de violações de direitos humanos;

FORMA DE COAÇÃO DO ESTADO INFRATOR

As consequências do não cumprimento:

COAÇÃO E APLICAÇÕA DE SANÇÕES abalo moral, constrangimento político e POLÍTICAS PELA AG DA OEA perda da credibilidade perante os outros membros da OEA

* TODAS AS ATIVIDADES REALIZADAS PELA ComIDH NO PERÍODO DE SESSÕES (em todas as fases do procedimento geral, inclusive o descumprimento de suas decisões pelos Estados) SERÃO DESCRITOS NO RELATÓRIO ANULA ENCAMINHADO À ASSEMBLÉIA GERAL DA OEA.

**** A ComIDH também exerce funções como entidade autônoma da OEA, podendo receber petições individuais relativas a violações de direitos humanos por Estados infratores da Carta da OEA e da Declaração Americana de Direitos e Deveres do Homem, de 1948 e recomendar ao Estado infrator a suspensão das violações e a reparação dos prejuízos.

FONTE: Quadro baseado em COELHO, Rodrgio Merirelles Gaspar. Proteção Internacional dos direitos Humanos: a Corte Interamericana e a implementação d e suas sentenças no Brasil. Curitiba: Juruá, 2008, pp. 71-86. 


\section{APÊNDICE E - Procedimento especial do Sistema Interamericano}

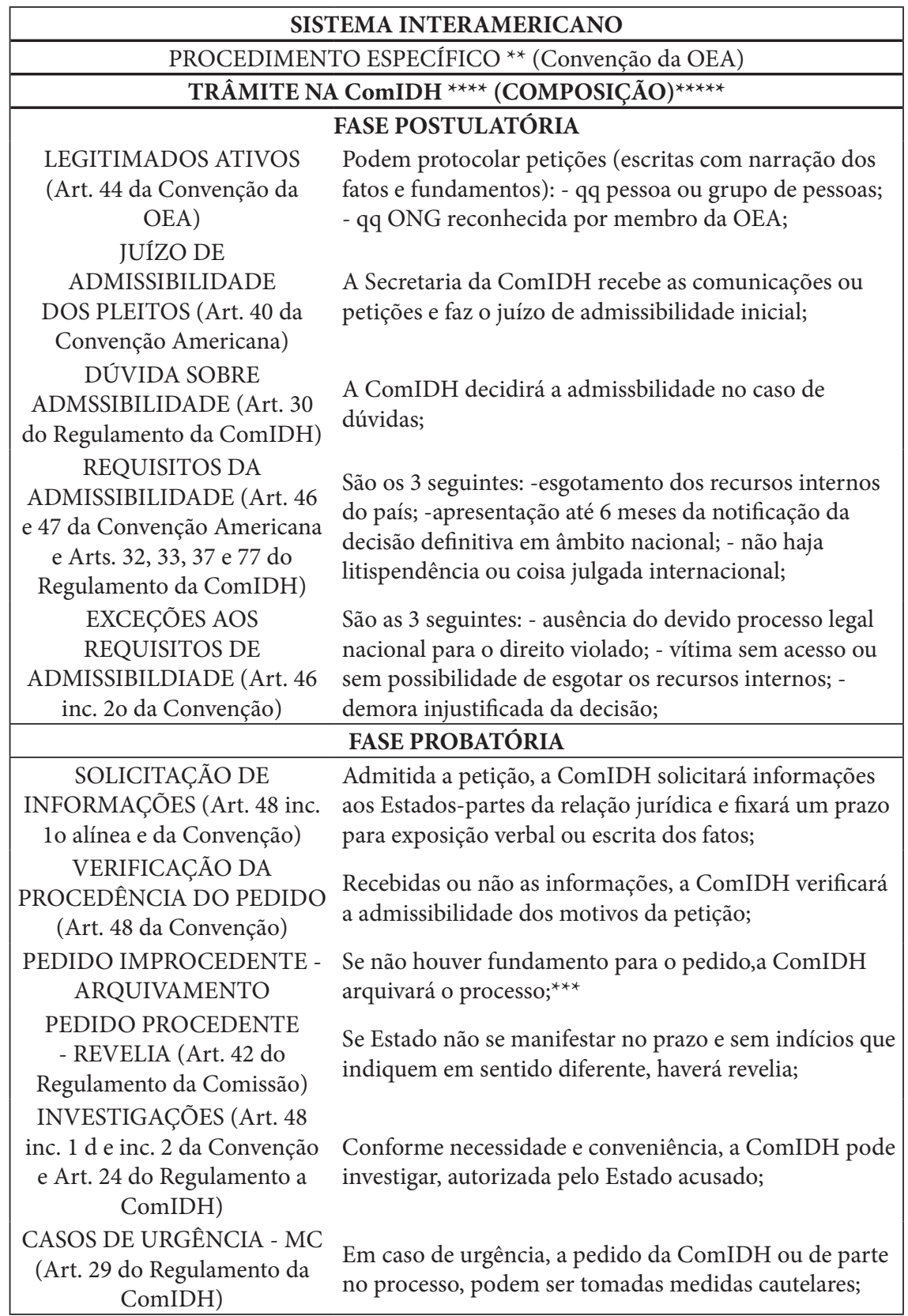




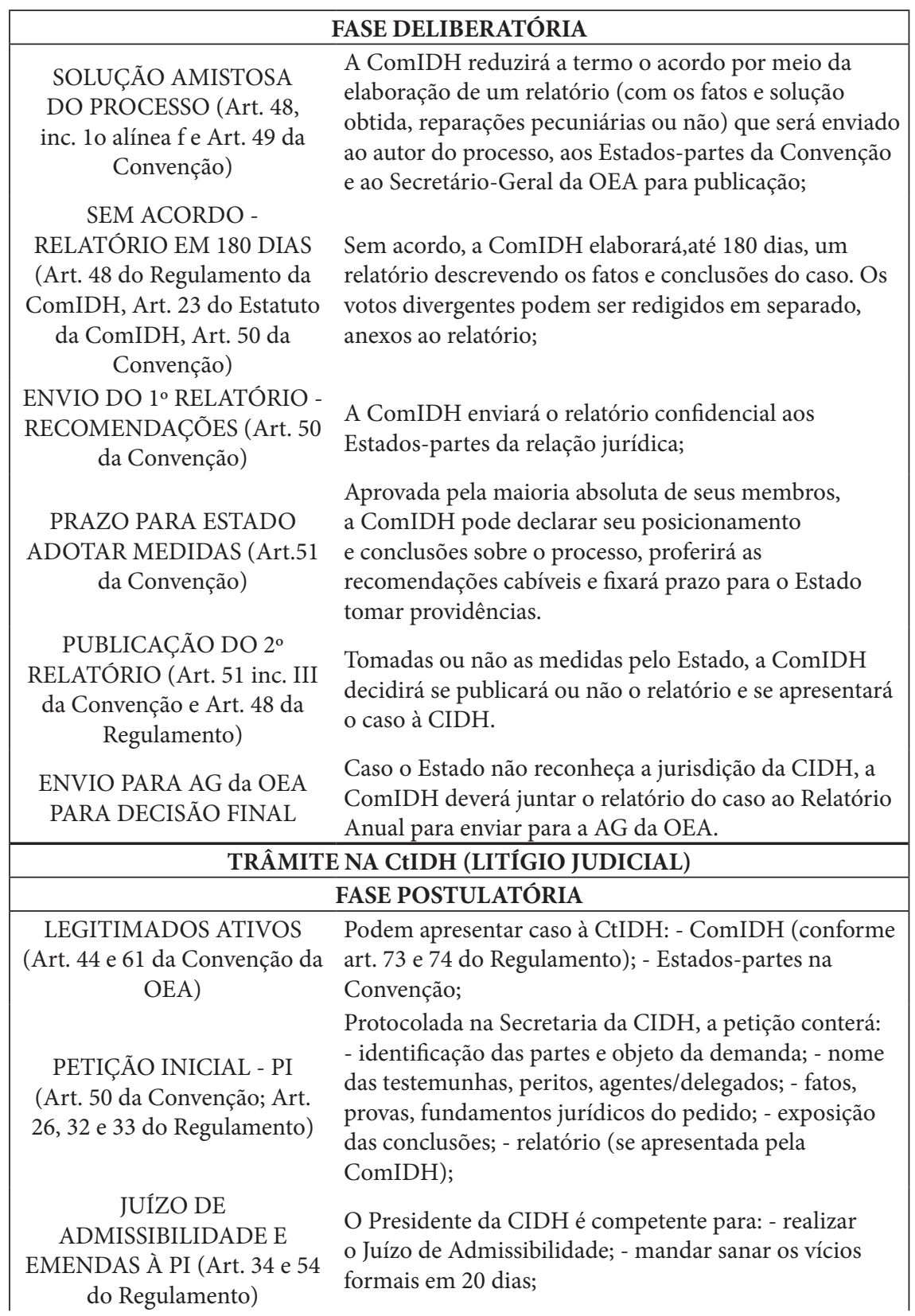


NOTIFICAÇÃO OFICIAL DA DEMANDA (Art. 35 do Regulamento)

DESIGNAÇÃO DE DELEGADOS E AGENTES (Art. 35 p3 do Regulamento)

EXCEÇÕES PRELIMINARES (Art. 36 do Regulamento)

CONTRA-RAZÕES ÀS EXCEÇÕES PRELIMINARES (Art. 36 do Regulamento)

\begin{tabular}{c}
\hline \\
\hline FASE ESCRITA DE \\
CONTESTAÇÕES (Art. 37 \\
DO Regulamento) \\
JUNTADA DE \\
DOCUMENTOS (Art. 38 do \\
Regulamento) \\
\\
FASE ORAL DE \\
CONTESTAÇÕES (Art. 39, 40 \\
e 41 do Regulamento)
\end{tabular}

AUDIÊNCIAS (Art. 42 do Regulamento)

DELEGADOS, AGENTES E REPRESENTANTES DAS VÍTIMAS OU SEUS FAMILIARES (Art. 23 do Regulamento)

A PROVA (Art. 43 a 51 do Regulamento)

ÔNUS DA PROVA (Art. 45 do Regulamento)

A CIDH E A INSTRUÇÃO PROCESSUAL (Art. 28 e 44 do Regulamento)
O Secretário da CIDH comunicará o caso: - ao presidente e juízes da CIDH; - ao Estado demandado e aos Estados-partes da Convenção; - à ComIDH e ao Secretário-Geral da OEA; - ao denunciante original; - à vitima e seus familiares;

Até 1 (um) mês após a notificação oficial, o demandante poderá designar delegados e agentes;

Até 2 (dois) meses após a notificação oficial, poderão ser apresentadas exceções preliminares, sem efeito suspensivo:

Até 30 dias após a comunicação de recebimento das exceções, as partes do caso podem contrarrazoar;

\section{FASE PROBATÓRIA}

Até 4 meses da notificação para apresentar contestação, o Estado pode contestar por escrito.

Antes da fase oral de contestações, as partes podem solicitar ao Presidente da CIDH a juntada de documentos;

O Presidente da CIDH: - estabelecerá a data de incio da fase oral de contestações e a data das audiências; - conduzirá os debates e demais medidas cabíveis durantes as audiências; - poderá indagar as pessoas presentes às audiências, e decidirá sobre a pertinácia das perguntas alheias;

As audiências serão reduzidas a termo por meio de Atas;

Os delegados, agentes e representantes das vítimas ou seus familiares poderão, com aval do Presidente da CIDH, inquirir testemunhas, peritos ou demais indivíduos;

As provas do processo deverão constar na denúncia ou na contestação. Exceções somente por motivo de força maior, impedimento grave ou outros fatos;

O ônus (custos) da prova será arcado por quem alegar;

No campo da instrução processual, a Corte poderá:

- requerer outras provas e esclarecimentos às partes; - requisitar informações, pareceres e relatórios a quaulquer entidades, repartição, órgão ou autoridade; - determinar averiguações, inspeções judicias ou qualquer outra medida que auxilie coleta de dados; 
MEDIDAS PROVISÓRIAS (Art. 63 inc 2 da Convenção e Art. 25 e 76 do Regulamento)

\section{RECOMENDAÇÕES (}

OITIVA E IMPUGNAÇÃO

DAS TESTMUNHAS (Art. 46

E 48 do Regulamento)

OITIVA E

IMPUGNAÇÃODOS

PERITOS (Art. 47 E 49 do

Regulamento)

VALOR DAS PROVAS/

DESGINAÇÃO DE NOVO PERITO

PROTEÇÃO DAS

TESTEMUNHAS E PERITOS

(Art. 50 do Regulamento)

\section{PUNIÇÃO DE \\ TESTEMUNHAS E PERITOS}

(Art. 51 do Regulamento)
Em casos de extrema gravidade e urgência, poderão ser tomadas MPs (presentes no relatório anual enviado pela CIDH à AG da OEA), por iniciativa da CIDH ou das partes ou a pedido da ComIDH, para evitar danos irreparáveis.

As determinações não adequadamente executadas no prazo, a CIDH proporá recomendações.

Data designada pela Corte, que citará as testemunhas, informando o objeto do interrogatório. $\mathrm{Na}$ audiência prestarão juramento solene e poderão ser contestadas, decidindo a Corte.

Data designada pela Corte, que citará os peritos, informando o objeto da perícia. Até 15 dias da notificação da designação dos peritos, poderão ser impugnados. Na audiência prestarão declaração solene. Cabe à CIDH decidir sobre o valor das provas e designação de novo perito, mas o Presidente da CIDH pode decidir provisoriamente.

As testemunhas, peritos e seus respectivos familiares são protegidos pelo sistema interamericano, não podendo ser processado e nem sofrer represálias dos Estados pelas informações e laudos fornecidos. A CIDH pode requisitar aos Estados a aplicação de sanções de seus ordenamentos jurídicos internos contra nacionais que forem convocados,mas não comparecerem,se recusarem a depor sem motivo legítimo ou desrespeitarem o juramento solene da $\mathrm{CIDH}$.

\section{FASE DELIBERATÓRIA}

DELIBERAÇÃO DA CIDH

(Art. 56 e 68 inc. I da Convenção)

EMPATE (Art. 23 do Estatuto e Art. 13 a 15 do Regulamento)

COMPOSIÇAÕ DA SENTENÇA (Art. 16 e 55 do Regulamento e Art. 66 inc. 2 da Convenção)

COMUNICAÇÃO E EXECUÇÃO DA SENTENÇA (Art 29,30 e 57 do Regulamento)
A CIDH adotará sentença por meio de votação maioria simples, com quórum mínimo de 5 juízes.

No caso de empate nas votações, o voto de minerva é do Presidente.

A sentença será composto das seguintes partes:

- Relatório (procedimentos e fatos ocorridos); Conclusões das partes; - Fundamentação de direito; -Deliberação final; -Votos dissidentes, se houverem, de qualquer juiz do caso;

Expedida a Ordem de Comunicação e Execução da sentença - assinada pelo presidente e secretário da Corte -, serão entregues cópias certificadas da decisão aos interessados no processo e informados da decisão os Estados signatários da Convenção. 
DETERMINAÇÕES IMPRECISAS E ACORDOS (Art. 56 do Regulamento)

INTERPRETAÇÕES (Art. 67 da Convenção e Art. 58 do Regulamento)

DESISTÊNCIA OU SOLUÇÃO AMISTOSA (Art.

52 a 54 do Regulamento)

\section{INSTRUMENTOS DA OEA}

RELATÓRIO ANUAL À
Se faltar determinação especifica sobre reparações, a CIDH designará data e procedimento para decisão. Se houve acordo entre lesado e demandado, a CIDH fará observações sobre este.

As partes e a Comissão poderão solicitar à CIDH interpretação quanto ao sentido ou ao alcance das sentenças, sem modificar os efeitos ou execução da mesma.

A CIDH decidirá sobre o pedido de desistência da parte demandante e decidirá sobre os efeitos da homologação de acordo entre as partes do processo, fiando as reparações e indenizações adequadas. Nestas hipóteses a CIDH poderá cancelar o processo e declara-l encerrado.

\section{INSTÂNCIA POLÍTICA}

Caso o Estado infrator não cumpra a sentença da $\mathrm{CIDH}$, esta poderá acionar a AG da OEA, indicando os casos de descumprimento de decisões e as recomendações cabíveis em seu Relatório Anual. O resultado será constrangimento político e moral perante a comunidade internacional.

A atuação da OEA pode gerar constrangimento político e moral do Estado infrator perante a comunidade internacional. Embora não seja suficiente para garantir a segurança e estabilidade jurídicas ao sistema americano.

** Quadro baseado em COELHO, Rodrgio Merirelles Gaspar. Proteção Internacional dos Direitos Humanos: a Corte Interamericana e a implementação d e suas sentenças no Brasil. Curitiba: Juruá, 2008, pp. 71-86.

*** A ComIDH na qualidade de dominus litis absoluto da ação de responsabilidade internacional do Estado impede qualquer recurso pelo peticionário, caso a ComIDH entenda pela não existência de violação.

***** O Brasil procura negociar soluções amistosas (transação extrajudicial) em parâmetros razoáveis, como no caso de Edson Damião Calisto e no caso de Robson William da Silva Cassiano, de conformidade com o despacho telegráfico ostensivo $n$ o 37, de 4/3/05, transmitido pela Secretaria de Estado das Relações Exteriores para a Embaixada do Brasil em São José.

FONTE: Quadro baseado em COELHO, Rodrgio Merirelles Gaspar. Proteção Internacional dos direitos Humanos: a Corte Interamericana e a implementação d e suas sentenças no Brasil. Curitiba: Juruá, 2008, pp. 71-86. 


\section{APÊNDICE F - RESUMO DA IMPLEMENTAÇÃO DE SENTENÇAS DA CtIDHs NO BRASIL}

No Caso José Pereira versus Brasil (Relatório no 95/03 da ComIDHs), o Brasil aceitou uma solução amistosa perante a ComIDH e pagou reparação por danos materiais e morais através da Lei 10706/03, que autorizou a União a pagar à vítima $\mathrm{R} \$ 52.000,00$, de recursos alocados ao programa de Trabalho Direitos Humanos, Direito de Todos, da Secretaria Especial dos DHs da Presidência da República. Fora este caso, no Brasil (regido pelos princípios da inalienabilidade e impenhorabilidade dos bens públicos e do princípio da legalidade da despesa pública para estabilidade das contas publicas, sob pena de crime de responsabilidade, conforme LC 101/2000) a execução das sentenças internacionais da CIDH contra o Brasil - até que o STF reconheça a dispensa dos créditos de natureza alimentar da ordem de precatórios conforme art. 100 caput da CF (revisão da S. 655/03) ou a lei orçamentária anual disponibilize créditos adicionais suplementares para reparações de violações internacionais de direitos humanos (Lei 4320/64) ou as execuções das sentenças internacionais sejam equiparadas a execuções dos Juizados Federais (desde que não ultrapassem o teto estabelecido) ou tenha lei especifica de indenizações pagas diretamente pelo Executivo (concedidas por decreto do Presidente após parecer favorável da Comissão Especial como a Lei 9140/95 para mortos ou desaparecidos por participação em atividades políticas ou concedidas por portaria do Ministro de Estado da Justiça após parecer favorável da Comissão de Anistia como na Lei 10559/02 para anistiado político) ou se houver previsão de efeito imediato das decisões do sistema interamericano (projetos de lei 3214/00 e 4.667/04)- as sentenças internacionais da CIDH , terão que se submeter ao regime especial de execução de pagamento de quantia certa contra a Fazenda Pública Federal (conforme art. 100 da CF e arts. 730 e 731 do CPC e desde que seja inclui da sentença internacional no rol do art. 584 do CPC para evitar inexigibilidade do título como justificativa adicional nos embargos do devedor da Fazenda Publica, assim como a lei 9307/96 que inclui a sentença arbitral no art. 583 do CPC), dos precatórios (criticado pelo inadimplemento e morosidade, violando os princípios da razoável duração do processo e celeridade de sua tramitação). O Brasil ainda se depara com o problema de saber qual a autoridade competente para transigir nas soluções amistosas da ComIDH, já que a Lei 9469/97 (conforme parecer informa- 
tivo no GQ-03/93, disponível em <http://200.181.70.163/pareceres/index_default. htm>) autoriza o Advogado-Geral da União e os dirigentes máximos das autarquias e fundações e empresas publicas federais a realizar acordos ou transações em juízo e não nas extrajudiciais.

FONTE: Resumo baseado em PETIOT, Patrick. A responsabilidade internacional do Estado brasileiro por violação de diretos humanos: o pagamento de reparações. Brasília, 2005, pp. $157-187$.

\section{Lista de abreviaturas e siglas}

ACNUR

AES

AG/OEA

AGNU

APCoE

BR

CC

CDPDNU

$\mathrm{CE}$

CECA

CEDMNU

CEDRNU
Alto Comissariado das Nações Unidas para Refugiados Ato Europeu Simples de 1986

Assembléia Geral da OEA

Assembléia Geral das Nações Unidas

Assembléia Parlamentar do Conselho da Europa

Brasil

Código Civil

Comitê dos Direitos das Pessoas com Deficiências das Nações Unidas

Comunidade Européia

Comunidade Européia do Carvão e do Aço

Comitê sobre a Eliminação da Discriminação contra Mulheres das Nações Unidas

Comitê sobre a Eliminação de todas as formas de Discriminação Racial das Nações Unidas

CEE Comunidade Econômica Européia

CEEA

Comunidade Européia da Energia Atômica

CFB
Constituição Federal Brasileira 
$\mathrm{CICV}$

CIDI/OEA

CIECC/OEA

CIES/OEA

CIJ

CJI/OEA

$\mathrm{CMCoE}$

$\mathrm{CoE}$

ComDHsNU

ComDINU

ComEDHs

ComIDHs

ConDHsNU

CP/OEA

CPC

CPE

CPJI

CPJMC

CRHNU

CSNU

CSP

CtEDHs

CtEJ
Conferências Internacionais da Cruz Vermelha

Conselho Interamericano de Desenvolvimento Integral da OEA

Conselho Interamericano de Educação, Ciência e Cultura da OEA

Conselho Interamericano Econômico Social da OEA

Corte Internacional de Justiça

Comissão Jurídica Interamericana da OEA

Comitê de Ministros do Conselho da Europa

Conselho da Europa

Comissão de Direitos Humanos das Nações Unidas

Comissão de Direito Internacional das Nações Unidas

Comissão Européia de Direitos Humanos

Comissão Interamericana de Direitos Humanos

Conselho de Direitos Humanos das Nações Unidas

Conselho Permanente da OEA

Código Civil Brasileiro

Cooperação Política Européia

Corte Permanente de Justiça Internacional

Cooperação Política e Judicial em Matérias Criminais

Comitê de Recursos Humanos das Nações Unidas

Conselho de Segurança das Nações Unidas

Convenção sobre as substâncias psicotrópicas de 1971

Corte Européia de Direitos Humanos

Corte Européia de Justiça 
CtIDHs

CTMNU

CTNU

CTS

$\mathrm{CU}$

DHs

DI

Di

DIDHs

DIP

DUDHs

EC/TPI

ECIJ

ECOSOC

ETIPI

ETIPR

ETMIN

ETMIT

ETPI

EUA

JJPI

JR
Corte Interamericana de Direitos Humanos

Comitê dos Trabalhadores Migrantes das Nações Unidas

Comitê contra Tortura das Nações Unidas

Convenção contra o tráfico ilícito de entorpecentes e de substâncias psicotrópicas

Convenção Única da ONU de 1961

Direitos Humanos

Direito Internacional

Direito Interno

Direito Internacional dos Direitos Humanos

Direito Internacional Público

Declaração Universal dos Direitos do Homem

Elementos dos Crimes do TPI

Estatuto da Corte Internacional de Justiça

Conselho Econômico e Social

Estatuto do Tribunal Internacional Penal para a exIugoslávia

Estatuto do Tribunal Internacional Penal para Ruanda

Estatuto do Tribunal Militar Internacional de Nuremberg

Estatuto do Tribunal Militar Internacional de Tóquio

Estatuto do Tribunal Penal Internacional

Estados Unidos da América

Juízos de Julgamento em Primeira Instância

Juízo de Recursos 
JRD

LICC

MC/MCs

MP/MPs

OI/OIs

ONGsIs

ONU

PDHsNU

PESC

PIDCP

PIDESC

PIDHs

RIs

RISTF

RMRE

RP/TPI

STF

STJ

TCE

TCUE

TUE

TIAR
Justiça e Relações Domésticas

Lei de Introdução ao Código Civil

Medida Cautelar/ Medidas Cautelares

Medida Provisória/Medidas Provisórias

Organização

Internacional/Organizações

Internacionais

Organizações Não Governamentais Internacionais Organização das Nações Unidas

Pactos de Direitos Humanos das Nações Unidas

Política Externa de Segurança Comum

Pacto Internacional sobre Direitos Civis e Políticos

Pacto sobre Direitos Econômicos, Sociais e Culturais

Proteção Internacional dos Direitos Humanos

Relações Internacionais

Regimento Interno do STF

Reunião dos Ministros de Ministérios das Relações Exteriores

Regulamento Processual do TPI

Supremo Tribunal Federal

Superior Tribunal de Justiça

Tratado da Comunidade Européia

Tratado Constitutivo da União Européia

Tratado da União Européia

Tratado Interamericano de Assistência de 1947

TIPI
Tribunal Internacional Penal para a ex-Iugoslávia 
TIPR

TMIN

TMIT

TPI

UE

UEO
Tribunal Internacional Penal para Ruanda

Tribunal Militar Internacional de Nuremberg

Tribunal Militar Internacional de Tóquio

Tribunal Penal Internacional

União Européia

União da Europa Ocidental

\section{Errata}

\begin{tabular}{|l|l|l|l|}
\hline Folha & Linha & Onde se lề & Leia-se \\
\hline & & & \\
\hline & & & \\
\hline & & & \\
\hline & & & \\
\hline & & & \\
\hline & & & \\
\hline
\end{tabular}

